UNIVERSIDADE DE SÃO PAULO

ESCOLA DE EDUCAÇÃO FÍSICA E ESPORTE

\title{
INFLUÊNCIA DA NEUROPATIA DIABÉTICA NO COMPORTAMENTO DE RESPOSTAS BIOMECÂNICAS E SENSORIAIS NO ANDAR EM ESTEIRA ROLANTE
}

Isabel de Camargo Neves Sacco

SÃO PAULO

2001 


\section{INFLUÊNCIA DA NEUROPATIA DIABÉTICA NO COMPORTAMENTO DE RESPOSTAS BIOMECÂNICAS E SENSORIAIS NO ANDAR EM ESTEIRA ROLANTE}

ISABEL DE CAMARGO NEVES SACCO

Tese apresentada à Escola de Educação

Física e Esporte da Universidade de São

Paulo, como requisito parcial para obtenção do grau de Doutor em Educação Física.

ORIENTADOR: PROF. DR. ALBERTO CARLOS AMADIO 


\section{AGRADECIMENTOS}

Dirijo meus sinceros agradecimentos a todos aqueles que direta ou indiretamente contribuíram para o produto final desta importante etapa de minha vida. Agradeço especialmente:

Ao meu amado marido, José Gustavo Marques da Silva, pelo amor, carinho e eterna paciência em agüentar minhas crises e me apoiar durante todos os anos de desenvolvimento deste projeto;

Ao Departamento de Fisioterapia, Fonoaudiologia e Terapia Ocupacional da Universidade de São Paulo, em especial aos docentes, funcionários e alunos do Curso de Fisioterapia, pela compreensão e apoio durante meu doutoramento;

Ao Hospital Universitário, representado pela equipe da Clínica Médica e Cirúrgica, que permitiu gentilmente 0 estudo de seus pacientes diabéticos;

À FAPESP - Fundação de Amparo à Pesquisa do Estado do São Paulo, pelo financiamento parcial do presente estudo e financiamento total do projeto de pesquisa de apoio a este doutoramento;

Ao Prof. Dr. Antônio Carlos Stringhini Guimarães, membro da Comissão examinadora do Exame de Qualificação, pelas inestimáveis contribuições dadas, assim como pelo seu empenho e disposição;

Aos funcionários da EEFEUSP e aos pacientes diabéticos, voluntários essenciais nesta pesquisa, por sua disponibilidade e empenho;

À equipe da biblioteca da EEFEUSP, em especial à Lúcia, Selma e Regiane, pela inestimável ajuda na busca da literatura utilizada e na leitura dedicada e eficiente deste manuscrito;

À Maria de Lourdes Silva e à Célia Yamaoka, pela atenção especial, carinho e competência nos assuntos da Pós-graduação da EEFEUSP;

À equipe do Laboratório de Biomecânica da EEFEUSP, cujos esforços, ajuda inestimável e sincera compreensão permitiram que este projeto fosse concluído com êxito;

À Márcia Regina de Sá, por sua imensa dedicação, organização, desde a coleta de dados até a elaboração e correção deste manuscrito, à sua preciosa amizade e carinho em todos os momentos de minha formação, que para mim não tem palavras de agradecimento que sejam suficientes;

Ao Prof. Dr. Júlio Cerca Serrão, por seus questionamentos, sugestões e pelos seus ensinamentos indispensáveis para minha formação acadêmica e desenvolvimento de todo o projeto, 
Ao Prof. Dr. Marcos Duarte, cujo rigor científico e competência, contribuiu fortemente com suas sugestões e críticas construtivas nos momentos mais decisivos;

Aos amigos Denise Rolim, Denise Alignani, Fernanda Vivolo, Maria Carolina Fornari, Iris Rotger, Gil Konno, Daniel Pardal, Ana Assumpção e Maria Clara, pelo carinho especial e pela compreensão demonstrada nos momentos críticos desta jornada;

Ao Bachir, Marli e todo o grupo que me deram um suporte psicológico e crescimento interior responsável pelo sucesso desta finalização;

Ao Prof. Dr. Alberto Carlos Amadio, por sua amizade, seu primor no tratamento com seus alunos, seu poder de agregar um grupo maravilhoso do qual tenho o privilégio de fazer parte, sua imensa competência e esforço em nos ensinar e orientar a cada passo de nossas vidas. Agradeço à sua indispensável dedicação em todas as decisões acadêmicas, científicas e até pessoais que tomei ao longo de todos estes anos de orientação;

E finalmente, aos meus queridos pais, Reinaldo e Sandra, a quem devo o valor que dou ao conhecimento e à educação e à minha amada irmã Paula, família a quem agradeço o grande incentivo para minha formação acadêmica, 0 amor dedicado e 0 apoio durante todo esse longo processo de formação acadêmica, desde minha graduação em 1992. 


\section{SUMÁRIO}

Página

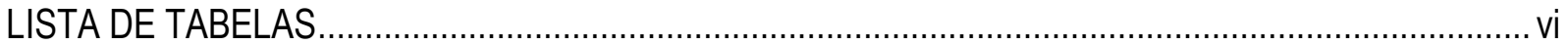

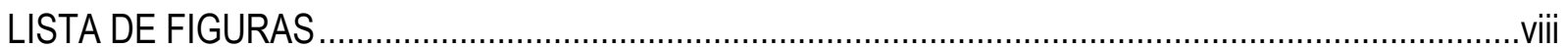

LISTA DE ANEXOS

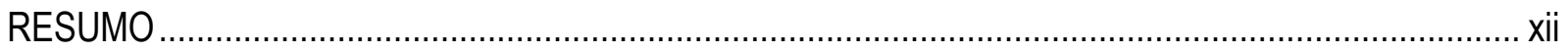

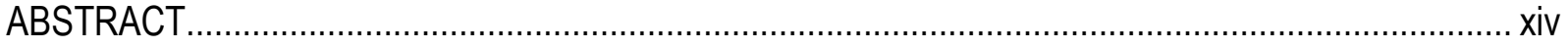

1 INTRODUÇÃO

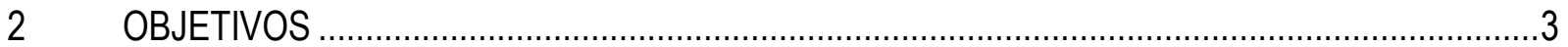

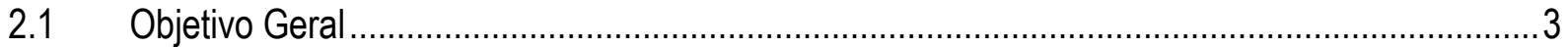

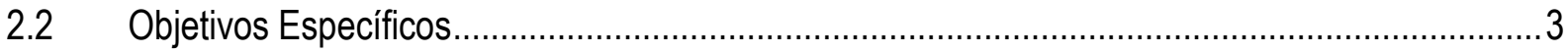

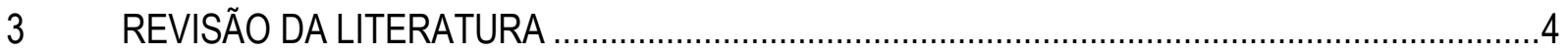

3.1 A neuropatia periférica diabética: aspectos da fisiopatologia e características funcionais........... 4

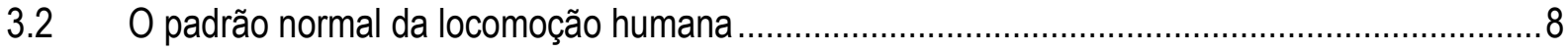

3.3 Caracterização anatômica da região plantar: estrutura e função...............................................11

3.4 Alterações morfológicas e funcionais dos pés em decorrência de solicitações mecânicas extremas

3.5 Características biomecânicas e mecanismos de adaptação da locomoção em esteira rolante.17

3.5.1 Aspectos biomecânicos relacionados ao processos de acomodação e habituação à esteira

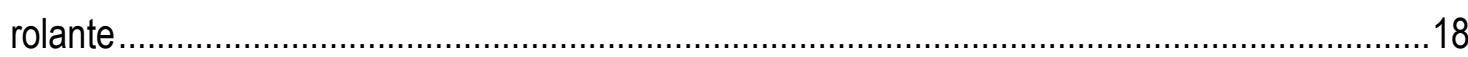

3.5.2 Caracterização espacial, temporal e variação angular da locomoção na esteira rolante............20

3.5.3 Parâmetros dinâmicos da locomoção na esteira rolante............................................................24

3.5.4 Atividade eletromiográfica dos músculos envolvidos na locomoção em esteira rolante ............25

3.6 Alterações biomecânicas da marcha de portadores da neuropatia periférica diabética.............26

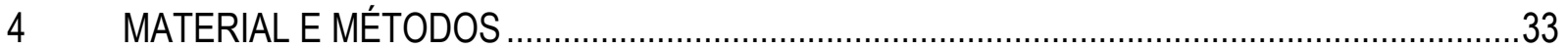

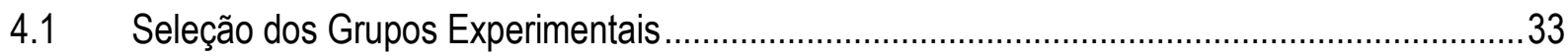

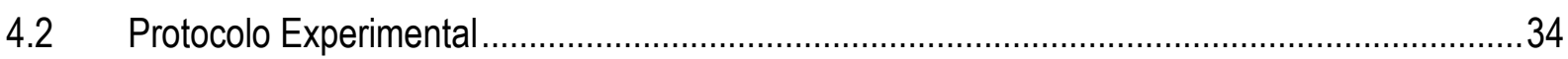

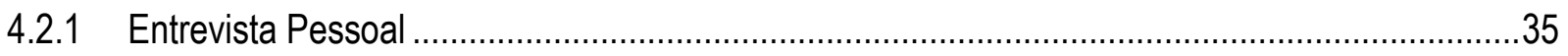


4.2.2 Avaliação da cronaxia sensitiva e tolerância à dor na superfície plantar e cronaxia motora nos músculos selecionados. .35

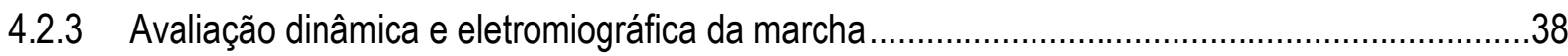

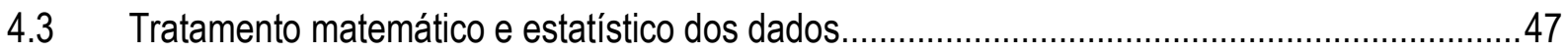

4.4 Controle do erro metodológico e limitações experimentais.........................................................49

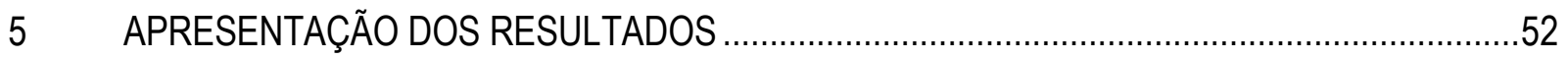

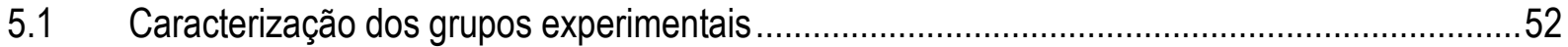

5.2 Resultados da Avaliação da sensibilidade plantar e motora e limiar de tolerância à dor ...........54

5.3 Resultados da avaliação do andar - força reação do solo e variáveis temporais e espaciais do andar.

5.4 Resultados da atividade eletromiográfica durante a marcha ....................................................60

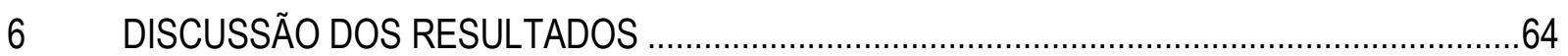

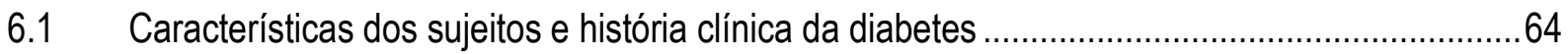

6.2 Limiares de sensibilidade: tolerância à dor, cronaxia sensitiva e motora..................................66

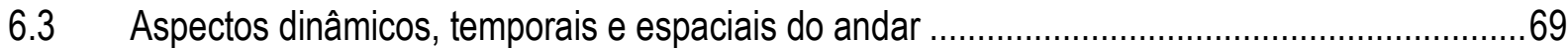

6.4 Padrão de recrutamento muscular durante 0 andar.............................................................

6.5 Parâmetros biomecânicos do andar, respostas somatossensoriais e motoras a partir da análise

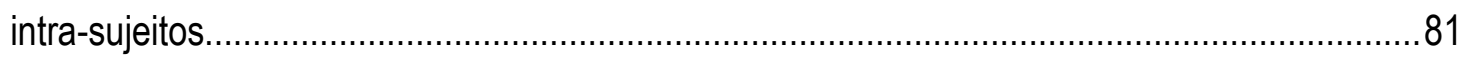

6.6 Análise intra-sujeitos para a mesma velocidade auto-selecionada ..........................................86

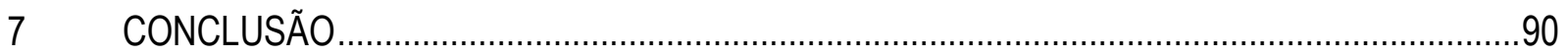

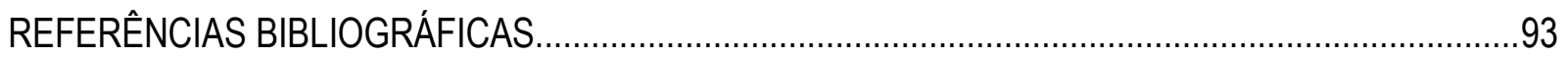




\section{LISTA DE TABELAS}

TABELA 1 - Características antropométricas, idade e gênero dos grupos controle (GC) e diabético (GD) estudados.

TABELA 2 - Valores médios e desvios padrão da cronaxia sensitiva (ms) e tolerância à dor $(\mathrm{mA})$ em quatro áreas plantares, para o grupo controle (GC) $(n=20)$ e grupo diabético (GD) $(n=16)$

TABELA 3 - Valores médios e desvios padrão da cronaxia motora (ms) em três músculos da perna e coxa, para o grupo controle (GC) $(n=20)$ e grupo diabético (GD) $(n=15)$.

TABELA 4 - Valores médios e desvios padrão das variáveis da Força reação do solo, temporais e espaciais durante o ciclo da marcha dos sujeitos do grupo controle (GC) $(n=20)$ e do grupo diabético (GD) $(n=15)$...

TABELA 5 - Padrão temporal de ativação dos músculos $\mathrm{m}$. vasto lateral, $\mathrm{m}$. tibial anterior e $\mathrm{m}$. gastrocnêmio lateral direito $(D)$ e esquerdo $(E)$ dos sujeitos do GC e dos sujeitos GD......61

TABELA 6 - Distribuição das idades máximas e mínimas (anos) e CV (\%) dos dois grupos estudados: GC e GD.

TABELA 7 - Tempo de ocorrência do primeiro pico de força vertical nos sujeitos do grupo controle e diabético (\% do tempo de apoio)......

TABELA 8 - Coeficientes de variação (\%) das variáveis da força reação do solo para os grupos GC e GD..

TABELA 9 - Coeficientes de variação (\%) das variáveis temporais do ciclo do andar para os grupos GC e GD.

TABELA 10 - Coeficientes de variação (\%) das variáveis espaciais do ciclo do andar para os grupos GC e GD.

TABELA 11 - Tempo de ocorrência da força vertical mínima nos sujeitos do grupo controle e diabético ( $\%$ do tempo de apoio). 
TABELA 12- Características dos sujeitos diabéticos neuropatas para análise individual (HAHipertensão Arterial).

TABELA 13 - Áreas plantares e músculos cujos valores de sensibilidade somatossensorial e motora representaram alterações para os sujeitos diabéticos neuropatas selecionados.

TABELA 14 - Padrão de recrutamento temporal (\% tempo de apoio) dos m. gastrocnêmio lateral, $\mathrm{m}$. tibial anterior e m. vasto lateral do GC e dos sujeitos diabéticos neuropatas selecionados. Destacado em cinza os valores atrasados em relação aos sujeitos controle.

TABELA 15 - Valores médios e desvios padrão das variáveis da Força reação do solo e parâmetros temporais durante o ciclo da marcha do grupo GC e dos sujeitos diabéticos neuropatas selecionados.

TABELA 16- Características do sujeito diabético GD09 e do sujeito controle GC14 para análise comparativa.

TABELA 17 - Valores da cronaxia sensitiva $(\mathrm{ms})$ e tolerância à dor $(\mathrm{mA})$ em quatro áreas plantares, para o GC14 e para o GD09.

TABELA 18- Padrão de recrutamento temporal (\% tempo de apoio) dos $\mathrm{m}$. gastrocnêmio lateral, $\mathrm{m}$. tibial anterior e m. vasto lateral do GC14 e do GD09.

TABELA 19 - Valores médios e desvios padrão das variáveis da Força reação do solo e variáveis temporais durante o ciclo da marcha do GC14 e do GD09. 


\section{LISTA DE FIGURAS}

Página

FIGURA 1 - Diagrama mostrando vista (A) longitudinal e (B) superior do coxim do calcanhar. Os septos fibrosos são demonstrados sem o tecido adiposo interposto (adaptado de BRESSLER \& BRESSLER, 1991)

FIGURA 2 - (A) Tecido adiposo elástico normal com os septos fibrosos normais do coxim do calcanhar de uma criança de 4 anos (ampliação de 60 x). (B) Tecido adiposo elástico do coxim do calcanhar de uma mulher de 60 anos (ampliação de $60 \mathrm{x}$ ); o tecido conectivo é menos denso, células adiposas achatadas, infiltração de gordura pelos septos e perda de tecido que pode ser vista na parte superior direita da figura, na parte mais esbranquiçada (adaptado de KUHNS, 1949)...

FIGURA 3 - Índice de compressibilidade visual (adaptado de JORGENSEN, 1985)............................17

FIGURA 4 - Diagrama de blocos representando as etapas do protocolo experimental.........................36

FIGURA 5 - Áreas plantares estudadas na avaliação eletrofisiológica dos sujeitos: cronaxia sensitiva e tolerância à dor.

FIGURA 6- Representação esquemática da determinação da reobase e da cronaxia sensitiva e motora.

FIGURA 7- Gerador Universal de pulsos Omni Pulse 901.

FIGURA 8 - Sistema Gaitway da Kistler. esteira rolante com duas plataformas de força embutidas.

(adaptado de GAITWAY, 1996).

FIGURA 9 - Curva esquemática da Força reação do solo representando as variáveis estudadas: (a) pico de força vertical máxima 1 e 2 (números 1 e 3), (b) força vertical mínima (número 2), (c) taxa de crescimento 1 e 2 (TC 1 e TC2), (d) deflexão da força. 42

FIGURA 10 - Ilustração esquemática de variáveis espaciais do ciclo da marcha: comprimento de um passo, comprimento da passada e apoio duplo.

FIGURA 11 - Sistema Bagnoli-8 com oito canais da Delsys. 
FIGURA 12 - Etapas do tratamento matemático do sinal eletromiográfico para a elaboração dos envoltórios lineares. (A) Sinal EMG bruto. (B) Sinal EMG retificado e retirado o off-set. (C) Sinal EMG retificado (cinza) e sinal filtrado com freqüência de corte de $5 \mathrm{~Hz}$ (preto).

(D) Envoltórios lineares.

FIGURA 13 - Envoltórios lineares dos m. vasto lateral, m. tibial anterior e m. gastrocnêmio lateral representando as variáveis estudadas. Para o m. vasto lateral: (1) 10 pico de ativação, (2) início da $2^{\mathrm{a}}$ ativação, (3) $2^{\circ}$ pico de ativação. Para o m. tibial anterior: (4) $1{ }^{\circ}$ pico de ativação, (5) início da 2a ativação, (6) $2^{\circ}$ pico de ativação. Para 0 m. gastrocnêmio lateral: (7) início da ativação, (8) pico de ativação e (9) término da ativação.

FIGURA 14 - Força vertical média em função do peso corporal (PC) do pé direito e esquerdo do grupo controle $(n=20)$, durante 0 andar em esteira.

FIGURA 15- Força vertical média em função do peso corporal (PC) do pé direito e esquerdo do grupo diabético $(n=16)$, durante 0 andar em esteira.

FIGURA 16 - Curvas média dos envoltórios lineares da EMG (normalizado pela média) dos $\mathrm{m}$. vasto lateral, m. tibial anterior e m. gastrocnêmio lateral direito do grupo controle $(n=20)$ e do grupo diabético $(n=15)$ durante 0 apoio na marcha em esteira.

FIGURA 17- Curvas médias dos envoltórios lineares da EMG (normalizado pela média) dos $\mathrm{m}$. vasto lateral, $\mathrm{m}$. tibial anterior e $\mathrm{m}$. gastrocnêmio lateral esquerdo do grupo controle $(n=20)$ e do grupo diabético $(n=15)$ durante 0 apoio na marcha em esteira.

FIGURA 18 - Representação das áreas plantares estudadas para avaliação da cronaxia sensitiva. A cor cinza claro identifica as áreas cujos valores de cronaxia sensitiva apresentaram-se maiores para o grupo GD e fora dos padrões de normalidade. A cor cinza escuro identifica as áreas cujos valores de cronaxia sensitiva apresentaram-se significativamente maiores para o grupo GD, conforme TABELA 2.

FIGURA 19 - Representação das áreas plantares estudadas para avaliação do limiar de tolerância à dor. A cor cinza claro identifica as áreas cujos valores de tolerância à dor apresentaram-se maiores para o grupo GD e fora dos padrões de normalidade. A cor cinza escuro identifica as áreas cujos valores de tolerância à dor apresentaram-se significativamente maiores para o grupo GD, conforme TABELA 2. 
FIGURA 20 - Força vertical em função do peso corporal (PC) do pé direito e esquerdo do sujeito GC02 ( $n=30$ ) (vide texto). Linha vertical sinalizando a ocorrência da Fy1 em 19\% do tempo de apoio.

FIGURA 21 - Força vertical em função do peso corporal (PC) do pé direito e esquerdo do sujeito GD06 $(n=30)$ (vide texto). Linha vertical sinalizando a ocorrência da Fy1 direita em 30\% do tempo de apoio e da Fy1 esquerda em 29\%.

FIGURA 22 - Curvas médias e desvios padrão da EMG normalizado pela média do $\mathrm{m}$. vasto lateral direito e esquerdo do sujeito GD03, durante o andar em esteira. A linhas verticais indicam o pico de ativação atrasado $(17 \% \mathrm{D}, 16 \% \mathrm{E})$, o final da atividade $(66 \% \mathrm{D}, 58 \%$ E) e a duração da ativação do $m$. vasto lateral no início da fase de apoio.

FIGURA 23 - Força vertical em função do peso corporal (PC) do pé direito e esquerdo do sujeito GD12 (vide texto). Linha vertical sinalizando a ocorrência da Fymin direita e esquerda em $51 \%$ do tempo de apoio.

FIGURA 24 - Força vertical em função do peso corporal (PC) do pé direito e esquerdo do sujeito GC20 (vide texto). Linha vertical sinalizando a ocorrência da Fymin direita em 41\% do tempo de apoio e da Fymin esquerda em 40\% 


\section{LISTA DE ANEXOS}

Página

ANEXO I - Termo de consentimento informado em participação da pesquisa. 101

ANEXO II - Questionário elaborado para a etapa da entrevista pessoal, para caracterização dos grupos experimentais segundo história clínica da diabetes e cuidados com os pés........102

ANEXO III - Resultados do pré-experimento - teste piloto realizado durante a elaboração do

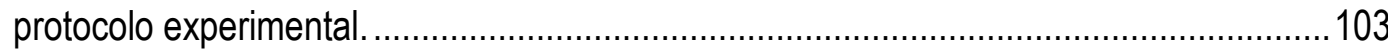

ANEXO IV- Função Matemática GAITWAY desenvolvida em ambiente Matlab v. 5.3. .....................105

ANEXO V - Função Matemática BIONICA desenvolvida em ambiente Matlab v. 5.3........................116

ANEXO VI - Curvas da FRS e eletromiografia referentes ao andar em esteira de todos os sujeitos do grupo controle (GC).

ANEXO VII - Curvas da FRS e eletromiografia referentes ao andar em esteira de todos os sujeitos do grupo diabético (GD). 


\title{
RESUMO
}

\section{INFLUÊNCIA DA NEUROPATIA DIABÉTICA NO COMPORTAMENTO DE RESPOSTAS BIOMECÂNICAS E SENSORIAIS NO ANDAR EM ESTEIRA ROLANTE}

\author{
Autora: ISABEL DE CAMARGO NEVES SACCO \\ Orientador: ALBERTO CARLOS AMADIO
}

A investigação de parâmetros biomecânicos no movimento humano tem trazido importantes discussões sobre a função do sistema músculo-esquelético e 0 controle deste movimento. $O$ andar humano é um dos comportamentos motores mais investigados pela biomecânica e seus aspectos mecânicos contribuem de forma a caracterizar, identificar e intervir em situações patológicas. A investigação de parâmetros dinâmicos, cinemáticos e eletromiográficos na marcha patológica pode beneficiar de forma significativa a compreensão dos mecanismos de controle do andar e as alterações compensatórias geradas, assim como contribuir nas intervenções terapêuticas e preventivas em sujeitos portadores de alguma doença que acometa o sistema músculo-esquelético. No presente estudo, buscou-se descrever e interpretar, sob a perspectiva da biomecânica, 0 andar em cadência auto-selecionada de sujeitos diabéticos neuropatas em esteira rolante, considerando os parâmetros dinâmicos, temporais, espaciais e eletromiográficos durante a fase de apoio. Investigou-se também aspectos sensoriais plantares e motores a fim de caracterizar os sujeitos neuropatas e controles estudados. Valores da sensibilidade somatossensorial e limiares de tolerância à dor nos sujeitos diabéticos neuropatas apresentaram significativamente maiores em relação ao grupo de sujeitos controle estudado, valores considerados fora do padrão de normalidade esperado. A cadência autoselecionada e a velocidade obtida na esteira rolante foram significativamente menores durante 0 andar dos neuropatas em relação aos sujeitos controle. Os tempos de apoio simples, duplo, comprimento da passada e do passo durante a marcha nos sujeitos diabéticos neuropatas apresentaram-se significativamente maiores em relação ao grupo controle. Foram observados menores picos de força 
vertical nos sujeitos neuropatas e menores deflexões da força vertical, conseqüências secundárias da estratégia de redução da velocidade do andar em neuropatas que buscam um padrão mais conservativo e estável do seu andar. As respostas eletromiográficas dos músculos da perna e coxa apresentaram-se com menores magnitudes e com picos de ativação atrasados em relação ao padrão normal de recrutamento, especialmente $0 \mathrm{~m}$. tibial anterior bilateralmente nos neuropatas. Interpreta-se tal fato como uma provável alteração no mecanismo de controle central e/ou periférico da marcha em sujeitos diabéticos neuropatas decorrente dos déficits sensoriais periféricos e motores conseqüentes da doença investigada. O mecanismo de redução de choques na marcha apresentou-se de forma ineficiente em função das respostas atrasadas eletromiográficas tanto de $\mathrm{m}$. vasto lateral, quanto de $\mathrm{m}$. tibial anterior. Conclui-se que a neuropatia diabética periférica acomete não só respostas somatossensoriais e motoras periféricas mas também mecanismos intrínsecos de controle modificando a eficiência do tornozelo em seu papel na marcha, comprometendo desta forma alguns dos principais requisitos para o andar que são a progressão e o equilíbrio.

Palavras-chave: Biomecânica, andar, neuropatia diabética periférica, força reação do solo, eletromiografia, esteira rolante 


\title{
ABSTRACT \\ INFLUENCE OF THE DIABETIC NEUROPATHY ON THE BEHAVIOR OF BIOMECHANICAL AND SENSORIAL RESPONSES IN TREADMILL GAIT
}

\author{
Author: ISABEL DE CAMARGO NEVES SACCO \\ Advisor: ALBERTO CARLOS AMADIO
}

\begin{abstract}
Biomechanical investigation of the human movement has been bringing important discussions about the musculoskeletal system functions and the control of movement. The human walking is one of the most studied motor behaviors and its mechanical aspects contribute to characterize, identify, and intervene in pathological conditions. Dynamic, kinematic, and electromyographic analyses of pathological gait can significantly help the comprehension of the control mechanism of gait and its compensatory alterations. These analyses can also contribute to therapeutic and preventive interventions in patients whose walking behavior is altered due to some disease that accomplish the neuromotor system. In the present study, we described and interpreted self-cadence walking in a treadmill of neuropathic diabetic subjects under biomechanical considerations, such as dynamic, temporal, spatial, and electromyographic analysis during stance phase. We also studied sensorial and motor aspects in order to characterize the neuropathic and control subjects. The somatossensorial responses and pain tolerance threshold in the neuropathic subjects were significantly higher and considered away from the normal patterns. The self-cadence and the treadmill velocity were significantly lower in neuropathic gait. Single and double stance time, stride and step length were significantly higher during neuropathic gait. The neuropathic subjects showed lower vertical force peaks and lower deflections of vertical force and those findings were secondary consequences of the conservative strategy of lowering the gait velocity adopted by the neuropathic in order to reach a more stable locomotor pattern. The electromyographic responses of the thigh and leg muscles in neuropathic subjects showed lower magnitudes and were delayed comparing to the normal recruitment pattern,
\end{abstract}


specially the anterior tibialis muscle right and left. These findings lead us to conclude that probably central and/or peripheral control mechanisms of the gait of neuropathic diabetic patients are altered due to somatossensorial and motor deficits. The mechanism of load reduction during walking was considered inefficient because of the activation delay of the lateral vastus and anterior tibialis muscles. We conclude that the peripheral diabetic neuropathy damages not only somatossensorial and motor sources but also intrinsic mechanisms of motor control leading to alterations in the ankle efficiency in gait. This resulting distal inefficiency compromises some of the principal requirements to gait, which are progression and balance.

Keywords: Biomechanics, gait, peripheral diabetic neuropathy, ground reaction force, electromyography, treadmill 


\section{INTRODUÇÃO}

A análise da locomoção humana apresenta-se como uma área de estudos de características marcadamente multidisciplinares dentro do domínio de conhecimentos da Biomecânica, para a interpretação da complexa estrutura funcional do movimento humano. A Biomecânica examina o corpo humano e seus movimentos, fundamentando-se nas leis, princípios e métodos mecânicos e conhecimentos anátomo-fisiológicos (AMADIO \& DUARTE, 1998). Constitui-se em uma área interdisciplinar e reúne em seu domínio profissionais das áreas de educação física, esporte, fisioterapia, biologia, medicina, engenharia, física, entre outros. A Biomecânica utiliza, portanto, diversas ferramentas multidisciplinares para a compreensão de fenômenos relacionados ao movimento humano, buscando explicar como ele acontece na natureza, a partir de parâmetros cinemáticos e cinéticos (ZERNICKE, 1981).

Através da análise biomecânica buscamos uma interpretação quantitativa e objetiva dos fenômenos relacionados à organização das interações entre processos centrais e periféricos e as forças reativas do ambiente físico. Isto é feito através de um registro complexo do movimento em sua manifestação total, através dos métodos de medição em biomecânica: dinamometria, cinemetria, eletromiografia e antropometria. Devido a dificuldade de se quantificar parâmetros da biomecânica interna e consequentemente das causas do movimento, o estudo sobre o funcionamento físico das estruturas biológicas tem se baseado principalmente em medidas experimentais externas (AMADIO, LOBO DA COSTA, SACCO, SERRÃO, ARAUJO, MOCHIZUKI \& DUARTE, 1999).

Muitos estudos têm se dedicado à investigação da marcha patológica com o objetivo de descrever parâmetros biomecânicos que identifiquem e/ou caracterizem a doença presente. Estas investigações buscam de alguma maneira determinar parâmetros que diferenciem uma marcha normal de uma marcha de um sujeito que apresente uma específica doença que comprometa funcional e/ou estruturalmente o sistema neuromuscular. Até mesmo, algumas destas investigações buscam um diagnóstico precoce da doença preexistente através da identificação de um determinado parâmetro biomecânico já alterado durante a marcha. No presente estudo, a neuropatia diabética periférica será investigada, assim como suas manifestações na marcha. A neuropatia periférica diabética é uma complicação crônica comum em diabéticos longo termo, levando o indivíduo à perda progressiva de sensibilidade somatossensorial, propriocepção e função muscular (PIRART, 1979). Uma das consequêencias mais trágicas para o paciente diabético neuropata é o procedimento cirúrgico da amputação de parte do membro inferior, decorrente de infecções sucessivas em lesões cutâneas 
principalmente na superfície plantar (úlceras plantares), que levam 0 tecido à necrose e consequentemente à amputação (THOMAS, 1991).

O estudo Multicêntrico da Prevalência de Diabetes Mellitus no Brasil (TAXA, 1999), popularmente denominada diabetes, estimou a prevalência dessa doença em $7,6 \%$ da população brasileira entre 30 e 69 anos de idade, o que corresponderia a uma prevalência de diabetes na população geral de 33,8 diabéticos por 1000 habitantes. Observa-se ainda nos últimos anos, a importância da diabetes como um problema de saúde crescente, tanto em relação ao aumento de sua prevalência e incidência, quanto em relação às repercussões sociais e econômicas dessa doença traduzidas pelas mortes prematuras, absenteísmo e incapacidade para o trabalho, além dos custos associados ao seu controle ou ao tratamento de suas complicações.

No Brasil, estima-se que os custos diretos e indiretos com a diabetes, isto é, internações hospitalares, monitoração da doença, perda de rendimento devida à morbidade e mortalidade, ultrapassam 1 bilhão de reais ao ano, ou seja, 0,3\% do PIB (TAXA, 1999). Grande parte dessas internações é conseqüência das complicações que se desenvolvem em diabéticos quando não há tratamento adequado, e dentre elas destaca-se a neuropatia diabética, a insuficiência renal e a retinopatia. A Diabetes mellitus é apontada como um importante fator que aumenta em 40 vezes o risco do diabético sofrer amputações em membros inferiores, quando comparado à população em geral. 0 Diabetes Control and Complications Trial - DCCT (THE DIABETES, 2000) destacou que o bom controle metabólico do diabetes representa um papel de fundamental importância para se evitar o aparecimento e o desenvolvimento de complicações microvasculares em diabéticos, tendo sido demonstrado que uma queda de dois pontos nos níveis de hemoglobina glicosilada representa uma diminuição de $50 \%$ nos riscos dessas complicações.

A quantificação de variáveis biomecânicas em diabéticos neuropatas durante o movimento ou em postura estática tem demonstrado ser importante ferramenta para a prevenção, diagnóstico e controle da terapia de portadores do complexo quadro denominado popularmente de "Pé diabético". Estudos sobre a distribuição da pressão plantar deram grande contribuição para a interpretação das conseqüências mecânicas da neuropatia periférica diabética, de forma a intervir terapeuticamente em regiões plantares onde a pressão plantar excedia limites aceitáveis podendo levar a formação de ulcerações (CAPUTO, CAVANAGH, ULBRECHT, GIBBONS \& KARCHMER; 1994). 


\section{OBJETIVOS}

A partir das considerações tecidas nesta breve introdução, destaca-se a importância social do estudo devido a alta incidência de diabetes na população brasileira, bem como a incidência da neuropatia periférica em diabéticos médio - longo termo. Portanto, em função das conseqüências prejudiciais decorrentes da neuropatia periférica diabética relacionadas à perda da sensibilidade somatossensorial e da função motora destes sujeitos, o presente estudo busca investigar o andar destes sujeitos neuropatas a partir de uma abordagem biomecânica.

\subsection{Objetivo Geral}

O presente estudo busca descrever e interpretar a neuropatia periférica diabética a partir de parâmetros biomecânicos: dinâmicos, eletromiográficos e eletrofisiológicos. 0 conhecimento acerca destes parâmetros biomecânicos permitirá estabelecer parâmetros de referência como possíveis indicadores para a interpretação do movimento na investigação e análise clínica.

\subsection{Objetivos Específicos}

Mais especificamente, este estudo buscará estudar o comportamento dinâmico e eventos temporais do andar em esteira rolante de sujeitos diabéticos neuropatas e comparar com um grupo de sujeitos saudáveis. Buscar-se-á também estudar as respostas eletromiográficas da perna e coxa durante 0 andar em esteira rolante de sujeitos diabéticos neuropatas e comparar com um grupo de sujeitos saudáveis. De forma a caracterizar melhor a neuropatia, buscar-se-á estudar as respostas eletrofisiológicas - cronaxia motora e sensitiva e limiar de tolerância à dor - nos sujeitos neuropatas e controles de forma a comparar as condições eletrofisiológicas de ambos os grupos. E finalmente, buscar-se-á verificar relações de dependência entre os parâmetros eletrofisiológicos e biomecânicos (dinâmicos e eletromiográficos) durante 0 andar destes sujeitos. Com isso, pode-se identificar prováveis mecanismos compensatórios criados nas articulações estudadas durante a marcha, a fim de minimizar os efeitos deletérios da diminuição progressiva da sensibilidade e da função muscular das extremidades em função da evolução da neuropatia diabética. 


\section{REVISÃO DA LITERATURA}

A neuropatia periférica diabética pode ser caracterizada como uma doença decorrente da diabetes longo termo que acomete o sistema nervoso periférico comprometendo funções somatossensoriais, bem como motoras nos sujeitos diabéticos, especialmente nas extremidades distais. Considerando estas características, as seções que se seguem discutirão características fisiopatológicas, funcionais e neurológicas desta doença; características estruturais e funcionais do tecido plantar que normalmente é o primeiro a ser acometido pela doença e cuja preservação é fundamental para a execução de tarefas locomotoras. Esta revisão e discussão da literatura também buscará discutir aspectos relacionados à lesão deste tegumento e as conseqüências destas degenerações para a função do pé e para o comportamento normal do andar.

Nas seções que se seguem também serão discutidos aspectos relacionados ao andar em piso fixo e em piso móvel, pois estudaremos aplicações da locomoção na esteira rolante, aspectos estes relacionados às respostas dinâmicas, cinemáticas e eletromiográficas durante 0 andar neste piso específico. E finalmente serão discutidas as alterações biomecânicas na marcha de sujeitos diabéticos neuropatas de forma a viabilizar a possível comparação dos resultados apresentados na literatura com os resultados a serem obtidos no presente estudo.

\subsection{A neuropatia periférica diabética: aspectos da fisiopatologia e características funcionais}

A neuropatia periférica diabética mais comumente encontrada é a polineuropatia simétrica distal, que promove distúrbios sensoriais e motores distais inicialmente e progridem para distúrbios mais proximais e autonômicos (SIMONEAU, DERR, ULBRECHT, BECKER \& CAVANAGH, 1996; COURTEMANCHE, TEADSDALE, BOUCHER, FLEURY, LAJOIE \& BARD, 1996). Estes distúrbios promovem déficits sensoriais que comprometem uma série de funções na postura e locomoção humana. Estes déficits sensoriais e motores têm influências significativas nestes sujeitos neuropatas diminuindo a mobilidade articular e promovendo instabilidades importantes tanto em posturas estáticas como em movimento (COURTEMANCHE et al., 1996).

A etiologia e patogênese da neuropatia periférica diabética ainda é desconhecida mas, segundo CELIKER, BASGÖZE \& BAYRAKTAR (1996), há duas grandes categorias de explicação para tal etiologia: vascular e metabólica e diante disso, há ainda muitas controvérsias relacionando o controle glicêmico e metabólico rígido e a melhora ou até mesmo a prevenção do aparecimento da neuropatia periférica. Os fatores metabólicos envolvidos na etiologia da neuropatia diabética estão relacionados ao 
acúmulo de determinados metabólitos oriundos da via bioquímica da Poliólise, dentre eles o sorbitol, devido a neurotoxidade da glicose, metabólitos esses que seriam responsáveis por lesões estruturais nas fibras nervosas, e consequentemente alterações na velocidade de condução do estímulo (CATTALINE \& CANCIAN, 1994; THOMAS, 1991). Isto leva à diminuição progressiva da sensibilidade somatossensorial e motora. As fibras nervosas mais atingidas por estes subprodutos bioquímicos da glicose são as fibras tipo C, amielínicas, de pequeno diâmetro, responsáveis pela condução do estímulo da dor. Estas fibras não dependem da insulina para a entrada de glicose, portanto são muito vulneráveis a qualquer alteração glicêmica. Desta forma, qualquer instabilidade do controle glicêmico seria facilmente percebido por estas fibras (CRUTCHFIELD \& BARNES, 1984). Considerando o fato exposto anteriormente, em se tratando de indivíduos diabéticos cujos controles são instáveis e descompensados, existe uma maior probalidade de lesão das fibras nervosas periféricas e que, a longo prazo, caracteriza-se pela polineuropatia diabética.

Além da natureza metabólica da etiologia da neuropatia diabética, estudos apontam causas de natureza vascular. Ocorre o aumento da espessura dos vasos satélites aos nervos periféricos relacionado à reduplicação da lâmina basal e acúmulo de fibrina na parede deste vaso, estreitando-o e consequentemente alterando a nutrição dos nervos e comprometendo a sua velocidade de condução (THOMAS, 1991).

As lesões periféricas em sujeitos diabéticos, segundo PIRART (1979), ocorrem em 25\% deles após 10 anos de diagnóstico de diabetes, em mais do que 50\% dos diabéticos com mais de 20 anos de diagnóstico e, segundo ORCHARD, DORMAN, MASER, BECKER, DRASH \& ELLIS (1990) em mais de $75 \%$ dos diabéticos com mais de 30 anos de diagnóstico. Segundo SIMONEAU et al. (1996), 50\% dos sujeitos diabéticos com tempo de diagnóstico superior a 25 anos apresentam a neuropatia periférica. Nos Estados Unidos, estima-se que 30,6 \% dos homens diabéticos e 39,8 \% das mulheres apresentam a neuropatia periférica (WEERASURIYA, SIRIBADDANA, WIJEWEERA, DISSANAYEKA, WIJESEKERA \& FERNANDO, 1998). Na Finlândia, verifica-se que dos diabéticos recém diagnosticados, $1,5 \%$ já apresentam a neuropatia periférica sintomática, 2,3\% já apresentam sinais desta doença e 15,2\% já apresentam respostas eletrofisiológicas anormais (WEERASURIYA et al., 1998).

Na literatura, muito se tem abordado o tema que relaciona o tempo de diabetes e o grau de severidade da neuropatia, e isto se deve às teorias metabólicas existentes para explicar a etiologia da neuropatia diabética, mas ainda não se chegou a um consenso, uma vez que existem outras teorias que conjuntamente com esta, explicam a patogênese desta doença. CAVANAGH, DERR, ULBRECHT, 
MASER \& ORCHARD (1992) encontraram alta associação entre o grau da neuropatia diabética avaliado através de eletroneuromiografia dos nervos fibular raiz motora e sural raiz sensitiva, e o tempo de diagnóstico da diabetes. CELIKER et al. (1996) encontraram significativa correlação entre o tempo de diagnóstico da neuropatia e variáveis eletrofisiológicas dos nervos periféricos, assim quanto maior o tempo de diagnóstico da neuropatia periférica, maiores alterações eletrofisiológicas em diabéticos neuropatas. Os mesmos resultados foram encontrados por WEERASURIYA et al. (1998).

HIRAI, YASUDA, JOKO, MAEDA \& KIKKAWA (2000) avaliaram a velocidade de condução nervosa, entre outras análises imuno-histoquímicas de nervos cutâneos em diabéticos neuropatas e verificaram uma diminuição consistente no número de fibras nervosas cutâneas nestes sujeitos, assim como uma importante diminuição de velocidade de condução nervosa especialmente no nervo sural.

DICK, KARNES, DAUBE, O'BRIEN \& SERVICE (1985) discutem que em diabéticos neuropatas o nervo fibular é o que apresenta maior anormalidade em testes eletrofisiológicos, seguido do nervo sural e medial. Portanto, pode-se inferir desta informação que com a evolução da neuropatia periférica, os m. fibular longo e curto, m. tibial anterior e m. gastrocnêmio, respectivamente, irão ser os mais acometidos, tendo suas funções mais prejudicadas (RICHARDSON, CHING, HURVITZ, 1992). Neste mesmo estudo, os autores sugerem que o potencial de ação do nervo sural é um excelente preditor para a presença da neuropatia diabética.

Outra correlação comumente feita em trabalhos clínicos é entre medidas metabólicas, tais como glicemia e hemoglobina glicosilada, e a neuropatia periférica diabética. WEERASURIYA et al. (1998) encontraram correlações negativas entre a glicemia e a severidade da neuropatia diabética determinada através de estudos eletrofisiológicos, ou seja, quanto maior a glicemia, menor a velocidade de condução nervosa especialmente do nervo fibular e medial. Da mesma forma, CELIKER et al. (1996) observaram uma importante correlação entre as medidas de glicemia e hemoglobina glicosilada e parâmetros eletrofisiológicos, ou seja, quanto maiores os níveis de glicemia e hemoglobina glicosilada, menores as velocidade de condução nervosa sensitiva e motora, menores as amplitude do potencial de ação, e maior dispersão temporal destes potenciais de ação. Os autores identificaram, portanto, uma estreita relação entre o controle metabólico, representado aqui pelas medidas de glicemia e hemoglobina glicosilada, e os acometimentos neurológicos decorrentes da neuropatia; e concluem que o controle metabólico é um importante fator determinante no nível da lesão nervosa em neuropatas e portanto um aspecto primordial a ser controlado rigorosamente no tratamento e prevenção da neuropatia periférica diabética. 
Já YOUNGER, ROSOKLIJA \& HAYS (1998) destacam que o controle glicêmico e terapia sintomática trazem importantes benefícios para alguns diabéticos neuropatas, mas não previnem a progressão da neuropatia periférica, especialmente em sujeitos que já apresentam severas disfunções motoras que já se manifestam na locomoção.

Considerando a sintomatologia da doença, importante indicativo da neuropatia em avaliações clínicas, esta não apresentou correlação com as medidas metabólicas de glicemia e hemoglobina glicosilada em diabéticos neuropatas (CELIKER et al., 1996). Considerando-se estes achados, pode-se concluir que a presença de sintomas decorrentes da neuropatia periférica não está relacionada ao controle metabólico da diabetes, demonstrando uma certa independência entre estas respostas. Portanto, não se pode predizer pelo controle glicêmico do paciente, o status da neuropatia.

Uma importante consideração a ser feita é quanto às formas de avaliação da neuropatia. BERGIN, BRONSTEIN, MURRAY, SANCOVIC \& ZEPPENFELD (1995) discutem que somente a eletroneuromiografia não é suficiente para avaliar a severidade da neuropatia, uma vez que nem todos os neuropatas que apresentam ausência do potencial de ação em determinados nervos avaliados têm a mesma severidade clínica da doença. Dessa forma, não há como usar estes resultados para padronizar e classificar a neuropatia em diferentes sujeitos. Os autores enfatizam que a eletroneuromiografia muitas vezes não coincide com o status funcional da doença, representado pela sintomatologia da mesma, pois alterações na eletroneuromiografia podem ser encontradas em diabéticos assintomáticos e ausência de alterações pode ser encontrada em diabéticos com sintomatologia já presente. Portanto, esta avaliação não indicaria de maneira eficiente o status funcional da doença, mesmo sendo um bom instrumento diagnóstico.

SIMONEAU et al. (1996) discutem que estudos eletrofisiológicos são importantes e fundamentais desde que associados à testes quantitativos sensoriais, tais como de percepção de vibração e percepção cutânea de tato e de pressão, testes estes que têm apresentado alta fidedignidade com os sintomas clínicos da doença.

Em diabéticos não insulino-dependentes, a neuropatia periférica apresenta um longo período assintomático (WEERASURIYA et al., 1998) podendo ocasionar diversos acometimentos sensitivos, motores e até autonômicos antes mesmo de qualquer diagnóstico clínico. Com isso, pode-se verificar severas neuropatias em sujeitos diabéticos com diagnóstico de neuropatia recente. No estudo de WEERASURIYA et al. (1998), dos 112 diabéticos recém diagnosticados, 9,8\% já apresentavam a neuropatia periférica sintomática e $15,2 \%$ apresentaram velocidade de condução nervosa diminuída de forma importante, porém não apresentavam qualquer sintoma ou sinal relacionados à neuropatia 
periférica. Estes autores concluem que há uma alta incidência de neuropatia periférica em diabéticos recém diagnosticados, muito provavelmente devido à longa duração da diabetes ainda não diagnosticada e não pela falta de cuidados adequados de saúde a estes diabéticos.

\subsection{0 padrão normal da locomoção humana}

Locomoção é toda ação que move o corpo de um animal através do espaço aéreo, aquático ou terrestre (CAPPOZZO, MACHETTI \& TOSI, 1991). Ela é executada através de movimentos coordenados dos segmentos corporais numa interação dinâmica das forças internas (muscular, articular) e forças externas (inercial, gravitacional, friccional). A compreensão de como o comportamento locomotor humano é gerado e regulado representa um importante desafio para diferentes áreas do conhecimento científico. Segundo WHITTLE (1996), a análise da marcha como é concebida atualmente, transformou-se em um importante instrumento de avaliação para médicos, fisioterapeutas, profissionais da Educação Física e Esporte, entre outros profissionais da saúde.

$\mathrm{O}$ andar está entre os atos motores mais automatizados. A seqüência de eventos que geram 0 andar é altamente repetitiva de ciclo após ciclo e também entre diferentes sujeitos. Tal regularidade permite que se estabeleça critérios objetivos para a distinção entre padrões normais e patológicos, bem como para a discriminação daquelas mudanças qualitativas causadas pelo desenvolvimento do indivíduo. Dessa forma, entendemos que todo ato locomotor depende de interações dinâmicas entre 0 sistema motor e as forças externas, entendidas como causas do movimento nesta interação do corpo com o meio ambiente. Portanto, a compreensão da locomoção humana enquanto fenômeno complexo só pode ser entendida se diferentes aspectos forem considerados concomitantemente e de maneira integrada.

É de especial interesse a análise da marcha em algumas situações particulares, tais como quando alguma perturbação é inserida no aparelho locomotor e o padrão de movimento tem que se ajustar de forma a compensar os efeitos que esta perturbação gerou. Estas perturbações podem ser criadas de diversas maneiras e dentre as quais tem-se uma doença que acometa o sistema neuromuscular, tal como a paralisia cerebral, distrofia muscular ou ainda a neuropatia periférica diabética. Portanto, um parâmetro importante para uma análise do movimento humano refere-se às doenças que afetam o aparelho locomotor através do acometimento de estruturas neuro-musculares.

Segundo KATOULIS, EBDON-PARRY, LANSHAMMAR, VILEIKYTE, KULKARNI \& BOULTON (1997), o andar humano normal é resultante da correlação harmônica entre a ação coordenada neural, 
muscular e a função esquelética. Qualquer alteração nessa harmonia, provocará mudanças importantes no padrão locomotor podendo trazer conseqüências neuro-musculares e de equilíbrio para o indivíduo.

Tradicionalmente um ciclo completo do andar é determinado por dois contatos consecutivos do mesmo calcanhar no solo e o intervalo de tempo entre estes eventos é a duração do ciclo do andar (WINTER, 1991; WHITTLE, 1996). A distância percorrida neste intervalo é chamada de passada e o intervalo de tempo entre o contato inicial do calcanhar e a perda de contato deste mesmo calcanhar (ipsilateral) com o solo é chamado de duração da fase de apoio. Pode-se utilizar de descritores temporais para a locomoção, os quais são simples medidas de relações temporais e de comprimentos, como: tempo de apoio simples e duplo e tempo de balanço (PERRY, 1992). Parâmetros temporais básicos têm sido identificados em função de mudanças que ocorrem a partir de diferentes velocidades de deslocamento, diferentes dimensões corporais ou diferenças na tarefa de movimento, como por exemplo 0 andar em esteira rolante.

$\mathrm{O}$ andar caracteriza-se por deslocamento do centro de gravidade predominantemente no eixo horizontal, apesar do caráter senoidal desta trajetória evidenciar também um movimento no eixo vertical. Esta trajetória senoidal evidencia os movimentos de rotação dos segmentos corporais do membro inferior que resultam no movimento de translação do corpo durante a locomoção.

Durante 0 andar, tem-se o constante deslocamento da linha de gravidade à frente da articulação do tornozelo o que tende a desequilibrar o corpo para a frente obrigando que estratégias de restabelecimento do equilíbrio sejam impostas pelo sistema neuromuscular, conferindo uma situação de equilíbrio dinâmico durante todo o ciclo. Além disso, as exigências bilaterais devem ser iguais conferindo uma relativa simetria.

A força reação do solo representa uma das mais importantes grandezas para análise biomecânica do movimento, por ser soma algébrica da aceleração da massa de todos os segmentos corporais, ou seja, o total líquido de todas as forças musculares e gravitacionais atuando em cada instante durante a fase de apoio (WINTER, 1991). O padrão desta variável biomecânica mostrou-se sob a forma de um padrão constante e repetitivo independente das condições do solo, idade dos sujeitos ou velocidade do andar. Este padrão apresenta determinadas características temporais e de magnitude que podem ser alteradas devido as condições ambientais ou do sujeito como a presença de uma patologia, por exemplo; porém sua forma geral é constante e regular (WINTER, 1991).

Esta função apresenta um primeiro pico de força máxima vertical referente ao ataque do calcanhar no solo, correspondente ao primeiro terço da fase de apoio; também denominado de pico passivo uma vez que está relacionado à desaceleração do membro de apoio. Também apresenta um 
segundo pico referente à propulsão do antepé, correspondente ao terço final da fase de apoio; também denominado de pico ativo uma vez que já envolve a participação de ações voluntárias para propulsão do corpo à frente. Os valores destes picos guardam uma dependência com o velocidade do movimento. Entre os dois picos, esta força se reduz em função de alguns fatores indicando a capacidade do sistema motor em responder ao impacto no início do apoio através da ação muscular da perna de apoio e da influência da dinâmica da perna de balanço (SERRÃO \& AMADIO, 1992).

Considerando o coeficiente de variação (CV) dos dados da força reação do solo, em relação à componente vertical, o CV varia de 15-20\% para sujeitos saudáveis em piso fixo (WINTER, 1991).

A análise dos padrões da atividade eletromiográfica permite a identificação de padrões motores e sinergias musculares sendo um componente essencial para o estudo biomecânico da locomoção humana. A representação da atividade eletromiográfica através de envoltórios lineares é considerada como a melhor técnica para descrever padrões locomotores (ARSENAULT, WINTER, MARTENIUK \& HAYES, 1996; SHIAVI \& GREEN, 1983) e é a técnica mais freqüentemente empregada. Consiste em representar perfis individuais ou padrões das diferentes tentativas de um sujeito normalizados na base de tempo, facilitando a interpretação da eletromiografia para uma boa estimativa do nível médio de ativação muscular. Segundo KLEISSEN (1995), a avaliação eletromiográfica durante a marcha, traz importantes informações sobre a coordenação do movimento e doenças neuro-musculares periféricas ou centrais preexistentes.

$\mathrm{Na}$ transição do balanço para o apoio, ou seja, na fase de acomodação do peso, observa-se uma atividade elétrica aumentada dos $\mathrm{m}$. vasto lateral e oblíquo médio, coordenada à atividade do $\mathrm{m}$. bíceps da coxa, resultando em uma sinergia extensora que garante a estabilidade do joelho durante 0 instante de choque mecânico com o solo. Nesta fase, o m. bíceps da coxa auxilia na extensão do quadril através de atividade concêntrica e tende a flexionar o joelho. As atividades flexoras de joelho, do $\mathrm{m}$. bíceps da coxa e deste choque mecânico no instante do contato contrapõe-se a contração excêntrica do $\mathrm{m}$. vasto lateral, estendendo o joelho. A co-contração de $\mathrm{m}$. vasto lateral e $\mathrm{m}$. bíceps da coxa no início do apoio está de acordo com outros autores (SHIAVI, 1985; TOWNSEND, LAINHART, SHIAVI, CAYLOR, 1978).

A partir do segundo terço do apoio, ou seja, no início do apoio simples, os m. gastrocnêmio e m. sóleo passam a predominar no movimento, agindo excentricamente, realizando a flexão plantar do tornozelo para o controle do movimento de translação do segmento inferior, de acordo com McFADYEN \& WINTER (1988). Sua principal fase ativa termina antes da fase de propulsão, ao final do apoio. 
Ao final do apoio, no último terço, há uma redução na atividade do m. gastrocnêmio, que se contrai concentricamente para gerar energia para a progressão na transição do apoio para o balanço. $\mathrm{Na}$ fase de balanço, há um aumento na atividade do m. vasto lateral que deve acelerar o segmento, enquanto que ao final desta fase predomina a atividade do $\mathrm{m}$. bíceps da coxa, agindo excentricamente para controlar a velocidade descendente do segmento antes do apoio.

A interpretação do andar humano normal fornece uma importante base de dados para a interpretação do andar patológico. Assim, ao se introduzir um fator de perturbação na marcha, tal como a presença de uma doença, identifica-se um padrão locomotor distinto do encontrado normalmente, trazendo importantes referências para a interpretação da própria doença, acompanhamento de sua evolução e degenerações decorrentes, de comportamentos motores criados e de compensações motoras dos déficits sensoriais ou motores gerados pela doença.

\subsection{Caracterização anatômica da região plantar: estrutura e função}

A fáscia e pele plantares respondem aos esforços e forças constantemente aplicadas aos pés com uma variedade de respostas adaptativas; tais como: aumento da espessura dessas estruturas; rígidas ligações com tecidos mais profundos; aumento de inervações sensoriais e coxins adiposos elásticos (BRESSLER \& BRESSLER, 1991). A pele plantar apresenta algumas diferenças em relação à pele de outras regiões, diferenças essas que acabam caracterizando suas funções e resistência à sobrecarga. Na epiderme, o estrato do epitélio de queratinócitos, células que produzem a proteína queratina, é bastante espesso; também há a presença de receptores de Merkle sensitivos e outros receptores, além de poucos melanócitos. Os queratinócitos são as principais células que formam os estratos da epiderme e essas células migram da membrana basal próxima à derme até a superfície, e vão se diferenciando em estratos especializados os quais são unidos uns aos outros por junções fibrosas rígidas.

Com 0 atrito do pé contra o solo durante a locomoção, ocorre uma hipertrofia das camadas granulosas da epiderme nos pontos de maior apoio plantar: calcanhar, margem lateral e primeira cabeça metatarsiana, caracterizando a denominada hiperqueratinização (BRESSLER \& BRESSLER, 1991). Em algumas doenças com implicações metabólicas, tais como a diabetes, essa hiperqueratinização ocorre em resposta a menores estímulos mecânicos, resultando na formação de calosidades na superfície, que como conseqüência alteram a distribuição de pressão na superfície plantar. 
Ainda segundo BRESSLER \& BRESSLER (1991), além da densa rede vascular e de receptores sensoriais encontrada na derme plantar, na camada reticular há a ausência de unidades pilosebáceas e glândulas sudoríparas apócrinas relacionadas ao estresse emocional, tais como encontramos em dermes de outras regiões do corpo; porém há abundância de glândulas sudoríparas écrinas.

$\mathrm{Na}$ fáscia plantar existe uma camada de gordura subcutânea para proteção contra traumas. Nesta camada, existem compartimentos de gordura separados por septos fibrosos. Com as solicitações mecânicas constantes aplicadas ao pé, estes compartimentos de gordura vão se deformando e se degenerando e, se além dessa degeneração natural houver associação de outros fatores permissivos, tais como: obesidade crônica, envelhecimento ou polineuropatias, essa degeneração dos coxins plantares é acelerada, provocando dores e até mesmo degeneração da pele plantar produzindo ulcerações, tais como as encontradas em diabéticos neuropatas (BRESSLER \& BRESSLER, 1991).

KUHNS (1949) definiu dois tipos distintos de tecido adiposo presentes no corpo humano, quais sejam: (1) o subcutâneo, cujas funções são de proteção e envolvimento de órgãos, bem como é uma fonte de nutrição para o corpo; (2) e o elástico, cuja função principal é de suporte e resistência à pressão constante ou impactos. Este último está presente nas pontas dos dedos das mãos e pés, eminências tenar e hipotenar, tuberosidade isquiática, região abaixo da patela e no calcanhar. Nestas regiões, especialmente no calcanhar, este tecido apresenta uma arquitetura firme mantendo a gordura comprimida em compartimentos delimitados por um tecido fibroso resistente em forma de $U$, com a parte aberta do U voltada para o osso calcâneo (FIGURA 1). Após cada solicitação mecânica e conseqüente deformação, estes tecidos voltam às suas características e propriedades originais, mas se em algum momento houver um trauma, estes tecidos não se regeneram, conforme demonstra a FIGURA 2. 


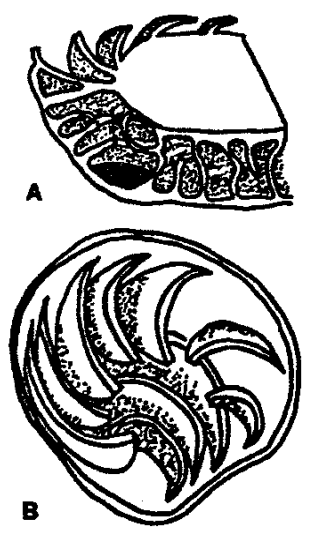

FIGURA 1 - Diagrama mostrando vista (A) longitudinal e (B) superior do coxim do calcanhar. Os septos fibrosos são demonstrados sem o tecido adiposo interposto (adaptado de BRESSLER \& BRESSLER, 1991).

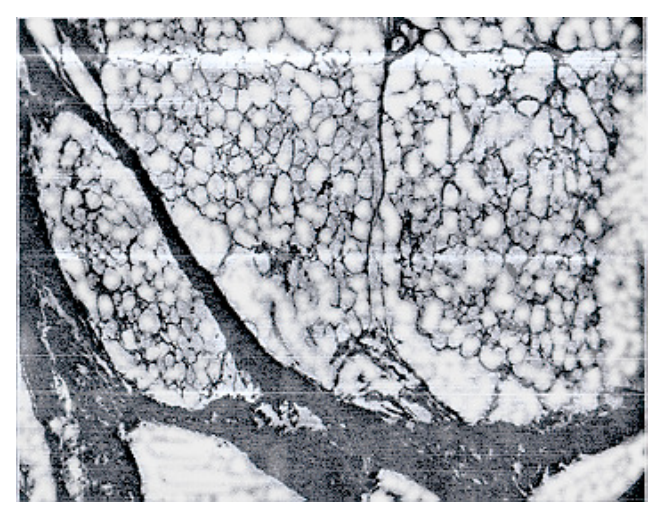

A

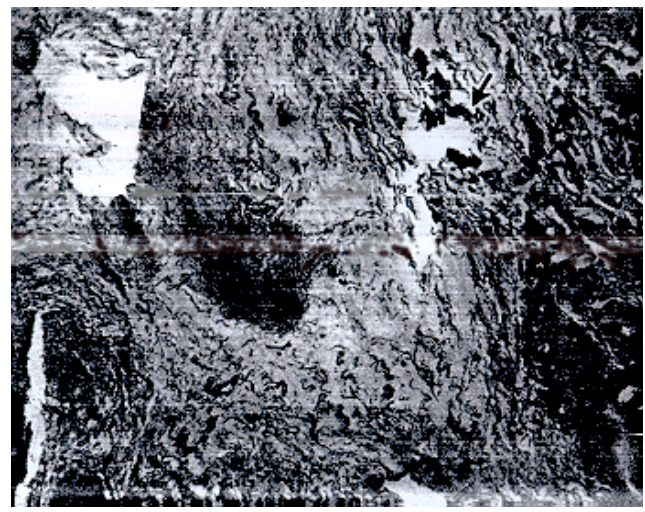

B

FIGURA 2 - (A) Tecido adiposo elástico normal com os septos fibrosos normais do coxim do calcanhar de uma criança de 4 anos (ampliação de 60 x). (B) Tecido adiposo elástico do coxim do calcanhar de uma mulher de 60 anos (ampliação de $60 \mathrm{x}$ ); o tecido conectivo é menos denso, células adiposas achatadas, infiltração de gordura pelos septos e perda de tecido que pode ser vista na parte superior direita da figura, na parte mais esbranquiçada (adaptado de KUHNS, 1949).

O coxim do calcâneo tem como principal função sustentar a pressão imposta às estruturas do pé através de colunas de gordura arranjadas anatomicamente de forma a ficarem alinhadas verticalmente (FIGURA 1). São compartimentalizadas por septos fibro-elásticos e monitoradas pelas terminações nervosas e receptores de pressão da pele à aponeurose plantar (MILLER, 1982). Uma vez 
rompidos estes septos das colunas de gordura, não há como reconstituí-los à estrutura original, muito menos restituir sua função protetora e de absorção, conforme demonstra a FIGURA 2. Dessa forma, concluí-se que se deve conservar o coxim do calcanhar a qualquer custo, uma vez que é altamente diferenciado na monitorização da distribuição de pressão dinâmica e não pode ser reconstituído após a lesão.

KINOSHITA, FRANCIS, MURASE, KAWAI \& OGAWA (1996) estudaram as propriedades do coxim gorduroso do calcanhar em absorver choque durante uma queda em velocidades de $0,57 \mathrm{~m} / \mathrm{s}$ e $0,94 \mathrm{~m} / \mathrm{s}$ e compararam grupos de adultos jovens e idosos. Observaram que em velocidade lenta de impacto $(0,57 \mathrm{~m} / \mathrm{s})$, a idade não interferiu nas medidas de pico de desaceleração e pico de deformação do coxim, bem como do tempo para se atingir esses picos. Em velocidade rápida de impacto $(0,94 \mathrm{~m} / \mathrm{s})$, observaram maiores valores de pico de desaceleração e menores deformações para os adultos idosos, bem como menor energia absorvida. Com isso os autores concluíram que a capacidade dos coxins gordurosos de absorver choques diminui com a idade (KINOSHITA et al., 1996). Este fato também foi observado por BRESSLER \& BRESSLER (1991), em seus estudos anatômicos, onde os compartimentos de gordura no coxim calcâneo degeneram-se e se deformam com o envelhecimento, traumas ou doenças que alterem as solicitações mecânicas na superfície plantar, tais como polineuropatias e obesidade.

KUHNS (1949) já descrevia a deterioração gradual típica sem regeneração de um tecido adiposo elástico, devido a pressões excessivas, obesidade, traumas ou envelhecimento. Neste último fenômeno, há a perda de colágeno das estruturas, diminuição progressiva de tecido elástico fibroso e de água; consequentemente há a distorção e ruptura dos tecidos fibrosos subcutâneos e destruição dos compartimentos de gordura da superfície plantar. Além disto, há a proliferação de tecido ósseo nas margens da tuberosidade do calcâneo provocando dor em queimação difusa no local quando em repouso após caminhadas. Esta tuberosidade do calcâneo acentuada torna-se palpável através do tecido menos rígido abaixo do calcanhar que pode ter sido modificado pela própria degeneração e estreitamento dos compartimentos de tecido adiposo do coxim do calcanhar, onde as colunas tornam-se irregulares ou rompidas, não paralelas e os septos saem da formação em U característica destes compartimentos.

MILLER (1982) apontou a necessidade de estudos mais aprofundados na descrição anatômica das características e propriedades dos coxins gordurosos do calcanhar, bem como suas inervações periféricas ainda não bem descritas. Esta necessidade pode ser confirmada ao rever a literatura anatômica em estudos de DUJARIER (1905); HAYMARKER \& WOODHALL (1945), LAZORTHES 
(1971) e ROUVIËRE \& DELMAS (1974), na busca da distribuição de fibras nervosas principais e suas ramificações periféricas na superfície plantar e os territórios de inervação mista e exclusiva nesta região. Porém, embora toda esta erudição em se tratando da anatomia humana, verifica-se ainda uma lacuna na literatura quando se investiga a planta do pé e, principalmente, sua inervação periférica.

Em dissecações finas, é possível identificar receptores especializados para funções sensoriais, tais como: corpúsculos de Meissner, mecanoreceptores que detectam toque na pele e vibração de baixas freqüências; corpúsculos de Paccini, mecanoreceptores que detectam toque na pele e vibração de altas freqüências (profundas); terminações nervosas livres, termoreceptores e nociceptores que enervam a fáscia e tecidos conjuntivos mais profundos detectando sensação de dor em agulha, queimação ou coceira; além dos discos de Merkel, mecanoreceptores que detectam pressão na pele (CRUTCHFIELD \& BARNES, 1984).

Mesmo considerando estes receptores sensoriais, há um número limitado de terminações para dor que não correspondem às dores sentidas na região do calcanhar em determinadas doenças ou solicitações mecânicas extremas. Dessa forma, parecem ser as terminações nervosas periféricas do calcanhar responsáveis pela sensação de dor comum a pessoas cujas atividades sejam de extrema solicitação (MILLER, 1982). Ainda segundo MLLLER (1982), quando há perda de material do coxim devido uma queda de 100 a $130 \mathrm{~cm}$ com aterrissagem em superfície dura sobre o calcâneo, há destruição dos septos suficiente para provocar dor intensa na região do calcanhar independente da existência de fraturas no osso calcâneo. Destarte, confirma-se a hipótese de que são as terminações nervosas periféricas do calcanhar, os elementos responsáveis pela resposta de dor na região e não outros fatores comumente relacionados.

\subsection{Alterações morfológicas e funcionais dos pés em decorrência de solicitações mecânicas extremas}

Alterações na morfologia do pé de corredores já foram apontadas por ROBBINS \& HANNA (1987) em estudo de pés descalços de corredores fundistas. Os autores observaram que com 0 treinamento descalço, os pés sofreram alterações no seu comprimento longitudinal quando eram observados apoiados no solo com ou sem aplicação de carga (marcha). Dessa forma, os sujeitos quando em apoio de ambos os pés no solo sem carga apresentavam uma diminuição consistente em seu comprimento longitudinal, e este estudo supôs que durante atividades dinâmicas com aumento das 
solicitações mecânicas, como andar e correr, este comprimento poderia aumentar, o que poderia ser um ajuste para promover uma maior atenuação de impactos.

WARREN \& JONES (1987) observaram que corredores experientes com reincidências de lesões do tipo fascite plantar apresentavam arcos longitudinais plantares mais altos e pés mais pronados durante 0 apoio na corrida. Estes autores propuseram-se a identificar parâmetros anatômicos e biomecânicos como preditores da fascite plantar, lesão esta extremamente comum em corredores, acometendo cerca de 70\% deles (WARREN \& JONES, 1987). Conseguiram identificar alguns fatores característicos presentes em sujeitos com fascite, tais como ângulo de pronação do pé durante o apoio, altura do arco plantar, flexibilidade de tornozelo, idade, características antropométricas, entre outros; mas esses não conseguiram predizer tal lesão nos corredores já com a presença da fascite.

KIM \& VOLOSHIN (1995) através de seus estudos com modelos matemáticos verificaram que pés cuja geometria era alterada, como a diminuição da altura da articulação do tornozelo e, consequentemente, da altura do arco longitudinal e comprimento do mesmo em situações estáticas, apresentavam capacidade de recebimento de cargas diminuída proporcionalmente à redução da altura da articulação, bem como aumentavam a amplitude do deslocamento vertical do tornozelo na marcha em até 3,7 vezes maior do que em pés com geometria e arco normais. Este movimento ampliado do pé pode resultar numa fadiga mais rápida da estrutura, fato esse que corrobora com achados clínicos de que indivíduos com pés planos não são capazes de manter uma marcha mais longa sem prejuízo na eficiência e sem provocar dores.

Considerando esta característica de degeneração do tecido adiposo do calcanhar, JORGENSEN \& EKSTRAND (1988) usaram como critério de seleção para sua amostra, a palpação da tuberosidade do calcâneo abaixo do coxim gorduroso do calcanhar e aqueles sujeitos cuja tuberosidade pudesse ser palpada, seriam caracterizados pela menor capacidade de absorver e restituir energia durante impactos e, consequentemente, estariam mais sujeitos a lesões e dores nessa região.

JORGENSEN (1985) desenvolveu um método para investigar a compressibilidade do tecido adiposo do calcanhar em situação de apoio plantar de forma a poder discutir a capacidade deste em absorver choques durante atividades de locomoção. 0 método parte de uma radiografia de perfil do pé com e sem apoio e recorre a técnicas utilizadas em mamografia que através de segmentos de reta traçados tangentes ao calcâneo e ao coxim gorduroso do calcanhar, determina um índice de compressibilidade visual, conforme demonstra a FIGURA 3. Porém, este método parte de imagens planas e traçados na própria imagem o que acarretaria na multiplicação dos erros na medida. Outros métodos poderiam ser adaptados utilizando-se de imagens de ressonância magnética onde os limites 
histológicos apresentam-se mais nítidos e existe a possibilidade de cálculos automáticos de índices de compressibilidade. JORGENSEN (1985) demonstrou que lesões crônicas no aparelho locomotor, como a aquilondinia, decorrentes da prática de atividades de impacto esportivas ou não, podem ser resultado da diminuição da espessura do coxim do calcanhar pela perda de gordura local ou ruptura de septos fibrosos do tecido abaixo do calcâneo, resultando na diminuição de sua espessura e a conseqüente redução na capacidade de atenuação de choques. Para compensar esta perda na capacidade de atenuação, o músculo sóleo aumenta sua atividade no ciclo da marcha em 40 a 60\%, sobrecarregando o tendão calcâneo.

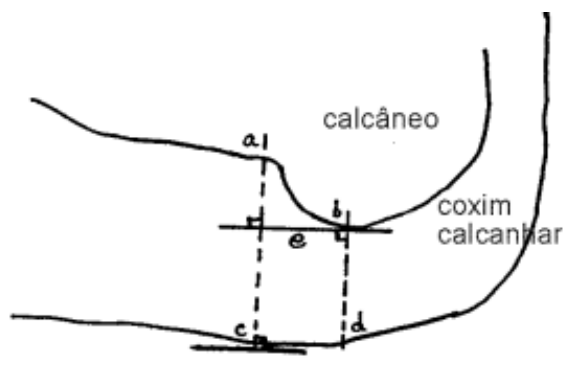

b e c são tangentes do calcâneo e do coxim do calcanhar na posiçăo vertical. e é a distância prependicular entre os segmentos a-c e b-d.

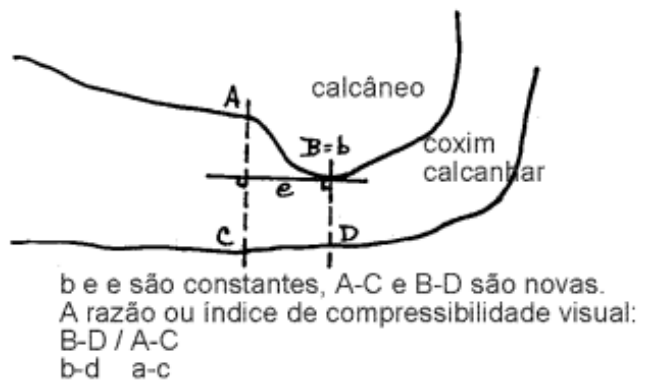

FIGURA 3 - Índice de compressibilidade visual (adaptado de JORGENSEN, 1985).

\subsection{Características biomecânicas e mecanismos de adaptação da locomoção em esteira rolante}

Muitos autores têm demonstrado a importância da utilização de uma esteira rolante para análise da marcha, avaliação fisiológica, para fins clínicos e de reabilitação. Estes autores destacam algumas vantagens da utilização da esteira para tais fins, entre eles: o maior controle de fatores ambientais envolvidos na coleta de dados, tais como a velocidade, dessa forma o ambiente torna-se padronizado e reprodutível para estudar tarefas de locomoção. Destacam também que um espaço menor é necessário para este tipo de estudo. Faz-se desnecessário seguir os sujeitos do estudo com o equipamento, além de permitir o registro de sucessivos ciclos da marcha sem a necessidade de realizar várias tentativas para se obter um número representativo de ciclos (CHARTERIS \& TAVES, 1978; STRATHY, CHAO \& LAUGHMAN, 1983; WALL \& CHARTERIS, 1980; WHITE, YACK, TUCKER \& LIN, 1998; ALTON, BALDEY, CAPLAN \& MORRISSEY, 1998). Dessa forma, as seções seguintes serão dedicadas a 
discussão de aspectos relacionados às características biomecânicas da marcha quando realizada em esteira, bem como os processos de habituação em piso móvel antecedendo a aquisição de dados dinâmicos, eletromiográficos e cinemáticos.

STRATHY et al. (1983) discutem que o padrão de marcha obtido na esteira pode não ser semelhante ao obtido em piso fixo, como se poderia prever. Variações cinemáticas podem ocorrer em função das características do ambiente móvel e restritivo imposto, tais como diferenças nos parâmetros temporais do ciclo da marcha: tempo de apoio simples e tempo de apoio duplo.

AMADIO, BAUMANN \& POZZO (1992) destacam diferenças importantes entre o correr em esteira rolante e correr em piso fixo em termos de quantidade de energia mecânica necessária para realizar o movimento e em termos da relação força em função do tempo de apoio, aspectos estes que demonstram-se menores na esteira. Os autores destacam também que as características e propriedades materiais do piso da esteira podem exercer influência no padrão de movimento executado na esteira.

VAN INGEN SCHENAU (1980) destaca que as diferenças mecânicas entre piso fixo e esteira podem ser devidas principalmente à diferença de informação visual, auditiva e vestibular que o sujeito sobre a esteira recebe. Estas informações são de fundamental importância para a manutenção de equilíbrio e estabilidade durante a locomoção e consequentemente pode causar uma alteração na regulação do padrão de movimento resultando em diferenças cinemáticas entre estes dois ambientes observadas por vários autores (WALL \& CHARTERIS, 1980, 1981; STRATHY et al., 1983; MURRAY, SPURR, SEPIC, GARDNER \& MOLLINGER, 1985; GHELUWE, SMEKENS \& ROOSEN, 1994; LANGE, HINTERMEISTER, SCHLEGEL, DILLMAN \& ATEADMAN, 1996; DINGWELL, ULBRECHT, BOCH, BECKER, O'GORMAN \& CAVANAGH, 1999). Em função destas diferenças nas informações visuais e vestibulares quando o sujeito se locomove na esteira, ARSENAULT, WINTER \& MARTENIUK (1986) relatam que alguma adaptação na regulação do movimento deve ocorrer, tal como um rearranjo na atividade muscular.

\subsubsection{Aspectos biomecânicos relacionados ao processos de acomodação e habituação à esteira rolante}

WHITE et al. (1998) discutem que as possíveis diferenças encontradas no padrão biomecânico do andar na esteira e no piso fixo dependem da velocidade imposta durante a tarefa de locomoção e a habituação antecedente à aquisição dos dados para a análise. 
Distingue-se dois processos ao caminhar pela primeira vez em esteira rolante: a acomodação e a habituação. A acomodação foi definida como sendo a adaptação inicial às exigências que a esteira impõe, e esta acomodação feita pelo aparelho locomotor caracteriza-se por um aumento na flexão de joelho no apoio, de forma a abaixar o centro de gravidade do corpo, um aumento do tempo da passada, um menor comprimento de passada e um aumento na variabilidade das variáveis cinemáticas (WALL \& CHARTERIS, 1980, 1981). Essa acomodação persiste apenas nas passadas iniciais da primeira exposição, e nas seguintes exposições à esteira, ela permanece apenas no primeiro ciclo completo da marcha, enquanto os outros ciclos permanecem mais estáveis diminuindo a variabilidade com o tempo (WALL \& CHARTERIS, 1981).

WALL \& CHATERIS $(1980,1981)$ discutem que a constância passada a passada, isto é, reprodutibilidade de padrões cinemáticos, dinâmicos e de cadência, é que determina o processo denominado de habituação, ou seja, a adaptação do sujeito ao ambiente móvel e mais restritivo da esteira até a estabilização dos parâmetros biomecânicos e redução significativa da variabilidade. Dessa forma, um importante aspecto a se analisar seria a variabilidade da marcha em esteira durante um determinado período.

WHITE et al. (1998) adotaram um critério para estabelecer quando o sujeito estaria habituado à nova condição e a partir desse critério, estabeleceu o tempo necessário para a adaptação à esteira antes de iniciar a aquisição dos dados. Os autores estudaram o coeficiente de variação (CV) da força reação do solo vertical de seis passadas consecutivas nos 30 primeiros segundos e depois a cada três minutos por 21 minutos. Observaram que os maiores CVs foram os dos primeiros 30 segundos de coleta e dos nove minutos, e os menores foram os obtidos aos três minutos. Dessa forma, adotaram três minutos como tempo de prática prescrita antes da aquisição dinâmica dos dados e recomendam não coletar antes dos dois minutos iniciais de habituação.

CHARTERIS \& TAVES (1978) compararam o andar na esteira e no piso fixo com o objetivo de estudar o processo de habituação no piso móvel. Relatam que a variabilidade cinemática determinada a partir do estudo da variação angular de joelho a cada passada foi maior na exposição inicial, porém 0 padrão obtido aos sete minutos não diferiu do obtido aos 15 minutos, mesmo sendo esse padrão de variabilidade maior do que em piso fixo. Já WALL \& CHARTERIS (1981) estudaram a habituação por um período maior, ou seja, em períodos de uma hora de habituação e repetiram o procedimento quatro vezes, completando assim quatro horas para investigar o comportamento de variáveis temporais e cinemáticas no andar na esteira. Observaram que o processo de acomodação se repetia em cada primeiro ciclo da marcha a cada hora estudada, mesmo após uma, duas ou três horas de habituação; 
mas os ciclos subsequentes ao longo da coleta permaneciam mais estáveis e o desvio padrão das variáveis cinemáticas estudadas após uma hora de habituação, apresentaram-se bem reduzidos em relação ao início do processo de habituação. Os autores recomendam assim que o processo de habituação deva ser de uma hora em sessões distribuídas de prática.

Dessa forma, tem-se de maneira geral que a variabilidade apresentada pelas variáveis temporais e cinemáticas da marcha em esteira diminuem com o processo de habituação, muito embora a acomodação, processo inicial de adaptação à esteira e em cujo período há relativa variabilidade no padrão mecânico, se mantenha a cada tentativa no primeiro ciclo do andar, mesmo quando o sujeito já estiver habituado.

MURRAY et al. (1985) utilizaram um tempo de habituação de 30 minutos em sessões distribuídas de prática em várias velocidades: livre, mais acelerada do que a natural e mais lenta do que a natural. Já DINGWELL et al. (1999), com sujeitos diabéticos neuropatas, usou um tempo de habituação de 15 minutos na esteira com velocidade de $3,6 \mathrm{~km} / \mathrm{h}$ até encontrar um padrão estável cinemático.

A fonte de variações nos padrões mecânicos do andar e correr em esteira tem sido fator motivador para muitos estudos. DAL MONTE, FUCCI \& MANONI (1973) discutem como fator determinante para 0 aparecimento ou não destas diferenças mecânicas, o treinamento na esteira rolante. NIGG, De BOER \& FISCHER (1995) confirmaram a importância deste fator "treinamento" para permitir qualquer inferência da situação da esteira rolante para o piso fixo.

WALL \& CHARTERIS (1980) utilizaram a constância da marcha como fator indicativo de adaptação à esteira rolante. Neste estudo demonstram que os indivíduos ainda estão se habituando após 10 min na esteira rolante. Em trabalho posterior, WALL \& CHARTERIS (1981) descreveram que quando se desejar utilizar as medidas na marcha ou na corrida na esteira rolante para direta aplicação às condições no solo, os indivíduos devem ser previamente treinados na esteira em sessões distribuídas em um total de uma hora, e não devem ser analisados nos dois primeiros minutos de execução e desta maneira relatam sobre o necessário treinamento para que os indivíduos se sintam confortáveis na execução da marcha e não necessitem de auxílio externo para manter a marcha.

\subsubsection{Caracterização espacial, temporal e variação angular da locomoção na esteira rolante}

Observa-se que a literatura referente às diferenças mecânicas dos movimentos de andar e de correr na esteira e no piso fixo tem apresentado resultados bastante controversos, e neste sentido, para 
se estudar as variações acarretadas no cálculo de energia mecânica é importante rever os fatores cinemáticos intervenientes, em acordo com CORRÊA, AMADIO, GLITSCH \& BAUMANN (1999). Vários fatores já foram estudados como intervenientes nestas diferenças: velocidade do andar e do correr, características anatômicas e musculares; tipos de superfícies; condições experimentais, entre outros fatores.

Foram encontrados poucos estudos relacionados às diferenças no andar. Duas importantes referências (ISACSON, GRANSBERG \& KNUTSSON, 1986 e TAVES, CHARTERIS \& WALL, 1985) não relatam qualquer diferença significativa nas medidas temporais da marcha e com isso naturalmente nenhuma diferença no comprimento e freqüência de passada para a marcha na esteira com relação ao piso fixo, mas ambos encontraram diferenças nas medidas angulares. ISACSON et al. (1986) relatam diferenças nos ângulos médios de flexão máxima nas articulações do joelho e do quadril durante 0 apoio, sendo respectivamente 2,4 e 2 graus menores durante o andar no chão. TAVES et al. (1985) descreveram que as diferenças apareceram durante 0 apoio duplo e na fase inicial e final do balanço no ciclo da marcha, no entanto sem definir quantitativamente o valor dessas diferenças.

CHARTERIS \& TAVES (1978) observaram através da avaliação da variação angular de joelho, que o padrão da flexão de joelho apresentou-se de forma diferente em relação ao piso fixo, ou seja, maior flexão de joelhos na fase de apoio da marcha em piso fixo.

AMADIO et al. (1992) estudaram o correr em esteira rolante e compararam padrões cinemáticos obtidos com os padrões em piso fixo. Os autores verificaram uma menor extensão de joelho na corrida em esteira, assim como uma menor oscilação de tronco, mantendo-o mais vertical em relação à corrida em piso fixo.

WALL \& CHARTERIS (1980) investigaram o comportamento de padrões cinemáticos do andar por 10 minutos na esteira, em sujeitos não habituados a ela, em velocidade relativizada pela estatura. Os autores observaram que o tempo de apoio e tempo de apoio do calcanhar durante a marcha ao longo do período que foi investigado são menores no início da exposição (primeiros 10 segundos) e com o decorrer do tempo, este tempo de apoio aumenta, bem como o tamanho dos passos com 0 decorrer do aumento da confiança na esteira. Observaram também maior flexão de joelho na fase de apoio e menor extensão durante o balanço final de forma a aumentar a estabilidade da passada no novo ambiente retirando o calcanhar prematuramente do solo. Com o decorrer do tempo de habituação, esta maior flexão diminui, bem como a variabilidade das variáveis estudadas, mas ainda não se estabilizam com 10 minutos de aquisição de dados. 
ALTON et al. (1998) encontraram valores significativamente maiores do tempo de apoio durante a marcha, bem como maiores cadências para a manutenção da mesma velocidade em relação ao chão; caracterizando, dessa forma, uma necessidade urgente de colocar 0 pé à frente enquanto 0 contralateral é deslocado para trás.

VAN INGEN SCHENAU (1980) também relata através de comparação do andar na esteira e em piso fixo, um aumento no tempo de duplo apoio em relação ao padrão temporal no piso fixo, indicando da mesma forma uma busca de estabilização e equilíbrio em um ambiente mais instável imposto pelo piso móvel; e destaca que se a esteira for construída ao nível do solo, essa insegurança dos sujeitos pode ser minimizada e as alterações biomecânicas observadas podem ser minimizadas. Da mesma forma, MURRAY et al. (1985) também encontraram valores de tempo de duplo apoio significativamente maiores na esteira em relação ao piso fixo, bem como menores tempos de balanço.

Semelhante aos achados de WALL \& CHARTERIS (1980) e MURRAY et al. (1985), STRATHY et al. (1983) encontraram uma diminuição no comprimento da passada, assim como um padrão diferente de extensão de joelho durante o balanço final na marcha em esteira e durante a fase de apoio. Os sujeitos apresentaram uma menor extensão de joelho antes do ataque do calcanhar ao solo em relação ao andar em piso fixo e maior flexão de joelhos no apoio, bem como o tempo de contato do calcanhar diminui e o tempo de contato dos dedos aumenta na esteira e estes últimos padrões foram atribuídos justamente a esta menor extensão de joelhos no balanço. GHELUWE et al. (1994) e ALTON et al. (1998) também observaram padrões semelhantes: menor tempo de contato do calcanhar com o solo em cerca de $20 \%$ em relação ao piso fixo, maior tempo de contato das cabeças metatarsianas e hálux, bem como uma maior fase de propulsão.

MURRAY et al. (1985) observaram que a articulação do quadril durante a marcha em esteira apresenta-se significativamente menos estendida logo antes da fase de balanço (apoio final) e isso foi atribuído ao menor comprimento de passo observado. ALTON et al. (1998) também encontraram valores significativamente maiores de flexão de quadril no apoio e os autores discutem se este fato é devido a maior inclinação do tronco a frente durante o andar na esteira, ou se há maior elevação da coxa. Estudos para determinação de momentos de força articulares são necessários para esclarecer este comportamento observado por ALTON et al. (1998) e MURRAY et al. (1985). Também foram observados maiores ângulos de flexão de joelho durante o apoio no andar em esteira.

Nos estudos de MURRAY et al. (1985) foi observada uma diminuição importante na dorsiflexão de tornozelo na fase que antecede o início do balanço, e este fato foi decorrente do aumento e da antecipação da atividade dos mm. gastrocnêmios durante a marcha. 
Pode-se minimizar os efeitos da diferença entre os dois ambientes distintos adequando-se a velocidade e cadência para a esteira, de forma que torne 0 andar na esteira mais confortável para 0 sujeito causando-lhe menores instabilidades e desequilíbrios. LANGE et al. (1996) destacam que uma velocidade auto-selecionada produziria menor consumo de energia, menor atividade muscular e menores variabilidades intrínsecas ao movimento.

STRATHY et al. (1983) determinaram a velocidade mais confortável para os sujeitos do estudo em piso fixo e após obter-se uma média da velocidade do andar no chão, impuseram esta mesma velocidade auto-selecionada na esteira. Para uma mesma velocidade imposta na esteira, os sujeitos aumentaram de forma significativa a cadência de passos, fato este também observado por MURRAY et al. (1985) e ALTON et al. (1998). A partir da determinação da cadência natural mais confortável para cada indivíduo no piso fixo, pode-se ajustar a velocidade na esteira de forma a atingir a cadência obtida no chão fixo e com isso obter um padrão de marcha mais natural e mais adaptado ao novo ambiente (WHITE et al., 1998; ARSENAULT et al., 1986a). Para uma mesma cadência auto-selecionada no piso fixo e imposta para a marcha na esteira, ARSENAULT et al. (1986a) encontrou uma velocidade significativamente menor na esteira em relação ao chão.

ARSENAULT et al. (1986a) discutem que durante a locomoção em esteira há uma maior estabilidade de padrão cinemático indicando que o ambiente móvel imposto estaria regulando e guiando a marcha limitando a variabilidade normalmente apresentada na marcha em piso fixo. DINGWELL et al. (1999) encontraram CVs de variação angular de tornozelo e joelho na esteira menores do que os encontrados por WINTER (1991) e o que os autores discutem é que a esteira pode ter guiado o padrão do andar dos sujeitos e artificialmente gerou um padrão cinemático mais consistente e com menor variabilidade, devido o ambiente mais restritivo, velocidade constante imposta e consequentemente diminui a variabilidade passo a passo durante a marcha.

DINGWELL et al. (1999) estudaram o andar de diabéticos neuropatas na esteira e compararam a variabilidade das variáveis cinemáticas na esteira e no piso fixo. Os autores discutem duas hipóteses prováveis quanto à variabilidade dos padrões na marcha. A primeira discute que a perda sensorial provocada pela neuropatia periférica diminui a habilidade dos sujeitos de perceber e responder a estímulos dolorosos tornando a marcha mais estável e com menor variabilidade. Justamente essa menor variabilidade nos padrões da marcha, levaria à formação de úlceras plantares. Ao contrário da primeira hipótese levantada, uma outra discussão feita é que a perda da recepção e regulação das informações temporais, cinéticas e espaciais leva o sujeito a apresentar maior variabilidade nos padrões da marcha observados, tal como observado por SACCO \& AMADIO (2000). 
Durante a marcha em esteira, foi observada uma tendência em relação ao grupo controle dos diabéticos neuropatas e diabéticos não neuropatas, em apresentarem maiores variabilidades (CV) para a variação angular de joelho e tornozelo e distância dos dedos ao solo. Dessa forma, DINGWELL et al. (1999) suportaram a hipótese de que com a perda sensorial característica da neuropatia diabética há aumento de variabilidade nos padrões cinemáticos, porém não há aumento significativo de CV durante o andar na esteira em relação ao piso fixo. Os autores atribuíram este fato ao ambiente mais restritivo e constante imposto pela esteira e a menor importância das informações sensoriais para o controle da locomoção nestes ambientes mais restritivos. Já em condições menos restritas e desafiadoras, as informações aferentes teriam um papel fundamental no controle e regulação dos padrões da marcha, logo a perda sensorial levaria a um aumento da variabilidade nestes padrões.

\subsubsection{Parâmetros dinâmicos da locomoção na esteira rolante}

GHELUWE et al. (1994) estudaram respostas dinâmicas durante 0 andar na esteira, considerando que diferenças cinemáticas já haviam sido descritas em estudos anteriores. Os autores limitaram a cadência do andar em 100 a 120 passos por minuto e determinaram a velocidade em piso fixo mais confortável e transferiram para a esteira. Foi observado picos de pressão maiores na região anterior do pé e mais prolongados, devido o maior tempo de contato das cabeças metatarsianas e dedos, assim como picos menores no calcanhar. O tempo para subida do pico de pressão foi bem menor para as regiões anteriores, apresentando assim um padrão mais rígido na função do pé na esteira.

Quanto a força reação do solo, WHITE et al. (1998) encontraram correlação de 0,983 entre as curvas de força do andar na esteira e no piso fixo, sendo o padrão das curvas bastante semelhantes. Porém algumas diferenças foram observadas, tais como uma menor deflexão da força mínima, menor segundo pico de força e menor tempo para a subida desse segundo pico da força reação durante 0 andar na esteira. Os autores discutiram a possibilidade da ocorrência de um menor segundo pico de força devido a menor atividade muscular durante a fase de propulsão, porém ARSENAULT et al. (1986a) não encontraram diferenças significativas na atividade elétrica do músculo sóleo na esteira. As diferenças mais evidentes foram encontradas quando a velocidade da esteira aumentada, ou seja, 0 segundo pico da força era menor quanto maior a velocidade. 


\subsubsection{Atividade eletromiográfica dos músculos envolvidos na locomoção em esteira rolante}

MURRAY et al. (1985) estudaram atividade eletromiográfica de músculos de membros inferiores durante 0 andar em esteira e relatam que a variabilidade da EMG intra-sujeito tanto na esteira quanto em piso fixo é alta, porém algumas diferenças podem ser destacadas. Os autores discutem que, muito embora o padrão das curvas de EMG e o timing das ativações musculares terem se apresentado semelhantes, a atividade do m. gastrocnêmio medial apresentou-se antecipada em relação ao padrão de atividade elétrica muscular durante 0 andar em piso fixo, bem como a atividade do $\mathrm{m}$. reto da coxa foi significativamente maior na esteira. A menor variabilidade da EMG encontrada foi a do $\mathrm{m}$. tibial anterior e a maior a dos $\mathrm{m}$. abdutor de quadril e $\mathrm{m}$. semitendinoso e m. semimembranoso. $\mathrm{O}$ padrão de atividade muscular dos mm. glúteos, m. eretor da espinha, $\mathrm{m}$. abdutor e m. adutor do quadril, cabeça longa do $\mathrm{m}$. bíceps da coxa, $\mathrm{m}$. gastrocnêmio medial e $\mathrm{m}$. tibial anterior não foram diferentes dos padrões encontrados em piso fixo.

Já AMADIO et al. (1992), diferentemente de MURRAY et al. (1985), encontraram menores magnitudes e menores tempos de ativação dos $\mathrm{m}$. glúteo máximo e m. eretor da espinha durante 0 correr em esteira, comparando-se com o correr em piso fixo.

Comparando-se a atividade elétrica dos músculos do membro inferior (m. tibial anterior, $\mathrm{m}$. sóleo, $m$. reto da coxa, m. bíceps da coxa, m. vasto medial) em situação de piso móvel e fixo, ARSENAULT et al. (1986a) obtiveram uma correlação média de 0,949 entre as curvas médias da EMG dos músculos analisados para todos os sujeitos na esteira e no piso fixo. Dessa forma, os autores discutem que mesmo apresentando padrões cinemáticos distintos, o padrão das curvas de EMG e, consequentemente a atividade muscular selecionada, apresenta-se perfeitamente em fase e com funções semelhantes. Porém, quando analisaram os dados intra-sujeitos, observaram uma tendência de aumento da amplitude da atividade eletromiográfica dos músculos estudados, especialmente $0 \mathrm{~m}$. reto da coxa e o m. vasto medial, além do m. bíceps da coxa apresentar uma atividade mais evidente logo após o contato do calcanhar com o solo, fato este atribuído à diferença na acomodação passiva da carga na esteira, sendo esta sempre maior devido a maior reação da esteira móvel com o pé dos sujeitos. Esta tendência de aumento de amplitude de atividade muscular é um resultado consistente com estudos de NASHNER (1980), ou seja, em função de um distúrbio na marcha, tal como o andar em piso móvel, tende a aumentar a atividade muscular. 
Outra observação feita por ARSENAULT et al. (1986a) é a baixa variabilidade do sinal EMG dos músculos do membro inferior estudados na condição de andar na esteira em relação ao andar em piso fixo, sinalizando um provável controle externo que a esteira impõe a regulação da atividade muscular.

\subsection{Alterações biomecânicas da marcha de portadores da neuropatia periférica diabética}

Na marcha humana, existem fases complexas que exigem maior controle postural e portanto demandam mais atenção supra-segmentar, mesmo sendo uma tarefa comum e bastante praticada. Por exemplo, a fase de apoio simples envolve a oscilação do membro contralateral e demanda a correta trajetória e colocação do pé, dessa forma, demanda mais atenção e controle do que a fase de apoio duplo. A neuropatia diabética produz uma modificação nas informações sensoriais periféricas necessárias para o controle das tarefas motoras executadas, assim como os centros corticais aumentam as demandas para o processamento de informações durante os movimentos (COURTEMANCHE et al., 1996).

COURTEMANCHE et al. (1996) discutem a hipótese que o principal fator contribuinte para 0 aumento da instabilidade na marcha de diabéticos portadores da neuropatia periférica já avançada, não é a fraqueza muscular, mas sim a perda de informações proprioceptivas. Da mesma forma, BERGIN et al. (1995) discutem que em função de déficits proprioceptivos, devido a doenças que acometem as vias somatossensoriais, ocorrem sérias alterações no equilíbrio postural e na marcha. Estes autores também concluem de seus estudos que a propriocepção é o mais importante input sensorial para o controle postural e da marcha. Portanto, pode-se concluir que nos casos em que a neuropatia está presente e em conseqüência disso há a ausência ou diminuição de informações proprioceptivas e sensoriais, os padrões na marcha e no controle postural estarão alterados em relação ao normal.

A instabilidade e portanto a oscilação do centro de pressão quando em posturas estáticas é maior quando o sujeito é portador da neuropatia diabética, especialmente se estiver com os olhos fechados. Nesta situação, as informações visuais não entram como feedback para o sistema e portanto tais informações não são processadas e utilizadas para controlar as instabilidades na postura provocadas pela falta de informação sensorial devido ao déficit decorrente da neuropatia diabética periférica (CAVANAGH et al., 1992).

Foram observadas maiores instabilidades e 15 vezes maior suscetibilidade à quedas durante a postura parada e durante 0 andar em diabéticos neuropatas em função de alguns fatores, conforme discute CAVANAGH et al. (1992), tais como, a perda de fibras nervosas largas com função 
proprioceptiva, a diminuição de feedback sensorial somático dos pés e pernas e fraqueza muscular pelo componente motor da neuropatia diabética. Estes autores também observaram muito maior freqüência de lesões em mulheres do que em homens em função desta perda de sensibilidade somatossensorial.

Alguns estudos têm demonstrado que na ausência ou diminuição de informação somatossensorial, há um deslocamento anterior do centro de pressão durante a postura em pé (CAVANAGH et al., 1992; NURSE \& NIGG, 2000; KIMMESKAMP, HENNIG \& LEMMEN, 2000)., também manifestado por maiores valores de pressão plantar na região do antepé durante a marcha (SACCO, 1997). Este fato pode ocorrer devido às maiores possibilidades de controle postural durante a marcha que esta região do pé fornece, uma vez que existe maior flexibilidade no antepé em termos musculares, ligamentares e articulares, e portanto haveria um deslocamento anterior da variável que os sistemas de controle do equilíbrio controlam, e sesta forma os sujeitos estariam buscando formas mais eficientes de controle postural, considerando que as vias normais sensoriais estariam comprometidas.

O corpo humano, através do importante feedback sensorial, detecta pequenas mudanças nas características biomecânicas externas em função de alguma disfunção ortopédica ou funcional e altera o padrão de marcha de forma defensiva. Em alguns cujo tema central era a locomoção humana, foram identificadas perigosas variações no padrão locomotor que levaram ao uso de órteses para proteger o aparelho locomotor (NURSE \& NIGG, 1999).

Existe uma hipótese na literatura já muito discutida sobre a localização dos picos de pressão plantares que coincidiriam com o local das dores plantares e por um mecanismo de proteção, os diabéticos neuropatas alterariam a mecânica da marcha. Porém esta relação entre pico de pressão e localização das dores ou problemas funcionais, não é sempre coincidente e portanto é somente especulativa (ABBOUD, ROWLEY, NEWTON, 2000). Estes distúrbios dinâmicos quando associados à neuropatia diabética ou ainda à deformação estrutural dos pés, podem dar origem à formação de ulcerações plantares e até mesmo amputações, caso o tratamento seja ineficaz para a sua cicatrização.

NURSE \& NIGG (1999) correlacionaram respostas sensoriais de vibração, pressões plantares e picos de força durante 0 andar e 0 correr e obtiveram correlações negativas entre vibração média em algumas regiões da superfície plantar e picos de força durante o correr, e entre vibração média e picos de pressão durante 0 andar e o correr. Em função das relações entre o déficit sensorial (perda sensorial decorrente da neuropatia) e respostas dinâmicas durante a marcha, os autores sugerem que o feedback neurológico deve ser incorporado em qualquer modelo que tente explicar padrões de marcha. Dessa forma, discute-se a importância de informações sensoriais para o controle das respostas dinâmicas nas tarefas de locomoção e portanto a importância de se quantificar e analisar modalidades de respostas 
sensoriais conjuntamente com respostas da biomecânica interna e externa para se interpretar 0 movimento humano e as estratégias de seu controle. 0 entendimento desta relação deve ajudar no desenvolvimento de critérios para a devida aplicação de órteses e na prevenção de lesão nas extremidades inferiores (NURSE \& NIGG, 1999).

COURTEMANCHE et al. (1996) estudaram características estruturais do padrão da passada para 0 andar de sujeitos diabéticos neuropatas durante a emissão de um estímulo auditivo que aumentasse a demanda cognitiva durante a sua execução. Os autores verificaram que os sujeitos neuropatas apresentaram menores passadas ao longo do ciclo da marcha, menores cadências, menor velocidade do ciclo, maiores tempos de apoio simples e maior tempo de duração do ciclo da marcha. Dessa forma, conclui-se que os neuropatas adaptaram sua marcha a um padrão menos instável e mais conservativo de forma a reduzir as demandas de atenção necessárias para controlar uma marcha já instável devido à diminuição de entrada de informação sensorial pela neuropatia. Da mesma forma, MUELLER, MINOR, SAHRMANN, SCHAAF \& STRUBE (1994) também encontraram resultados semelhantes em seu estudo, e discutem que estas adaptações também podem ser devido à perda de automação da marcha.

Quanto maior a severidade da neuropatia, maior a perda somatossensorial e proprioceptiva, além de existir comprometimento na sensibilidade do fuso muscular especialmente em segmentos mais distais, fato este constatado por VAN DEURSEN (1997), levando portanto a conseqüências importantes no controle postural e no controle da marcha. Com esta perda de sensibilidade periférica das extremidades inferiores, associada à perda de sensibilidade dos fusos musculares na perna de neuropatas, diminui a quantidade de informações que são provenientes do tornozelo e como conseqüência, aumenta a importância das informações vindas do quadril (VAN DEURSEN, 1997). Dessa forma, tem-se que indivíduos diabéticos portadores da neuropatia periférica compensam a menor atividade de tornozelo e as informações sensoriais perdidas desta região, através do aumento da atividade muscular e articular de quadril.

MUELLER, DIAMOND, DELITTO \& SINACORE (1989), DELBRIDGE, PERRY \& MARR (1988) e VAN DEURSEN (1997) identificaram em diabéticos neuropatas menor mobilidade de tornozelo em movimentos voluntários isolados, assim como durante a marcha. SIMONEAU et al. (1996) destacam a importância da percepção sensorial e cinestésica do tornozelo, além das informações somatossensoriais de membros inferiores no controle da marcha. MUELLER et al. (1989) destaca que em diabéticos neuropatas esta função dinâmica do tornozelo está diminuída e provavelmente será 
compensada de alguma forma por outro segmento articular no aparelho locomotor, gerando como resultado menores comprimentos de passo e menores velocidades na marcha.

SIMONEAU et al. (1996) investigaram a sensibilidade à vibração e a percepção ao movimento de tornozelo em diabéticos neuropatas e observaram diferenças significativas em relação aos sujeitos controle estudados. Assim, os neuropatas apresentavam um déficit significativo na percepção de movimento do tornozelo, comprometendo o controle da sua locomoção.

MULLER et al. (1994) estudaram estas compensações no aparelho locomotor anteriormente mencionadas. Estes autores estudaram respostas cinéticas, cinemáticas e de mobilidade articular na fase do apoio durante o andar de diabéticos neuropatas e compararam estas respostas com um grupo de sujeitos controle de mesma idade. Os autores verificaram nos diabéticos neuropatas menores velocidades, menores comprimentos de passo, menores amplitudes de movimento articular de tornozelo, menores momentos de força de tornozelo, menor potência de tornozelo e menores componentes de força reação do solo ântero-posterior. Segundo estes autores, todas estas respostas foram geradas em função do menor torque extensor de tornozelo que leva a uma menor propulsão na fase final do apoio na marcha. Porém, ao mesmo tempo MUELLER et al. (1994) observaram maiores momentos de força de quadril e maior potência de quadril e com isso concluem que diabéticos neuropatas com déficits importantes em pé e tornozelo, levam o membro inferior à frente na fase de balanço na marcha através do maior recrutamento dos músculos flexores de quadril - estratégia do quadril, ao invés de usar a musculatura extensora de tornozelo para propulsionar o corpo à frente. Importante notar que estas estratégias a que os autores se referem não são as estratégias discutidas por HORAK \& NASHNER (1986) no controle postural humano. Estas estratégias do quadril e tornozelo na marcha são representações dinâmicas das estratégias posturais, porém ainda não se definiu a relação de dependência entre estas duas estratégias.

Uma importante constatação deste estudo de MUELLER et al. (1994) é o uso da estratégia de quadril na marcha na fase de balanço principalmente, em detrimento da estratégia de tornozelo, e com isso há uma antecipação importante do recrutamento dos músculos flexores de quadril, especialmente 0 m. reto da coxa, em relação às fases do ciclo da marcha. Resta determinar a relação entre a severidade da neuropatia e o uso destas estratégias de quadril e tornozelo na marcha. Há evidências de que quanto mais severa a neuropatia, maior a contribuição da estratégia do quadril e muito menor a contribuição de tornozelo no andar. Terapeuticamente, sugere-se o fortalecimento dos músculos flexores de quadril e de joelho para compensar a ineficiência da mobilidade de tornozelo em neuropatas (MUELLER et al., 1994). 
O maior uso da estratégia do quadril, considerando esta como sendo uma compensação biomecânica na marcha feita em algumas situações, ou ainda um aumento da energia mecânica neste segmento, já foi referida em outras doenças e condições fisiológicas, tais como em idosos (WINTER, 1991; McGIBBON, KREBS \& PUNIELLO; 2001).

LORD \& HOSEIN (2000) estudaram as forças de atrito nas cabeças metatarsianas e calcanhar em diabéticos neuropatas durante 0 andar com sapatos ortopédicos através de um transdutor de atrito magneto-resistivo. Estes autores partiram da premissa já muito discutida na literatura de que altas pressões plantares aumentam a incidência de ulcerações e que estas forças de atrito devem ser igualmente danosas para a estrutura plantar. Os autores não encontraram diferenças nas forças de atrito entre os sujeitos neuropatas e os sujeitos controle, porém foram encontradas maiores forças nas primeira e segunda cabeças metatarsianas e maior variabilidade intra-sujeito nos indivíduos neuropatas, o que confere uma mudança medial de apoio no antepé nestes diabéticos.

BEVANS (1992) discute que a formação de úlceras plantares decorrentes da neuropatia diabética, se devem aos movimentos e posição da articulação subtalar. Dessa forma, a formação de úlceras plantares laterais está associada à posição de supinação do pé e a formação de úlceras plantares mediais, com a posição de pronação do pé. KATOULIS et al. (1997) destacam que diabéticos neuropatas apresentam uma alteração importante na mecânica do pé e que provavelmente aumentaria a probabilidade de provocar lesões plantares, alterações estas que aumentam a sobrecarga na lateral do pé em posição supinada, e durante a progressão do corpo no andar, esta sobrecarga desloca-se lateralmente para as terceira e quarta cabeças metatarsianas. Em função desta discussão anterior, um aspecto interessante de ser investigado, é a relação entre os picos de pressão plantar comuns em diabéticos neuropatas e a atividade muscular especialmente aquela relacionada à articulação do pé e tornozelo (ABBOUD et al., 2000).

ABBOUD et al. (2000) estudaram a distribuição de pressão plantar e padrões eletromiográficos dos $\mathrm{m}$. tibial anterior, $\mathrm{m}$. fibular curto, $\mathrm{m}$. fibular longo e $\mathrm{m}$. sóleo durante $\mathrm{o}$ andar em indivíduos diabéticos, e da atividade EMG adquirida, eles analisaram a magnitude dos picos de ativação e início dessa ativação. Com relação à EMG, todos os músculos estudados apresentaram um atraso importante no seu recrutamento durante 0 andar de indivíduos neuropatas, especialmente o $\mathrm{m}$. tibial anterior e por este motivo estes indivíduos levavam o antepé a entrar em contato com o solo mais cedo em relação aos sujeitos controle na fase de apoio médio, além disso o antepé permaneceu por mais tempo em contato com o solo durante a marcha e apresentou os maiores picos de pressão. Dessa forma os autores, discutem que a presença de picos de pressão não seria a causa direta da formação de úlceras 
plantares no paciente neuropata, mas sim uma disfunção do $\mathrm{m}$. tibial anterior que não impede que a recepção da carga pelo antepé seja tão excessiva.

Da mesma forma que MULLER et al. (1994) destacaram em seus estudos de momentos de força articulares, ABBOUD et al. (2000) destacam uma disfunção flexora do m. tibial anterior durante a fase de aplainamento do pé no médio apoio na marcha e o atraso característico na ativação dos $\mathrm{m}$. tibial anterior, m. fibular curto, m. fibular longo e m. sóleo, promove uma duração maior da fase de apoio simples do pé.

Como forma de prevenir a formação de ulcerações plantares nestes diabéticos neuropatas, ABBOUD et al. (2000) sugerem que deve-se criar mecanismos de intervenção para se evitar 0 aplainamento do pé de forma brusca, tal como ocorre em neuropatas cujo comprometimento motor já acarreta alterações nesta fase da marcha. Mecanismos de intervenção tais como o fortalecimento de músculos adjacentes à articulação do tornozelo que auxiliam a dorsiflexão ou ainda órteses que impedem o pé de aplainar bruscamente.

CAVANAGH, PERRY, ULBRECHT, DERR \& PAMMER (1998) estudaram a distribuição de pressão plantar em diabéticos neuropatas de forma a investigar os efeitos da variabilidade do padrão dinâmico na formação de ulcerações plantares. Os autores não observaram diferenças no coeficientes de variação (CV) da pressão plantar durante a marcha entre os grupos estudados: controle, diabéticos não neuropatas e neuropatas, dados estes contraditórios aos já encontrados em outros estudos, tal como o de SACCO \& AMADIO (2000) que encontraram maiores CV nos parâmetros dinâmicos de pressão plantar e força reação do solo em diabéticos neuropatas em relação a um grupo controle saudável.

CAVANAGH et al. (1998) discutem que diabéticos neuropatas podem apresentar maior variabilidade em relação a sujeitos controle nas respostas de variáveis cinemáticas e no cálculo dos momentos de força durante 0 andar, mas a pressão plantar reflete as últimas conseqüências do controle motor entre a interface pé-calçado e portanto não exprimem as causas do movimento. Outra hipótese defendida pelos autores é a de que devido a diminuição de informação aferente decorrente da doença, o controle da marcha passa a ser mais conservativo, mais inflexível, apresentando padrões fixos de controle e portanto de movimentos e consequentemente diminui a capacidade de adaptação do movimento às exigências do ambiente ou do local da dor e portanto apresentariam menores valores de CV. Ainda assim, os autores observaram maiores CV de pressão plantar nos indivíduos neuropatas nas regiões do antepé e hálux e menores CVs, no calcanhar. Os autores relacionaram estas regiões de 
maior variabilidade na distribuição de pressão com as regiões de maior incidência de ulcerações em diabéticos neuropatas.

Diante do exposto, pode-se concluir que os diabéticos neuropatas apresentam importantes alterações comportamentais no andar e significativas alterações nas respostas sensitivas e motoras, e dentre estas alterações discutidas nestas seções anteriores, analisaremos no presente estudo respostas de ativação elétrica muscular, parâmetros da força reação do solo, parâmetros espaciais e temporais do ciclo da marcha e parâmetros de respostas sensitiva e motora do segmento inferior. Segundo DINGWELL, CUSUMANO, STERNAD \& CAVANAGH (2000), a diminuição dos parâmetros cinéticos observados por MUELLER et al. (1994), COURTEMANCHE et al. (1996) e KATOULIS et al. (1997) parece ser uma conseqüência secundária da diminuição da velocidade auto-selecionada dos sujeitos diabéticos neuropatas e não uma conseqüência direta da perda sensorial.

Somente o estudo de MUELLER et al. (1994) demonstrou através do cálculo de momentos de força de quadril e tornozelo que os sujeitos diabéticos neuropatas utilizam muito mais a estratégia de quadril durante as fases de toe clearance e balanço no andar ao invés de utilizarem a estratégia de tornozelo nestas mesmas fases, estratégia esta normalmente utilizada em sujeitos normais.

Desta forma, pode-se concluir que poucos estudos têm demonstrado estratégias biomecânicas adotadas durante a marcha de sujeitos diabéticos neuropatas, considerando o importante déficit neuromotor decorrente da doença. Um estudo demonstrou a possibilidade destes sujeitos doentes modificarem a estratégia de tornozelo pela de quadril durante a marcha, demonstrando isto através da redução de momentos de força na articulação do tornozelo (MUELLER et al., 1994). Outro importante estudo revisado demonstra alteração no padrão de recrutamento muscular durante a marcha nestes sujeitos neuropatas (ABBOUD et al., 2000). Isto nos leva a interpretar que provavelmente alterações nas estratégias de controle da marcha ocorreram e como conseqüência a biomecânica externa se altera.

A importância do presente estudo se justifica na medida em que se propõe a investigar exatamente estes padrões de recrutamento muscular possivelmente já alterados, respostas da biomecânica externa e inferências sobre o controle da marcha em pacientes diabéticos neuropatas, de forma a intervir nas condutas terapêuticas e profiláticas nestes sujeitos, assim como modificando antigos protocolos de reabilitação neuromuscular em neuropatas. Pode ainda servir de base para investigar e adaptar órteses que o movimento de articulações acometidas pela neuropatia diabética periférica e portanto que auxiliem na sua locomoção. 


\section{MATERIAL E MÉTODOS}

O presente projeto de doutorado está inserido dentro do contexto do projeto que foi desenvolvido junto ao Hospital Universitário da USP, projeto FAPESP n. 98/09992-4. Este projeto propôs-se a integrar uma avaliação biomecânica complexa da marcha nos sujeitos diabéticos neuropatas na rotina de pesquisa e atendimento ambulatorial do Hospital. No presente estudo, buscouse, de forma integrada, interpretar a biomecânica do andar deste sujeitos, assim como buscar possíveis indicadores que caracterizem a neuropatia diabética periférica.

\subsection{Seleção dos Grupos Experimentais}

Nossos grupos experimentais foram constituídos e selecionados intencionalmente. Foram compostos de 36 adultos voluntários de ambos os sexos, com consentimento prévio esclarecido, obedecendo a características metodológicas éticas orientadoras do presente projeto. Esses 36 sujeitos foram distribuídos em dois grupos distintos, a saber:

a) Grupo Diabético (GD) ( $n=16)$ sendo composto por diabéticos tipo 1 ou 2, portadores da neuropatia periférica diabética, diagnosticada por eletroneuromiografia ou clinicamente através de testes de sensibilidade específicos para tal fim. Os diabéticos foram encaminhados pelo Ambulatório Multidisciplinar Padronizado de Atenção ao Diabético do Hospital Universitário. Neste serviço, os diabéticos são acompanhados por uma equipe multidisciplinar composta por nutricionistas, médicos endocrinologistas, vasculares, otorrinos, oftalmologistas, neurologistas, e equipe de apoio do Hospital Universitário. Sendo assim, estes pacientes são avaliados periodicamente por esta equipe multidisciplinar e, associada a ela, está o Laboratório de Biomecânica da Escola de Educação Física e Esporte da USP. Estes sujeitos já haviam sido preliminarmente avaliados quanto às características comportamentais apresentadas nas respostas dinâmicas durante 0 ciclo da marcha voluntária e demais características antropométricas dos pés, medidas estas que foram confrontadas com o diagnóstico clínico, a partir do encaminhamento médico. Desta maneira pode-se selecionar a amostra que participou deste grupo de diabéticos portadores da neuropatia periférica, onde através do prontuário clínico e biomecânico procedeu-se a estratificação da amostra experimental a partir do acompanhamento e avaliações realizadas com 95 diabéticos oriundos do HU-USP.

Os diabéticos encaminhados pelo Hospital Universitário foram selecionados intencionalmente segundo critérios definidos, e conforme os procedimentos da Comissão de Pesquisa e Ensino do Hospital Universitário. Os critérios de seleção estabelecidos para constituição do grupo GD foram: 
diabéticos com diagnóstico há mais de 5 anos, diagnóstico clínico de neuropatia periférica pelo médico responsável, resultados dos testes de sensibilidade e tolerância à dor alterados em conformidade com a doença estudada e sintomatologia associada segundo entrevista pessoal.

Os critérios de exclusão adotados para seleção da amostra experimental coincidem com os critérios adotados por outros estudos na literatura (MUELLER et al., 1994; BERGIN et al., 1995; COURTEMANCHE et al., 1996; KATOULIS et al., 1997; ABBOUD et al., 2000) e foram: idade acima de 65 anos, ulcerações no momento da avaliação que prejudiquem o andar independente, acuidade visual prejudicada e que comprometa a marcha, uso de bengala para locomover-se, doença periférica vascular ou claudicação intermitente, história de doenças vestibulares, neurológicas, musculares ou reumáticas, fora da etiologia da diabetes, história de uso excessivo de álcool, amputação parcial ou total.

b) Grupo Controle (GC) ( $n=20)$ sendo composto por indivíduos não diabéticos, saudáveis, sem qualquer comprometimento ósteo-mio-articular. Os sujeitos analisados foram em sua maioria funcionários da Escola de Educação Física e Esporte da USP, e outros eram acompanhantes dos sujeitos diabéticos, porém sempre procedentes da cidade de São Paulo. Estes sujeitos voluntários foram selecionados com o intuito de buscar que suas características fossem semelhantes ao grupo GD, características estas de idade, massa, proporção de gênero na amostra, e ausência de doenças que comprometessem o desempenho na marcha.

\subsection{Protocolo Experimental}

De forma comparativa, parâmetros biomecânicos dinâmicos e eletromiográficos selecionados para uma população não diabética não neuropata (controle) e outra portadora da neuropatia diabética, foram avaliados durante a marcha em esteira rolante, de forma a estudar apoios na marcha e sua regularidade. As medições foram realizadas em ambiente de laboratório e os procedimentos de medição foram submetidos à análise e posteriormente foram aprovados pela Comissão de Ética do Hospital Universitário, representada pela Comissão de Ensino e Pesquisa do HU-USP. Esta conduta de encaminhamento foi conduzida uma vez que o protocolo experimental está inserido no contexto do projeto FAPESP desenvolvido em conjunto com 0 hospital. Os sujeitos estudados tomaram conhecimento dos procedimentos experimentais e consentiram a sua participação no estudo através de um termo de consentimento informado de pesquisa, conforme ANEXO I. 
O protocolo experimental foi constituído de três etapas: entrevista pessoal, avaliação eletrodiagnóstica (somatossensorial e motora), avaliação do andar (análise dinâmica e eletromiográfica), com duração de aproximadamente uma hora (FIGURA 4).

\subsubsection{Entrevista Pessoal}

Uma avaliação preliminar foi feita através de uma entrevista pessoal com o uso de um instrumento previamente elaborado, baseado inicialmente em REDMOND, MCKENNA, FEINGOLD \& AHMAD (1992) e validado para este fim. Este instrumento investigou alguns aspectos relevantes para a investigação da neuropatia diabética, tais como: hábitos diários de consumo de álcool e fumo, micro e macrocomplicações crônicas da diabetes, presença de calos e história de ulcerações plantares, sintomatologia associada à neuropatia diabética, entre outros aspectos. Este questionário já foi previamente aplicado em análises e intervenções anteriores (AMADIO, SACCO, SÁ, PEREIRA \& TOLOSA, 1997; SACCO \& AMADIO, 2000), tendo sido elaborado e submetido a julgamento por pares para verificar a adequação das questões, conforme ANEXO II.

Os dados da entrevista foram analisados item por item de forma a caracterizar os grupos estudados. As informações foram dadas pelos próprios sujeitos diabéticos neuropatas e portanto de difícil interpretação e análise correlacional com outros dados obtidos da análise biomecânica.

\subsubsection{Avaliação da cronaxia sensitiva e tolerância à dor na superfície plantar e cronaxia motora nos músculos selecionados}

A cronaxia sensitiva e a tolerância à dor foram avaliadas em cinco regiões da superfície plantar do pé direito e esquerdo anatomicamente selecionadas, a saber: hálux, antepé medial (1 ${ }^{\text {a }}$ e $2^{\text {a }}$ cabeças metatarsianas), antepé lateral ( $3^{\mathrm{a}}, 4^{\mathrm{a}}$ e $5^{\mathrm{a}}$ cabeças metatarsianas), meio-pé e calcanhar (SACCO, 1997) (FIGURA 5).

A cronaxia sensitiva é definida como o tempo mínimo em milisegundos para o indivíduo perceber um estímulo aplicado sobre a pele com o dobro da intensidade da reobase sensitiva (FIGURA 6), e esta é definida como a menor intensidade de um estímulo elétrico necessário para ser percebido (KIMURA, 1989). A corrente utilizada para se determinar a reobase é uma corrente monopolar sob forma de pulsos elétricos de $1000 \mathrm{~ms}$ por $2000 \mathrm{~ms}$ de repouso (FIGURA 6). A tolerância à dor foi avaliada através de aplicação de corrente monopolar sob forma de pulsos elétricos de $1000 \mathrm{~ms}$ por 
2000 ms de repouso nos mesmos sítios anatômicos avaliados na cronaxia sensitiva e os sujeitos respondem quando se instalar o limiar suportável da sensação dolorosa.

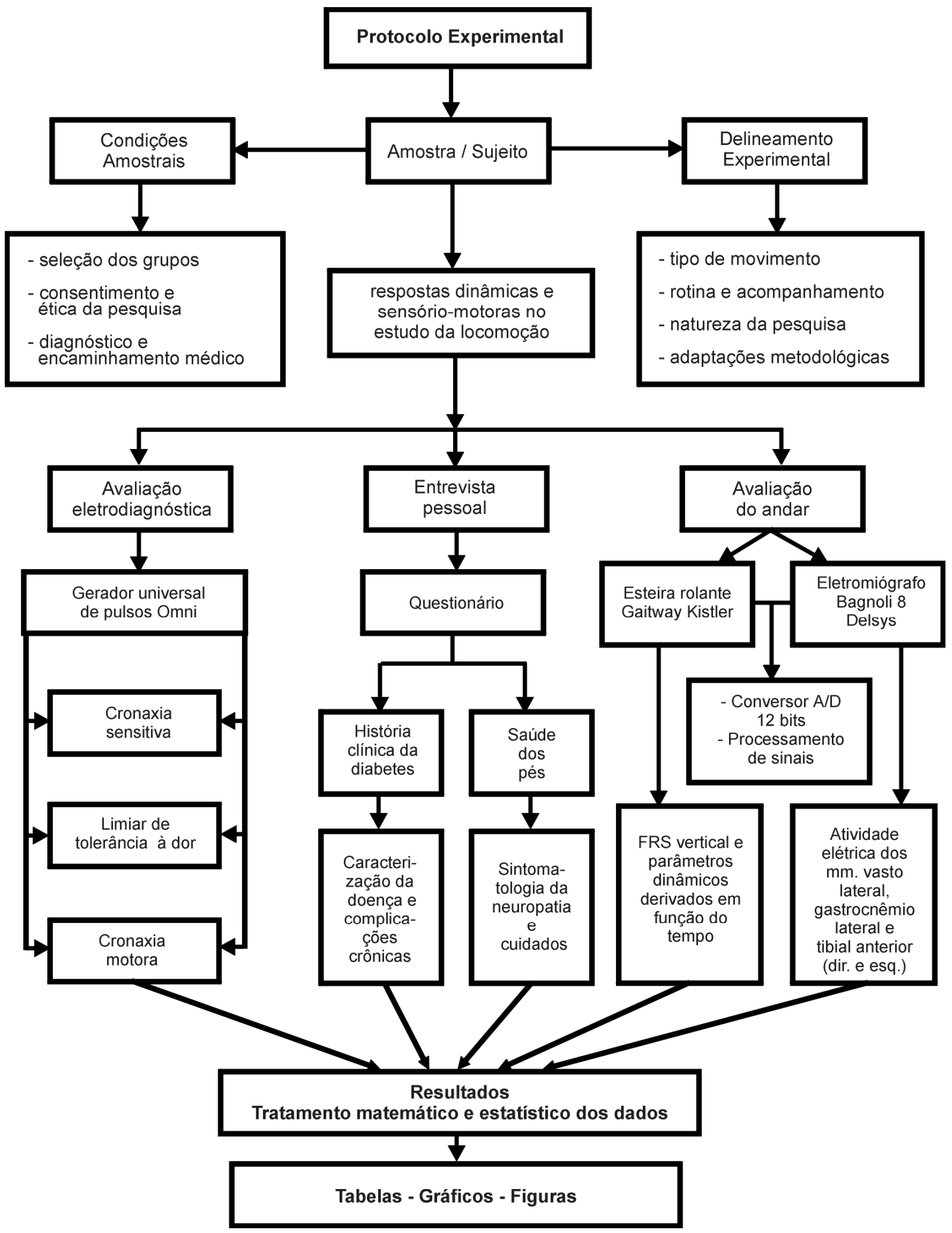

FIGURA 4 - Diagrama de blocos representando as etapas do protocolo experimental. 

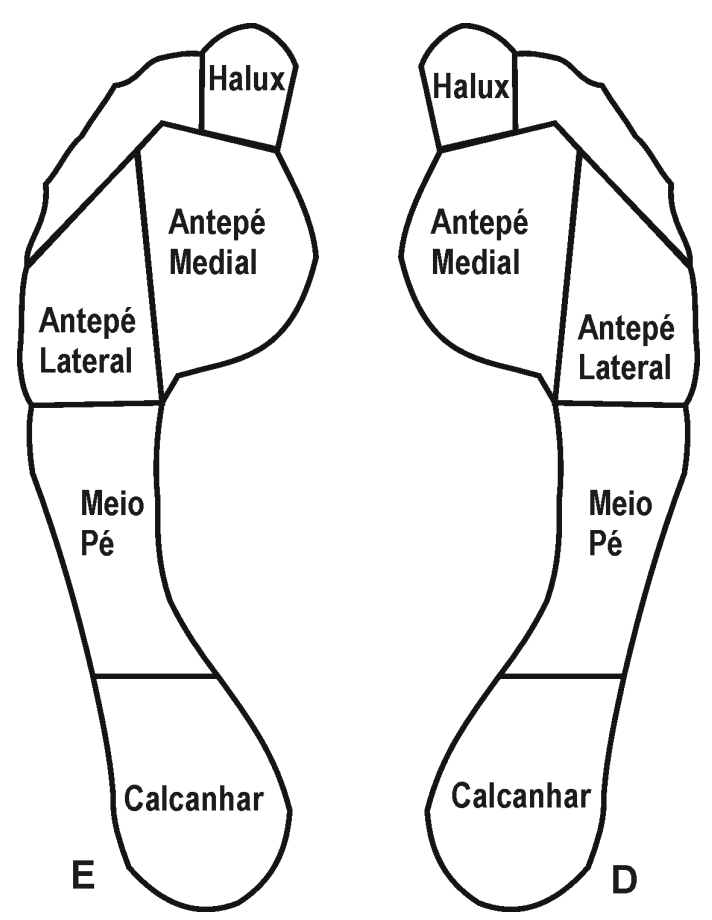

FIGURA 5 - Áreas plantares estudadas na avaliação eletrofisiológica dos sujeitos: cronaxia sensitiva e tolerância à dor.
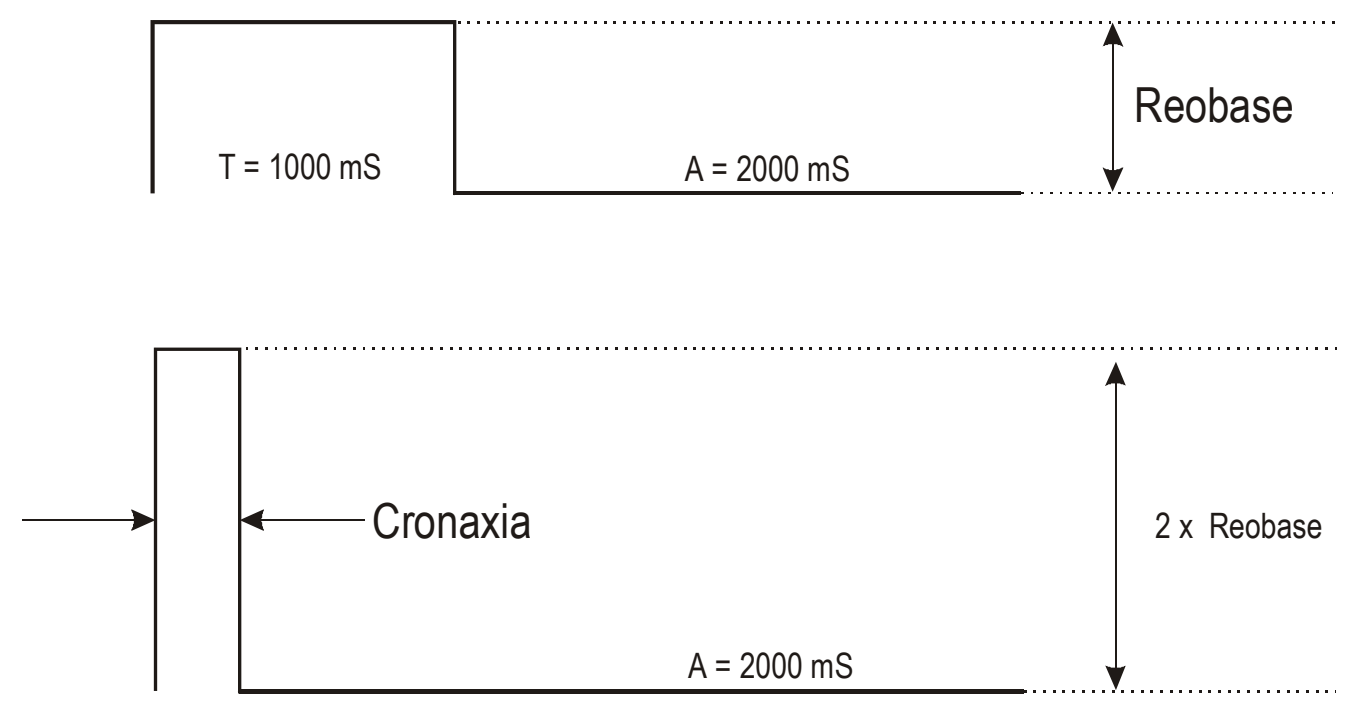

FIGURA 6- Representação esquemática da determinação da reobase e da cronaxia sensitiva e motora.

A cronaxia motora foi avaliada em músculos selecionados do membro inferior, segundo suas funções na marcha, e estes mesmos músculos foram avaliados na eletromiografia: $\mathrm{m}$. vasto lateral, $\mathrm{m}$. tibial anterior e m. gastrocnêmio lateral, direito e esquerdo. A cronaxia motora é definida como o tempo 
mínimo para estimular uma contração muscular mínima visível ou palpável decorrente da aplicação de um estímulo elétrico com o dobro da intensidade da reobase motora (FIGURA 6), e esta é definida como a menor intensidade de um estímulo elétrico necessário para estimular uma contração muscular mínima visível ou palpável (KIMURA, 1989) (FIGURA 6).

Estas variáveis eletrofisiológicas foram determinadas através de um gerador universal de pulsos Omni Pulse 901 (Quark, Piracicaba) (FIGURA 7). Este equipamento é controlado por um microprocessador que gerencia ondas pré-programadas permitindo realizar procedimentos envolvidos na eletroterapia, no eletrodiagnóstico e pesquisa relativa à estimulação transcutânea. Este gerador universal de pulsos tem as seguintes características: faixa de operação de corrente elétrica de 0 a 70 $\mathrm{mA}$, corrente podendo ser bi ou monopolar, largura do pulso e o repouso entre os pulsos ajustável de 0 a 4.000 ms e trens de pulso ajustáveis de 0 a $10 \mathrm{~s}$.

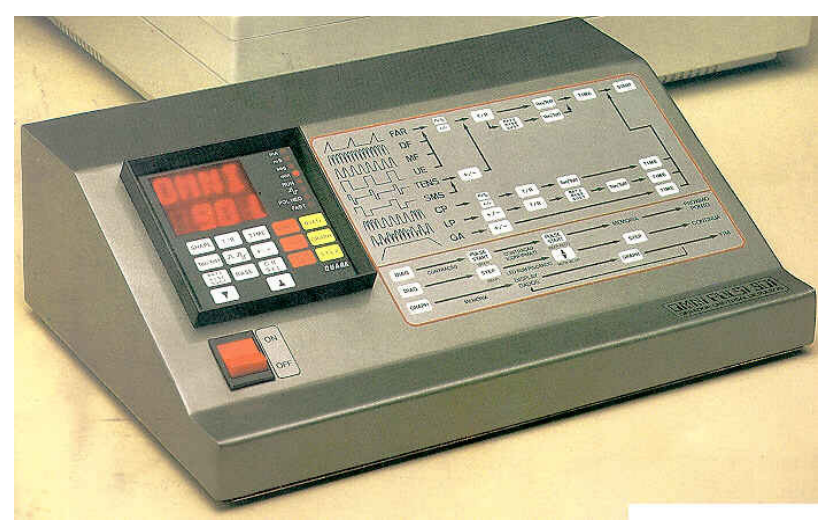

FIGURA 7- Gerador Universal de pulsos Omni Pulse 901.

\subsubsection{Avaliação dinâmica e eletromiográfica da marcha}

A marcha foi avaliada segundo parâmetros biomecânicos dinâmicos e eletromiográficos em uma esteira rolante. Os sujeitos andaram inicialmente em piso fixo por uma passarela de aproximadamente $20 \mathrm{~m}$ em cadência auto-selecionada, tal como em COURTEMANCHE et al. (1996), para ser determinada a velocidade que foi imposta na esteira rolante. A aquisição durante a marcha das respostas dinâmicas, através das plataformas de força montadas na esteira rolante, e das respostas eletromiográficas, através de um eletromiógrafo, foi simultânea e sincronizada através do sistema Gaitway - Kistler e administradas pelo software Gaitway.

Para descrevermos esta terceira etapa do protocolo experimental, dividiremo-na em duas partes: (1) determinação das variáveis dinâmicas e (2) determinação das variáveis eletromiográficas. 
4.2.3.1 Determinação das variáveis dinâmicas: Força reação do solo, Parâmetros temporais e espaciais do ciclo da marcha

Foi utilizado o Sistema Gaitway Instrumented - Kistler Type 9810S1x \& Software Version 1.0x, que consiste de uma esteira rolante (Trotter Treadmill Type N01-06560201) com duas plataformas de força montadas na sua superfície (FIGURA 8), gerenciadas por um conversor Analógico/Digital (A/D) e programa de funções Gaitway que realizou a aquisição, análise parcial e armazenamento dos dados. Utilizou-se um conversor A/D DAS - 1600/ 1400 Series Keithley Instruments Inc. com 16 canais e resolução de 12 Bits.
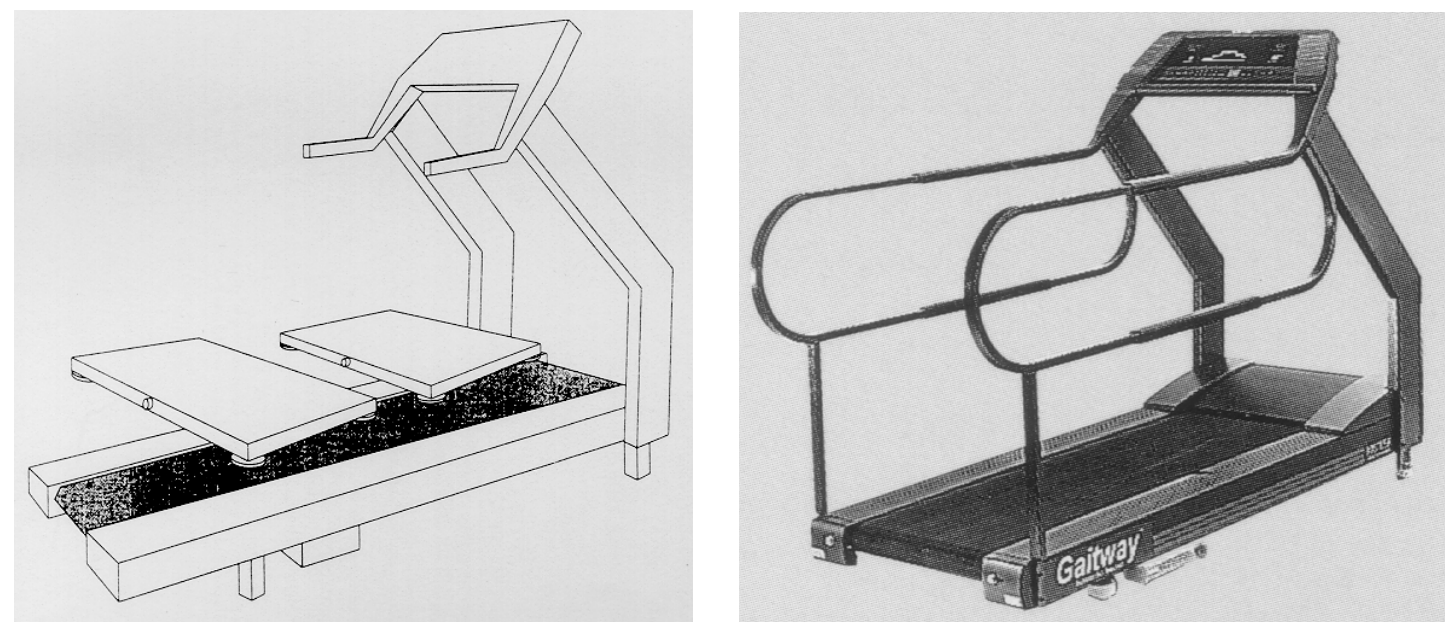

FIGURA 8 - Sistema Gaitway da Kistler. esteira rolante com duas plataformas de força embutidas. (adaptado de GAITWAY, 1996).

O sistema Gaitway Instrumented Treadmill utiliza-se de duas plataformas Kistler montadas em série na base da referida esteira, cujo layout permite a discriminação dos passos em função dos apoios nas plataformas e para isto possui um dispositivo auxiliar gaitway foot discriminator que se constitui de um sinal infravermelho retro-reflexivo que informa ao software de gerenciamento e de coleta de dados quando o apoio é com o pé direito ou pé esquerdo no ciclo da passada. A esteira rolante Trotter tem as seguintes dimensões: 0,8 $\mathrm{m}$ de largura e $2 \mathrm{~m}$ de comprimento.

A calibragem nominal (Gaitway System Calibration) do sistema respondeu aos seguintes valores: sensibilidade das células de carga piezoelétricas (valor médio de oito células) $=4,438 \pm 0,23$ [pC/N]; faixa de variação 1 (valor médio para oito canais) = 944,3 $\pm 5,61[\mathrm{pC} / \mathrm{N}]$; faixa de variação 2 (valor médio para oito canais $)=2833,7 \pm 16,95[\mathrm{pC} / \mathrm{V}]$; sensor de velocidade parâmetro "m"= 158,52; sensor 
de velocidade parâmetro "b"= $-0,0526$; sensibilidade do foot discriminator $=>50 \mathrm{~cm}$. Para o controle da calibragem, dois procedimentos foram utilizados: (a) inicialmente, o ajuste do nível da plataforma em relação a horizontal controlado por rotina específica do software, e (b) registro da força peso adquirido a partir da massa do próprio sujeito de pesquisa que posicionou-se em repouso por 10 segundos sobre a plataforma da esteira para posterior averiguação da reprodutibilidade do registro, considerando-se a massa do sujeito já anteriormente conhecida. Dentre os diversos parâmetros possíveis para a análise pelo software Gaitway, foram selecionadas as variáveis derivadas da curva força $X$ tempo; variáveis temporais descritoras da distribuição do tempo para cada uma das fases do ciclo da passada, comprimento do passo e passada, índices de simetria entre os tempos de apoio simples com o pé direito e esquerdo e índices de simetria entre o comprimento do passo direito e esquerdo.

Os sujeitos caminharam nesta esteira em cadência auto-selecionada transferida do piso fixo após a habituação ao instrumento, usando um calçado de liga sintética leve $(60$ - $70 \pm 6,5 \mathrm{~g})$ construído de forma a simular a situação de pé descalço.

Por ser um ambiente provavelmente novo para muitos sujeitos, foi necessário um processo de habituação na esteira e este foi composto de algumas etapas a serem descritas a seguir. Os sujeitos caminharam em piso fixo por aproximadamente cinco minutos de forma a estabelecer a cadência natural mais confortável para cada sujeito. Utilizando-se um metrônomo, foi determinada a cadência no piso fixo durante 0 andar dos sujeitos. Uma vez determinada a cadência em piso fixo, a velocidade na esteira foi ajustada de forma a atingir a cadência obtida no piso fixo. A partir de definida a velocidade auto-selecionada, os sujeitos caminharam na esteira por 10 minutos aproximadamente. No início em velocidade lenta até que se adaptassem ao novo ambiente e condição de equilíbrio, e a partir daí, a velocidade foi aumentada progressivamente até que se atingiu a cadência previamente determinada. As coletas iniciais serviram de controle para garantir a reprodutibilidade do tempo de apoio simples e garantir que a cadência estipulada em piso fixo fosse atingida. Estas verificações foram feitas através do software da Gaitway que gera gráficos da cadência média obtida em cada uma das tentativas iniciais e dos tempos de apoio simples.

Em alguns casos, o tempo de habituação estabelecido de 10 minutos não foi alcançado, especialmente pelos diabéticos neuropatas devido cansaço ou sintomatologia associada à doença, então a habituação na esteira rolante foi controlada através da estabilização do tempo de contato do pé com a esteira (tempo de apoio) em cada passada durante todo o tempo destinado à habituação. Uma vez estabilizado este parâmetro, o sujeito estaria habituado e portanto a coleta de dados teve prosseguimento. 
Após a habituação na esteira rolante, foram feitas dez coletas com duração de 12 segundos, cada uma com freqüência de amostragem de $1000 \mathrm{~Hz}$, e destas coletas feitas foram selecionadas três delas que melhor representaram o fenômeno estudado. A seleção destas três tentativas foi baseada na regularidade do padrão dinâmico e temporal da marcha durante os $12 \mathrm{~s}$ de coleta. Esta reprodutibilidade do movimento foi controlada pela verificação dos tempos de apoio simples e pela variação das respostas de força na marcha (picos de força máxima e força mínima). Cada uma das tentativas em média foi composta de 10 passos de cada membro, e portanto 20 passos no total. Dessa forma, considerando as três tentativas que foram selecionadas de cada sujeito, totalizou-se 30 passos aproximadamente para cada membro (direito e esquerdo) para cada sujeito estudado. Foi feita a média destes 30 passos de cada membro (direito e esquerdo) das três tentativas selecionadas.

As variáveis dinâmicas, temporais e espaciais que foram analisadas durante o ciclo do andar na esteira rolante, foram as seguintes:

a) pico da força vertical máxima 1 e 2 (Fy1 e Fy2), correspondente na FIGURA 9 aos números um e três, respectivamente;

b) força vertical mínima (Fymin), correspondente na FIGURA 9 ao número dois;

c) taxa de crescimento do 10 pico da força vertical (TC1) e do $2^{\circ}$ pico (TC2) ou taxa de aceitação do peso corporal: são definidas como a razão entre 010 ou $2^{\circ}$ pico da força vertical e 0 tempo até este

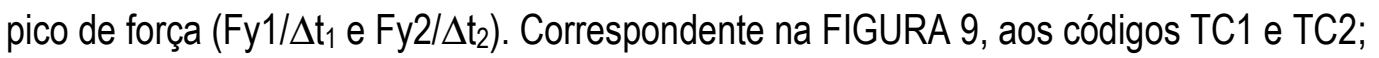

d) deflexão da força vertical: é definida como sendo a taxa de decréscimo da Fy1 até a força mínima (Fy1 - Fymin/ $\Delta \mathrm{t}_{3}$ ). Esta variável está representada na FIGURA 9 como "deflexão";

e) tempo de apoio simples para cada apoio, correspondente na FIGURA 10 ao intervalo entre o início e o fim do apoio simples;

f) tempo de apoio duplo, correspondente na FIGURA 10 ao intervalo entre 0 início e o fim do apoio duplo;

g) comprimento do passo direito e esquerdo, ilustrado na FIGURA 10 como apoio simples direito e esquerdo;

h) comprimento da passada direita, que é definida como o espaço percorrido pelo sujeito entre o início do contato do membro direito até o início do próximo contato com o mesmo membro, ilustrado na FIGURA 10 como passada;

i) comprimento da passada esquerda, que é definida como o espaço percorrido pelo sujeito entre 0 início do contato do membro esquerdo até o início do próximo contato com o membro esquerdo, ilustrado na FIGURA 10 como passada; 
j) simetria entre os tempo de apoio simples esquerdo e direito, sendo definida como a razão entre 0 tempo de apoio simples direito e o tempo de apoio simples esquerdo;

k) simetria entre o comprimento do passo direito e esquerdo, sendo definido como a razão entre 0 comprimento do passo direito e o comprimento do passo esquerdo (definidos no item g).

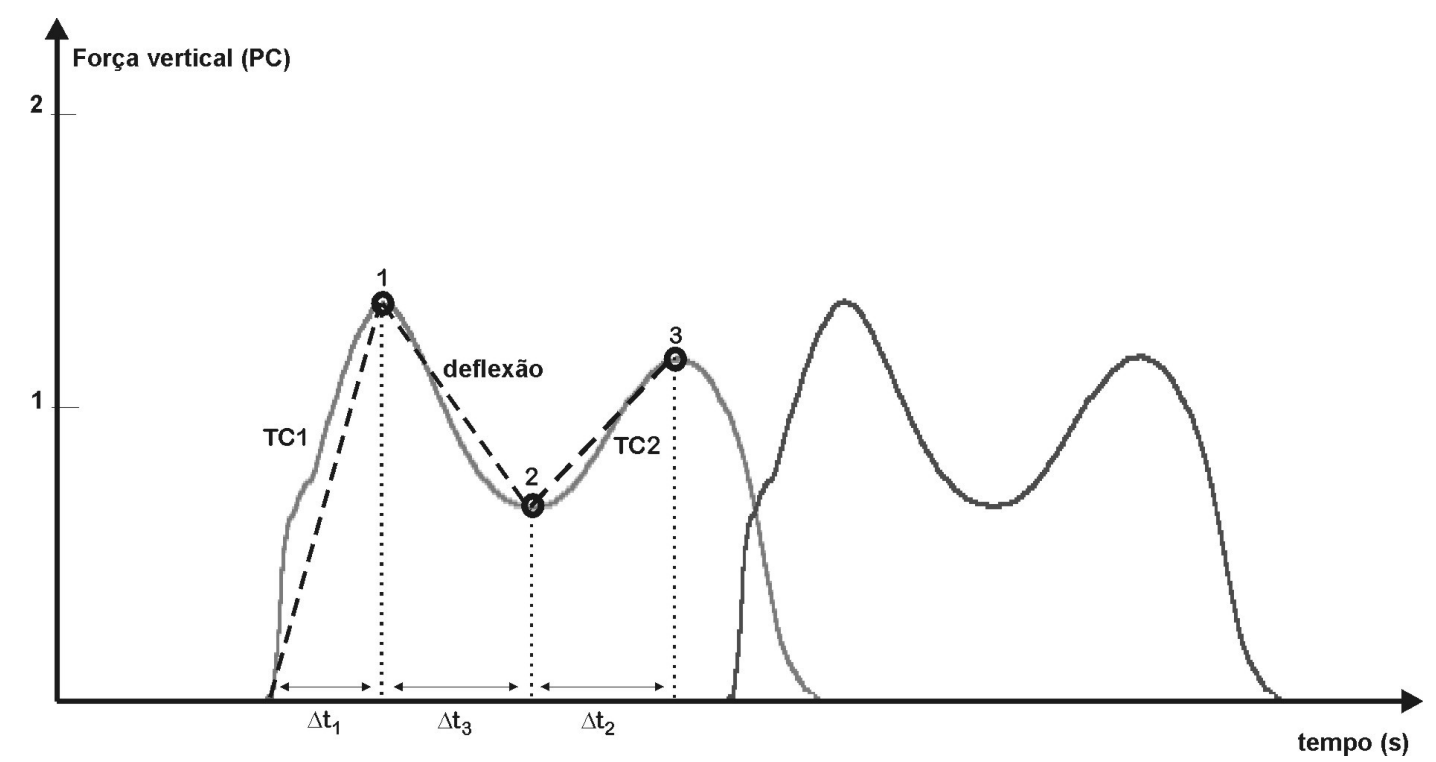

FIGURA 9 - Curva esquemática da Força reação do solo representando as variáveis estudadas: (a) pico de força vertical máxima 1 e 2 (números 1 e 3), (b) força vertical mínima (número 2), (c) taxa de crescimento 1 e 2 (TC 1 e TC2), (d) deflexão da força.

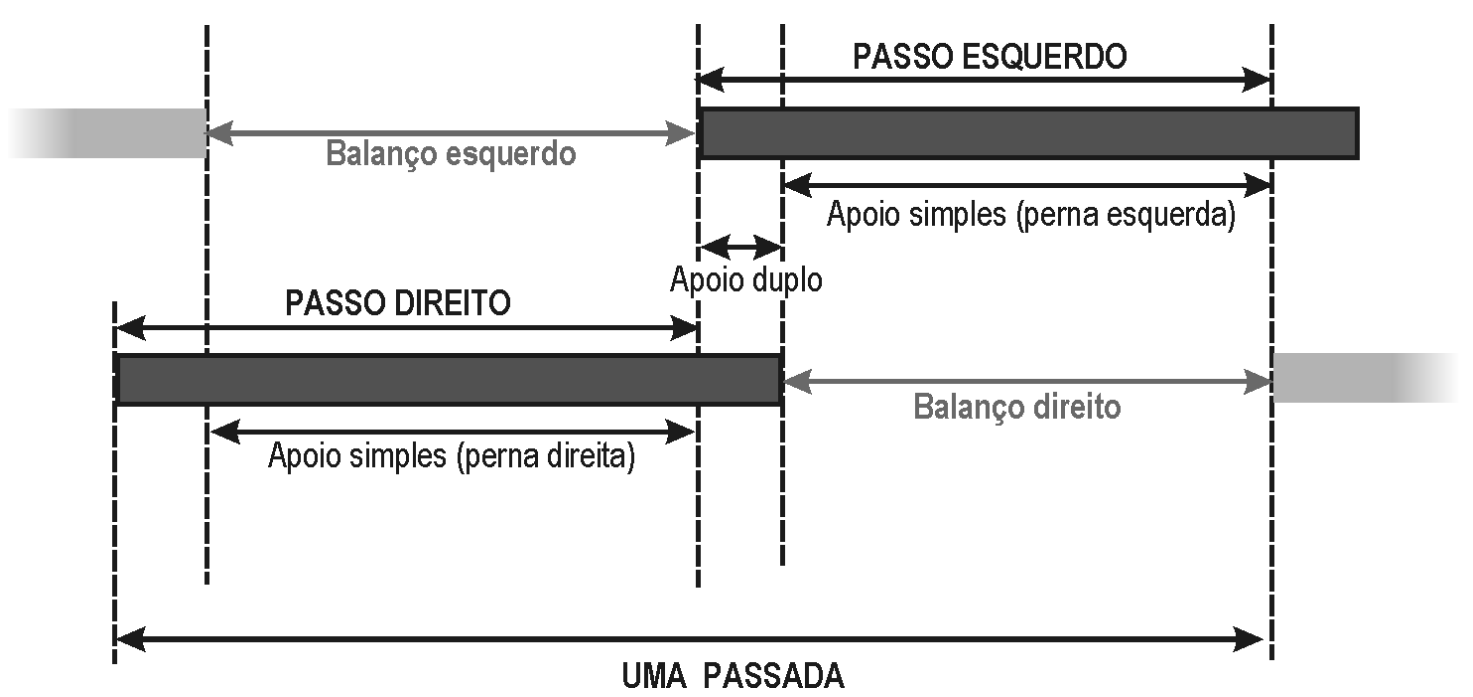

FIGURA 10 - llustração esquemática de variáveis espaciais do ciclo da marcha: comprimento de um passo, comprimento da passada e apoio duplo. 


\subsubsection{Determinação das variáveis eletromiográficas no ciclo da marcha}

Para o registro da atividade elétrica de grupos musculares foi utilizado o eletromiógrafo Bagnoli 8 EMG System - Delsys (FIGURA 11), que possibilitou a análise dos músculos selecionados através de eletrodos diferenciais ativos de superfície, colocados no ponto motor dos músculos selecionados que foram determinados experimentalmente, cuja transmissão do sinal foi bipolar para as alterações do potencial elétrico em função da fase do movimento analisado.

O amplificador do sistema Bagnoli-8 da Delsys possui oito canais analógicos cujas faixas de amplificação são de 100 a 10000 vezes por canal e no presente estudo foi usado o fator de amplificação de 100 vezes (DELSYS, 1999). Cada canal analógico tem uma freqüência de resposta de $20 \pm 5 \mathrm{~Hz}$ a $450 \pm 50 \mathrm{~Hz}$. A amplitude da voltagem máxima de saída do amplificador é de \pm 5 Volts. 0 amplificador do sistema Bagnoli-8 apresenta um modo comum de rejeição (CMRR) de 92dB (valor típico) (DELSYS, 1999). Este amplificador fica apoiado em uma mesa próxima do computador que processará os dados após a aquisição (FIGURA 11).

Além destas especificações do amplificador dos sinais eletromiográficos, faz-se necessário a descrição das características dos eletrodos do sistema Bagnoli-8. Os eletrodos são constituídos de duas barras de prata das seguintes dimensões: $10 \times 1 \mathrm{~mm}$ (FIGURA 11) e sua estrutura tem as seguintes dimensões: 19,8 X 5,4 X 35 mm (DELSYS, 1999). Os eletrodos estão afastados entre si por $10 \mathrm{~mm}$. Eles já são pré-amplificados com fator 10, totalizando um ganho de 1000 vezes (DELSYS, 1999). Estes eletrodos de superfície foram fixados na pele com uma fita adesiva de dupla face entre a pele e 0 eletrodo e uma fita adesiva do tipo transpore por cima do eletrodo, que devido sua composição plástica, evita que o eletrodo se descole em função da provável sudorese provocada pela caminhada na esteira.

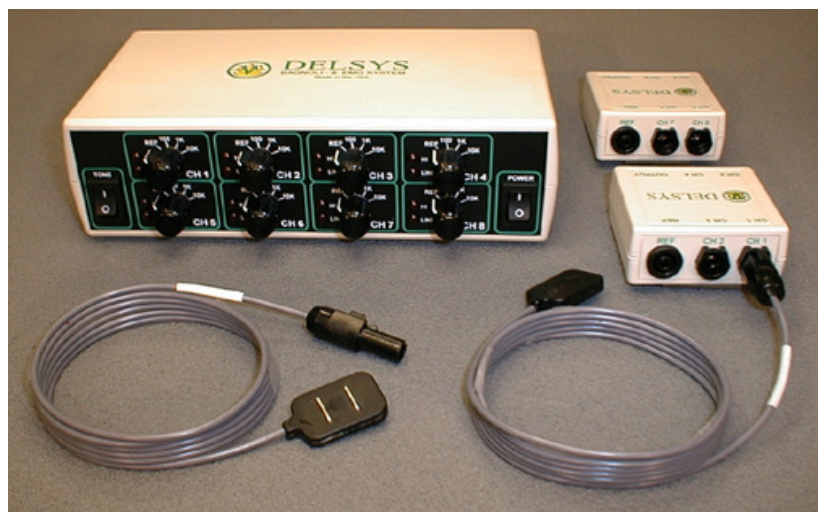

FIGURA 11 - Sistema Bagnoli-8 com oito canais da Delsys. 
A freqüência de amostragem de sinais foi de $1000 \mathrm{~Hz}$ e o tempo de aquisição foi de $12 \mathrm{~s}$ para cada tentativa. $O$ critério de seleção destas três tentativas, seguiu os mesmos padrões para a seleção das variáveis de força, descritos no item anterior, ou seja, reprodutibilidade do padrão e reduzido componente de ruído.

A intensidade média da atividade elétrica dos músculos investigados foi representada por envoltórios lineares em função da duração da passada em diferentes tentativas e indicam qualitativamente a coordenação temporal da atividade muscular durante o movimento (FIGURA 12). Para se obter os envoltórios lineares, procedeu-se algumas etapas matemáticas (FIGURA 12): após a retirada do off-set do sinal bruto, retificar o sinal eletromiográfico por onda completa, filtrar com filtro passa-baixa tipo butterworth de 4a ordem com freqüência de corte de $5 \mathrm{~Hz}$, normalizar o sinal pela sua média e normalizar o sinal em função do tempo de apoio no andar (de 0 a $100 \%$ do tempo de apoio).A representação por envoltórios lineares é recomendada por muitos estudos, dentre eles 0 de ARSENAULT et al. (1986b).
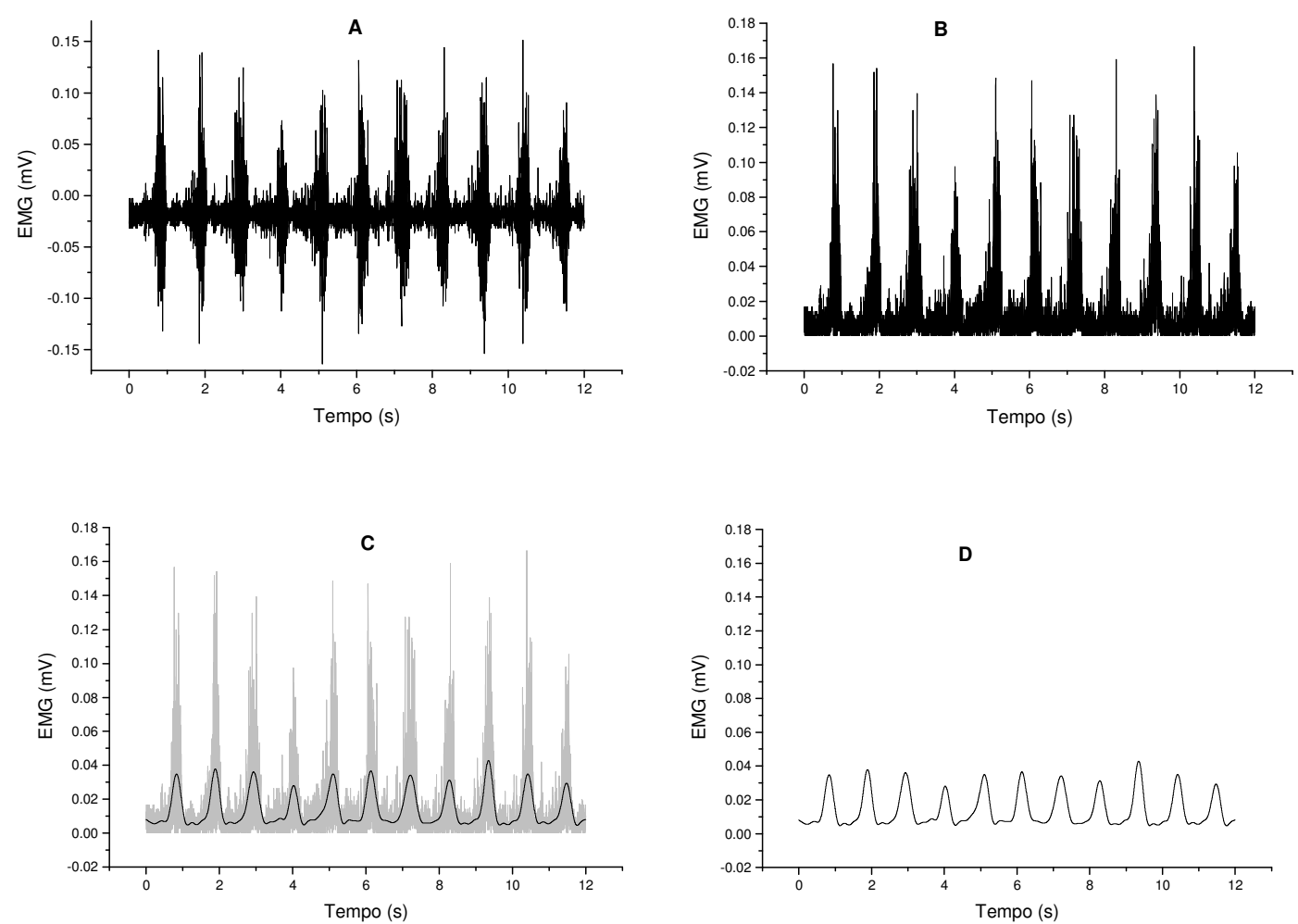

FIGURA 12 - Etapas do tratamento matemático do sinal eletromiográfico para a elaboração dos envoltórios lineares. (A) Sinal EMG bruto. (B) Sinal EMG retificado e retirado o off-set. (C) Sinal EMG retificado (cinza) e sinal filtrado com freqüência de corte de $5 \mathrm{~Hz}$ (preto). (D) Envoltórios lineares. 
A distribuição da atividade muscular durante as diferentes fases do andar foram analisadas a fim de se identificar a flexibilidade das sinergias musculares que precisam se reorganizar quando interpretadas em situações mais criticas, tais como as perturbações oriundas da neuropatia periférica diabética. Estas variáveis foram descritas temporalmente em termos da porcentagem do ciclo do andar.

A motivação inicial do estudo era de verificar a atividade EMG relacionada às articulações do quadril e do tornozelo, já que a literatura aponta para as estratégias compensatórias de quadril que os neuropatas adotam quando a função distal de tornozelo já está acometida (MUELLER et al., 1994). Portanto, o melhor músculo superficial para representar esta articulação do quadril seria o m. reto da coxa. Porém, sua atividade é pouco descrita na literatura e apresenta importante cross-talk, conforme resultados preliminares em nosso laboratório.

Em um pré-experimento - teste piloto realizado, pode-se observar uma importante sincronia temporal da ativação do $\mathrm{m}$. reto da coxa e do $\mathrm{m}$. vasto lateral, além deste último apresentar um sinal mais bem definido e com menos cross-talk. No ANEXO III, estão apresentados resumidamente os resultados do pré-experimento - teste piloto, realizado com um sujeito saudável, onde comparou-se a atividade do $\mathrm{m}$. vasto lateral direito e $\mathrm{m}$. reto da coxa direito. $0 \mathrm{~m}$. vasto lateral e $\mathrm{m}$. reto da coxa deste sujeito apresentaram semelhante padrão de recrutamento temporal CVs de 15,1\% e 9,3\%, respectivamente, e magnitudes um pouco distintas (ANEXO III). Assim, apoiando-se nestes resultados, optou-se metodologicamente pela seleção do $\mathrm{m}$. vasto lateral para seu registro protocolar conforme os objetivos deste estudo.

Desta forma, o m. vasto lateral foi selecionado dentro do grupo do m. quadríceps da coxa, por ter sua atividade eletromiográfica bem descrita na literatura e sujeito a menor interferência em comparação ao flexor de quadril $\mathrm{m}$. reto da coxa, inicialmente escolhido para o estudo. Outro ponto a ser considerado é que indivíduos diabéticos foram estudados e estes muitas vezes apresentam maior quantidade de gordura corporal, e o sinal do $\mathrm{m}$. reto da coxa estaria mais sujeito a interferências devido a esta camada de gordura. Já os músculos posteriores da coxa (flexores de joelho e extensor de quadril) não foram estudados por não haver interesse direto com o presente estudo, assim como haveria dificuldade em se localizar o ponto motor do extensor de quadril, m. bíceps da coxa cabeça longa, por causa da camada de gordura mais evidente em neuropatas nesta região, fato este observado em estudos prévios em nosso laboratório.

Portanto, foi registrada a atividade elétrica de seis músculos selecionados dos membros inferiores direito e esquerdo, quais sejam: m. gastrocnêmio lateral, m. tibial anterior e m. vasto lateral. Estes músculos foram selecionados com o objetivo de representar o grupo muscular extensor e o grupo 
muscular flexor da articulação do tornozelo e do grupo muscular extensor do joelho, respectivamente, articulações estas que tem papel fundamental durante a locomoção humana. São músculos já reportados na literatura como sendo focos da degeneração provocada pela neuropatia motora, especialmente os relacionados à extremidade mais distal - articulação de tornozelo (DICK et al., 1985; RICHARDSON et al., 1992).

Um dos eletrodos de superfície foi colocado no ponto motor de cada músculo e o outro eletrodo foi colocado distalmente ao ponto motor, conforme recomendação da literatura (ARAÚJO, 1998). 0 eletrodo referência foi colocado em uma proeminência óssea mais próxima do músculo em estudo, que no presente trabalho foi a patela direita e esquerda (ARAÚJO, 1998). O ponto motor é a região no ventre muscular de maior sensibilidade à estimulação elétrica e sua localização pode ser determinada experimentalmente (ROY, De LUCA \& SCHNEIDER, 1986). O ponto motor foi determinado através de estimulação elétrica do músculo por um gerador de pulsos universal, Omni Pulse 901 (Quark, Piracicaba), que gerou trens de pulso de $1 \mathrm{~ms}$, em freqüência tetanizante (20 a $80 \mathrm{~Hz}$ ) de intensidade progressiva até que atingisse o limiar motor do músculo.

Para a aquisição das variáveis eletromiográficas e dinâmicas, necessitou-se de um tratamento que permita a sincronia durante a coleta dos canais provenientes do Sistema Bagnoli, assim como dos canais do Sistema Gaitway. Para atender esta necessidade, utilizou-se o conversor A/D já descrito, associado a um computador digital. A função do conversor é transformar o sinal analógico, proveniente das plataformas e do eletromiógrafo, em digital, para que se possa armazenar e analisar os dados, considerando que as fontes de erro foram conhecidas e controladas.

As variáveis eletromiográficas analisadas foram: relativas ao $\mathrm{m}$. vasto lateral $\mathrm{D}$ e $E(1) 10$ pico de ativação, (2) início da $2^{\mathrm{a}}$ ativação, (3) $2^{\circ}$ pico de ativação; relativas ao m. tibial anterior D e E (4) $1^{\circ}$ pico de ativação, (5) início da 2a ativação, (6) $2^{\circ}$ pico de ativação; relativas ao m. gastrocnêmio lateral $D$ e E (7) início da ativação, (8) pico de ativação e (9) término da ativação (conforme FIGURA 13). 


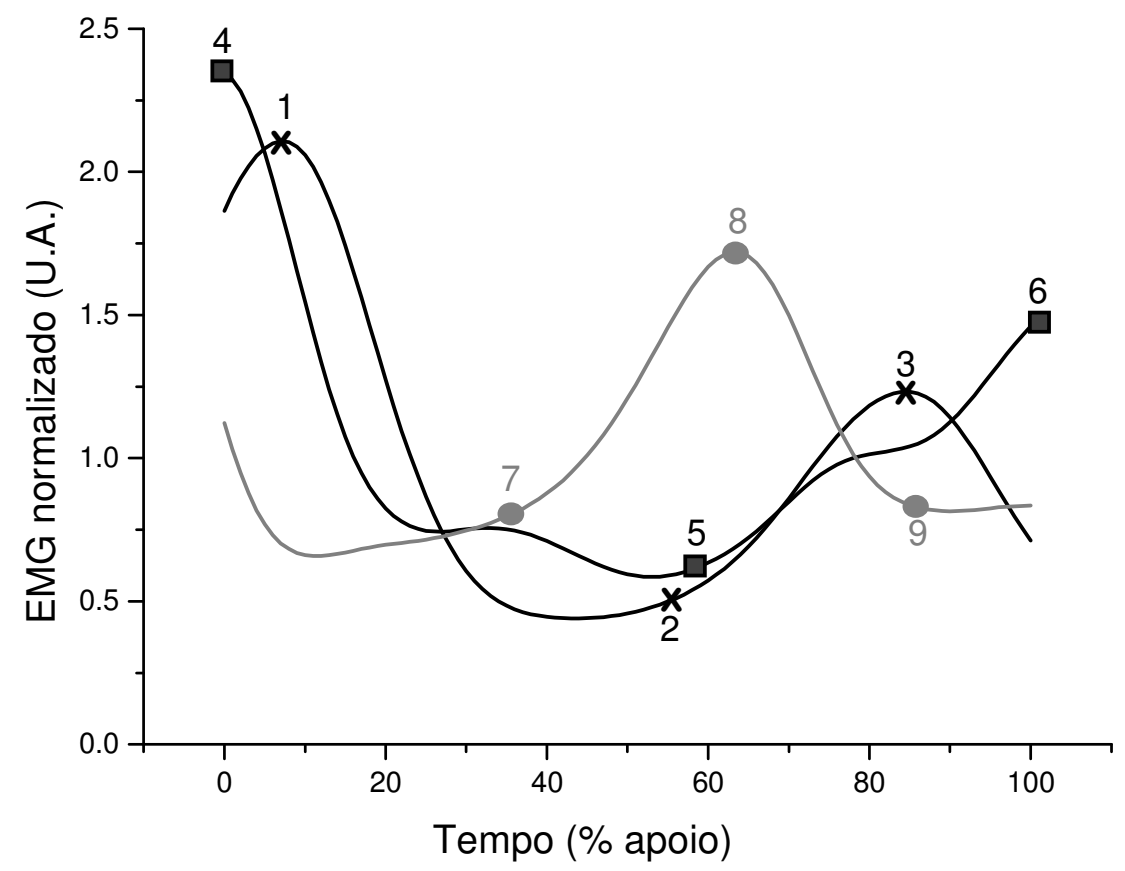

FIGURA 13 - Envoltórios lineares dos m. vasto lateral, m. tibial anterior e m. gastrocnêmio lateral representando as variáveis estudadas. Para o m. vasto lateral: (1) 10 pico de ativação, (2) início da $2^{\mathrm{a}}$ ativação, (3) $2^{\circ}$ pico de ativação. Para $0 \mathrm{~m}$. tibial anterior: (4) 10 pico de ativação, (5) início da $2^{\mathrm{a}}$ ativação, (6) $2^{\circ}$ pico de ativação. Para o m. gastrocnêmio lateral: (7) início da ativação, (8) pico de ativação e (9) término da ativação.

\subsection{Tratamento matemático e estatístico dos dados}

As variáveis de interesse obtidas a partir das curvas da força reação do solo na esteira Gaitway foram calculadas por uma função matemática, denominada por nós de GAITWAY, desenvolvida em ambiente Matlab v. 5.3. (ANEXO IV). Através da programação de algoritmos matemáticos em ambiente Matlab, a rotina GAITWAY construída filtra os dados de força com um filtro passa-baixa de $2^{\mathrm{a}}$ ordem butterworth com $100 \mathrm{~Hz}$ de freqüência de corte, retira o off-set das curvas, normaliza os valores da força pelo peso corporal do sujeito, e interpola os dados para a obtenção das curvas normalizadas na base do tempo em função do apoio. Após este tratamento matemático dos dados, a programação permite ainda o reconhecimento automático dos inícios e finais de apoio, e das variáveis definidas da força reação do solo. A função matemática construída também permite, quando necessário, a correção manual destes parâmetros identificados pela rotina em casos de padrões dinâmicos diferenciados do 
normal. Foi necessária esta adaptação da função para esta correção manual, uma vez que foram encontradas dificuldades principalmente na determinação do início e fim dos apoios em função do próprio sistema de medição Gaitway. Estas dificuldades ocorreram em função de um pequeno off-set encontrado nos dados de força reação do solo ao final de alguns apoios, porém estes erros foram corrigidos com o auxílio desta função matemática desenvolvida no Matlab.

Estas variáveis de interesse calculadas através desta função construída por nós, foram: Fy1, Fy2, força vertical mínima, taxa de crescimento 1 e 2, deflexão da força, tempo de apoio simples para cada apoio e tempo de apoio duplo. As variáveis comprimento do passo e passada, índice de simetria entre o passo direito e o esquerdo e índice de simetria entre tempo de apoio simples direito e esquerdo, foram obtidas diretamente do software da Gaitway Kistler.

Os envoltórios lineares têm sido a maneira mais freqüente de se estimar a intensidade da atividade muscular em movimentos cíclicos como a locomoção (MOFFET et al., 1993; SHIAVI \& GREEN, 1983; WINTER, 1983) e, para efeito deste estudo, estes foram obtidos a partir de uma outra função matemática (BIONICA), desenvolvida em ambiente Matlab, versão 5.3 (ANEXO V).

A partir dos dados eletromiográficos adquiridos, foi ajustado dos sinais brutos a linha de base ou referência zero, quando os mesmos se apresentaram com off-set, através de rotina matemática em ambiente Matlab. Após isso, estes dados foram retificados em onda completa, filtrados usando um filtro passa-baixa de $4^{\mathrm{a}}$ ordem butterworth com $5 \mathrm{~Hz}$ de freqüência de corte, seguidos de interpolação para a obtenção das curvas normalizadas na base do tempo em função do apoio.

O procedimento de normalização da atividade elétrica muscular baseia-se no critério temporal e estabelece as durações das passadas em 100\%. Em seguida, a cada intervalo de $1 \%$ da duração da passada foi obtida uma média desta atividade elétrica muscular. Assim, padrões de ativação muscular para as diferentes tarefas locomotoras foram comparados nos mesmos pontos críticos do ciclo do andar. Além da normalização na base do tempo, o sinal EMG foi normalizado pela sua média naquele intervalo, obtendo assim os envoltórios lineares.

Considerando a natureza assimétrica da neuropatia diabética, a análise dos dados da sensibilidade plantar e motora, análise da atividade elétrica muscular, das forças reação do solo e dos parâmetros temporais do ciclo da marcha, foi feita separadamente para o membro esquerdo e membro direito.

As variáveis biomecânicas estudadas foram inicialmente analisadas para verificação da distribuição estatística dos dados. $O$ teste $\mathrm{W}$ de Shapiro Wilk testou a normalidade da distribuição de todas as variáveis contínuas do presente estudo. As variáveis foram descritas para cada grupo 
experimental em termos de sua medida de tendência central e seu erro: média e desvio padrão. Para as variáveis provenientes do questionário, representaremos os dados para cada grupo através de porcentagens. O coeficiente de variação (CV) também foi utilizado como forma de representar a variabilidade dos dados eletromiográficos, dinâmicos e temporais. O CV foi calculado através da razão entre o desvio padrão e a média das variáveis e representado em termos de porcentagem.

Para as variáveis com distribuição normal, então a comparação das médias de cada variável estudada entre os dois grupos experimentais foi feita através de teste t. Em casos de distribuição não normal, então um teste não-paramétrico equivalente ao teste $t$, teste $U$ de Mann-Whitney, foi utilizado para comparação das variáveis dinâmicas e temporais contínuas.

Considerando a variabilidade dos dados eletromiográficos, especialmente entre os sujeitos neuropatas, uma análise intra-sujeitos foi realizada para a comparação das variáveis em questão.

Foram consideradas significativas as diferenças encontradas para as variáveis entre os dois grupos experimentais, aquelas com significância menor do que $5 \%(p \leq 0,05)$.

0 tratamento estatístico foi realizado nos programas Excel (Microsoft), Primer v. 1.0 (MacGraw Hill) e Statistica v.5.1 (Statsoft Inc.) e o tratamento matemático foi realizado nos programas Matlab v.5.3 (Mathworks) e Origin v.5.0 (Microcal Software).

\subsection{Controle do erro metodológico e limitações experimentais}

A cientificidade de uma medida empírica depende da determinação do erro presente no procedimento de mensuração de uma determinada grandeza. Estes erros podem resultar de fontes sistemáticas não controláveis como, por exemplo, da imprecisão do procedimento de conversão dos dados, ou de erros eventuais devidos a leituras incorretas de escalas, oscilações da eletricidade local, entre outras fontes. Entretanto, a complexidade do sistema motor biológico gera flutuações na resposta que são características importantes do fenômeno estudado e que não podem ser consideradas ruídos e sim discutidos com certo cuidado.

Algumas características do protocolo experimental, assim como dos procedimentos metodológicos devem exercer alguma influência sobre os resultados que foram obtidos e desta forma, existirão limitações nas discussões subsequentes. Tais limitações sempre existirão em qualquer procedimento experimental, cabe ao pesquisador delimitá-las e descrevê-las de forma a não produzir interpretações incorretas dos resultados discutidos. 
As coletas experimentais foram realizadas em ambiente de laboratório (Laboratório de Biomecânica EEFE-USP), dessa forma os voluntários se deslocaram do ambiente ambulatorial do Hospital Universitário a que estão habituados e foram avaliados em ambiente mais restritivo e diferenciado de uma condição habitualmente vivenciada por eles. A avaliação do andar foi feita em uma esteira rolante e tal ambiente impõe certas restrições ao movimento humano, podendo causar algumas alterações no padrão do andar dos sujeitos. A presença de fios e cabos junto ao corpo dos sujeitos conectando os eletrodos ao eletromiógrafo também podem causar alterações no padrão do andar destes sujeitos. $O$ conjunto destas alterações no padrão do movimento, devido o ambiente ou ainda os equipamentos de medição, denomina-se efeito retroativo. De forma a minimizar este efeito retroativo causado pelos equipamentos utilizados, os sujeitos foram submetidos a uma fase de habituação na esteira, já com os eletrodos colocados, por aproximadamente 10 minutos e durante esta fase, seus tempos de apoio simples foram controlados de forma a determinar quando tal padrão fosse significativamente reprodutível. Espera-se que com esta habituação na esteira rolante, o sujeito se torne mais familiar ao equipamento e adeqüe seu andar considerando a superfície móvel, considerando o porte dos eletrodos e cabos do eletromiógrafo, e portanto reduza o efeito retroativo.

As variáveis dinâmicas e eletromiográficas foram avaliadas de três tentativas cada uma com 12 $s$ de duração, totalizando aproximadamente 30 passos com cada pé para cada sujeito, quantidade esta acima do recomendado em um estudo de ARSENAULT et al. (1986b) para análise de variáveis EMG. Neste estudo, ARSENAULT et al. (1986b) verificou alta confiabilidade dos dados eletromiográficos em três passadas de sujeitos não doentes, devido a baixa variabilidade intra-individuo de passada a passada. Porém, como no presente estudo, foram analisados sujeitos neuropatas e devido a natureza dessa doença, espera-se maior variabilidade no padrão de recrutamento muscular de passada a passada, optou-se por aumentar o número de passadas coletadas para garantir de certa forma a confiabilidade e reprodutibilidade dos dados.

Embora foram impostos alguns critérios de exclusão para selecionar a amostra experimental, alguns cuidados nos procedimentos metodológicos e no protocolo experimental ainda foram tomados considerando as características antropométricas, clínicas e de idade dos sujeitos, especialmente os sujeitos neuropatas. Cuidados tais como, preservar a identidade dos sujeitos, respeitar suas limitações motoras, cuidados na colocação dos eletrodos e na determinação de seus limiares sensitivos. Houve também uma adequação na etapa do andar na esteira em casos em que as limitações de equilíbrio ou motoras foram importantes, adequações estas tais como diminuição no tempo de habituação ou mesmo nas tentativas a serem coletadas. Ainda considerando as características dos sujeitos analisados, faz-se 
necessário destacar uma possível influência da idade dos sujeitos especialmente nas variáveis biomecânicas durante o andar, uma vez que o processo de envelhecimento traz conseqüências motoras que poderiam ter um efeito interveniente em nossas medidas. Porém, considerando a média de idade dos grupos analisados, deve ser pouco provável a influência deste fator em uma tarefa motora tão comum e freqüentemente praticada como a que foi analisada no presente estudo.

Outro fator importante a ser considerado durante as coletas na esteira rolante é a velocidade imposta durante 0 andar. Esta velocidade da esteira foi baseada na cadência do andar em piso fixo para cada sujeito, porém devido as características distintas dos dois grupos experimentais, variações na velocidade do andar estarão sujeitas. Tais variações de velocidade podem interferir nas respostas dinâmicas, temporais e eletromiográficas (WINTER, 1991). De forma a diminuir estas diferenças entre os grupos experimentais, foi estipulada uma margem de tolerância de variação inter-sujeitos desta velocidade de $10 \%$. Porém, ainda se deve considerar tais efeitos da velocidade sobre as respostas biomecânicas ao se interpretar os resultados obtidos.

O procedimento experimental de aquisição de dados simultâneos sofre influência de um conjunto de fontes de erros relativos à precisão da medição para cada sistema e/ou equipamento: esteira Gaitway Kistler e eletromiógrafo Bagnoli-8 Delsys. O controle da precisão da medida, considerando-se a incerteza do procedimento, foi determinado pelos valores da calibração e ajustes experimentais dos sistemas de medição envolvidos e terá influência na interpretação dos resultados.

Com relação à esteira rolante Gaitway da Kistler, esta é composta por duas plataformas de força montadas em sua estrutura (FIGURA 8) constituídas de transdutores piezoelétricos que apresentam um comportamento bem estável. Do valor nominal estabelecido pelo fabricante, tem-se que os limites de erro de medição para as forças de reação do solo são de $\pm 2 \%$ e para o ponto de aplicação da força, de $\pm 3 \%$. Estes valores foram determinados a partir de testes de respostas de sensibilidade dos componentes por canais das plataformas de força montadas no sistema Kistler Gaitway nr. 9810510 (GAITWAY, 1996). Os erros associados à determinação das grandezas derivadas da força vertical limitam-se à $\pm 1 \%$, considerando-se a base de cálculo e o necessário controle da calibração (GAITWAY, 1996). Durante a rotina de calibração das plataformas deve-se manter fixo o nível horizontal das plataformas e deve-se determinar experimentalmente o peso corporal de cada sujeito tendo-o sobre uma das plataformas. Ainda com relação às limitações metodológicas da esteira Gaitway, deve-se destacar que a esteira não permite a determinação das componentes horizontais da força reação do 
solo durante as tarefas de locomoção, somente a componente vertical e devido a este fato a análise da fase de desaceleração e propulsão da marcha não é possível de ser realizada.

Considera-se limitações metodológicas relativas ao sistema eletromiográfico, inicialmente as causas de ruídos que podem ser provenientes de várias fontes que devem ser controladas para não interferirem na interpretação e processamento do sinal EMG. Desta maneira, destacam-se as seguintes possíveis fontes de erro:

a) ruído inerente aos componentes eletrônicos do sistema Bagnoli-8;

b) ruído ambiental, originário de possíveis fontes de radiação eletromagnética. 0 principal possível ruído ambiental é a radiação de $60 \mathrm{~Hz}$, gerada pela rede de energia elétrica;

c) artefatos do movimento, originários da fixação do eletrodo com a superfície da pele e do movimento da pele e dos cabos os quais transmitem o sinal dos eletrodos ao amplificador;

d) instabilidade inerente ao sinal EMG, considerando-se a natureza estocástica da freqüência de disparo das unidades motoras, observa-se que esta freqüência pode influenciar os componentes de freqüência do sistema;

e) presença de off-set, interpretado como valor de saída do sinal quando a entrada é nula, para esta situação há que se reduzir este valor para não comprometer a interpretação dos resultados da EMG.

\section{APRESENTAÇÃO DOS RESULTADOS}

\subsection{Caracterização dos grupos experimentais}

Com o propósito de caracterizar a amostra, a TABELA 1 apresenta algumas características antropométricas, de gênero e características clínicas dos sujeitos do grupo controle (GC) e diabético (GD) estudados.

TABELA 1 - Características antropométricas, idade e gênero dos grupos controle (GC) e diabético (GD) estudados.

\begin{tabular}{ccccccccc}
\hline & $\mathbf{n}$ & Idade (anos) & Massa (kg) & Estatura (cm) & $\begin{array}{c}\text { Sexo } \\
\text { Masculino }\end{array}$ & $\begin{array}{c}\text { Sexo } \\
\text { feminino }\end{array}$ & $\begin{array}{c}\text { Tempo } \\
\text { diabetes }\end{array}$ & $\begin{array}{c}\text { Última glicemia } \\
\text { (mg/dl) }\end{array}$ \\
\hline GC & 20 & $40,1 \pm 10,4^{*}$ & $66,1 \pm 10,9$ & $167,3 \pm 7,6$ & $60 \%(12)$ & $40 \%(8)$ & & \\
\hline GD & 16 & $51,5 \pm 11,2^{*}$ & $70,6 \pm 14,2$ & $165,6 \pm 10,3$ & $50 \%(8)$ & $50 \%(8)$ & $11,9 \pm 10,4$ & $200,4 \pm 62,4$ \\
\hline
\end{tabular}


Os grupos estudados apresentaram-se estatisticamente diferentes quanto à idade dos voluntários avaliados $(p=0,0033)$, porém não diferentes quanto à massa $(p=0,2871)$ e estatura $(p=0,5577)$. Muito embora os grupos apresentavam sujeitos com idades significativamente diferentes, destaca-se, pelo desvio padrão, a variação das idades inter-sujeitos dentro de um mesmo grupo.

Dentre os sujeitos do grupo controle (GC), $85 \%$ eram funcionários da Escola de Educação Física e Esporte da USP e outros 15\% de outros locais, porém sempre procedentes da cidade de São Paulo. A partir do questionário de avaliação inicial, foi verificado que $75 \%$ dos sujeitos GC eram fisicamente ativos, 80\% consumiam álcool durante a semana em média 1596,9 $\pm 2108,7 \mathrm{ml}$, e somente $10 \%$ eram fumantes. Os sujeitos controle não apresentavam qualquer queixa de alteração de sensibilidade, tais como queimação, dormência, formigamento, agulhadas, dor em repouso noturno ou em atividade, bem como não apresentavam história de ulcerações plantares ou de membros inferiores, caracterizando assim a saúde neurológica periférica e vascular destes sujeitos. Com relação aos cuidados com os pés, $35 \%$ dos sujeitos apresentavam calos plantares na parte externa dos dedos, parte medial da planta do pé na altura das cabeças metatarsianas e no hálux, e estes sujeitos usavam, em sua maioria lixa e pedra pome para reduzir estas calosidades plantares.

Dentre os sujeitos do grupo diabético (GD), 75\% dos sujeitos eram provenientes do Hospital Universitário da Universidade de São Paulo, e os outros 25\%, de outros ambulatórios clínicos da cidade de São Paulo. Considerando o tipo de diabetes, $87,5 \%$ dos sujeitos eram portadores da Diabetes mellitus tipo 2 e 13,5\%, da diabetes tipo 1. O tempo médio de diagnóstico da diabetes entre os sujeitos GD foi de 11,9 $\pm 10,4$ anos. Segundo informações obtidas dos prontuários dos diabéticos estudados, os valores médios das duas últimas glicemias feitas em jejum com intervalos de 2 meses cada uma, foram: $188,6 \pm 80,3 \mathrm{mg} / \mathrm{dl}$ e 200,4 $\pm 62,4 \mathrm{mg} / \mathrm{dl}$. Pode-se verificar que os valores glicêmicos estão muito acima dos valores esperados normais (até $140 \mathrm{mg} / \mathrm{dl}$ ) e assim aumentando a vulnerabilidade destes diabéticos à lesões nervosas decorrentes da toxicidade dos subprodutos bioquímicos da glicose. Dentre os sujeitos do GD, $75 \%$ usavam hipoglicemiantes orais como forma de tratamento, $25 \%$ usavam insulina como forma de tratamento, e $81,3 \%$ utilizavam dieta específica como forma complementar de tratamento.

A partir da avaliação inicial, foi verificado que $37,5 \%$ dos sujeitos diabéticos eram fisicamente ativos, $31,3 \%$ consumiam álcool durante a semana, em média $362,5 \pm 160,1 \mathrm{ml}$, e somente 18,8\% eram fumantes. Dentre as doenças associadas à diabetes e à neuropatia diabética, 56,3\% apresentavam hipertensão arterial sistêmica, 6,3\%, ou seja, apenas um apresentava nefropatia diagnosticada, 6,3\% tinha vasculopatia incluindo episódios de formação de úlcera varicosa, 31,3\% tinham retinopatia 
diagnosticada, 25\% eram portadores de distúrbios de dislipidemia, sendo 12,5\% obesos. Seis pacientes $(37,5 \%)$ já haviam tido alguma história de ulcerações plantares em decorrência da neuropatia diabética e dois (13,5\%) apresentavam um úlcera plantar no momento da avaliação, porém não interferiram na execução do andar independente e automático destes sujeitos. Esta importante incidência $(37,5 \%)$ de diabéticos com história de ulceração, demonstra de forma evidente a severidade da neuropatia diabética presente nestes sujeitos avaliados (CAPUTO et al., 1994). Os sujeitos diabéticos neuropatas apresentavam queixas importantes de alteração de sensibilidade, tais como queimação, dormência, formigamento, agulhadas, dores, sensação de "bota" nos pés. Aproximadamente $50 \%$ dos diabéticos informaram ter sintomatologia associada à neuropatia, sendo que a maioria deles $(62,5 \%)$ apresentavam tais sintomas quando estavam em repouso noturno, característica esta também altamente discutida na literatura quando se trata de neuropatia periférica diabética (THOMAS, 1991).

Com relação aos cuidados com os pés, $25 \%$ dos sujeitos diabéticos apresentavam calos plantares na parte externa dos dedos, parte medial da planta do pé na altura das cabeças metatarsianas e no hálux, e estes sujeitos usavam na maioria lixa e pedra pome para reduzir as calosidades plantares.

Tivemos acesso a algumas informações dos prontuários dos sujeitos diabéticos que foram provenientes do Hospital Universitário da USP, tais como: presença de doenças correlacionadas à diabetes, últimas glicemias, complicações vasculares e o diagnóstico da neuropatia diabética periférica. Porém, ainda não foram suficientes para determinarmos o grau de severidade da neuropatia, lado predominante das lesões, ou ainda a extensão dos acometimentos. Devido a falta destas informações complementares, deve-se ser mais cauteloso ao se interpretar se as alterações dinâmicas e eletromiográficas encontradas nos sujeitos do GD foram devido a acometimentos motores oriundos da neuropatia diabética motora, ou ainda se as alterações mais significativas em um membro foram devido à predominância de um lado mais acometido. Mas ainda assim, pode-se estabelecer de certa forma um quadro definido da neuropatia diabética dos sujeitos do grupo GD em função da sintomatologia apresentada associada à neuropatia e em função da presença de doenças relacionadas à diabetes.

\subsection{Resultados da Avaliação da sensibilidade plantar e motora e limiar de tolerância à dor}

A cronaxia sensitiva e a tolerância à dor foram determinadas em cinco regiões plantares, conforme descrição da metodologia experimental. A TABELA 2 apresenta os dados médios da cronaxia sensitiva e tolerância à dor para cada região plantar para os dois grupos estudados: GC e GD, assim 
como as diferenças encontradas entre cada região quando comparadas as medidas de tendência central (medianas) dos grupos através do teste $U$ de Mann-Whitney. Este teste foi utilizado considerando o comportamento estatístico não normal de todas as variáveis somatossensoriais. Muito embora este teste não paramétrico utiliza como medida de tendência central a mediana dos dados para comparar os grupos, a TABELA 2 e, futuramente, a TABELA 3, representam a média dos valores somente como forma de padronizar a visualização dos dados no presente trabalho.

TABELA 2 - Valores médios e desvios padrão da cronaxia sensitiva (ms) e tolerância à dor (mA) em quatro áreas plantares, para o grupo controle (GC) $(n=20)$ e grupo diabético (GD) $(n=16)$.

\begin{tabular}{|c|c|c|c|c|c|c|c|}
\hline \multirow[b]{2}{*}{ Áreas plantares } & \multicolumn{4}{|c|}{ CRONAXIA SENSITIVA (ms) } & \multicolumn{3}{|c|}{ TOLERÂNCIA Ȧ DOR (mA) } \\
\hline & Pé & $\overline{G C}$ & GD & $\bar{p}$ & $\overline{G C}$ & GD & $p$ \\
\hline \multirow[t]{2}{*}{ Calcanhar } & $\bar{E}$ & $0,25 \pm 0,07$ & $0,38 \pm 0,37$ & 0,1812 & $12,73 \pm 9,27$ & $17,72 \pm 9,36$ & 0,0885 \\
\hline & D & $0,32 \pm 0,15$ & $0,64 \pm 0,56$ & 0,0672 & $9,75 \pm 5,93$ & $19,16 \pm 9,06$ & 0,0010 * \\
\hline \multirow[t]{2}{*}{ Meio-pé } & $E$ & $0,28 \pm 0,11$ & $0,32 \pm 0,14$ & 0,3477 & $8,43 \pm 5,81$ & $10,41 \pm 5,96$ & 0,0582 \\
\hline & D & $0,30 \pm 0,14$ & $0,39 \pm 0,25$ & 0,1613 & $8,83 \pm 5,66$ & $10,97 \pm 5,39$ & 0,0177 * \\
\hline \multirow[t]{2}{*}{ Antepé medial } & $E$ & $0,23 \pm 0,08$ & $0,85 \pm 1,39$ & 0,0065 * & $8,63 \pm 4,14$ & $9,69 \pm 5,89$ & 0,5994 \\
\hline & D & $0,32 \pm 0,35$ & $0,30 \pm 0,11$ & 0,1661 & $7,50 \pm 3,01$ & $10,16 \pm 4,85$ & 0,0432 * \\
\hline \multirow[t]{2}{*}{ Antepé lateral } & $E$ & $0,24 \pm 0,09$ & $0,37 \pm 0,23$ & $0,0201^{*}$ & $8,48 \pm 5,33$ & $8,81 \pm 6,29$ & 0,6558 \\
\hline & D & $0,29 \pm 0,10$ & $0,28 \pm 0,10$ & 0,5666 & $8,00 \pm 4,14$ & $9,75 \pm 3,94$ & 0,0582 \\
\hline \multirow[t]{2}{*}{ Hálux } & $E$ & $0,23 \pm 0,08$ & $0,32 \pm 0,33$ & 0,4640 & $4,73 \pm 1,47$ & $6,69 \pm 2,68$ & 0,0082 * \\
\hline & D & $0,21 \pm 0,06$ & $0,28 \pm 0,16$ & 0,1265 & $4,75 \pm 1,56$ & $6,38 \pm 2,31$ & $0,0269 *$ \\
\hline
\end{tabular}

Os dados referentes à cronaxia sensitiva na TABELA 2 demonstram claramente valores maiores para o sujeito diabético em todas as regiões plantares estudadas, exceto em duas (antepé medial $D$ e antepé lateral $D$ ). Estes valores de cronaxia sensitiva para o grupo GC apresentaram-se dentro do limite de respostas esperadas normais: de 0 a aproximadamente 0,30ms, considerando as características da amostra estudada (SACCO, 1997). Já os sujeitos do grupo GD, apresentaram valores de cronaxia sensitiva acima do esperado normal para as características de seus sujeitos, porém poucas diferenças significativas foram encontradas. Observou-se diferenças significantes entre os grupos na região do antepé medial $E(p=0,0065)$, território de inervação do nervo plantar medial, e na região do antepé lateral $E(p=0,0201)$, território de inervação do nervo plantar lateral.

Já para os valores de tolerância à dor, encontramos valores acentuadamente maiores para os sujeitos diabéticos em todas as regiões plantares estudadas. Especialmente no calcanhar $D(p=0,010)$, meio-pé $D(p=0,0177)$, antepé medial $D(p=0,0432)$ e hálux $D(p=0,0269)$ e $E(p=0,0082)$, as diferenças 
entre os dois grupos experimentais foram estatisticamente significativas. Pode-se ainda considerar alterações neurológicas periféricas importantes na região do calcanhar $E$ do grupo neuropata que apresentam valores de limiar de tolerância à dor acentuadamente altos, fora dos padrões de normalidade (SACCO, 1997).

Como forma de controlar qualquer alteração motora nos músculos estudados pela eletromiografia, a cronaxia motora foi determinada, conforme descrição anterior na metodologia experimental. A TABELA 3 apresenta os dados médios da cronaxia motora para cada músculo estudado na eletromiografia, assim como os valores da estatística $p$ do teste $U$ Mann-Whitney para comparação entre as medidas de tendência central dos dados.

TABELA 3 - Valores médios e desvios padrão da cronaxia motora (ms) em três músculos da perna e coxa, para o grupo controle (GC) ( $n=20)$ e grupo diabético (GD) $(n=15)$.

\begin{tabular}{lcccc}
\hline \multicolumn{5}{c}{ CRONAXIA MOTORA (ms) } \\
\hline Músculos & Pé & GC & GD & p \\
\hline m. gastrocnêmio lateral & E & $0,32 \pm 0,14$ & $0,26 \pm 0,17$ & 0,1185 \\
\hline & D & $0,29 \pm 0,09$ & $0,34 \pm 0,28$ & 0,2571 \\
\hline m. tibial anterior & E & $0,26 \pm 0,07$ & $0,28 \pm 0,13$ & 0,6892 \\
\hline m. vasto lateral & D & $0,25 \pm 0,10$ & $0,31 \pm 0,13$ & 0,1824 \\
\hline & E & $0,20 \pm 0,09$ & $0,18 \pm 0,07$ & 0,6054 \\
\hline & D & $0,15 \pm 0,07$ & $0,19 \pm 0,10$ & 0,3771 \\
\hline
\end{tabular}

A cronaxia motora para os dois grupos experimentais apresentou-se dentro dos limites da normalidade, que segundo ERVILHA \& ARAÚJO (1997) os valores devem ser de até 0,50 ms para estarem com o limiar que não caracterize qualquer lesão nervosa periférica. Outro fato a ser observado é que os grupos estudados não foram diferentes em nenhum sítio muscular analisado. Se considerarmos somente este teste eletrodiagnóstico motor utilizado (cronaxia motora), estes sujeitos neuropatas não apresentariam lesões nervosas periféricas características desta doença, fato este improvável considerando as outras características e sintomas clínicos típicos investigados no presente estudo. Portanto, pode-se concluir que as alterações motoras periféricas promovidas pela neuropatia presente nos sujeitos avaliados não puderam ser acessadas por este teste motor. Ou ainda, estes sujeitos apresentaram valores de cronaxia motora considerados normais para ERVILHA \& ARAÚJO (1997), mas teriam outra interpretação se considerarmos o tipo de lesão decorrente da neuropatia: de instalação lenta e progressiva, enquanto que no estudo citado, a lesão nervosa investigada foi 
traumática e portanto de instalação instantânea. Com isso, pode-se interpretar que as eventuais alterações das respostas eletromiográficas que ocorram na marcha dos sujeitos do GD, possam ser devido ao estágio da doença, muito embora este não pôde ser identificado por estes testes eletrodiagnósticos superficiais.

\subsection{Resultados da avaliação do andar - força reação do solo e variáveis temporais e espaciais do andar}

Os dados derivados da curva força reação do solo em função do tempo, tais como, parâmetros temporais, parâmetros espaciais e parâmetros dinâmicos do ciclo da marcha dos sujeitos dos grupos controle e diabético, estão demonstrados na TABELA 4.

Os sujeitos do grupo controle andaram em piso fixo com uma cadência média de 112,10 $\pm 4,02$ passos/min, enquanto que os sujeitos do grupo diabético andaram em piso fixo em média de 106,13 $\pm 4,50$ passos/min. Estas cadências foram significativamente diferentes entre os grupos estudados quando foram comparadas as medidas de tendência central dos dados através do teste $U$ MannWhitney $(p=0,0012)$. Com relação ao andar na esteira, o grupo controle apresentou uma velocidade média de 4,56 $\pm 0,44 \mathrm{~km} / \mathrm{h}$, enquanto que o grupo diabético andou a $3,81 \pm 0,39 \mathrm{~km} / \mathrm{h}$. Estas velocidades foram significativamente diferentes entre os grupos experimentais, quando foram comparadas suas médias através do teste $t(p=0,0000)$. 
TABELA 4 - Valores médios e desvios padrão das variáveis da Força reação do solo, temporais e espaciais durante o ciclo da marcha dos sujeitos do grupo controle (GC) ( $n=20)$ e do grupo diabético (GD) (n=15).

\begin{tabular}{|c|c|c|c|c|}
\hline Variáveis & Pé & GC & GD & $p$ \\
\hline \multirow{2}{*}{ Pico da Força vertical máxima 1 (Fy1) (x PC) ${ }^{1}$} & D & $1,15 \pm 0,09$ & $1,10 \pm 0,15$ & 0,0718 \\
\hline & $E$ & $1,15 \pm 0,1$ & $1,11 \pm 0,15$ & 0,1518 \\
\hline \multirow[t]{2}{*}{ Pico da Força vertical máxima 2 (Fy2) (x PC) ${ }^{1}$} & $D$ & $1,16 \pm 0,06$ & $1,14 \pm 0,17$ & 0,0329 * \\
\hline & E & $1,17 \pm 0,05$ & $1,15 \pm 0,17$ & 0,0643 \\
\hline \multirow[t]{2}{*}{ Força vertical mínima (x PC) ${ }^{1}$} & D & $0,76 \pm 0,07$ & $0,84 \pm 0,14$ & 0,0234 * \\
\hline & $E$ & $0,77 \pm 0,07$ & $0,87 \pm 0,14$ & 0,0693 \\
\hline \multirow[t]{2}{*}{ Deflexão da força vertical (PC/s) ${ }^{1}$} & $D$ & $2,63 \pm 0,86$ & $1,84 \pm 0,72$ & 0,0343 * \\
\hline & $E$ & $2,55 \pm 0,96$ & $1,95 \pm 0,76$ & 0,1518 \\
\hline \multirow[t]{2}{*}{ Taxa de crescimento da Fy1 (PC/s) ${ }^{2}$} & D & $7,55 \pm 1,29$ & $6,12 \pm 1,32$ & $0,0030 *$ \\
\hline & $\mathbf{E}$ & $7,57 \pm 1,36$ & $6,19 \pm 1,34$ & 0,0054 * \\
\hline \multirow[t]{2}{*}{ Taxa de crescimento da Fy2 (PC/s) ${ }^{2}$} & D & $6,32 \pm 0,63$ & $5,89 \pm 1,03$ & 0,1383 \\
\hline & $\mathbf{E}$ & $6,33 \pm 0,55$ & $5,84 \pm 0,98$ & 0,0698 \\
\hline \multirow[t]{2}{*}{ Tempo de apoio simples (s) ${ }^{2}$} & D & $0,40 \pm 0,02$ & $0,42 \pm 0,03$ & 0,0238 * \\
\hline & $E$ & $0,40 \pm 0,02$ & $0,42 \pm 0,03$ & 0,0109 * \\
\hline Simetria do tempo de apoio simples (\%) ${ }^{1}$ & & $1,62 \pm 1,29$ & $2,59 \pm 2,52$ & 0,0909 \\
\hline Tempo de apoio duplo (s) ${ }^{1}$ & & $0,12 \pm 0,01$ & $0,14 \pm 0,02$ & $0,0037^{*}$ \\
\hline \multirow[t]{2}{*}{ Comprimento do passo $(\mathrm{cm})^{2}$} & D & $66,64 \pm 5,11$ & $60,28 \pm 5,66$ & $0,0000 *$ \\
\hline & $E$ & $67,77 \pm 5,41$ & $60,55 \pm 5,73$ & $0,0000 *$ \\
\hline \multirow[t]{2}{*}{ Comprimento da passada $(\mathrm{cm})^{2}$} & D & $134,06 \pm 9,66$ & $120,64 \pm 10,46$ & $0,0000 *$ \\
\hline & $E$ & $134,15 \pm 9,73$ & $120,62 \pm 10,54$ & $0,0000 *$ \\
\hline Simetria do comprimento do passo (\%) ${ }^{1}$ & & $4,85 \pm 4,02$ & $5,54 \pm 4,88$ & 0,4844 \\
\hline
\end{tabular}

${ }^{1}$ Teste U Mann-Whitney; ${ }^{2}$ Teste $t$ 

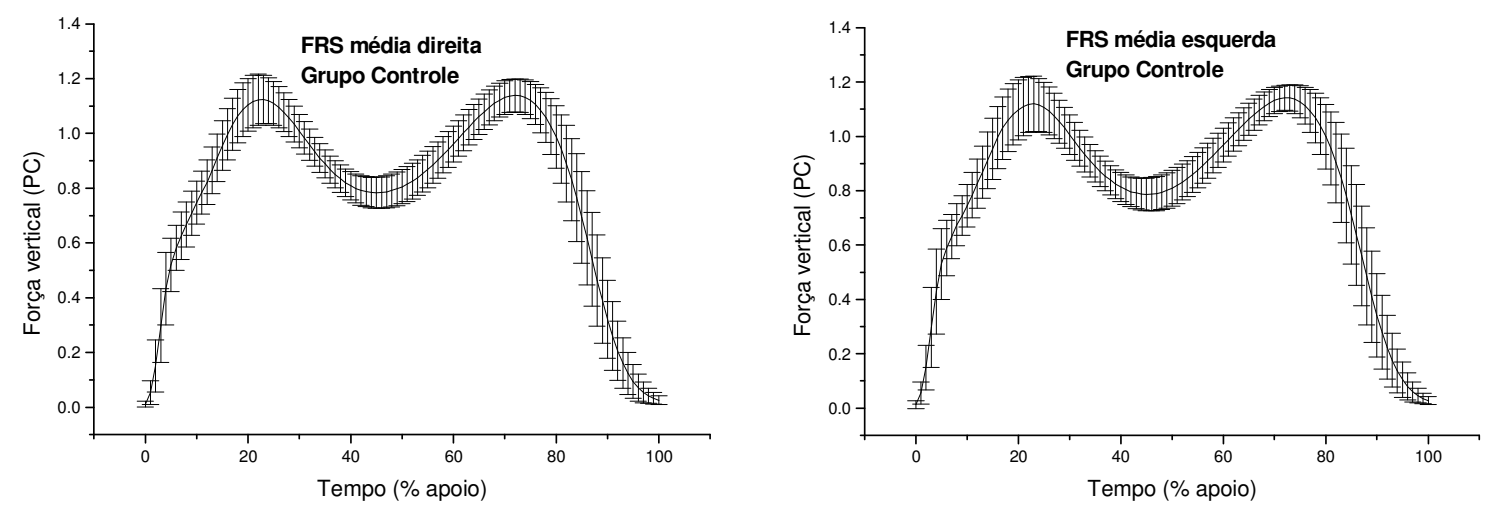

FIGURA 14 - Força vertical média em função do peso corporal (PC) do pé direito e esquerdo do grupo controle $(n=20)$, durante 0 andar em esteira.
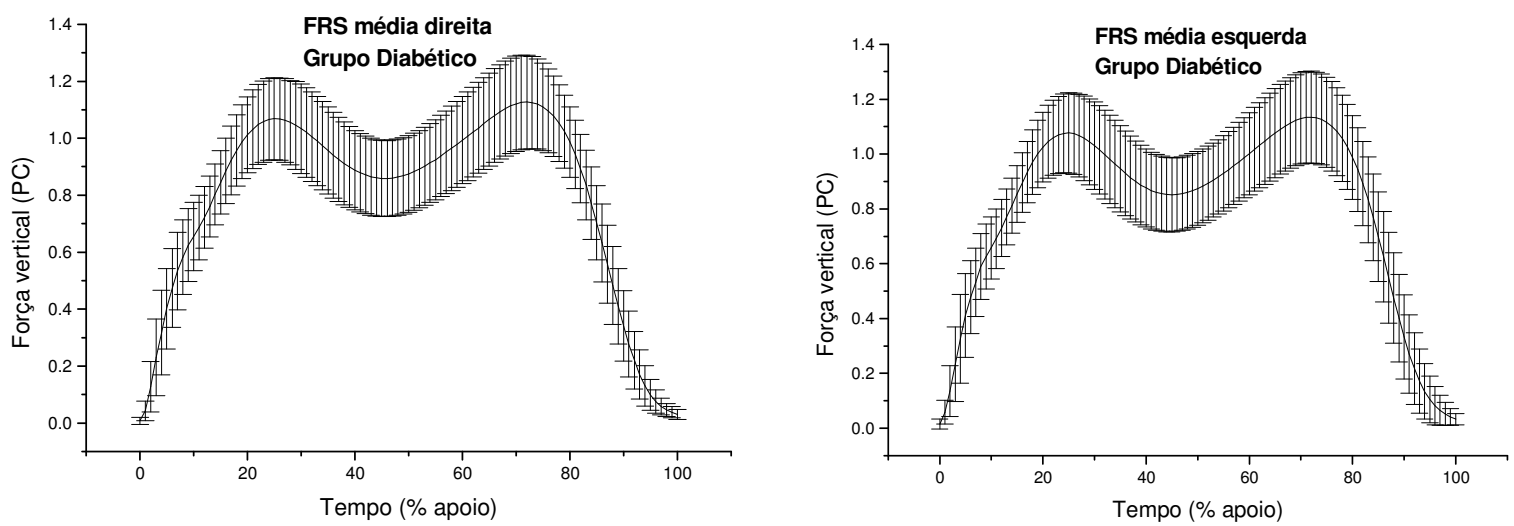

FIGURA 15- Força vertical média em função do peso corporal (PC) do pé direito e esquerdo do grupo diabético $(n=16)$, durante 0 andar em esteira.

Os dados apresentados na TABELA 4 foram tratados estatisticamente conforme 0 descrito na metodologia, ou seja, foi testada a normalidade dos dados pelo teste W de Shapiro Wilk e aquelas variáveis que não apresentaram comportamento normal, foram comparadas utilizando o teste $U$ de Mann-Whitney, sinalizadas na tabela pelo número 1 sobrescrito. As variáveis com comportamento estatístico normal, foram comparadas utilizando-se o teste $t$, sinalizadas na tabela pelo número 2 sobrescrito.

Destaca-se a partir da interpretação da TABELA 4 e das FIGURAS 14 e 15 que ilustram as curvas médias da força reação do solo dos grupos estudados GC e GD, que o grupo GD apresenta um padrão dinâmico distinto do GC. Algumas diferenças estatisticamente significativas foram encontradas quando foram comparadas as variáveis dinâmicas, temporais e espaciais do andar dos sujeitos 
neuropatas com o sujeitos controle. O segundo pico da força vertical para o pé direito do GD é significativamente menor em relação ao segundo pico do grupo controle $(p=0,0329)$. A força mínima para o pé direito é significativamente maior em relação ao $\mathrm{GC}(\mathrm{p}=0,0234)$. Ainda considerando a força mínima, a deflexão da primeira força máxima para a força mínima do grupo diabético apresentou-se significativamente menor em relação à apresentada pelo grupo controle $(p=0,0343)$. Já as taxas de crescimento do primeiro pico da força vertical tanto para o direito como para o pé esquerdo são significativamente menores para o GD ( $p=0,0030 ; p=0,0054$; respectivamente).

Considerando as variáveis temporais durante 0 andar, o tempo de apoio simples para 0 membro direito e para o membro esquerdo foram significativamente maiores nos sujeitos $G D$ ( $p=0,0238$; $p=0,0109$; direito e esquerdo, respectivamente). Muito embora os índices de simetria entre os tempos de apoio simples direito e esquerdo para os sujeitos GD apresentaram-se altos e distintos em relação ao GC, a razão de simetria entre estes tempos não foi estatisticamente diferente entre os grupos estudados $(p=0,0909)$, muito provavelmente pela variação dos dados nos grupos estudados. 0 tempo de apoio duplo dos sujeitos neuropatas apresentaram-se estatisticamente maiores em relação ao GC $(p=0,0037)$.

Todas as variáveis espaciais estudadas apresentaram-se significativamente diferentes entre os grupos estudados. 0 comprimento do passo direito e esquerdo foram estatisticamente menores nos

sujeitos neuropatas ( $p=0,0000 ; p=0,0000$; direito e esquerdo respectivamente). E o comprimento da passada direita e esquerda dos sujeitos diabéticos foram significativamente menores $(p=0,0000$; $p=0,0000$; direito e esquerdo respectivamente). Da mesma forma como ocorreu com as simetrias dos tempos de apoio simples, o índice de simetria do comprimento do passo para os sujeitos do GD apresentou-se maior em relação aos sujeitos do grupo controle, porém considerando a alta variação dos dados, evidenciada pela magnitude do desvio padrão, estas diferenças não foram significativas $(p=0,4844)$.

\subsection{Resultados da atividade eletromiográfica durante a marcha}

Os resultados do padrão de recrutamento temporal dos seis músculos estudados, são resumidamente apresentados na TABELA 5. 
TABELA 5 - Padrão temporal de ativação dos músculos m. vasto lateral, m. tibial anterior e m. gastrocnêmio lateral direito (D) e esquerdo $(E)$ dos sujeitos do GC e dos sujeitos $G D$.

\begin{tabular}{|c|c|c|c|c|c|c|}
\hline \multirow[t]{2}{*}{ Músculo } & & \multirow[t]{2}{*}{ Eventos } & \multirow{2}{*}{$\begin{array}{c}\text { GC } \\
\text { (\% tempo apoio) }\end{array}$} & CV (\%) & \multirow{2}{*}{$\begin{array}{c}\text { GD } \\
\text { (\% tempo apoio) }\end{array}$} & \multirow[t]{2}{*}{$\mathrm{CV}(\%)$} \\
\hline & & & & & & \\
\hline \multirow[t]{3}{*}{ m. vasto lateral } & $\bar{D}$ & 10 Pico de ativação (1) & $7,40 \pm 3,30$ * & 44,58 & $10,27 \pm 4,27$ * & 41,56 \\
\hline & & Início da 2a ativação (2) & $59,13 \pm 7,38$ & 12,47 & $59,31 \pm 8,29$ & 13,98 \\
\hline & & 20 Pico de ativação (3) & $85,47 \pm 4,81$ & 5,63 & $86,85 \pm 4,67$ & 5,38 \\
\hline \multirow[t]{3}{*}{ m. vasto lateral } & $\bar{E}$ & 10 Pico de ativação & $8,10 \pm 4,27$ & 52,67 & $8,40 \pm 4,00$ & 47,58 \\
\hline & & Início da 2a ativação & $57,79 \pm 7,38$ & 12,77 & $58,93 \pm 5,66$ & 9,61 \\
\hline & & 20 Pico de ativação & $87,00 \pm 4,88$ & 5,61 & $85,79 \pm 3,58$ & 4,17 \\
\hline \multirow[t]{3}{*}{ m. tibial anterior } & $\bar{D}$ & 10 Pico de ativação (4) & $1,35 \pm 2,43$ ** & 180,29 & $8,20 \pm 10,61$ ** & 129,41 \\
\hline & & Início da 2a ativação (5) & $62,68 \pm 11,98$ & 19,11 & $59,07 \pm 14,17$ & 24,00 \\
\hline & & $2^{\circ}$ Pico de ativação (6) & $85,00 \pm 12,01$ & 14,13 & $85,47 \pm 11,96$ & 14,00 \\
\hline \multirow[t]{3}{*}{ m. tibial anterior } & $\bar{E}$ & 10 Pico de ativação & $3,00 \pm 4,95$ *** & 165,08 & $9,73 \pm 10,38$ *** & 106,66 \\
\hline & & Início da 2a ativação & $63,42 \pm 11,38$ & 17,94 & $61,93 \pm 9,62$ & 15,53 \\
\hline & & 20 Pico de ativação & $87,42 \pm 12,24$ & 14,00 & $86,20 \pm 9,97$ & 11,57 \\
\hline m. gastrocnêmio & $\bar{D}$ & Início Ativação (7) & $24,40 \pm 14,12$ & 57,86 & $28,13 \pm 14,92$ & 53,04 \\
\hline \multirow[t]{2}{*}{ lateral } & & Pico de ativação (8) & $64,30 \pm 6,59$ & 10,26 & $67,00 \pm 12,43$ & 18,55 \\
\hline & & Término da ativação (9) & $86,41 \pm 6,46$ & 7,48 & $88,33 \pm 9,06$ & 10,26 \\
\hline m. gastrocnêmio & $\bar{E}$ & Início Ativação & $26,30 \pm 13,66$ & 51,93 & $18,73 \pm 12,66$ & 67,60 \\
\hline \multirow[t]{2}{*}{ lateral } & & Pico de ativação & $64,25 \pm 8,45$ & 13,15 & $61,53 \pm 8,45$ & 13,73 \\
\hline & & Término da ativação & $86,00 \pm 4,68$ & 5,44 & $84,57 \pm 7,74$ & 9,16 \\
\hline
\end{tabular}

Os dados apresentados na TABELA 5 foram tratados estatisticamente conforme descrito na metodologia, ou seja, foi testada a normalidade dos dados pelo teste W de Shapiro Wilk e, posteriormente, as variáveis que apresentaram comportamento estatístico normal, foram comparadas utilizando $o$ teste $t$, sinalizado na tabela por um asterisco. E aquelas variáveis que não apresentaram comportamento normal, foram comparadas utilizando o teste $U$ de Mann-Whitney, sinalizadas na tabela por dois e três asteriscos. 

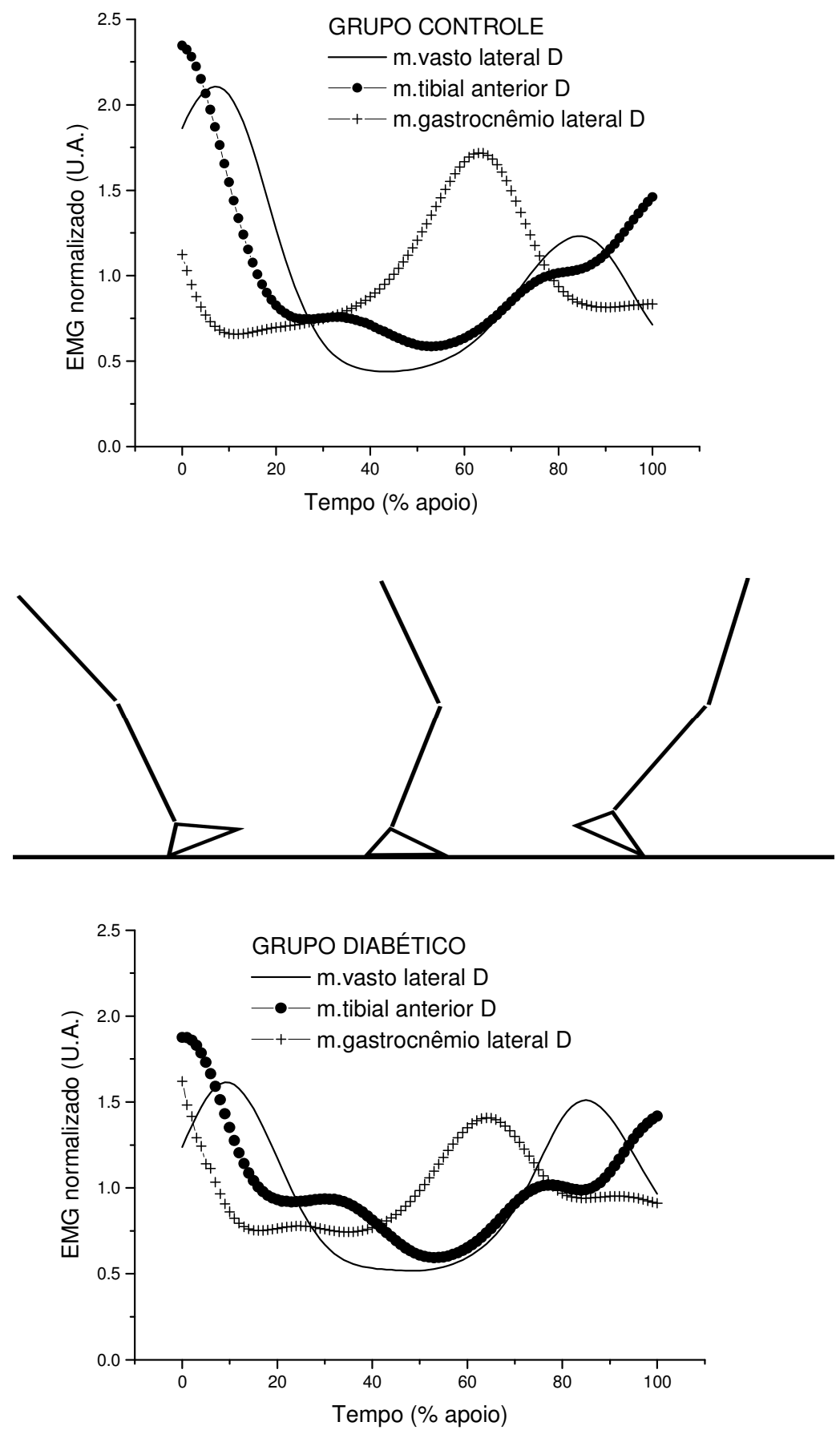

FIGURA 16 - Curvas média dos envoltórios lineares da EMG (normalizado pela média) dos m. vasto lateral, m. tibial anterior e m. gastrocnêmio lateral direito do grupo controle $(n=20)$ e do grupo diabético $(n=15)$ durante o apoio na marcha em esteira. 

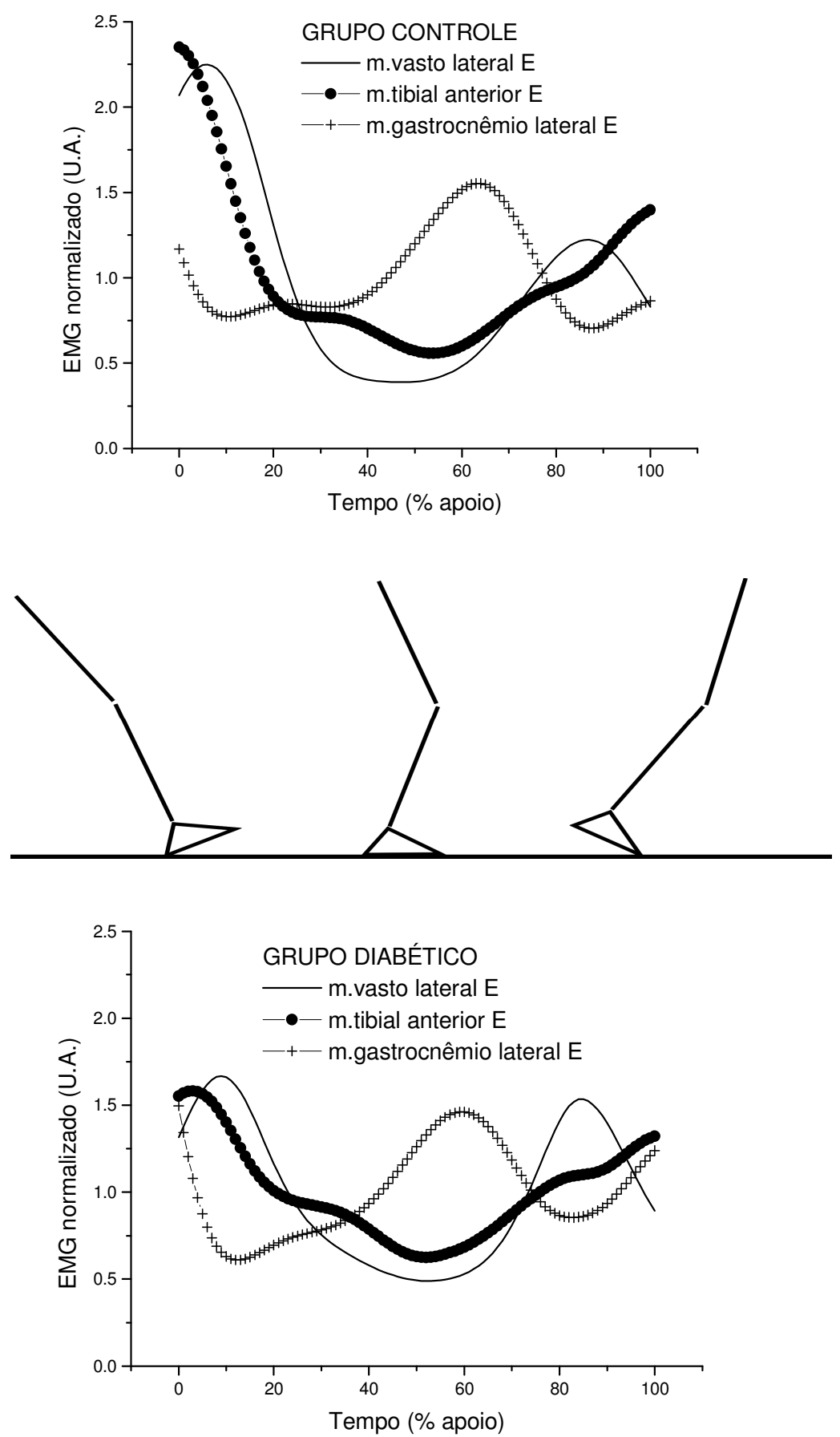

FIGURA 17- Curvas médias dos envoltórios lineares da EMG (normalizado pela média) dos $\mathrm{m}$. vasto lateral, m. tibial anterior e m. gastrocnêmio lateral esquerdo do grupo controle $(n=20)$ e do grupo diabético $(n=15)$ durante o apoio na marcha em esteira. 
Destaca-se a partir da interpretação da TABELA 5 e FIGURAS 16 e17, que o GD apresenta um padrão de recrutamento muscular distinto do GC. Algumas diferenças estatisticamente significativas foram encontradas quando foram comparadas as variáveis eletromiográficas durante 0 andar dos sujeitos neuropatas e dos sujeitos controle.

Pode-se observar uma diferença significativa $(p=0,0317)$ na ativação do $m$. vasto lateral direito entre o GC e GD, considerando-se os aspectos temporais desta ativação. O primeiro pico de ativação do m. vasto lateral direito no GC ocorre aproximadamente aos $7,4 \%$ do ciclo do apoio da marcha, enquanto que para $0 \mathrm{GD}$, este primeiro pico de ativação do $\mathrm{m}$. vasto lateral direito ocorre aproximadamente aos $10,27 \%$ do ciclo do apoio da marcha.

Conforme a TABELA 5, verificou-se diferenças significativas entre os padrões temporais de ativação do músculo tibial anterior direito $(p=0,0423)$ e esquerdo $(p=0,0215)$ quando comparou-se os sujeitos do GC e GD. O primeiro pico de ativação do m. tibial anterior direito nos sujeitos do GC ocorre aproximadamente aos $1,35 \%$ do ciclo do apoio da marcha, enquanto que para $\circ \mathrm{GD}$, este primeiro pico de ativação do m. tibial anterior direito ocorre aproximadamente aos $8,20 \%$ do ciclo do apoio da marcha. Já para o m. tibial anterior esquerdo, o primeiro pico de ativação para os GC ocorre aproximadamente aos $3 \%$ do ciclo do apoio na marcha e para os sujeitos do GD, este primeiro pico do m. tibial anterior esquerdo ocorre a aproximadamente aos $9,73 \%$ do ciclo do apoio na marcha.

Nos ANEXOS VI e VII estão apresentadas as curvas eletromiográficas para todos os músculos estudos e para todos os sujeitos do GC e do GD.

\section{$6 \quad$ DISCUSSÃO DOS RESULTADOS}

\subsection{Características dos sujeitos e história clínica da diabetes}

Os grupos foram constituídos de forma a obter sujeitos com distribuições semelhantes de idade, sexo, massa, estatura, e efetivamente o foram, exceto pela variável idade. Os sujeitos dos dois grupos estudados apresentaram idades estatisticamente diferentes. Esta diferença de aproximadamente 10 anos em média que foi encontrada para os dois grupos estudados, pode ter sido um possível fator de influência nas medidas biomecânicas, porém se considerarmos que os grupos apresentavam-se dentro da faixa etária que caracteriza a idade adulta, não devemos considerar este fator como de importante interferência em uma tarefa tão rotineira como 0 andar. 
Se considerarmos as idades máximas e mínimas destes grupos, pode-se observar uma distribuição semelhante porém com maior variabilidade na distribuição das idades no grupo GC, conforme a TABELA 6.

TABELA 6 - Distribuição das idades máximas e mínimas (anos) e CV (\%) dos dois grupos estudados: GC e GD.

\begin{tabular}{|l|c|c|c|}
\hline & Idade Máxima (anos) & Idade Mínima (anos) & CV (\%) \\
\hline GC & 66,5 & 25,9 & 25,9 \\
\hline GD & 68,6 & 25,5 & 21,7 \\
\hline
\end{tabular}

O grupo diabético é constituído em $87,5 \%$ de sujeitos portadores de diabetes tipo 2 , tipo este de instalação mais tardia e portanto, esperaría-se sujeitos com idades superiores. Ainda com relação à maior idade destes sujeitos, as complicações crônicas da diabetes, especialmente a neuropatia diabética, instalam-se após anos do diagnóstico da diabetes e portanto, também esperaríamos sujeitos com idades superiores, tal como DINGWELL et al. (2000) encontraram em seu estudo.

Uma informação obtida dos prontuários dos diabéticos foram as últimas duas glicemias de jejum que foram acima do normal e do esperado para um sujeito diabético com controle e tratamento adequado. Segundo SCARLET \& BLAIS (1989), THOMAS (1991), CATTALINE \& CANCIAN (1994) e DCCT (1993) glicemias altas e mantidas por um certo período, levam a acometimentos vasculares e nervosos ao longo do tempo ou ainda agravam as condições já patológicas do doente e portanto os valores altos encontrados nos sujeitos GD indicariam um provável quadro mais severo de diabetes e consequentemente de neuropatia.

Quanto ao consumo de álcool, verificou-se um maior consumo para o grupo controle em relação ao GD, porém dentre os 20 sujeitos controle, somente três consumiam entre 2,5 a 6 I de álcool por semana, o que elevou a média de consumo do GC. Esta diferença de consumo de álcool entre os grupos GC e GD, pode ser devido à necessidade que os sujeitos diabéticos têm de diminuir o consumo de álcool durante seu tratamento uma vez que ele é um derivado primário do açúcar, providência esta que não é tomada pelos sujeitos controle.

Diferenças também foram encontradas em relação ao nível médio de atividade física dos grupos experimentais, uma vez que $75 \%$ dos sujeitos do grupo GC eram fisicamente ativos e somente $37,5 \%$ dos sujeitos do grupo GD eram ativos. Esta diferença é um fator a ser considerado, muito 
embora o nível experiência motora de cada grupo tem muito pouca influência na tarefa cotidiana de andar que foi avaliada no presente estudo.

\subsection{Limiares de sensibilidade: tolerância à dor, cronaxia sensitiva e motora}

Os acometimentos periféricos de sensibilidade somatossensorial e dor apresentaram-se de maneira distinta nos dois membros considerando os sujeitos diabéticos.

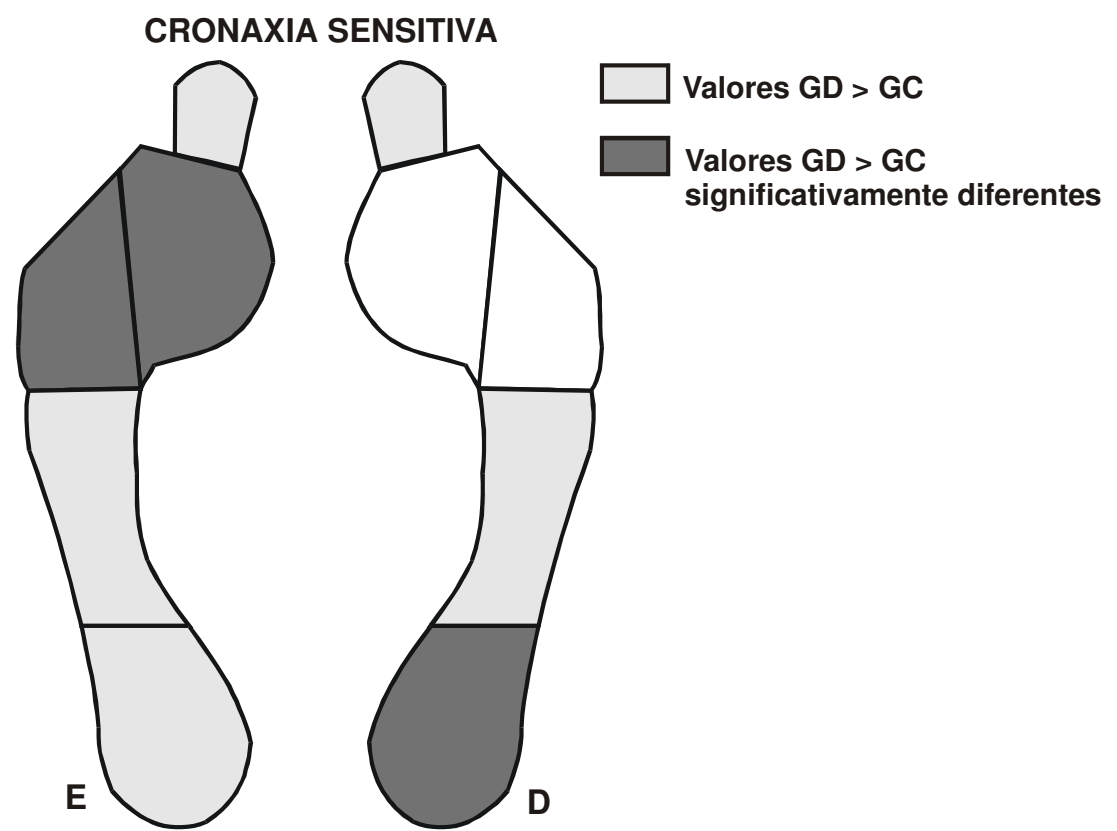

FIGURA 18 - Representação das áreas plantares estudadas para avaliação da cronaxia sensitiva. A cor cinza claro identifica as áreas cujos valores de cronaxia sensitiva apresentaram-se maiores para o grupo GD e fora dos padrões de normalidade. A cor cinza escuro identifica as áreas cujos valores de cronaxia sensitiva apresentaram-se significativamente maiores para 0 grupo GD, conforme TABELA 2. 


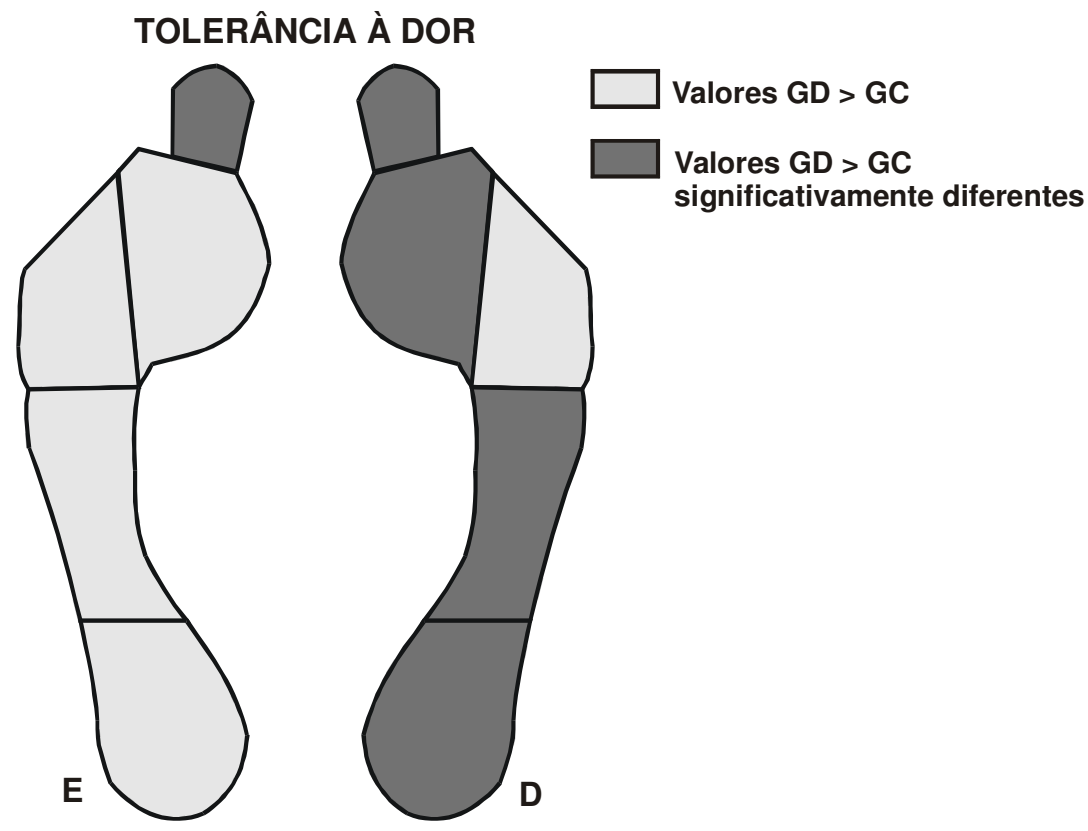

FIGURA 19 - Representação das áreas plantares estudadas para avaliação do limiar de tolerância à dor. A cor cinza claro identifica as áreas cujos valores de tolerância à dor apresentaram-se maiores para o grupo GD e fora dos padrões de normalidade. A cor cinza escuro identifica as áreas cujos valores de tolerância à dor apresentaram-se significativamente maiores para o grupo GD, conforme TABELA 2.

Analisando as FIGURAS 18 e 19, pode-se verificar que as áreas plantares acometidas, considerando-se a sensibilidade somatossensorial e a tolerância à dor, foram diferentes. Pode-se atribuir a isso a diferença nos mecanismos de percepção de estímulos táteis e dor no que se refere aos receptores e fibras aferentes acometidas, assim como suas vias de envio de informações para 0 sistema nervoso central. A percepção da dor é feita através de nociceptores que são terminações nervosas livres, e então as informações são encaminhadas através de neurofibras de menor diâmetro, mielinizadas $A$ $\delta$ e não mielinizadas $C$, e vão para o tálamo via sistema anterolateral na medula subindo contralateral ao estímulo (KANDEL, SCHWARTZ \& JESSELL, 2000; CRUTCHFIELD \& BARNES, 1984). Já a sensibilidade somatossensorial é percebida via discos de Merkel e corpúsculos de Meissner, e então estas informações de sensibilidade cutânea são encaminhas através de neurofibras mielinizadas de grande diâmetro $A \beta$ e vão para o tálamo via sistema medial leminiscal ipsilateral ao estímulo (KANDEL et al., 2000; CRUTCHFIELD \& BARNES, 1984).

Mas ainda assim, a região do calcanhar direito foi acometida em ambas as categorias investigadas: dor e sensibilidade somatossensorial. Esta região é a primeira a ter contato com o solo no 
início do apoio na marcha e portanto de grande importância para dar informações de pressão e propriocepção sobre esta fase aos centros superiores e que consequentemente irão programar as respostas musculares dos membros inferiores como forma de atenuar a carga nesta fase de contato inicial. Como estas informações importantes estão ausentes, pode-se inferir que o controle articular e muscular de recepção de carga esteja alterado e portanto os padrões de ativação muscular estarão de alguma forma atrasados em relação ao padrão regular durante 0 andar, especialmente os músculos mais relacionados à atenuação de choques mecânicos neste início da fase de apoio do andar: m. quadríceps da coxa e m. tibial anterior.

Outra consideração importante é o caráter assimétrico da neuropatia destacado pelos resultados de acometimentos em regiões distintas do pé direito e esquerdo, muito embora houve acometimento em ambos os lados: acometimentos bilaterais embora em regiões distintas nos sujeitos diabéticos.

As regiões plantares mais acometidas estão relacionadas aos nervo plantar lateral e medial e nervo sural, os quais são efetivamente os primeiros a serem degenerados pela neuropatia periférica diabética (DICK et al., 1985; RICHARDSON et al., 1992). As regiões do antepé medial e hálux direito e esquerdo dos sujeitos diabéticos apresentaram valores de cronaxia sensitiva e limiares de tolerância à dor mais altos em relação aos sujeitos controle. Considerando que estas regiões estão relacionadas com a propulsão durante a marcha, com a diminuição do fornecimento de informações sensoriais destas regiões, poder-se-ia esperar uma alteração na ativação da musculatura relacionada a esta fase na marcha, tal como encontrado em relação à fase inicial do contato do calcanhar com o solo. Mas tais alterações significativas no recrutamento temporal do m. gastrocnêmio lateral não foram encontradas quando comparou-se este padrão eletromiográfico com o dos sujeitos controle, muito embora observouse uma tendência para um atraso no lado direito.

Muito embora os valores da cronaxia motora não foram estatisticamente diferentes nos grupos GC e GD e se apresentaram dentro da normalidade, pode-se observar estes valores mais altos para os sujeitos do grupo diabético, especialmente para os $\mathrm{m}$. gastrocnêmio lateral direito, $\mathrm{m}$. vasto lateral direito e m. tibial anterior direito. Este fato pode caracterizar maiores limiares de sensibilidade para estes músculos do membro direito nos sujeitos diabéticos neuropatas. Deve-se considerar também a natureza da neuropatia diabética, progressiva e de instalação lenta e a natureza das lesões nervosas do estudo de ERVILHA \& ARAÚJO (1997), sendo de origem traumática e portanto de instalação instantânea e com potencial possibilidade de recuperação. Estas diferentes naturezas dos dados 
analisados em ambos os trabalhos podem gerar diferentes limiares que servirão para se interpretar alterações de respostas motoras.

O fato do teste superficial da cronaxia motora não ter sido um bom indicador para demonstrar disfunções musculares distais, como o esperado para estes sujeitos neuropatas, indica uma necessidade de se utilizar uma outra avaliação para este mesmo fim. Uma sugestão para se ter um acesso mais detalhado do status do acometimento neuromotor destes sujeitos neuropatas seria uma avaliação através da eletroneuromiografia dos nervos relacionados aos músculos estudados, investigando portanto a velocidade de condução dos nervos periféricos. Esta sugestão deve ser considerada em um próximo estudo.

Ainda assim, pode-se considerar um outro aspecto na interpretação dos dados das respostas motoras estudadas. Pode-se considerar que os sujeitos diabéticos avaliados não apresentavam complicações da neuropatia diabética de origem motora (fibras nervosas eferentes) e sim somente de origem sensitiva (fibras nervosas aferentes), tal como demonstra os resultados da cronaxia sensitiva. $\mathrm{E}$ dessa forma, as alterações do padrão de recrutamento muscular evidenciadas pela EMG nos sujeitos do GD, podem ter ocorrido em função de alterações nos comandos centrais no controle da marcha e não devido a disfunção nervosa motora local decorrente da progressão da neuropatia diabética.

\subsection{Aspectos dinâmicos, temporais e espaciais do andar}

A diferença nas velocidades do andar dos sujeitos GC e GD demonstra claramente o efeito da doença sobre a velocidade do andar dos sujeitos neuropatas e consequentemente poderá haver um efeito desta menor velocidade nos resultados da análise dinâmica, temporal, espacial e eletromiográfica do andar destes indivíduos. Ainda neste capítulo de discussão dos resultados, analisaremos o efeito da velocidade auto-selecionada de um sujeito diabético neuropata em suas respostas dinâmicas, temporais e eletromiográficas.

Menores velocidades na marcha de sujeitos neuropatas também foram encontradas nos estudos de MUELLER et al. (1994), COURTEMANCHE et al. (1996), KATOULIS et al. (1997) e DINGWELL et al. (2000). Estes autores especulam que esta diminuição da velocidade em neuropatas pode ser uma conseqüência do déficit sensorial e proprioceptivo e portanto eles andam mais cuidadosa e lentamente. COURTEMANCHE et al. (1996) discutem que esta diminuição da velocidade reflete um padrão adotado pelos neuropatas mais conservativo e menos desestabilizador. 
A diminuição de velocidade do andar tem como objetivo de buscar maior estabilidade e equilíbrio durante a marcha entretanto isto levaria a um aumento de variabilidade no padrão cinemático e dinâmico do andar, aumento dos coeficientes de variação de parâmetros biomecânicos, como observou DINGWELL et al. (1999). Como é tradicionalmente assumido, esse aumento de variação nos padrões provocaria uma diminuição da estabilidade no andar e aumento nos riscos de queda (DINGWELL \& CUSOMANO, 2000). Considerando que os sujeitos diabéticos neuropatas partiram de um padrão de variabilidade normal e só aumentado esta variabilidade com esta medida de diminuição de velocidade, esta busca por um padrão mais conservativo e estável contradiz um aumento no risco de quedas observado nestes sujeitos, como destacaram CAVANAGH et al. (1992).

Desta forma, há um paradoxo estabelecido: os sujeitos neuropatas buscam compensar um déficit sensorial e proprioceptivo diminuindo a velocidade do andar e com isto aumentam a estabilidade no andar, porém ao se diminuir a velocidade, aumenta-se a variabilidade dos padrões cinemáticos e dinâmicos e portanto a instabilidade. Pode-se verificar esta maior variabilidade nos padrões do andar através de maiores coeficientes de variação, porém segundo DINGWELL \& CUSUMANO (2000) e DINGWELL et al. (2000), esta medida estatística não quantifica a sensibilidade do sistema neuromuscular para controlar perturbações que ocorrem de passo a passo na marcha. Os autores sugerem que a medida de estabilidade local determinada por análise de sistemas dinâmicos poderia explicar esta diminuição de velocidade em busca de uma maior estabilidade local e foi exatamente isto que DINGWELL et al. (2000) demonstram em seu estudo: diminuição de velocidade auto-selecionada em sujeitos neuropatas gerando maior estabilidade local de tronco, sendo esta estabilidade superior considerada um dos objetivos primários na locomoção humana (McKINNON \& WINTER, 1993).

Outra hipótese levantada para explicar esta diminuição de velocidade, seria devido à menor força de flexores plantares e menor mobilidade de tornozelo em neuropatas levando a uma menor capacidade destes músculos em propulsionar o corpo e gerar momentos de força no tornozelo durante a fase final do apoio na marcha (KATOULIS et al., 1997). Desta forma, deve-se considerar este fato ao se interpretar os resultados subsequentes.

No presente estudo, a hipótese de que devido a uma menor atividade dos flexores plantares e extensores de tornozelo, em relação à aspectos temporais, ocorreu uma diminuição de velocidade na marcha dos sujeitos diabéticos, não foi comprovada, uma vez que a atividade EMG do m. gastrocnêmio lateral do GD não se apresentou diferente da atividade dos sujeitos GC. Mas ainda assim o limiar da cronaxia motora deste músculo apresentou maior para os sujeitos $\mathrm{GD}$, mesmo dentro dos limites de 
normalidade (ERVILHA \& ARAÚJO, 1997) estes valores mais altos podem indicar uma diminuição da resposta motora deste músculo.

Conclui-se que no presente estudo, em função dos déficits sensoriais decorrentes da neuropatia periférica diabética, os sujeitos neuropatas adotaram estratégias de controle mais conservativas durante 0 andar, tais como a diminuição importante da velocidade e provavelmente aumentaram a estabilidade dinâmica, especialmente dos movimentos no plano horizontal da parte superior do corpo, tal como destacaram outros autores (DINGWELL \& CUSOMANO, 2000; MUELLER et al., 1994; COURTEMANCHE et al., 1996).

Destaca-se novamente a importância da informação sensorial para o controle da estabilidade na marcha e na ausência do mesmo, esta estabilidade se perde tornando assim um andar mais instável pelo fato de imprescindíveis informações proprioceptivas, somatossensoriais plantares e musculares não contribuírem para um controle efetivo das fases da marcha, especialmente da fase inicial de contato (DINGWELL \& CUSOMANO, 2000).

Os parâmetros temporais durante 0 andar em esteira sofreram também o efeito desta estratégia dos sujeitos neuropatas de aumentar a estabilidade dinâmica com a redução da velocidade do andar. 0 tempo de apoio simples e o tempo de apoio duplo nos sujeitos neuropatas apresentou-se significativamente maior em relação aos sujeitos controle, aumentando assim o tempo de contato dos pés com o solo, característica esta também apresentada pelos sujeitos estudados por SACCO \& AMADIO (2000). Esta pode ser uma tentativa dos sujeitos de novamente buscar um padrão mais conservativo e equilibrado de andar para compensar a diminuição de feedback sensorial. Este fato reforça a estratégia adotada por estes sujeitos de diminuir sua velocidade do andar resultando neste contato maior dos pés com o solo. Estando mais tempo com os pés em contato com o solo, seria uma forma de aumentar o tempo de aquisição de informação sensorial cutânea mesmo que ainda de forma deficitária. ABBOUD et al. (2000) também observou maiores tempos de contato do pé com solo durante a marcha em sujeitos diabéticos neuropatas e atribui isso a uma disfunção da musculatura extensora nas fases de apoio médio e propulsão o que levaria a um aumento do tempo de contato dos pés com o solo na fase de apoio no andar. Porém, mais uma vez este motivo não foi a causa do aumento no tempo de apoio simples e duplo no presente estudo.

O comprimento do passo e da passada dos sujeitos diabéticos foram menores em relação ao sujeitos controle, e isto também pode-se atribuir à diminuição estratégica da velocidade pelos sujeitos neuropatas, pois com a redução da velocidade e aumento do tempo de apoio, destacado anteriormente, poder-se-ia esperar uma diminuição do tamanho do passo, tal como foi observado no presente estudo. 
Da mesma forma que KATOULIS et al. (1997) observaram em seu estudo, o primeiro pico de força vertical apresentou-se menor para os sujeitos neuropatas em relação controle, muito embora a diferença encontrada no presente estudo não foi significativa. Já o segundo pico de força vertical apresentou-se significativamente menor para os sujeitos diabéticos neuropatas e se associarmos com a fase de propulsão da força horizontal e a correspondência das fases da marcha com esta componente da força, este menor segundo pico de força vertical poderia indicar uma possível ineficiência do aparelho locomotor durante a fase de impulsão na marcha. Ou ainda, devido a diminuição estratégica de velocidade, promoveu-se um menor segundo pico de força vertical durante a marcha nestes sujeitos neuropatas. ABBOUD et al. (2000) discutem esta ineficiência na fase extensora da marcha através de medidas eletromiográficas. KATOULIS et al. (1997) também discutiram este mesmo tema considerando os menores momentos de força na articulação do tornozelo, reduzidos provavelmente devido a uma ineficácia dos músculos flexores plantares na geração de momentos de força no tornozelo e que deveriam garantir uma propulsão eficiente do corpo na fase final do apoio.

Observou-se menores deflexões da força vertical nos sujeitos neuropatas. Deflexões significativamente menores nos sujeitos neuropatas podem indicar uma ineficiência do aparelho locomotor em reduzir cargas durante o médio apoio na marcha. Pode-se discutir que os neuropatas apresentam uma menor capacidade de reduzir forças aplicadas ao aparelho locomotor. Outra consideração a ser feita em relação ao fato anteriormente exposto, é o atraso e menor magnitude na atividade elétrica muscular do $\mathrm{m}$. vasto lateral direito e esquerdo que pode estar relacionado com a função de reduzir forças e de reduzir o choque mecânico na marcha.

Os sujeitos diabéticos neuropatas apresentaram menores taxas de crescimento da força máxima 1 e este fato está relacionado tanto aos menores valores do primeiro pico da força vertical, como ao atraso significativo no primeiro pico da força vertical nos neuropatas, conforme demonstra a TABELA 7 e as FIGURAS 20 e 21 que ilustram um exemplo deste atraso. Desta forma, tem-se maior tempo para se atingir o pico e menor valor deste pico de força, variáveis estas usadas no cálculo da taxa de crescimento da força máxima 1. 
TABELA 7 - Tempo de ocorrência do primeiro pico de força vertical nos sujeitos do grupo controle e diabético (\% do tempo de apoio).

\begin{tabular}{lcc}
\hline & \multicolumn{2}{c}{ Primeiro pico da força vertical (\% tempo de apoio) } \\
\hline GC & Direito & Esquerdo \\
\hline GD & $23,20 \pm 2,02$ & $22,85 \pm 1,76$ \\
\hline $\mathbf{p}$ & $25,33 \pm 2,47$ & $25,00 \pm 2,33$ \\
\hline
\end{tabular}
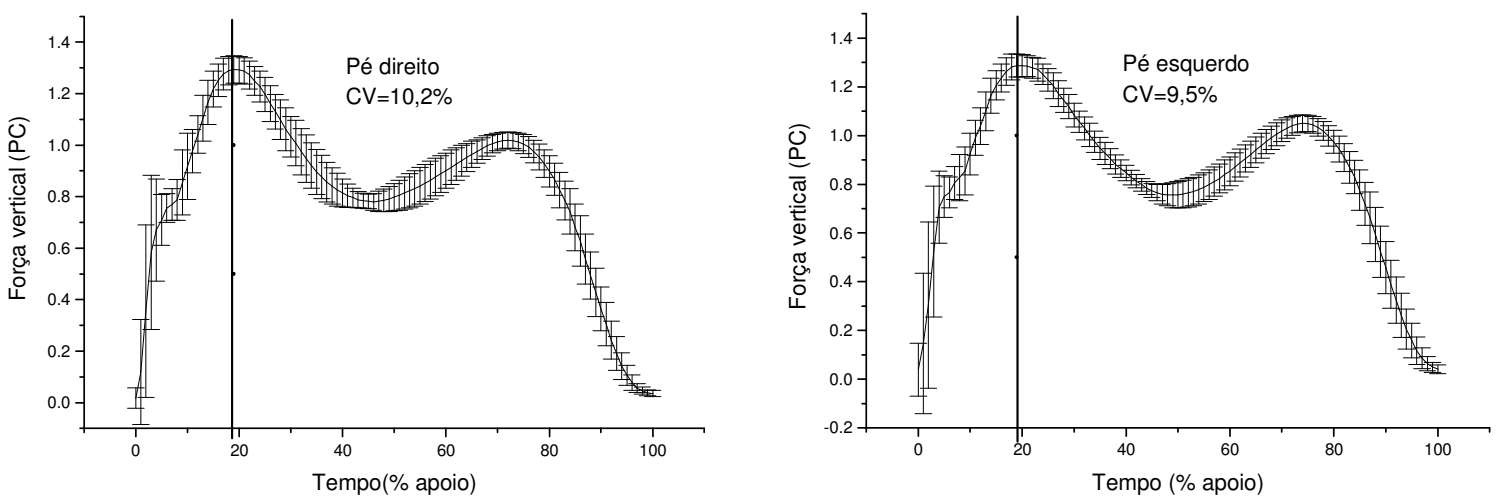

FIGURA 20 - Força vertical em função do peso corporal (PC) do pé direito e esquerdo do sujeito GC02

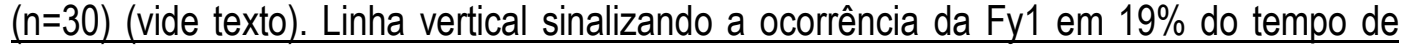
apoio.
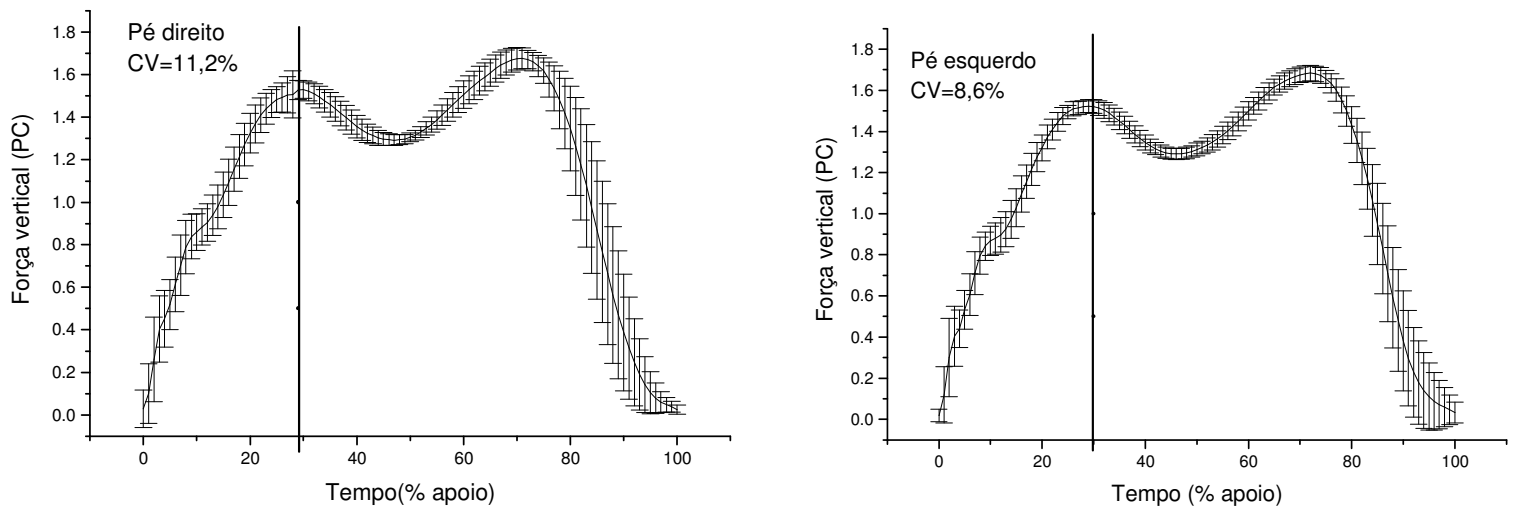

FIGURA 21 - Força vertical em função do peso corporal (PC) do pé direito e esquerdo do sujeito GD06 $\underline{(n=30)}$ (vide texto). Linha vertical sinalizando a ocorrência da Fy1 direita em $30 \%$ do tempo de apoio e da Fy1 esquerda em 29\%. 
Pode-se observar em função das discussões acima, que os sujeitos neuropatas apresentam padrões distintos dinâmicos em relação aos sujeitos controle e estas respostas dinâmicas são manifestações externas e resultantes de momentos articulares gerados, que são dependentes do padrão de recrutamento muscular e, consequentemente das estratégias de controle na marcha. MUELLER et al. (1994), COURTEMANCHE et al. (1996), KATOULIS et al. (1997) discutem que possivelmente estas alterações em parâmetros dinâmicos são conseqüências indiretas da diminuição da velocidade do andar e que por sua vez é decorrente da perda sensorial. Destarte, pode-se secundariamente atribuir como causa destas alterações das respostas dinâmicas, uma alteração no sistema de controle dos padrões da marcha nestes sujeitos doentes. Em função da degeneração progressiva periférica dos nervos decorrente da neuropatia diabética, a alimentação do sistema de controle por informações sensoriais, assim como as respostas motoras e de equilíbrio durante a locomoção, passam a ser comprometidas, resultando em ajustes motores durante 0 andar em diversos segmentos independentemente do lado acometido pela doença e independentemente do local determinado de lesão.

Outro destaque que deve ser dado dentre os dados temporais e espaciais no andar destes sujeitos diabéticos, é a ausência de assimetrias nas respostas de tempo de apoio simples entre o lado direito e esquerdo, assim como nos parâmetros espaciais de comprimento de passo. Se consideramos o fato de ter havido diferenças na sensibilidade somatossensorial e tolerância à dor entre os membros direito e esquerdo nos neuropatas, considerando ainda que houve diferença no padrão temporal de recrutamento muscular entre os dois membros nos mesmo sujeitos, e considerando finalmente que a neuropatia diabética pode ser assimétrica em sua manifestação, então 0 fato de não ter ocorrido assimetrias nas respostas da biomecânica externa, pode ser considerado como uma evidência de que 0 controle das respostas biomecânicas, ou seja, o controle das respostas motoras foi alterado bilateralmente buscando compensações destes déficits sensoriais e motores.

Quanto ao coeficiente de variação das variáveis dinâmicas, destacamos na TABELA 8 e nos ANEXOS VI e VII que os CVs para as variáveis da força vertical na esteira para o grupo diabético apresentaram-se maiores em relação ao grupo controle. 0 mesmo padrão variável repetiu-se para as variáveis temporais (TABELA 9), especialmente para o tempo de duplo apoio, e para as variáveis espaciais (TABELA 10), muito embora estas diferenças entre os CVs dos sujeitos neuropatas e controle não tenha sido tão expressiva quanto em relação às variáveis da força vertical. Esta maior variabilidade nos dados dos sujeitos diabéticos pode indicar um padrão biomecânico instável o que corresponderia a 
um controle instável e variável. Segundo DINGWELL et al. (2000), a variabilidade é um indicativo de instabilidade de padrão de controle motor, e esta pode ser uma provável hipótese para tal magnitude de variação nos dados encontrada .

TABELA 8 - Coeficientes de variação (\%) das variáveis da força reação do solo para os grupos GC e $\underline{G D}$.

\begin{tabular}{ccccccc}
\hline & \multicolumn{2}{c}{ Fy 1 (\%) } & \multicolumn{2}{c}{ Fy 2 (\%) } & \multicolumn{2}{c}{ Fy min (\%) } \\
\hline & D & E & D & E & D & E \\
\hline GC & 8,05 & 9,11 & 5,25 & 4,09 & 8,80 & 9,10 \\
\hline GD & 13,99 & 13,75 & 14,47 & 14,53 & 16,30 & 16,79 \\
\hline
\end{tabular}

TABELA 9 - Coeficientes de variação (\%) das variáveis temporais do ciclo do andar para os grupos GC e GD.

\begin{tabular}{cccc}
\hline & \multicolumn{2}{c}{ Tempo apoio simples (\%) } & Tempo apoio duplo (\%) \\
\hline & D & E & \\
\hline GC & 5,25 & 5,29 & 8,31 \\
\hline GD & 6,53 & 6,21 & 16,67 \\
\hline
\end{tabular}

TABELA 10 - Coeficientes de variação (\%) das variáveis espaciais do ciclo do andar para os grupos GC $\underline{\mathrm{e} G D}$.

\begin{tabular}{ccccc}
\hline & \multicolumn{2}{c}{ Comprimento do Passo (\%) } & \multicolumn{2}{c}{ Comprimento da Passada (\%) } \\
\hline & D & E & D & E \\
\hline GC & 7,67 & 7,98 & 7,21 & 7,25 \\
\hline GD & 9,38 & 9,46 & 8,67 & 8,74
\end{tabular}

Os CVs do grupo controle apresentaram-se relativamente menores quando comparando-os aos dados da literatura referentes à variabilidade destes parâmetros em piso fixo (WINTER, 1991). WHITE et al. (1998) também encontrou menores valores de CV para as variáveis de força reação do solo em esteira em relação ao piso fixo. Em seus dados, estes CVs para a esteira foram a metade dos valores reportados por WINTER (1991) em piso fixo. Este fato provavelmente deveu-se ao ambiente restritivo da esteira que impôs certas condições ao andar dos sujeitos. DINGWELL et al. (1999) e WHITE et al. (1998) discutiram que um ambiente restritivo, tal como o andar em esteira, poderia produzir um padrão locomotor extremamente reprodutivo e com baixa variabilidade na execução e este fato foi confirmado 
por este estudo. Já os sujeitos diabéticos neuropatas apresentaram CVs maiores para todas as variáveis dinâmicas, temporais e espaciais, indicando uma maior variabilidade e instabilidade na consistência e reprodutibilidade das respostas biomecânicas, tal como outros estudos também observaram (SACCO \& AMADIO, 2000; DINGWELL et al., 1999; DINGWELL et al., 2000).

\subsection{Padrão de recrutamento muscular durante 0 andar}

Quando analisamos as curvas de recrutamento do músculo tibial anterior direito e esquerdo (FIGURAS 16 e 17 e TABELA 5), identificamos padrões iniciais de recrutamento significativamente diferentes quando comparamos os sujeitos neuropatas com os controle. Estes músculos atrasam significativamente o pico de ativação na fase de apoio da marcha, tal como ABBOUD et al. (2000) encontraram em seu estudo.

Segundo RICHARDSON et al. (1992), o primeiro nervo a apresentar alterações eletrofisiológicas é o nervo fibular e portanto apresentar alterações estruturais e fisiológicas que levam a comprometimentos sensoriais e motores. Em conseqüência disso, um dos primeiros músculos a sofrer com o resultado desta degeneração progressiva periférica, é o m. tibial anterior, músculo este com padrão de recrutamento alterado no presente estudo.

O músculo tibial anterior tem um papel fundamental no controle do abaixamento do pé durante a fase de contato inicial na marcha e portanto desempenha uma função de grande importância no controle do choque inicial do antepé com o solo (WINTER, 1991). Com este atraso de ativação do m. tibial anterior, este mecanismo de controle de choque na fase inicial da marcha pode estar acometido e com isso aumenta a carga aplicada no antepé durante 0 apoio na marcha destes sujeitos neuropatas. A formação de ulcerações plantares em neuropatas, principalmente na região do antepé, pode estar associada à alterações na fase de contato do pé com o solo durante o abaixamento do pé (BEVANS, 1992; ABBOUD et al., 2000), e portanto esse contato mais abrupto e sem controle do antepé poderia estar aumentando o risco de formação de úlceras plantares nestes sujeitos. Até mesmo a discussão de que por um aumento da pressão plantar aumenta-se o risco de formação de úlceras, especialmente no antepé, fica mais justificada considerando-se este aspecto de atraso na ativação do $\mathrm{m}$. tibial anterior, ou até mesmo em função da alteração da mecânica do tornozelo durante 0 apoio do pé com o solo, aumentando a eversão do pé por disfunção muscular relacionada ao tornozelo (BEVANS, 1992) ou por diminuição da mobilidade de tornozelo nestes doentes, fato este observado por diversos autores (MUELLER et al., 1989; DELBRIDGE et al., 1988; VAN DEURSEN, 1997). 
MUELLER et al. (1994) discutem a possibilidade dos sujeitos neuropatas trocarem a estratégia de tornozelo durante a marcha pela estratégia de quadril, diminuindo assim os momentos de força de tornozelo e aumentando de quadril. E McGIBBON et al. (2001) também identificaram em idosos doentes essa diminuição de energia mecânica no tornozelo no médio apoio da marcha e maior energia mecânica dispendida no quadril na mesma fase. No presente estudo, pode-se inferir, pela menor atividade muscular do m. tibial anterior em relação à magnitude do $\mathrm{m}$. tibial anterior do grupo controle, que a contribuição do tornozelo durante a marcha e principalmente na fase inicial, está diminuída nos sujeitos diabéticos neuropatas. Porém, ainda é de grande interesse a investigação da atividade muscular relacionada ao quadril para que se possa esclarecer estas compensações na marcha de neuropatas. $E$ é também grande 0 interesse em se investigar a atividade elétrica destes grupos musculares distais e proximais durante o ciclo completo do andar, incluindo assim a fase de balanço.

Outro aspecto importante observado foi a alteração bilateral significativa deste padrão temporal de recrutamento do $\mathrm{m}$. tibial anterior. Muito embora os acometimentos sensoriais e motores foram unilaterais, dependendo da modalidade sensorial investigada, a alteração da atividade elétrica muscular do m. tibial anterior foi bilateral, ou seja, os músculos de ambos membros atrasaram sua atividade durante a fase de apoio na marcha. Com isso, pode-se inferir que de alguma forma o sistema de controle da marcha ajustou as respostas bilateralmente como forma de interagir e compensar os déficits sensoriais e motores decorrentes da neuropatia. Este comportamento de compensações e ajustes bilaterais já foi citado por DINGWELL et al. (2000) em seu estudo com sujeitos neuropatas.

Nos ANEXOS VI e VII estão representadas as curvas de EMG dos músculos estudados para todos os sujeitos dos grupos GC e GD. Em cada curva está descrito o CV de cada sujeito. O que podese observar nestes resultados são CVs dos sujeitos controle relativamente menores em relação à literatura que apresentou dados de variabilidade relativos ao piso fixo (WINTER, 1991). Este fato provavelmente deveu-se ao ambiente restritivo da esteira que impôs certas condições ao andar dos sujeitos. DINGWELL et al. (1999) discutiram que um ambiente restritivo, tal como 0 andar em esteira, poderia produzir um padrão locomotor extremamente reprodutivo e com baixa variabilidade na execução e este padrão foi o encontrado no presente estudo.

Os valores mais altos de coeficiente de variação (CV) foram encontrados para o primeiro pico de ativação do $\mathrm{m}$. tibial anterior tanto para a perna esquerda quanto para a perna direita dos sujeitos do GC e do GD (conforme TABELA 5). Quanto ao grupo diabético neuropata, o m. tibial anterior é um dos primeiros músculos a ser acometido pela neuropatia diabética (RICHARDSON et al., 1992) considerando a degeneração do nervo fibular que é uma das primeiras a ocorrer. Devido a degeneração 
da raiz motora do nervo fibular, o m. tibial anterior altera seu padrão de ativação durante a marcha, deixando de atuar durante 0 toe clearance e durante 0 aplainamento do pé, e consequentemente 0 tornozelo não flexiona suficientemente e cai no solo descontroladamente, deixando o pé "caído" como 0 padrão encontrado em crianças com paralisia cerebral (PERRY, 1992). E este padrão descrito anteriormente, foi exatamente o observado durante o andar do sujeito neuropata na esteira.

Considerando o fato de os sujeitos controle também apresentarem um alto CV para o m. tibial anterior durante a marcha, considera-se que tal fato não se deve exclusivamente à doença em questão - neuropatia diabética - mas sim uma característica de ativação deste músculo, tal como observou LOBO DA COSTA (1995).

Com relação à ativação do m. gastrocnêmio lateral dos sujeitos diabéticos neuropatas, 0 início da ativação deste músculo do lado direito, assim como o seu pico de ativação apresentam-se atrasados em relação aos sujeitos do grupo controle. Estes achados estão em acordo com os resultados de ABBOUD et al. (2000). Muito embora estes atrasos no início da ativação e no pico de ativação não foram significativos, estes eventos podem estar relacionados aos menores valores do segundo pico de força vertical que foram observados nos sujeitos GD. Faz-se necessário notar que o lado direito foi 0 lado cujos valores de cronaxia motora, especialmente para o m. gastrocnêmio lateral, assim como os valores de tolerância à dor, apresentaram-se mais altos em relação aos sujeitos controle. Portanto, pode-se observar uma certa correspondência nos acometimentos nervosos periféricos e nas respostas biomecânicas alteradas investigadas.

O padrão de recrutamento do músculo vasto lateral direito e esquerdo apresentou um atraso no pico da primeira ativação nos sujeitos do GD, muito embora este atraso tenha sido significativo somente para o lado direito. Este atraso também foi observado por ABBOUD et al. (2000). Considerando-se que os sujeitos neuropatas apresentam uma diminuição importante da informação sensorial periférica: informação dos fusos musculares, dos proprioceptores, mecanoceptores e nociceptores plantares, especialmente da região do calcanhar e antepé, tem-se que na fase de apoio na marcha, estas informações do choque mecânico do pé com o solo são informadas com significativo déficit para as estruturas responsáveis pelo controle da marcha, e com isso o primeiro pico de ativação do $\mathrm{m}$. vasto lateral atrasa e seu papel na recepção de carga é pobremente desempenhado. Possivelmente, as cargas recebidas pelo aparelho locomotor durante a marcha nestes sujeitos poderiam ser maiores tendo como conseqüência a médio e longo prazo, maiores sobrecargas articulares, ligamentares e musculares levando a degenerações de partes moles. 
Estes padrões de atraso do $\mathrm{m}$. tibial anterior e do $\mathrm{m}$. vasto lateral podem representar uma falência no mecanismo de redução de choque na fase de apoio na marcha, mecanismo este controlado pela ativação destes músculos e cujas ações no tornozelo (aplainamento do pé) e no joelho (flexão na recepção de carga) desempenham papel fundamental nesta redução. Dessa forma, o déficit sensorial periférico decorrente da neuropatia diabética resultou numa alteração dos padrões centrais de recrutamento muscular tanto do $\mathrm{m}$. tibial anterior, tipicamente degenerado na neuropatia, quanto do $\mathrm{m}$. vasto lateral, músculo este mais proximal e portanto mais tardiamente acometido.

Pode-se observar ainda uma menor magnitude nos picos de ativação do $\mathrm{m}$. vasto lateral nos sujeitos diabéticos neuropatas, mais uma vez indicando uma possível falência no mecanismo de redução de choque que deveria estar ativo e funcional no início da marcha.

Outro aspecto importante que foi observado no padrão de recrutamento do m. vasto lateral de alguns sujeitos neuropatas, foi o prolongamento de sua atividade durante a primeira ativação, muito embora este início de ativação está atrasado em relação ao padrão dos sujeitos controle, como pode ser observado analisando a TABELA 5 . Este prolongamento da atividade do $\mathrm{m}$. vasto lateral está ilustrado na FIGURA 22 para um sujeito GD e seus dados individuais podem ser comparados com os dados do GC na TABELA 5.
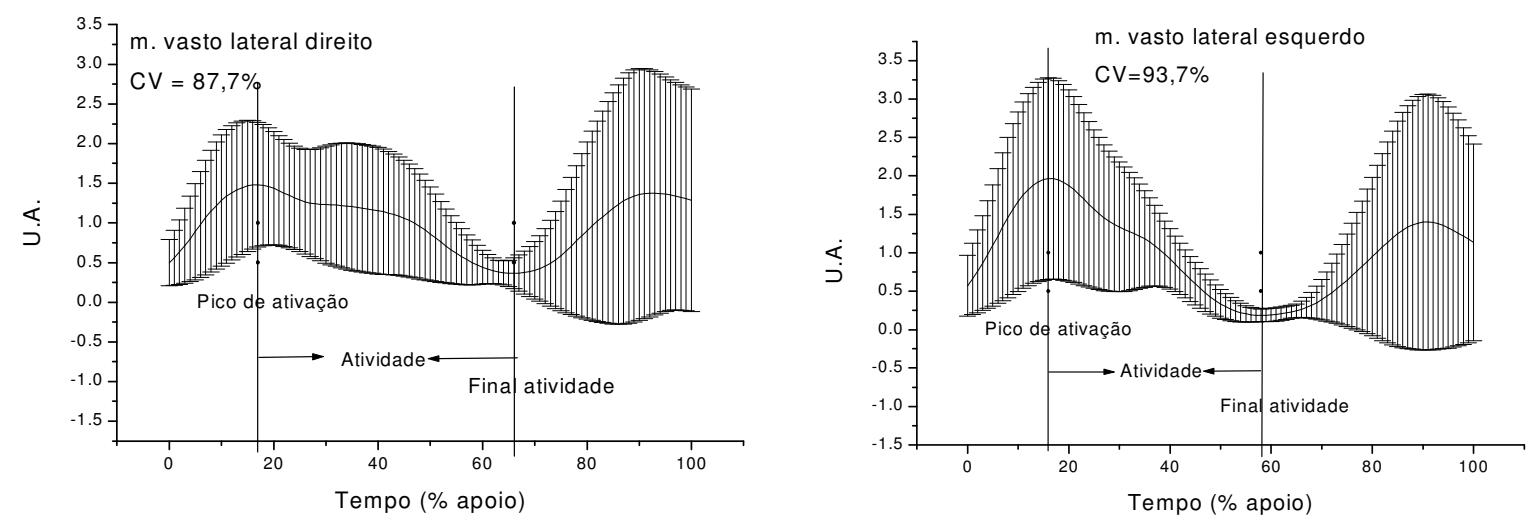

FIGURA 22 - Curvas médias e desvios padrão da EMG normalizado pela média do $\mathrm{m}$. vasto lateral direito e esquerdo do sujeito GD03, durante o andar em esteira. A linhas verticais indicam o pico de ativação atrasado $(17 \% \mathrm{D}, 16 \% \mathrm{E})$, o final da atividade $(66 \% \mathrm{D}, 58 \% \mathrm{E})$ e a duração da ativação do m. vasto lateral no início da fase de apoio.

Em função do prolongamento da atividade do $\mathrm{m}$. vasto lateral e considerando que o primeiro pico da força vertical corresponda de certa forma à flexão máxima de joelho e à resposta da ação 
excêntrica do m. quadríceps da coxa na recepção da carga durante a fase inicial de apoio na marcha, poder-se-ia esperar um atraso na ocorrência do primeiro pico da força nos sujeitos neuropatas, e isto foi observado como demonstrado pelas FIGURAS 20 e 21 e TABELA 7.

Considerando o atraso no pico de ativação do $\mathrm{m}$. vasto lateral, poder-se-ia esperar ainda que a força vertical mínima também ocorresse atrasada no ciclo da marcha dos diabéticos uma vez que esta força corresponde com a inversão de fase na força horizontal (WINTER, 1991) - da fase de recepção da carga para a propulsão - e consequentemente, corresponderia à ação do m. vasto lateral nesta fase. Porém, a força mínima nos sujeitos diabéticos neuropatas não ocorreu mais tarde em relação aos sujeitos controle, conforme demonstra a TABELA 11.

TABELA 11 - Tempo de ocorrência da força vertical mínima nos sujeitos do grupo controle e diabético (\% do tempo de apoio).

\begin{tabular}{lcc}
\hline & \multicolumn{2}{c}{ Força vertical mínima (\% tempo de apoio) } \\
\hline GC & Direito & Esquerdo \\
\hline GD & $44,90 \pm 2,40$ & $45,00 \pm 2,62$ \\
\hline $\mathbf{p}$ & $45,73 \pm 2,79$ & $45,40 \pm 2,92$ \\
\hline
\end{tabular}

A ocorrência da força vertical mínima não foi estatisticamente diferente entre os sujeitos controle e neuropatas, mas em alguns sujeitos este atraso ocorreu, como demonstram as FIGURAS 23 e 24.
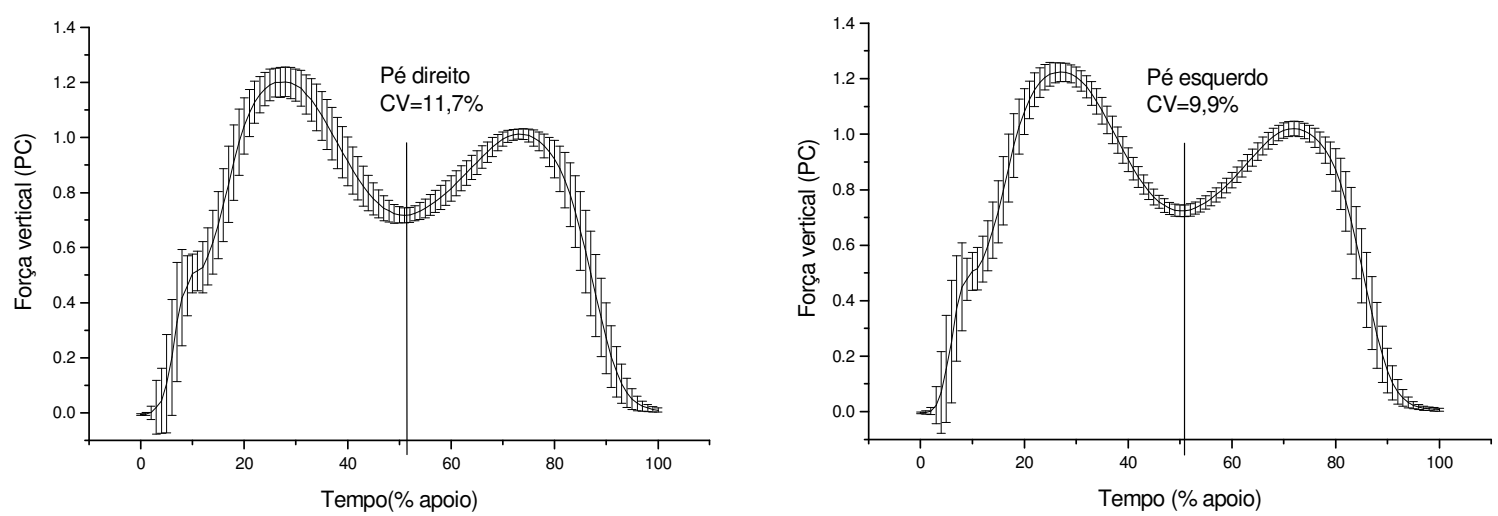

FIGURA 23 - Força vertical em função do peso corporal (PC) do pé direito e esquerdo do sujeito GD12 (vide texto). Linha vertical sinalizando a ocorrência da Fymin direita e esquerda em $51 \%$ do tempo de apoio. 

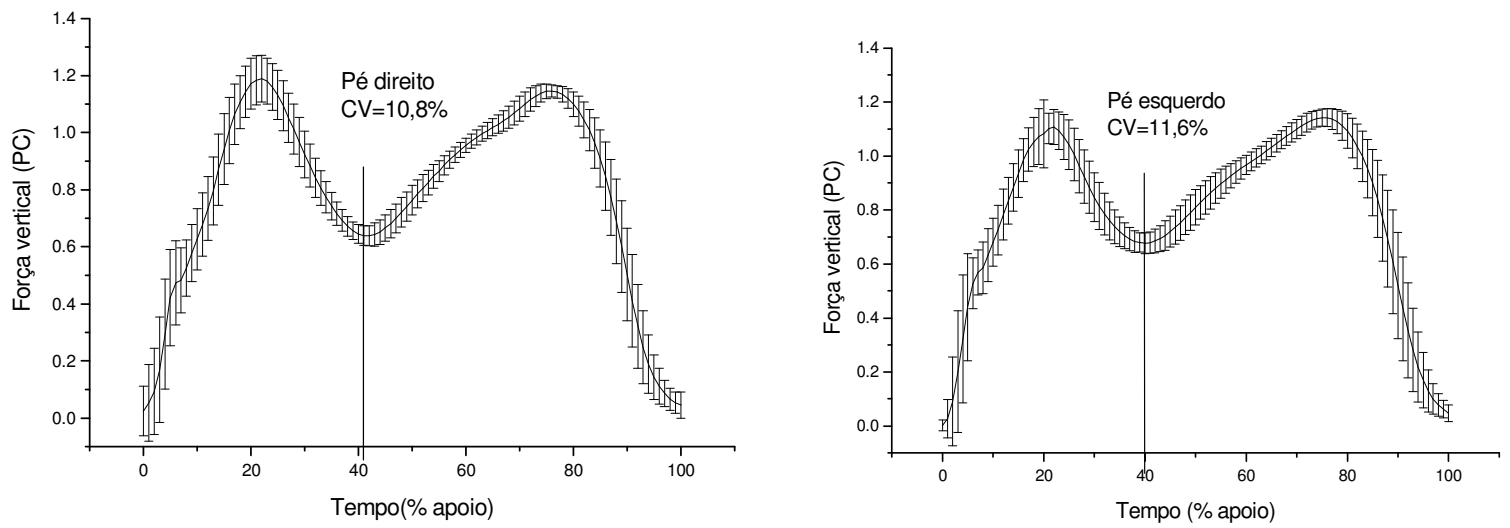

FIGURA 24 - Força vertical em função do peso corporal (PC) do pé direito e esquerdo do sujeito GC20 (vide texto). Linha vertical sinalizando a ocorrência da Fymin direita em $41 \%$ do tempo de apoio e da Fymin esquerda em $40 \%$.

Provavelmente, o padrão dinâmico na marcha dos sujeitos diabéticos neuropatas não se modificou, ou seja, aspectos da biomecânica externa não se alteraram como o esperado, por exemplo 0 atraso da ocorrência da força vertical mínima, pois a esteira impõem certas restrições ao movimento humano (DINGWELL et al., 1999, 2000) e mesmo com a alteração no padrão de controle da marcha nestes sujeitos, evidenciada pelos atrasos, prolongamentos e menores magnitudes na ativação dos $\mathrm{m}$. vasto lateral e m. tibial anterior, não houve modificação na mecânica do movimento na esteira.

\subsection{Parâmetros biomecânicos do andar, respostas somatossensoriais e motoras a partir da análise intra-sujeitos}

Conforme objetivo inicial do presente estudo, buscou-se interpretar os parâmetros biomecânicos da marcha de sujeitos diabéticos neuropatas considerando que esta doença acarretaria acometimentos sensitivos e motores em regiões e membros distintos, não necessariamente bilaterais ou simétricos, e com isso haveria alterações nas respostas motoras durante 0 andar, conseqüentes de um controle alterado deste comportamento. Entretanto, a análise inter-sujeitos feita nos itens anteriores, poderia ter descaracterizado o comportamento individual típico de alguns sujeitos que apresentaram acometimentos assimétricos com conseqüências biomecânicas relacionadas a estes acometimentos 
periféricos sensitivos e/ou motores. Desta forma, procedemos uma análise intra-sujeito de forma a relacionar individualmente estes aspectos biomecânicos e da doença estudada em cinco sujeitos diabéticos neuropatas selecionados intencionalmente segundo alguns critérios: presença de características típicas da doença, presença de sintomatologia, história prévia de ulceração, presença de doenças associadas à diabetes, alteração nas modalidades sensitivas de tolerância à dor, cronaxia sensitiva e motora.

Dentre os 16 sujeitos do grupo diabético (GD) analisados neste estudo, selecionamos para análise cinco sujeitos diabéticos neuropatas tipo 2, do sexo masculino, todos apresentando sintomatologia relacionada à neuropatia periférica diabética, e cujas características antropométricas e clínicas encontram-se na TABELA 12.

TABELA 12- Características dos sujeitos diabéticos neuropatas para análise individual (HAHipertensão Arterial).

\begin{tabular}{ccccccc}
\hline & $\begin{array}{c}\text { Idade } \\
\text { (anos) }\end{array}$ & $\begin{array}{c}\text { Massa } \\
(\mathbf{k g})\end{array}$ & $\begin{array}{c}\text { Tempo diagnóstico } \\
\text { (anos) }\end{array}$ & $\begin{array}{c}\text { História de } \\
\text { ulceração }\end{array}$ & Doenças associadas & $\begin{array}{c}\text { Uso de } \\
\text { Insulina }\end{array}$ \\
\hline GD01 & 68 & 98,4 & 20 & Sim & HA, dislipidemia & Não \\
\hline GD03 & 69 & 67,1 & 18 & Sim & $\begin{array}{c}\text { HA, nefro, retino e } \\
\text { artropatia }\end{array}$ & Sim \\
\hline GD04 & 62 & 65,4 & 5 & Sim & HA, retinopatia & Não \\
\hline GD06 & 60 & 60 & 6 & Sim & & Sim \\
\hline GD08 & 54 & 79,2 & 1 & Não & HA, dislipidemia & Não \\
\hline
\end{tabular}

Conforme a TABELA 12, os sujeitos selecionados para a análise individual, com exceção do GD08, apresentavam pelo menos mais do que 5 anos de diagnóstico de diabetes e apresentavam história anterior de ulceração plantar. Segundo CAPUTO et al. (1994), 80\% dos pacientes com lesões (ulcerações) nos pés são portadores de neuropatia diabética e portanto pode-se concluir que os sujeitos selecionados que apresentam história de ulcerações plantares encontram-se em estágio avançado da neuropatia periférica diabética.

Os sujeitos selecionados também apresentavam doenças associadas à diabetes, tais como hipertensão arterial, dislipidemias, nefropatia e retinopatia, destacando assim a evolução da diabetes nestes sujeitos.

As características da sensibilidade somatossensorial, tolerância à dor e cronaxia motora estão representadas na TABELA 13. 
TABELA 13 - Áreas plantares e músculos cujos valores de sensibilidade somatossensorial e motora representaram alterações para os sujeitos diabéticos neuropatas selecionados.

\begin{tabular}{|c|c|c|c|c|c|c|}
\hline & & GD01 & GD03 & GD04 & GD06 & GD08 \\
\hline \multirow[t]{2}{*}{ Cronaxia sensitiva } & D & Calcanhar & & Meio-pé & & Calcanhar \\
\hline & $E$ & & & Antepé medial & & Calcanhar \\
\hline \multirow[t]{2}{*}{ Tolerância dor } & D & & Calcanhar & $\begin{array}{c}\text { Calcanhar, } \\
\text { antepé medial }\end{array}$ & Calcanhar & Calcanhar \\
\hline & $E$ & Calcanhar & $\begin{array}{l}\text { Calcanhar, hálux, } \\
\text { antepé lateral }\end{array}$ & Calcanhar & $\begin{array}{c}\text { Calcanhar, } \\
\text { antepé medial }\end{array}$ & Calcanhar \\
\hline \multirow[t]{2}{*}{ Cronaxia motora } & D & & $\begin{array}{l}\text { m. gastrocnêmio } \\
\text { lateral }\end{array}$ & $\begin{array}{l}\text { m. gastrocnêmio } \\
\text { lateral }\end{array}$ & & $\begin{array}{c}\text { m. gastrocnêmio lateral, } \\
\text { m. tibial anterior }\end{array}$ \\
\hline & $\mathbf{E}$ & & & m. tibial anterior & & \\
\hline
\end{tabular}

Pode-se observar que os sujeitos selecionados apresentavam acometimentos em regiões distintas para as respostas de sensibilidade plantar - cronaxia sensitiva, e para respostas de tolerância à dor, exatamente como demonstrado para o grupo diabético (GD) em discussões anteriores neste capítulo. Em relação à cronaxia motora, pode-se observar que, diferentemente da tendência do grupo diabético em não apresentar alterações nos valores considerados normais, os sujeitos selecionados apresentaram valores alterados nas regiões destacadas na TABELA 13; entretanto estas alterações musculares não se manifestaram exatamente nos padrões de recrutamento muscular durante a marcha, tal como pode-se observar na TABELA 14.

A partir das análises inter-sujeitos (grupos), selecionamos as variáveis biomecânicas que apresentaram-se significativamente diferentes entre os grupos analisados para procedermos a análise intra-sujeitos. Portanto, nas tabelas e análises que se seguem são apresentadas somente as variáveis que foram estatisticamente diferentes entre os grupos ou ainda aquelas que apresentaram forte tendência a serem diferentes nos grupos.

Considerando as variáveis eletromiográficas que apresentaram diferenças estatisticamente significantes quando comparou-se os grupos GD e GC, destaca-se na TABELA 14 as respostas da EMG dos músculos destes cinco sujeitos analisados, cujos atrasos no recrutamento muscular apresentaram-se diferentes. 
TABELA 14 - Padrão de recrutamento temporal (\% tempo de apoio) dos m. gastrocnêmio lateral, m. tibial anterior e m. vasto lateral do GC e dos sujeitos diabéticos neuropatas selecionados. Destacado em cinza os valores atrasados em relação aos sujeitos controle.

\begin{tabular}{lccccccc}
\hline Recrutamento temporal (\%tempo de apoio) & GC & GD01 & GD03 & GD04 & GD06 & GD08 \\
\hline 10 Pico de ativação do m. vasto lateral D & $\mathbf{7 , 4}$ & 9 & 17 & 12 & 8 & 5 \\
\hline 10 Pico de ativação do m. vasto lateral E & $\mathbf{8 , 1}$ & 2 & 16 & 9 & 9 & 12 \\
\hline 10 pico de ativação do m. tibial anterior D & $\mathbf{1 , 3 5}$ & 16 & 19 & 0 & 7 & 0 \\
\hline 10 pico de ativação do m. tibial anterior E & $\mathbf{3}$ & 28 & 0 & 2 & 10 & 5 \\
\hline Pico de ativação do m. gastrocnêmio lateral D & $\mathbf{6 4}$ & 85 & 71 & 60 & 63 & 83 \\
\hline
\end{tabular}

O sujeito GD01 apresentou um atraso importante na ativação do $\mathrm{m}$. vasto lateral direito, tal como apresentou o grupo GD, atraso na ativação do m. tibial anterior direito e esquerdo, tal como apresentou o grupo GD, e atraso no $\mathrm{m}$. gastrocnêmio lateral direito, muito embora as respostas de sensibilidade motora (cronaxia motora) apresentaram-se normais para todos estes músculos. Já as respostas de sensibilidade somatossensorial e dor para o GD01 não se apresentaram normais tanto para o calcanhar direito quanto para o calcanhar esquerdo.

O sujeito GD03 apresentou um atraso importante na ativação do m. vasto lateral direito, tal como a tendência do $G D$, atraso no $\mathrm{m}$. vasto lateral esquerdo, $\mathrm{m}$. tibial anterior direito, tal como apresentou o grupo GD, e atraso na ativação do $\mathrm{m}$. gastrocnêmio lateral direito. A cronaxia motora do m. gastrocnêmio lateral direito apresentou-se anormal e portanto concordando com o padrão eletromiográfico atrasado deste músculo durante a marcha neste sujeito. Portanto, de maneira diferente ao que ocorreu com o sujeito GD01, o GD03 apresentou uma resposta eletromiográfica para $0 \mathrm{~m}$. gastrocnêmio lateral direito alterada, provavelmente por sua função já deteriorada (cronaxia motora) decorrente da neuropatia diabética periférica. Suas respostas de tolerância à dor não se apresentaram normais tanto para o calcanhar direito, como para o calcanhar, hálux e antepé lateral esquerdo.

O sujeito GD04 apresentou um atraso importante no padrão de recrutamento do m. vasto lateral direito, tendência já apresentada para o grupo diabético, muito embora suas respostas de cronaxia motora estiveram alteradas tanto para o $\mathrm{m}$. tibial anterior esquerdo e $\mathrm{m}$. gastrocnêmio lateral direito. As respostas de sensibilidade e tolerância à dor apresentaram-se alteradas em relação à normalidade em várias regiões plantares do pé direito e esquerdo, conforme aponta a TABELA 13.

O sujeito GD06 apresentou um padrão de recrutamento atrasado para $0 \mathrm{~m}$. tibial anterior esquerdo, muito embora os valores para a cronaxia motora apresentaram-se normais. Já as respostas 
de tolerância à dor apresentaram-se fora dos padrões de normalidade para o calcanhar direito e esquerdo e antepé medial esquerdo.

O sujeito GD08 apresentou um atraso importante no recrutamento do $\mathrm{m}$. vasto lateral esquerdo e m. gastrocnêmio lateral direito. A cronaxia motora do m. gastrocnêmio lateral direito do GD08 apresentou-se anormal e portanto concordando com o padrão eletromiográfico atrasado deste músculo durante a marcha. Portanto, tanto o GD03 quanto o GD08 apresentaram uma resposta eletromiográfica no m. gastrocnêmio lateral direito alterada provavelmente por sua função já deteriorada (cronaxia motora) decorrente da neuropatia diabética periférica. Assim como encontrado para o GD04, a cronaxia motora do m. tibial anterior direito para o GD08 apresentou valores anormais indicando uma provável disfunção deste músculo, mas que não se manifestou para ambos os sujeitos nos padrões eletromiográficos. Da mesma forma, o sujeito GD04 também apresentou respostas de cronaxia motora para $0 \mathrm{~m}$. gastrocnêmio lateral direito anormais, porém esta função provavelmente já alterada em função da neuropatia diabética, não se manifestou na EMG durante a marcha. As respostas de sensibilidade somatossensorial e tolerância à dor para o sujeito GD08 apresentaram-se com alterações para o calcanhar direito e esquerdo.

Da mesma forma como se procedeu com as variáveis eletromiográficas, também foram tratadas nesta análise intra-sujeitos, somente as variáveis derivadas da força reação do solo e parâmetros temporais que apresentaram-se significativamente diferentes quando comparou-se os grupos GC e GD.

TABELA 15 - Valores médios e desvios padrão das variáveis da Força reação do solo e parâmetros temporais durante o ciclo da marcha do grupo GC e dos sujeitos diabéticos neuropatas selecionados.

\begin{tabular}{lcccccc}
\hline & GC & GD01 & GD03 & GD04 & GD06 & GD08 \\
\hline Pico da Fy2 D (x PC) & $1,16 \pm 0,06$ & $1,05 \pm 0,04$ & $1,00 \pm 0,03$ & $1,05 \pm 0,01$ & $\mathbf{1 , 6 9 \pm 0 , 0 5 \&}$ & $1,13 \pm 0,02$ \\
\hline Pico da Fy2 E (x PC) & $1,17 \pm 0,05$ & $1,04 \pm 0,05$ & $0,99 \pm 0,04$ & $1,04 \pm 0,01$ & $1,70 \pm 0,03 \&$ & $1,14 \pm 0,03$ \\
\hline Força vertical mínima D (x PC) & $0,76 \pm 0,07$ & $0,84 \pm 0,03$ & $\mathbf{0 , 6 9 \pm 0 , 0 5 \&}$ & $0,83 \pm 0,02$ & $1,28 \pm 0,02$ & $0,79 \pm 0,02$ \\
\hline Deflexão da força vertical D (PC/s) & $2,63 \pm 0,86$ & $0,94 \pm 0,31$ & $1,27 \pm 0,49$ & $1,56 \pm 0,31$ & $1,79 \pm 0,38$ & $2,06 \pm 0,30$ \\
\hline Taxa de crescimento de Fy1 D (PC/s) & $7,55 \pm 1,29$ & $5,62 \pm 0,76$ & $3,94 \pm 0,59$ & $6,71 \pm 0,82$ & $6,59 \pm 0,54$ & $6,37 \pm 0,41$ \\
\hline Taxa de crescimento de Fy1 E (PC/s) & $7,57 \pm 1,36$ & $5,52 \pm 0,87$ & $3,96 \pm 0,47$ & $6,63 \pm 0,70$ & $6,47 \pm 0,68$ & $6,15 \pm 0,35$ \\
\hline Tempo de apoio simples D (s) & $0,40 \pm 0,02$ & $0,50 \pm 0,04$ & $0,45 \pm 0,04$ & $0,42 \pm 0,02$ & $0,42 \pm 0,01$ & $0,46 \pm 0,01$ \\
\hline Tempo de apoio simples E (s) & $0,40 \pm 0,02$ & $0,50 \pm 0,04$ & $0,44 \pm 0,03$ & $0,42 \pm 0,02$ & $0,43 \pm 0,02$ & $0,46 \pm 0,02$ \\
\hline Tempo de apoio duplo (s) & $0,12 \pm 0,01$ & $0,14 \pm 0,01$ & $0,20 \pm 0,03$ & $0,13 \pm 0,01$ & $0,18 \pm 0,01$ & $\mathbf{0 , 1 2 \pm 0 , 0 1 *}$ \\
\hline \& não refletem a tendência do grupo diabético em apresentar maiores Fymin, menores Fy2 direita e esquerda em relação ao & \\
grupo controle. * valor que não foi significativamente (p<0,05) diferente em relação aos sujeitos controle. &
\end{tabular}


A TABELA 15 apresenta os valores para as variáveis derivadas da força reação do solo e variáveis temporais do ciclo da marcha dos cinco sujeitos diabéticos neuropatas selecionados, variáveis estas que foram significativamente $(p<0,05)$ diferentes em relação ao grupo controle. Somente o tempo de duplo apoio do sujeito GD08 que não foi significativamente diferente do GC e as variáveis Pico da Fy2 D e E do sujeito GD06 e a força vertical mínima do GD03, que não seguiram a tendência dos dados gerais do GD. Desta forma, pode-se concluir que a tendência da análise de grupo (inter-sujeitos) e da análise individual dos dados, seguiu o mesmo comportamento, ou seja: valores significativamente menores de Fy2 D e E, significativos maiores valores de Fymin D, significativos menores valores de deflexão $D$, significativos menores valores da taxa de crescimento de Fy1 D e E, valores significativamente maiores para o tempo de apoio simples $\mathrm{D}$ e $\mathrm{E}$ e apoio duplo.

Pode-se concluir, observando a tendência bilateral de apresentação dos atrasos eletromiográficos e das alterações dinâmicas e sensoriais, que há um ajuste a longo prazo no controle das respostas motoras dos neuropatas, promovendo assim tais compensações e alterações biomecânicas bilaterais em decorrência dos déficits sensoriais e motores conseqüentes da neuropatia diabética periférica. Considerando a característica da instalação da neuropatia diabética como sendo lenta e progressiva, os sujeitos doentes fariam ajustes compensatórios ao longo da evolução da doença, e considerando ainda que quatro dos cinco sujeitos selecionados têm mais do que cinco anos de diagnóstico da doença, pode-se inferir que os resultados encontrados podem ser em decorrência destes ajustes que foram se instalando a longo prazo.

\subsection{Análise intra-sujeitos para a mesma velocidade auto-selecionada}

Dentre os diferentes fatores intervenientes que influenciam as respostas dinâmicas e eletromiográficas durante a locomoção humana, destacamos a velocidade do andar. Esta variável tem influência significativa especialmente sobre o comportamento da curva da força reação do solo vertical e no timing do recrutamento muscular (WINTER, 1991); por isso procedemos uma análise individual casocontrole que investigasse a influência da cadência auto-selecionada nos parâmetros biomecânicos estudados e desta forma verificar se as alterações biomecânicas observadas no grupo diabético tiveram expressiva influência da velocidade menor selecionada por estes sujeitos. Pode-se discutir a partir desta análise, até que ponto os déficits sensoriais e motores decorrentes da doença alteram os parâmetros 
biomecânicos investigados e até que ponto a estratégia de diminuição da velocidade tem influência direta nas respostas biomecânicas no andar destes sujeitos neuropatas.

Portanto, foi realizada uma comparação de caráter exemplar de um sujeito diabético neuropata com um sujeito controle que auto-selecionaram a mesma cadência durante 0 andar em piso fixo (112 passos/min), mesmo comprimento de passada, e consequentemente a mesma velocidade foi obtida na esteira rolante $(4,2 \mathrm{~km} / \mathrm{h})$, segundo critério protocolar estabelecido. Esta análise intra-sujeitos com mesma velocidade de andar foi feita de forma a analisar o comportamento das variáveis dinâmicas, temporais e eletromiográficas nesta condição controlada. Os sujeitos apresentavam características antropométricas, de gênero e características clínicas, conforme ilustra a TABELA 16.

TABELA 16- Características do sujeito diabético GD09 e do sujeito controle GC14 para análise comparativa.

\begin{tabular}{|c|c|c|c|c|c|c|c|c|c|c|}
\hline & $\begin{array}{l}\text { Idade } \\
\text { (anos) }\end{array}$ & $\begin{array}{c}\text { Massa } \\
(\mathrm{kg})\end{array}$ & Sexo & $\begin{array}{c}\text { Cadência } \\
\text { (passos/min) }\end{array}$ & $\begin{array}{c}\text { Velocidade } \\
(\mathrm{km} / \mathrm{h})\end{array}$ & Diabetes & $\begin{array}{c}\text { Tempo } \\
\text { diagnóstico }\end{array}$ & $\begin{array}{c}\text { História } \\
\text { ulceração }\end{array}$ & $\begin{array}{c}\text { Doenças } \\
\text { associadas }\end{array}$ & $\begin{array}{c}\text { Últimas } \\
\text { glicemias }\end{array}$ \\
\hline$\overline{\text { GC14 }}$ & 37 & 77 & $\bar{M}$ & 112 & 4,2 & & & & & \\
\hline \multirow[t]{2}{*}{ GD09 } & 45 & 60,3 & $F$ & 112 & 4,2 & Tipo 1 & 34 anos & $\operatorname{sim}$ & HAS, & $250 \mathrm{mg} / \mathrm{dl}$ \\
\hline & & & & & & & & & retinopatia & $300 \mathrm{mg} / \mathrm{dl}$ \\
\hline
\end{tabular}

Novamente, a análise intra-sujeito realizada neste momento levou em considerações as variáveis que se apresentaram estatisticamente diferentes na análise inter-sujeitos, ou ainda aquelas que apresentaram forte tendência em diferenciar os grupos GD e GC. Na TABELA 17, estão apresentados os resultados da avaliação sensorial e motora do sujeito GC14 e do sujeito GD09. Os valores para o sujeito controle são considerados normais para todas as categorias eletrofisiológicas analisadas. Entretanto, para o sujeito GD09, estão sinalizados com um asterisco na TABELA 17 os valores de cronaxia sensitiva para o calcanhar direito e para o hálux esquerdo, valores estes considerados anormais para esta população, podendo indicar uma alteração importante na função de sensibilidade periférica neste sujeito. 
TABELA 17 - Valores da cronaxia sensitiva $(\mathrm{ms})$ e tolerância à dor $(\mathrm{mA})$ em quatro áreas plantares, para o GC14 e para o GD09.

\begin{tabular}{lccccc}
\hline & \multicolumn{2}{c}{ CRONAXIA SENSITIVA (ms) } & \multicolumn{2}{c}{ TOLERÂNCIA Á DOR (mA) } \\
\hline Áreas plantares & Pé & GC14 & GD09 & GC14 & GD09 \\
\hline Calcanhar & E & 0,20 & 0,25 & 6,5 & 6,5 \\
\cline { 2 - 6 } & D & 0,25 & $1,10^{*}$ & 6,5 & 12 \\
\hline Meio-pé & E & 0,20 & 0,30 & 7,5 & 6 \\
\cline { 2 - 6 } & D & 0,30 & 0,30 & 7,5 & 8,5 \\
\hline Antepé medial & E & 0,40 & $0,60^{*}$ & 11 & 5 \\
\cline { 2 - 6 } & D & 0,50 & 0,20 & 4,5 & 6 \\
\hline Antepé lateral & E & 0,30 & 0,50 & 5,5 & 3,5 \\
\hline Hálux & D & 0,30 & 0,20 & 5,5 & 4,5 \\
\hline & E & 0,20 & $1,5^{*}$ & 3,5 & 4 \\
\hline
\end{tabular}

Na TABELA 18, estão representados os padrões de recrutamento temporal dos músculos estudados para estes dois sujeitos selecionados. Destaca-se para o sujeito GD09 010 pico de ativação do $\mathrm{m}$. vasto lateral direito e $01^{0}$ pico de ativação do m. tibial anterior esquerdo, recrutamentos estes atrasados em relação ao padrão do sujeito GC14 ou ainda em relação ao padrão do grupo controle GC.

TABELA 18- Padrão de recrutamento temporal (\% tempo de apoio) dos m. gastrocnêmio lateral, $m$. tibial anterior e m. vasto lateral do GC14 e do GD09.

\begin{tabular}{lcc}
\hline Recrutamento temporal (\%tempo de apoio) & GC14 & GD09 \\
\hline 10 Pico de ativação do m. vasto lateral D & 4 & $\mathbf{1 4}^{*}$ \\
\hline 10 Pico de ativação do m. vasto lateral E & 7 & 7 \\
\hline 10 pico de ativação do m. tibial anterior D & 0 & 0 \\
\hline 10 pico de ativação do m. tibial anterior E & 0 & $\mathbf{1 5}^{*}$ \\
\hline Pico de ativação do m. gastrocnêmio lateral D & 53 & 61 \\
\hline
\end{tabular}

Segundo a análise das TABELAS 17 e 18, o sujeito GD09 apresenta alteração de sensibilidade (cronaxia sensitiva) no calcanhar direito e atraso importante no primeiro pico de ativação do $\mathrm{m}$. vasto lateral no mesmo lado - direito. A informação de choque mecânico que ocorre nesta região do pé na fase inicial da marcha, não se apresenta de maneira eficiente para o sistema de controle da marcha e portanto a informação de contração do $\mathrm{m}$. vasto lateral e conseqüente proteção do aparelho locomotor, 
não ocorre a contento para o membro direito. Entretanto, $0 \mathrm{~m}$. tibial anterior direito apresenta-se com ativação intacta e preservada. Outra importante análise é o atraso significativo no primeiro pico de ativação do $\mathrm{m}$. tibial anterior esquerdo, o que provavelmente sinalizaria uma alteração no controle do recrutamento deste músculo na marcha e consequentemente alterando a recepção de carga pelo membro esquerdo também, visto que este músculo desempenha papel fundamental no aplainamento do pé na fase inicial de contato do pé com o solo. Este achado pode ser uma conseqüência da neuropatia diabética neste sujeito, muito embora não foi observada alteração nos valores de cronaxia motora em nenhum músculo do GD09.

Na TABELA 19, estão representados os valores para as variáveis da força reação do solo e parâmetros temporais da marcha do sujeitos GC14 e do GD09. Estão sinalizados com um asterisco $(p=0,000)$ e dois asteriscos $(p=0,001)$ os valores significativamente diferentes entre estes sujeitos.

TABELA 19 - Valores médios e desvios padrão das variáveis da Força reação do solo e variáveis temporais durante o ciclo da marcha do GC14 e do GD09.

\begin{tabular}{lcc}
\hline & GC14 (n=30 passos) & GD09 (n=30 passos) \\
\hline Pico da Fy2 D (x PC) & $1,12 \pm 0,04$ & $1,13 \pm 0,03$ \\
\hline Pico da Fy2 E (x PC) & $1,13 \pm 0,03$ & $1,13 \pm 0,03$ \\
\hline Força vertical mínima D (x PC) & $0,75 \pm 0,02^{*}$ & $0,83 \pm 0,02^{*}$ \\
\hline Deflexão da força vertical D (PC/s) & $2,86 \pm 0,36^{*}$ & $1,62 \pm 0,29^{*}$ \\
\hline Taxa de crescimento de Fy1 D (PC/s) & $7,85 \pm 0,63^{*}$ & $5,89 \pm 0,48^{*}$ \\
\hline Taxa de crescimento de Fy1 E (PC/s) & $7,65 \pm 0,66^{*}$ & $5,77 \pm 0,45^{*}$ \\
\hline Tempo de apoio simples D (s) & $0,43 \pm 0,01^{* *}$ & $0,42 \pm 0,01^{* *}$ \\
\hline Tempo de apoio simples E (s) & $0,43 \pm 0,02$ & $0,43 \pm 0,02$ \\
\hline Tempo de apoio duplo (s) & $0,12 \pm 0,01^{*}$ & $0,13 \pm 0,01$ * \\
\hline
\end{tabular}

${ }^{*} p=0,000 ;{ }^{* *} p=0,001$

Da mesma forma que observamos na tendência geral dos dados, o sujeito diabético apresenta menor deflexão da força vertical direita $(p=0,000)$, maior força mínima direita $(p=0,000)$ e menor taxa de crescimento da Fy1 direita $(p=0,000)$ e esquerda $(p=0,000)$. Quanto aos parâmetros temporais, 0 sujeito diabético apresenta maior tempo de apoio simples direito $(p=0,001)$ e maior tempo de apoio duplo $(p=0,000)$. As únicas variáveis que não se apresentaram estatisticamente diferentes e portanto não mantiveram a tendência do grupo diabético, foram a Fy 2 direita e esquerda e o tempo de apoio simples 
esquerdo. De qualquer forma, a tendência geral do comportamento biomecânico do grupo diabético se manteve para este sujeito GD09 selecionado e ainda, as diferenças nas respostas dinâmicas, temporais e eletromiográficas entre o grupo controle e o diabético foram mantidas para esta comparação individual mesmo na condição de velocidade auto-selecionada igual no andar para estes sujeitos.

Finalizando esta discussão a respeito da decisão protocolar de se estudar o andar a partir da cadência auto-selecionada, conforme LANGE et al. (1996), pode-se concluir a procedência, para este estudo, da interpretação dos dados do andar a partir da velocidade auto-selecionada para efeito de comparação inter e intra-sujeitos nas variáveis selecionadas, uma vez que neste estudo de caso, anteriormente explicitado, não houve interferência da cadência nas respostas biomecânicas e esta decisão de auto-seleção da cadência pelos sujeitos foi uma forma de manter a naturalidade deste comportamento motor nos sujeitos doentes e controles.

\section{CONCLUSÃO}

Considerando-se sinteticamente os propósitos do presente trabalho, caminhos metodológicos que foram seguidos e que nos auxiliaram a interpretar e discutir os resultados experimentais obtidos, permitimo-nos destacar as conclusões que se seguem.

As conseqüências sensoriais e motoras da neuropatia diabética periférica levam a alterações dos padrões esperados durante a marcha normal. Uma importante alteração observada foi uma diminuição na cadência do andar dos sujeitos diabéticos neuropatas, condizente com a literatura especializada. Muito embora se sabe do efeito da velocidade nos parâmetros biomecânicos investigados, esta redução na velocidade auto-selecionada em neuropatas foi um achado muito importante. Esta diminuição da velocidade define uma estratégia adotada pelos neuropatas a longo prazo como forma de aumentar a estabilidade local do andar, especial de tronco, e reduzir riscos de desequilíbrios e quedas conclusão esta que corrobora com estudos de CAVANAGH et al. (1992) e DINGWELL et al. (2000).

Observou-se uma sensível diminuição nas respostas de força reação do solo, tanto no pico passivo de recepção da carga, quanto no pico ativo de propulsão, conforme TABELA 4; e um importante aumento no tempo de apoio do pé com o solo, conforme TABELA 4, estratégia esta adotada pelos neuropatas como forma de compensar a estabilidade perdida parcial ou totalmente em decorrência das múltiplas complicações desta doença. 
Os resultados da análise biomecânica do andar intra-sujeitos seguiram a mesma tendência da análise inter-sujeitos, ou seja, o comportamento de cada indivíduo diabético selecionado reproduziu-se no comportamento do grupo GD. E ainda, os resultados encontrados para o grupo diabético, mantiveram-se mesmo quando a velocidade auto-selecionada do andar foi a mesma do sujeito controle analisado, indicando assim que mesmo sendo a velocidade um fator interveniente nas respostas biomecânicas, o padrão observado nos neuropatas que reduziram sua velocidade, manteve-se quando comparou-se um sujeito neuropata com um controle com mesma velocidade auto-selecionada do andar. Destaca-se a importância da análise de resultados individuais frente a complexidade das condições impostas pela doença evidenciando-se a necessidade de interpretação intra-sujeitos.

Ajustes no controle do recrutamento muscular foram também observados nos neuropatas resultando num mecanismo deteriorado de redução de choque mecânico durante a marcha. Atrasos na ativação dos $\mathrm{m}$. tibial anterior e $\mathrm{m}$. vasto lateral, conforme TABELA 5 , demonstram que a informação sensorial proveniente da extremidade distal do membro inferior através de mecanoceptores, proprioceptores e nociceptores é deficiente para controlar a fase inicial do andar destes sujeitos diabéticos neuropatas. Menores magnitudes de atividade elétrica do $\mathrm{m}$. tibial anterior e atraso de ativação do $\mathrm{m}$. gastrocnêmio lateral, podem indicar uma ineficiência da função destes músculo na articulação do tornozelo e, consequentemente, sua mobilidade e ação durante a marcha está prejudicada em neuropatas.

A estratégia de uma compensação da função deteriorada da articulação do tornozelo pela função maior da articulação do quadril, ainda não pôde ser comprovada, entretanto a menor função dos músculos distais relacionados ao tornozelo e o prolongamento, em alguns casos, da atividade de um músculo mais proximal, o m. vasto lateral, poderia indicar uma tendência para este comportamento compensatório de distal para proximal, como também já foi sugerido na literatura especializada por MUELLER et. al. (1994). Em futuros estudos com direcionamento mais clínico, poder-se-ia determinar estratégias de tratamento e reabilitação de determinados grupos musculares e articulações de forma a melhorar a função do aparelho locomotor nestes sujeitos neuropatas, enfocando, desta forma, a reabilitação motora da função mais proximal do membro inferior, o quadril, de forma a obter maiores benefícios na função locomotora destes indivíduos.

Estudos futuros serão destinados à investigação da função muscular relacionada à articulação do quadril para que possamos compreender melhor mecanismos de compensações proximais estratégia do quadril no andar - em sujeitos diabéticos neuropatas. Esforços serão conduzidos no sentido de investigar a função muscular distal e proximal do membro inferior durante o ciclo completo do 
andar, considerando tanto a fase de apoio quanto a de balanço, pois desta forma poderemos analisar a contribuição das articulações distal e proximal do membro inferior em todo o ciclo.

Outra tendência que se vê na literatura, conforme DINGWELL \& CUSUMANO (2000) e DINGWELL et al. (2000) e que também será foco de nossos próximos estudos, é a análise contínua do andar em esteira rolante através da análise de sistemas dinâmicos, enfocando desta forma, as variações, perturbações e ajustes passo a passo na marcha e verificar como ocorrem estes fenômenos em doentes com acometimentos neuromotores. Desta forma, poder-se-á aprofundar ainda mais a discussão dos padrões apresentados por diabéticos neuropatas no contexto de novos conhecimentos com bases na Biomecânica. 


\section{REFERÊNCIAS BIBLIOGRÁFICAS}

ABBOUD, R.J.; ROWLEY, D.I., NEWTON, R.W. Lower limb muscle dysfunction may contribute to foot ulceration in diabetic patients. Clinical Biomechanics, v.15, p.37-45, 2000.

ALTON, F.; BALDEY, S.; CAPLAN, S.; MORRISSEY, M.C. A kinematic comparison of overground and treadmill walking. Clinical Biomechanics, v.13, p.434-40, 1998.

AMADIO, A.C.; BAUMANN, W.; POZZO, R. Relações energéticas (trabalho mecânico) e neuromusculares para a corrida considerando-se o movimento na esteira rolante e em piso fixo a diferentes velocidades. In: CONGRESSO NACIONAL DE BIOMECÂNICA, 4., São Paulo, 1992. Anais. São Paulo, EEFEUSP, 1992. p.130-7.

AMADIO, A.C.; LOBO DA COSTA, P.H.; SACCO, I.C.N.; SERRÃO, J.C.; ARAUJO, R.C.; MOCHIZUKI, L.; DUARTE, M. Introdução à análise do movimento humano: descrição e aplicação dos métodos biomecânicos de medição. Revista Brasileira de Fisioterapia, v.3, n.2, p.41-54, 1999.

AMADIO, A.C.; DUARTE, M. Fundamentos biomecânicos para a análise do movimento. Laboratório de Biomecânica, Escola de Educação Física e Esporte, Universidade de São Paulo, 1998.

AMADIO, A.C.; SACCO, I.C.N.; SÁ, M.R.; PEREIRA, P.R.B.; TOLOSA, E.M.C. Avaliação de respostas dinâmicas na análise do andar de indivíduos portadores de diabetes: uma proposta metodológica. Revista de Medicina do Hospital Universitário, v.7, n.2, p.5-14, 1997.

ARAÚJO, R.C. Utilização da eletromiografia na análise biomecânica do movimento humano. São Paulo, 1998. 151p. Tese (Doutorado) - Escola de Educação Física e Esporte, Universidade de São Paulo.

ARSENAULT, A.; WINTER, D.A.; MARTENIUK, R.G. Treadmill versus walkway locomotion in humans: na EMG study. Ergonomics, v.29, n.5, p.665-76, 1986a.

ARSENAULT, A.; WINTER, D.A.; MARTENIUK, R.G.; HAYES, K.C. How many strides are required for the analysis of electromyographic data in gait? Scandinavian Journal of Rehabilitation Medicine, v.18, p.133-5, 1986b.

BERGIN, P.S.; BRONSTEIN, A.M.; MURRAY, N.M.F.; SANCOVIC, S.; ZEPPENFELD, K. Body sway and vibration perception thresholds in normal aging and in patients with polyneuropathy. Journal of Neurology, Neurosurgery and Psychiatry, v.58, p.335-40, 1995.

BEVANS, J.S. Biomechanics and plantar ulcer in diabetes. The foot, v.2, p.166-72, 1992. 
BRESSLER, R.S.; BRESSLER, C.H. Skin and superficial fascia of the foot. Journal of the American Podiatric Medical Association, v.81, n.7, p.379-83, 1991.

CAPPOZZO, A.; MARCHETTI, M.; TOSI, V. Biolocomotion: a century of research using moving pictures. Roma, Promograph, 1991.

CAPUTO, G.M.; CAVANAGH, P.R.; ULBRECHT, J.S.; GIBBONS, G.W.; KARCHMER, A.W. Assessment and management of foot disease in patients with diabetes. The New England Journal of Medicine, v.331, n.29, p.854-60, 1994.

CATTALINE, M.; CANCIAN, J. Diabetes mellitus: complicações crônicas e inibidores da aldose redutase. Ars Curandi, v.27, n.3, p.95-9, 1994.

CAVANAGH, P.R.; DERR, J.A.; ULBRECHT, J.S.; MASER, R.E.; ORCHARD, T.J. Problems with gait and posture in neuropathic patients with insulin-dependent diabetes mellitus. Diabetic Medicine, v.9, p.469-74, 1992.

CAVANAGH, P.R.; PERRY, J.E.; ULBRECHT, J.S.; DERR, J.A.; PAMMER, S.E. Neuropathic diabetic patients do not have reduced variability of plantar loading during gait. Gait and Posture, v.7, p.191-9, 1998.

CELIKER, R; BASGÖZE, O; BAYRAKTAR, M. Early detection of neurological involvement in diabetes mellitus. Electromyography Clinical Neurophysiology, v.36, p.29-35, 1996.

CHARTERIS, J.; TAVES, C. The process of habituation to treadmill walking: a kinematic analysis. Perceptual and Motor Skills, v.47, p.659-66, 1978.

CORREA, S.C.; AMADIO, A.C.; GLITSCH, U.; BAUMANN, W. Contribuição da energia mecânica dos segmentos para a análise biomecânica da locomoção humana. Revista Brasileria de Engenharia Biomédica, v.15, n.1-2, p.69-78, 1999.

COURTEMANCHE, R.; TEADSDALE, N.; BOUCHER, P.; FLEURY, M.; LAJOIE, Y.; BARD, C. Gait problem in diabetic neuropathic patients. Archives of Physical Medicine Rehabilitation, v.77, p.849-55, 1996.

CRUTCHFIELD, C.A.; BARNES, M.R. Peripheral componentes of motor control. In: CRUTCHFIELD, C.A; BARNES, M.R., eds. The neurophysiologic bases of patient treatment. Atlanta, Stokesville Publishing, 1984. p.320-39.

DAL MONTE, A.; FUCCI, S.; MANONI, A. The treadmill used as a training and a simulator instrument in middle and long distance running. In: CIRQUIGLINI, A.; VENERANDO, A.; WARTENWEILER, J., eds. Biomechanics III. Baltimore, University Park Press, 1973. p.359-63. 
DELBRIDGE, L.; PERRY, P.; MARR, S. Limited joint mobility in the diabetic foot: relationship to neuropathic ulceration. Diabetic Medicine, v.5, p.333-7, 1988.

DELSYS INC. The Bagnoli-8 EMG System. Boston, Delsys, 1999.

DCCT . The diabetes control and complications trial research group. The effect of intensive treatment of diabetes on the development and progression of long-term complications in insulin-dependent diabetes mellitus. The New England Journal of Medicine, v. 329, p.977-86, 1993.

DICK, P.J.; KARNES, J.L.; DAUBE, J.; O'BRIEN, P.; SERVICE, J. Clinical and neuropathological criteria for the diagnosis and staging of diabetic polyneuropathy. Brain, v.108, p.861-80, 1985.

DINGWELL, J.B.; ULBRECHT, J.S; BOCH, J.; BECKER, M.B.; O'GORMAN, J.T.; CAVANAGH, P.R. Neuropathic gait shows only trends towards increased variability of sagittal plane kinematics during treadmill locomotion. Gait and Posture, v.10, p.21-9, 1999.

DINGWELL, J.B.; CUSUMANO, J.P. Nonlinear time series analysis of normal and pathological human walking. Chaos, v.10, n.4, p.848-63, 2000.

DINGWELL, J.B.; CUSUMANO, J.P.; STERNAD, D.; CAVANAGH, P.R. Slower speeds in patients with diabetic neuropathy lead to improved local dynamic stability of continuous overground walking. Journal of Biomechanics, v.33, p.1269-77, 2000.

DUJARIER, C. Anatomie des membres: dissection - anatomie topographique. Paris, G. Steinheil, 1905.

ERVILHA, U.E.; ARAUJO, R.C. Estudo sobre a frequência de distribuição da cronaxia e a sua correlação com distintos graus de lesões nervosas periféricas. Revista Brasileira de Fisioterapia, v.1, n.2, p.15-20, 1997.

GAITWAY. Operating manual for type 9810S1x \& software version 1.0x. Winterthur, Kistler, 1996.

GHELUWE, B.V.; SMEKENS, J.; ROOSEN, P. Electrodynographic evaluation of the foot during treadmill versus overground locomotion. Journal of the American Podiatric Medical Association, v.84, n.12, p.598-606, 1994.

HAYMARKER, W.; WOODHALL, B. Peripheral nerve injuries: principles of diagnosis. Philadelphia, W.B. Sanders, 1945.

HIRAI, A.; YASUDA, H.; JOKO, M.; MAEDA, T.; KIKKAWA, R. Evaluation of diabetic neuropathy through the quantitation of cutaneous nerves. Journal of the Neurological Sciences, v.172, p.5562, 2000.

HORAK, F.B.; NASHNER, L.M. Central programming of postural movements: adaptation to altered support-surface configurations. Journal of Neurophysiology, v.55, n.6, p.1369-81, 1986. 
ISACSON, J.; GRANSBERG, L.; KNUTSSON, E. Three-dimensional electrogoniometric gait recording, Journal of Biomechanics, v.19, p.627-35, 1986.

JORGENSEN, U.F.F.E. Achillodynia and loss of heel pad shock absorbency. American Journal of Sports Medicine, v.13, n.2, p.128-32, 1985.

JORGENSEN, U.; EKSTRAND, J. Significance of heel pad confinement for the shock absorption at heel strike. International Journal of Sports Medicine, v.9, n.6, p.468-73, 1988.

KANDEL, E.R.; SCHWARTZ, J.H.; JESSELL, T.M. Principles of neural science. 4.ed., New York, Mc Graw Hill, 2000.

KATOULIS, E.C.; EBDON-PARRY, M.; LANSHAMMAR, H.; VILEIKYTE, L.; KULKARNI, J.; BOULTON,

A.J.M. Gait abnormalities in diabetic neuropathy. Diabetes Care, v.20, n.12, p.1904-7, 1997.

KIM, W.; VOLOSHIN, A.S. Role of plantar fascia in the load bearing capacity of the human foot. Journal of Biomechanics, v.28, n.9, p.1025-33, 1995.

KIMMESKAMP, S.; HENNIG, E.M.; LEMMEN, C. The influence of vision and proprioception perturbations on the balance control in parkinson patients. In: CONGRESS OF THE CANADIAN SOCIETY FOR BIOMECHANICS, 11., Montreal, 2000. Book of Abstracts. Montreal, Canadian Society for Biomechanics, 2000. p.222.

KIMURA, J. Electrodiagnosis in diseases of nerve and muscle: principles and practice. 2.ed. Philadelphia, F.A.Davis, 1989.

KINOSHITA, H.; FRANCIS, P.R.; MURASE, T.; KAWAI, S.; OGAWA, T. The mechanical properties of the heel pad in elderly adults. European Journal of Applied Physiology and Occupational Physiology, v.73, n.5, p.404-9, 1996.

KLEISSEN, R. Quantitative surface electromyography for clinical gait analysis. Gait and Posture, v.3, n.3, p.171, 1995.

KUHNS, J. Changes in elastic adipose tissue. The Journal of Bone and Joint Surgery, v.31-A, n.3, p.541-7, 1949.

LANGE, G.W.; HINTERMEISTER, R.A.; SCHLEGEL, T.; DILLMAN, C.J.; ATEADMAN, J.R. Electromyographic and kinematic analysis of graded treadmill walking and the implications for knee rehabilitation. Journal of Orthopaedic and Sports Physical Therapy, v.23, n.5, p.294-301, 1996.

LAZORTHES, G. Le systeme nerveux peripherique: description, systematisation, exploration. Paris, Masson et Cia., 1971. 
LOBO DA COSTA, P.H. Abordagem biomecânica da locomoção: parâmetros da função coordenativa em crianças durante o subir e descer escadas e o andar no plano. São Paulo, 1995. 112p. Dissertação (Mestrado). Escola de Educação Física e Esporte, Universidade de São Paulo.

LORD, M.; HOSEIN, R. A study of in-shoe plantar shear in patients with diabetic neuropathy. Clinical Biomechanics, v.14, n.4, p.278-83, 2000.

McFADYEN, B.J.; WINTER, D.A. An integraded biomechanical analysis of normal stair ascent and descent. Journal of Biomechanics, v. 21, p.733-44, 1988.

McGIBBON, C.A.; KREBS, D.E.; PUNIELLO, M.S. Mechanical energy analysis identifies compensatory strategies in disabled elders' gait. Journal of Biomechanics, v.34, p.481-90, 2001.

McKINNON, C.D.; WINTER, D.A. Control of whole body balance in the frontal plane during human walking. Journal of Biomechanics, v.26, n.6, p.633-44, 1993.

MILLER, W.E. The heel pad. American Journal of Sports Medicine, v.10, n.1, p.19-21, 1982.

MOFET, H.; RICHARDS, C. L.; MALOUIN, F.; BRAVO, G. Load carring during stair ascent: a demanding functional test. Gait \& Posture, v.1, p.35-44, 1993.

MUELLER, M.J.; DIAMOND, J.E.; DELITTO, A.; SINACORE, D.R. Insensitivity, limited joint mobility and plantar ulcers in patients with diabetes mellitus. Physical Therapy, v.69, p.453-62, 1989.

MUELLER, M.J.; MINOR, S.D.; SAHRMANN, S.A.; SCHAAF, J.A.; STRUBE, M.J. Differences in the gait characteristics of patients with diabetes and peripheral neuropathy compared with age-matched controls. Physical Therapy, v.74, n.4, p.299-308, 1994.

MURRAY, M.P.; SPURR, G.B.; SEPIC, S.B.; GARDNER, G.M.; MOLLINGER, L.A. Treadmill vs. floor walking: kinematics, electromyogram and heart rate. Journal of Applied Physiology, v.59, n.1, p.87-91, 1985.

NASHNER, L.M. Balance adjustments of human perturbed while walking. Journal of Neurophysiology, v.44, n.4, p. 650-64, 1980.

NIGG, B.M.; DE BOER, R.; FISCHER, V. A kinematic comparison of overground and treadmill running. Medicine and Science in Sports and Exercise, v.27, p.98-105, 1995.

NURSE, M.A.; NIGG, B.M. Quantifying a relationship between tactile and vibration sensitivity of the human foot with plantar pressure distribution during gait. Clinical Biomechanics, v.14, n.9, p.66772, 1999.

NURSE, M. A.; NIGG, B.M. Plantar pressures changes following sensory attenuation in human subjects. In: EMED SCIENTIFIC MEETING, Munich, 2000. Book of Abstracts. Munich, Novel, 2000. p.38. 
ORCHARD, T.J.; DORMAN, J.S.; MASER, R.E.; BECKER, D.J.; DRASH, A.L.; ELLIS, D. Prevalence of complications in IDDM by sex and duration. Diabetes, v. 39, p. 1116-24, 1990.

PERRY, J. Gait analysis: normal and pathological function. Thorofare, Slack, 1992.

PIRART, J. Diabetes mellitus and its degenerative complications: a prospective study of 4440 patients observed between 1947 and 1973. Diabetes Care, v.2, p.168-88, 252-63, 1979.

REDMOND, J.M.T. MCKENNA, M.J.; FEINGOLD, M.; AHMAD, B.K., Sensory testing versus nerve conduction velocity in diabetic polyneuropathy. Muscle and Nerve, v.15, n.12, p.1334-9, 1992.

RICHARDSON, J.K; CHING, C.; HURVITZ, E.A. The relationship between electromyographically documented peripheral neuropathy and falls. Journal of American Geriatric Society, v.40, n.10, p.1008-12, 1992.

ROBBINS, S.E.; HANNA, A.M. Running-related injury prevention through barefoot adaptations Medicine and Science in Sports and Exercise, v.19, n.2, p.148-56, 1987.

ROUVIĖRE, H.; DELMAS, A. Anatomie humaine: descriptive, topographique et functionnele. 11.ed. Paris, Masson et cia., 1974.

ROY, S.H.; DE LUCA, C.J.; SCHNEIDER, J. Effects of electrode localization on myoeletric conduction velocity and median frequency estimates. Journal of Applied Physiology, v.61, n.4, p.1510-7, 1986.

SACCO, I.C.N. Estudo dos parâmetros biomecânicos na marcha e limiares somato-sensoriais em pacientes portadores de neuropatia diabética. São Paulo, 1997. 123p. Dissertação (Mestrado) - Escola de Educação Física e Esporte, Universidade de São Paulo.

SACCO, I.C.N.; AMADIO, A.C. A study of biomechanics parameters in gait analysis and somatic sensorial thresholds of diabetic neuropathic patients. Clinical Biomechanics, v.15, n.3, p.196-202, 2000.

SCARLET, J.J.; BLAIS, M.R. Statistics on the diabetic foot. Journal of American Podiatric Medical Association, v.79, n.60, p.306-7, 1989.

SERRÃO, J.C.; AMADIO, A.C. Análise de características dinâmicas do andar em idosos e sua influência na seleção de atividades físicas. In: CONFERENCE OF EUROPEAN GROUP FOR RESEARCH INTO ELDERLY AND PHYSICAL ACTIVITY, 1., Oeiras, 1992. Proceedings. Oeiras, EGREPA, 1992. p.438-45.

SHIAVI, R. Electromyographic patterns in adult locomotion: a conmprehensive review. Journal of Rehabilitation Research and Development, v.22, p.85-98, 1985. 
SIMONEAU, G.G.; DERR, J.A.; ULBRECHT, J.S.; BECKER, M.B.; CAVANAGH, P.R. Diabetic sensory neuropathy effect on ankle joint movement perception. Archives of Physical Medicine Rehabilitation, v.77, p.453-60, 1996.

SHIAVI, R.; GREEN, N. Ensemble averaging of locomotor electromyographic patterns using interpolation. Medical and Biological Engineering and Computing, v.21, p.573-8, 1983.

STRATHY, G.M.; CHAO, E.Y.; LAUGHMAN, R.K. Changes in knee funcyion associated with treadmill ambulation. Journal of Biomechanics, v.16, n.7, p.517-22, 1983.

TAVES, C.; CHARTERIS, J.; WALL, J.C. A speed related kinematic analysis of overground and treadmill walking. In: WINTER, D.A.; NORMAN, R.W.; WEELS, R.P., eds. Biomechanics IX-A. Champaign, Human Kinetics, 1985.

TAXA de prevalência da diabetes mellitus. [on line] Disponível na Internet via www. URL: http://datasus.saude.gov.br/cgi/idb98/d09.htm. Arquivo capturado em 12 de dezembro de 1999.

THE DIABETES controle and complications trial. [on line] Disponível na internet via www. URL: http://datasus.saude.gov.br/cgi/idb98/d09.htm. Arquivo capturado em 20 de setembro de 2000.

THOMAS, P.K. Diabetic neuropathy: epidemiology and pathogenesis. In: PICKUP, J.; WILLIAMS, G., eds. Textbook of diabetes. London, Blackwell Scientific, 1991. p.613-22.

TOWNSEND, M.A.; LAINHART, S.P.; SHIAVI, R.; CAYLOR, J. Variability and biomechanics of synergy patterns of some lower-limb muscles during ascending and descending stairs ans level walking. Medical \& Biological Engineering \& Computing, v.16, p.681-8, 1978.

VAN DEURSEN, R.W.M. The effect of diabetic neuropathy on lower leg muscle spindle function and postural control strategies. Pennsylvania, 1997. 150p. Thesis (Doctorale) - Penn State University.

VAN INGEN SCHENAU, G.J. Some fundamental aspects of the biomechanics of overground versus treadmill locomotion. Medicine and Science in Sports and Exercise, v.12, n.4, p.257-61, 1980.

WALL, J.C.; CHARTERIS, J. The process of habituation to treadmill walking at different velocities. Ergonomics, v.23, n.5, p.425-35, 1980.

A kinematic study of long-term habituation to treadmill walking. Ergonomics, v.24, n.7, p.531-42, 1981.

WARREN, B.L.; JONES, J. Predicting plantar fasciitis in runners. Medicine and Science in Sports and Exercise, v.19, n.1, p.71-3, 1987. 
WEERASURIYA, N.; SIRIBADDANA, S.; WIJEWEERA, I.; DISSANAYEKA, A.; WIJESEKERA, J; FERNANDO, D.J.S. The prevalence of peripheral neuropathy in newly diagnosed patients with noninsulin-dependent diabetes mellitus. Ceylon Medical Journal, v.43, p.19-21, 1998.

WHITE, S.C; YACK, H.J.; TUCKER, C.A.; LIN, H.Y. Comparison of vertical ground reaction forces during overground and treadmill walking. Medicine and Science in Sports and Exercise, v.30, n.10, p.1537-42, 1998.

WHITTLE, M.W. Clinical gait analysis: a review. Human Movement Science, v.15, p.369-87, 1996.

WINTER, D.A. Biomechanical motor patterns in normal walking. Journal of Motor Behavior, v.15, n.4, p.302-30, 1983.

. The biomechanics and motor control of human gait: normal, elderly and pathological. Waterloo, University of Waterloo, 1991.

YOUNGER, D.S.; ROSOKLIJA, G.; HAYS, A.P. Diabetic peripheral neuropathy. Seminars in Neurology, v.18, n.1, p.95-104, 1998.

ZERNICKE, R.F. The emergence of human biomechanics. In: BROOKS, G.A., ed. Perspectives on the academic discipline of physical education. Champaign, Human Kinetics, 1981. p.124-36. 
ANEXO I - Termo de consentimento informado em participação da pesquisa.

\title{
CONSENTIMENTO INFORMADO EM PARTICIPAÇÃO DA PESQUISA
}

\author{
Projeto de Doutorado: \\ Análise biomecânica da marcha humana e repostas sensório-motoras \\ integradas ao diagnóstico de diabéticos neuropatas
}

Autora: Isabel de Camargo Neves Sacco

Orientador: Alberto Carlos Amadio

Este estudo faz parte do projeto de doutorado desenvolvido no Laboratório de Biomecânica da Escola de Educação Física e Esporte da USP. Este projeto tem como objetivo central estudar 0 andar de indivíduos diabéticos portadores da neuropatia diabética. Para isso, o(a) senhor(a) será solicitado(a) a executar alguns testes que estão descritos mais detalhadamente abaixo. Estes testes serão aplicados no laboratório e terão duração de aproximadamente 1 hora. Os resultados, guardadas as devidas identificações, serão analisados e utilizados única e exclusivamente para fins científicos.

- Estágio 1: entrevista pessoal através de um questionário sobre o controle da diabetes e alguns dados sobre doenças relacionadas a diabetes.

- Estágio 2: deitado de bruços, o(a) senhor(a) será avaliado(a) quanto à tolerância à dor e limite de sensibilidade da planta dos pés. Isto será feito através de um aparelho gerador de pulsos elétricos em alguns locais na planta do pé.

- Estágio 3: ainda permanencendo deitado o senhor (a) será avaliado em alguns músculos. Isto será feito através de um aparelho gerador de pulsos elétricos em alguns músculos da perna e coxa.

- Estágio 4: Análise do andar. O(A) senhor(a) caminhará em uma esteira elétrica rolante por aproximadamente 10 a 20 minutos, para coleta de dados e posterior análise.

Após o conhecimento dos testes aos quais serei submetido, concordo em participar deste projeto de pesquisa, na condição de voluntário permitindo a realização destes testes, conforme condições descritas acima, e ainda com a possibilidade de desistência durante o procedimento.

Assinatura do voluntário:

Data: 


\section{ANEXO II - Questionário elaborado para a etapa da entrevista pessoal, para caracterização dos grupos experimentais segundo história clínica da diabetes e cuidados com os pés.}

\section{AVALIACÃO INICIAL}

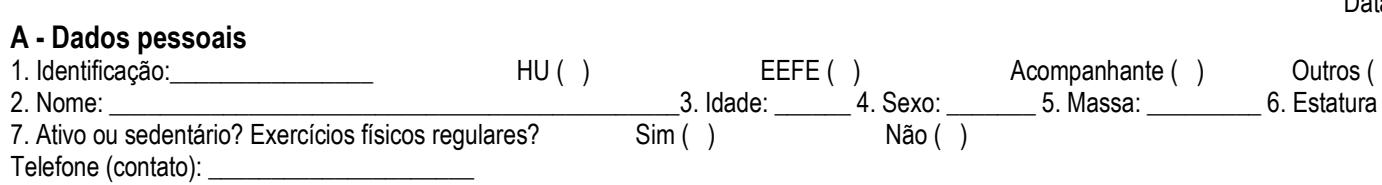

\section{B - História Clínica da Diabetes}
1. Diabético
( ) $\operatorname{sim}$
( ) não
2. Diabetes tipo:
3. Tempo diabetes: Pac. HU Dr(a):
4. Valores aproximados da últimas glicemias: $\mathrm{mg} / \mathrm{dl}$ $\mathrm{mg} / \mathrm{dl}$
5. Doenças associadas:
a. HAS
( )
d. Retinopatia
b. Nefropatia
()
e. Dislipidemia
c. Vasculopatias
insulina (
f. úlcera varicosa
( ) Polineuropatia
( ) f. Artropatia
( ) g. Obesidade
6. Tratamento:
dieta ( )
hipoglicemiantes orais ( )
C - Hábitos diários e Sobre a saúde dos pés
1. Álcoo
$\operatorname{sim}()$
não ( )
Freqüência:
Freqüência:
$\mathrm{ml} /$ semana
cigarros/dia $\mathrm{mg} / \mathrm{dl}$

Data:

3. Sintomatologia associada em membros inferiores. Classifique as questões abaixo segundo o código:

\begin{tabular}{|c|c|c|c|}
\hline 0 - não & 1 - pequenos problemas que podem ser ignorados & 2 - problemas que limitam minhas atividad & rias \\
\hline $\begin{array}{ll}\text { a. Agulhadas ( ) } \\
\text { b. Queimação ( ) }\end{array}$ & $\begin{array}{l}\text { c. Formigamento } \\
\text { d. Sensação de "bota e luva" }\end{array}$ & $\begin{array}{l}\text { e. Dor ( ) } \\
\text { f. dormência ( ) }\end{array}$ & $\begin{array}{l}\text { g) caimbra ( ) } \\
\text { h) outras ( ) }\end{array}$ \\
\hline
\end{tabular}

4. Momento do dia em aparecem estas sensações:
a. não apresenta ( )
b. em repouso noturno ( )
c. em repouso diurno ( )
d. em atividade ( )
e. outras ( )
5. Presença de calos?
$\operatorname{Sim}()$
Não ( )

6. Local calos:

a. metatarso lateral ( )

b. metatarso medial ( )

c. calcanhar ( )

d. hálux ( )

e. dedos externo ( )

7. Cuidado com calos:

$\begin{array}{ll}\text { a. reduz ( ) } & \text { b. não reduz ( ) }\end{array}$

a. lixa ( ) b. lâmina ( )

c. alicate ( )

d. pedicure ( )

e. pedra ( )

f. outros ( )

8. História prévia de ulcerações:

$\operatorname{sim}($ ) não ( )

9. Úlceras presentes?

$\operatorname{Sim}($ )

não ( )

onde?

\section{D - Avaliação Objetiva da dor e sensibilidade}

\begin{tabular}{|l|c|c|c|c|}
\hline & \multicolumn{2}{|c|}{ CRONAXIA SENITIVA (ms) } & \multicolumn{2}{|c|}{ AVALIAÇÃO DA DOR (mA) } \\
\hline & E & D & D \\
\hline Calcanhar & & & & \\
\hline Meio-pé & & & & \\
\hline Antepé medial: 1a e 2a cab. metat. & & & & \\
\hline Antepé lateral: 3a e 4a cab. metat. & & & & \\
\hline Hálux & & & & \\
\hline
\end{tabular}

E - Avaliação da cronaxia motora

\begin{tabular}{|l|c|c|}
\hline & \multicolumn{2}{|c|}{ CRONAXIA MOTORA (ms) } \\
\hline Gastro lateral & D & E \\
\hline M. tibial anterior & & \\
\hline M. vasto Latreral & & \\
\hline
\end{tabular}

(baseado Redmond, J.M.T. McKenna, M.J.; Feingold, M.; Ahmad, B.K., Muscle and Nerve, 15: 1334-9, 1992) 
ANEXO III - Resultados do pré-experimento - teste piloto realizado durante a elaboração do protocolo experimental.

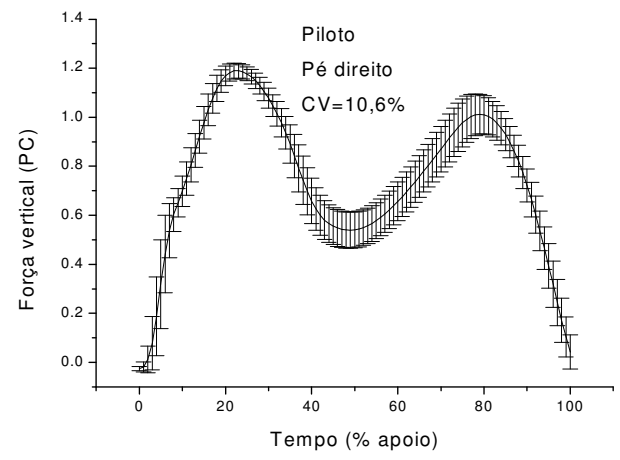

Curva média e desvios-padrão da componente vertical da força reação do solo durante 0 andar em esteira rolante de um sujeito no experimento piloto ( $\mathrm{n}=50$ passos).
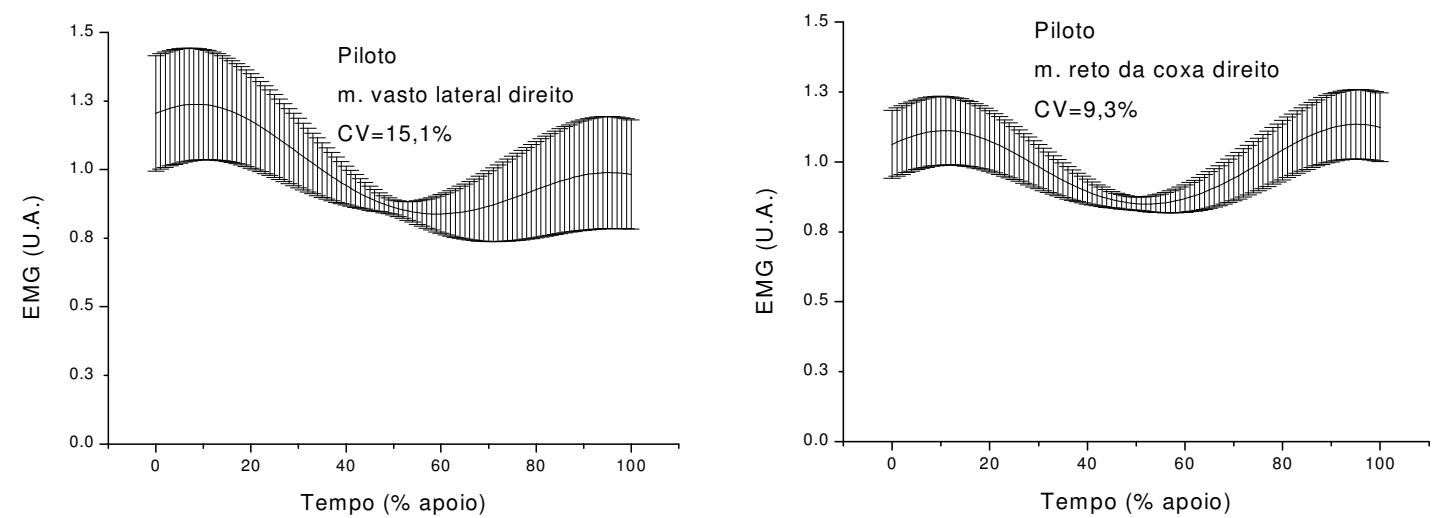

Curvas médias e desvios padrão da EMG do $\mathrm{m}$. vasto lateral direito e $\mathrm{m}$. reto da coxa direito durante $\mathrm{o}$ andar em esteira do sujeito no experimento piloto ( $n=50$ passos).

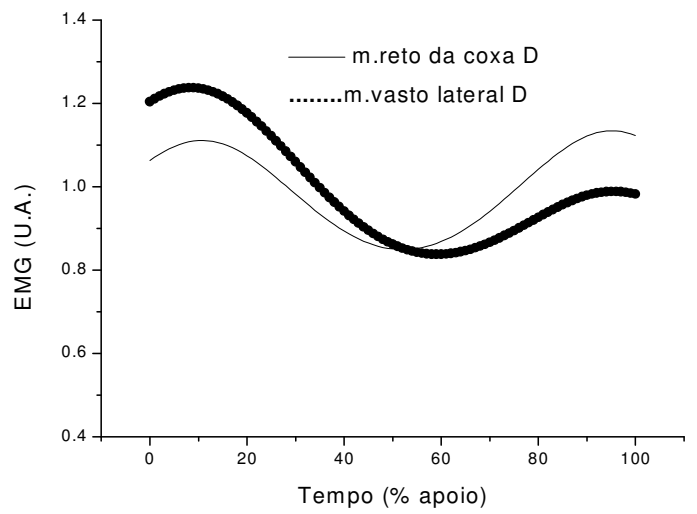

Curvas médias dos envoltórios lineares da EMG dos $\mathrm{m}$. vasto lateral direito e $\mathrm{m}$. reto da coxa direito durante 0 apoio na marcha em esteira do sujeito no experimento piloto ( $n=50$ passos). 
ANEXO III- $\quad$ Resultados do pré-experimento - teste piloto realizado durante a elaboração do protocolo experimental (cont.)

Padrão de recrutamento temporal e magnitudes de ativação do $\mathrm{m}$. reto da coxa direito e $\mathrm{m}$. vasto lateral direito durante 0 andar em esteira rolante do sujeito no experimento piloto.
m. reto da coxa $D$
m. vasto lateral D

\begin{tabular}{lcccc}
\hline & $\begin{array}{c}\text { Recrutamento temporal } \\
(\%)\end{array}$ & Magnitude (U.A.) & $\begin{array}{c}\text { Recrutamento temporal } \\
(\%)\end{array}$ & Magnitude (U.A.) \\
\hline $1^{\circ}$ pico de ativação & 11 & 1,11 & 9 & 1,24 \\
\hline Fim da 1a ativação & 52 & & 59 & 0,99 \\
\hline $2^{\circ}$ pico de ativação & 95 & 1,13 & 95 & \\
\hline
\end{tabular}




\section{ANEXO IV- Função Matemática GAITWAY desenvolvida em ambiente Matlab v. 5.3.}

\section{Função GAITWAY desenvolvida em ambiente Matlab v. 5.3}

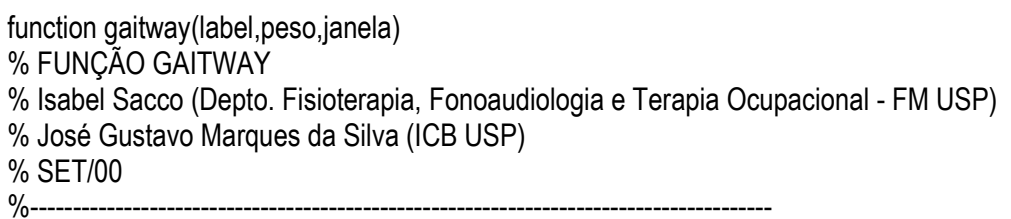

\% GAITWAY recebe arquivos gerados na esteira Gaitway -Kistler de FRS e determina as variáveis dinâmicas e temporais das curvas de $\%$ cada arquivo e calcula a média e sd de cada sujeito. O programa calculará o primeiro pico da força vertical reação do solo, o segundo $\%$ pico, a força mínima vertical, a taxa de crescimento do primeiro pico de força vertical, a taxa de crescimento do segundo pico da força $\%$ vertical, o tempo de apoio simples e o tempo de apoio duplo.

$\%$

$\%$ A rotina vai selecionar os extremos dos passos automaticamente e vai mostrar curva a curva por 3 segundos (isso pode mudar, se mudar a função). Voce deve anotar em um papel quais as curvas cujos extremos nao estão selecionados de forma correta. Entao, você $\%$ poderá corrigir os extremos de inicio e fim com o mouse, da seguinte forma:

$\%$ 1) A rotina irá perguntar qual passo a ser corrigido? e voce digita o numero do primeiro passo a ser corrigido.

\% 2) Para iniciar a correção, você deve corrigir primeiro o início do passo: clicar com o botão esquerdo do mouse no início do passo e em $\%$ seguida no fim do passo. Apertar o "enter" no fim.

\% 3) Se você nao quiser corrigir o início, você deve clicar com o botão direito do mouse primeiro em qualquer lugar da curva e em seguida $\%$ corrigir o fim com o botão esquerdo e depois aperta "enter" no fim.

\% 4) Se você nao quiser corrigir o fim, você deve corrigir o início com o botão esquerdo do mouse e em seguida clicar em qualquer lugar

$\%$ da curva com o botão direito do mouse e depois apertar "enter" no fim.

$\%$

\%ISSO IRÁ SE REPETIR PARA TODOS OS PASSOS DE TODOS OS ARQUIVOS QUE VOCÊ FOR ANALISAR. $\%$

$\%$ ROTINA GAITWAY GERA

$\%$ 1) UM Arquivo (em ASCII) com extensão .dt contendo:

$\% \quad-20$ linhas - 20 sujeitos (isso pode ser alterado conforme o tamanho de sua amostra)

$\% \quad-30$ colunas - 8 variáveis (média( $\mathrm{x}$ ), desvio padrão(sd) de cada uma) para os dois pés ( $\mathrm{r}$ - right e l- left)

$\% \quad$ - As colunas seguem a ordem: $F y 1 r(x, s d)$, Fy1l(x,sd), Fy2r(x,sd), Fy2l(x,sd), Fyminr(x,sd), Fyminl(x,sd), Deflexãor(x,sd),

$\% \quad$ Deflexãol $(x, s d)$, TxCrescimentoF1r $(x, s d)$, TxCrescimentoF1l( $x, s d)$, TxCrescimentoF2r $(x, s d)$,

$\% \quad$ TxCrescimentoF2I(x,sd), Tempo apoio simplesr(x,sd), Tempo apoio simplesL(x,sd), Tempo apoio

$\% \quad$ duplo(x,sd)

\% Conforme os arquivos vao sendo analisados, as variáveis são acrescentadas a este arquivo com 20 linhas e 30 colunas.

if nargin<2;error('Esta falta parametros > digite: help gaitway'); end;

if nargin<3;janela=100; end;

\%ABRE TODOS OS ARQUIVOS que tenham esta lógica de dar nome para o arquivo:

$\%$ GC(grupo)01(sujeito)T1(tentativas)

grupo=label(1:2); \% a 1a e 2a letra do label eh o grupo (ex: gc)

sujeito=label(3:4); \% a 3a e 4a letra do label eh o sujeito (ex: 02)

tentativa=\{'t1','t2','t3'\};

ext='.txt';

if grupo=='gc';caminho='//boteco/isabel/matlab/gc/';

else caminho='//boteco/isabel/matlab/gd/'; \% ALTERAR O CAMINHO

end;

clc;

disp('FRS2000: Carregando arquivos');

pause(.1);

$\mathrm{JR} 1=1 ; \mathrm{JL} 1=1 ; \mathrm{JR} 2=1 ; \mathrm{JL} 2=1 ; \mathrm{JR} 3=1 ; \mathrm{JL} 3=1 ;$

$\mathrm{J} 4=1 ; \mathrm{J} 5=1 ; \mathrm{J} 6=1 ; \mathrm{J} 7=1 ; \mathrm{J} 8=1$;

for tent=1:length(tentativa)

\%disp('- 
ANEXO IV- Função Matemática GAITWAY desenvolvida em ambiente Matlab v. 5.3 (cont.)

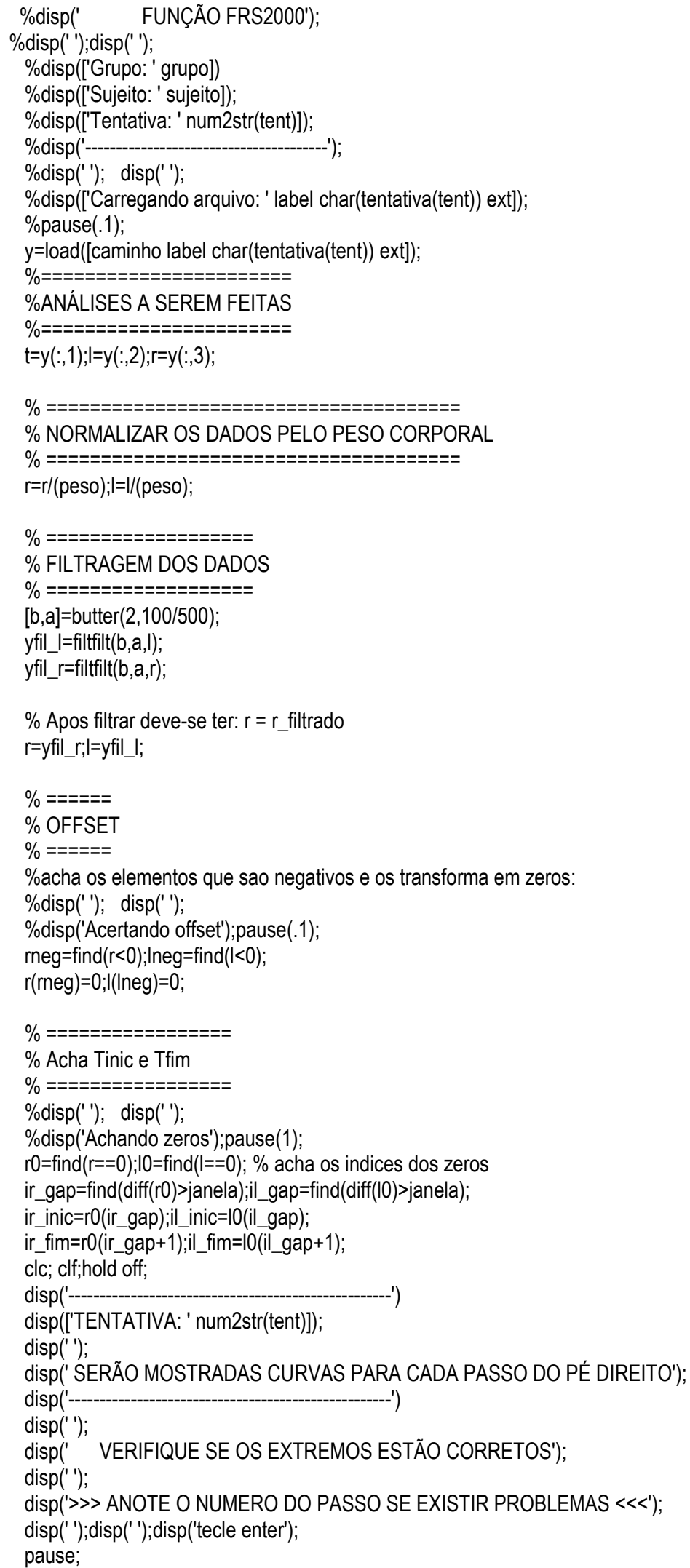


ANEXO IV- Função Matemática GAITWAY desenvolvida em ambiente Matlab v. 5.3 (cont.)

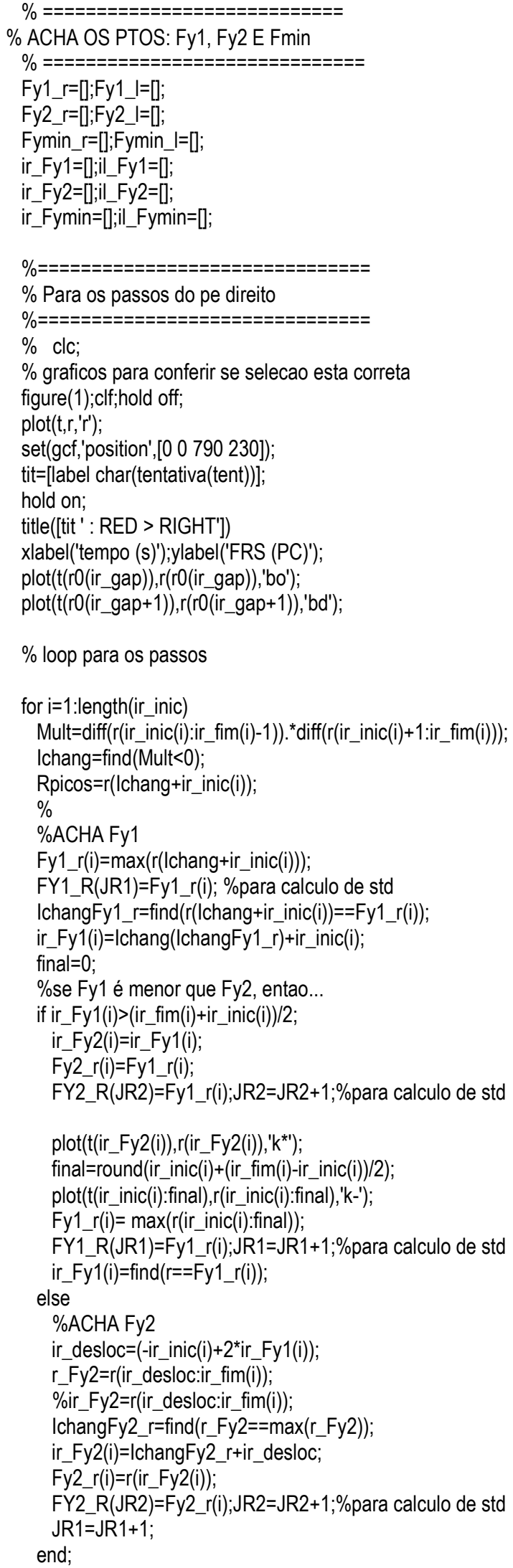


ANEXO IV- Função Matemática GAITWAY desenvolvida em ambiente Matlab v. 5.3 (cont.)

plot(t(ir_Fy1(i)),r(ir_Fy1(i)),'ko');hold on;

\%plot(t(ir_desloc:ir_fim(i)),ir_Fy2,'k-');

plot(t(ir_Fy2(i)),r(ir_Fy2(i)),'k*');

$\%$

\%ACHA Fymin

Fymin_r(i)=min(r(ir_Fy1(i):ir_Fy2(i)));

FYMIN_R(JR3)=Fymin_r(i);JR3=JR3+1;\%para calculo de std

$\%$ se Fymin possuir 2 minimos iguais: min(find) vai resolver

ir_Fymin(i)=min(find(r(ir_Fy1(i):ir_Fy2(i))==Fymin_r(i)))+ir_Fy1(i)-1;

plot(t(ir_Fymin(i)),r(ir_Fymin(i)),'bd');

axis([t(ir_inic(i)) t(ir_fim(i)) 0 max(r)]);

title([tit ' : RED > RIGHT : passo=' num2str(i)])

pause(2);

end;

axis([t(ir_inic(1)) t(ir_fim(end)) 0 max(r)]);

title([tit ' : RED > RIGHT '])

$\%$ Corrige os inicios e fins dos passos direito

corr=20;

clc;

$\operatorname{disp}('------1)$;

disp(' CORRIGE EXTREMOS')

$\operatorname{disp}(')$;

disp(['Sujeito: ' label]);

disp(['Tentativa: ' num2str(tent)]);

disp(' ');

disp('Se nao corrige nada >0 ');

disp('-

$\operatorname{disp}(')$;

while corr $\sim=0$

disp(['Qual passo (1 a ' num2str(length(ir_inic)) ')?'])

corr=input('>');

$\operatorname{disp}($ ' ');disp(' ');

if corr $=0$

axis([t(ir_inic(corr)) t(ir_fim(corr)) $0 \max (I)])$

title([tit ' : RED > RIGHT : passo=' num2str(corr)])

[t_ginput,r_ginput,buttom] =ginput(1);

if buttom $==1$;

inic_g=find (t>t_ginput(1));

ir_inic(corr)=inic_g(1);

end;

[t_ginput,r_ginput,buttom]=ginput(1);

if buttom==1;

fim_g=find(t<t_ginput(1));

ir_fim(corr)=fim_g(end);

plot(t(ir_inic(corr)), 0, 'mo')

plot(t(ir_fim(corr)), 0 ,'md')

end

\%pause;

axis([t(ir_inic(1)) t(ir_fim(end)) $0 \max (r)])$;

title([tit ' : RED > RIGHT '])

end;

end; 
ANEXO IV- Função Matemática GAITWAY desenvolvida em ambiente Matlab v. 5.3 (cont.)

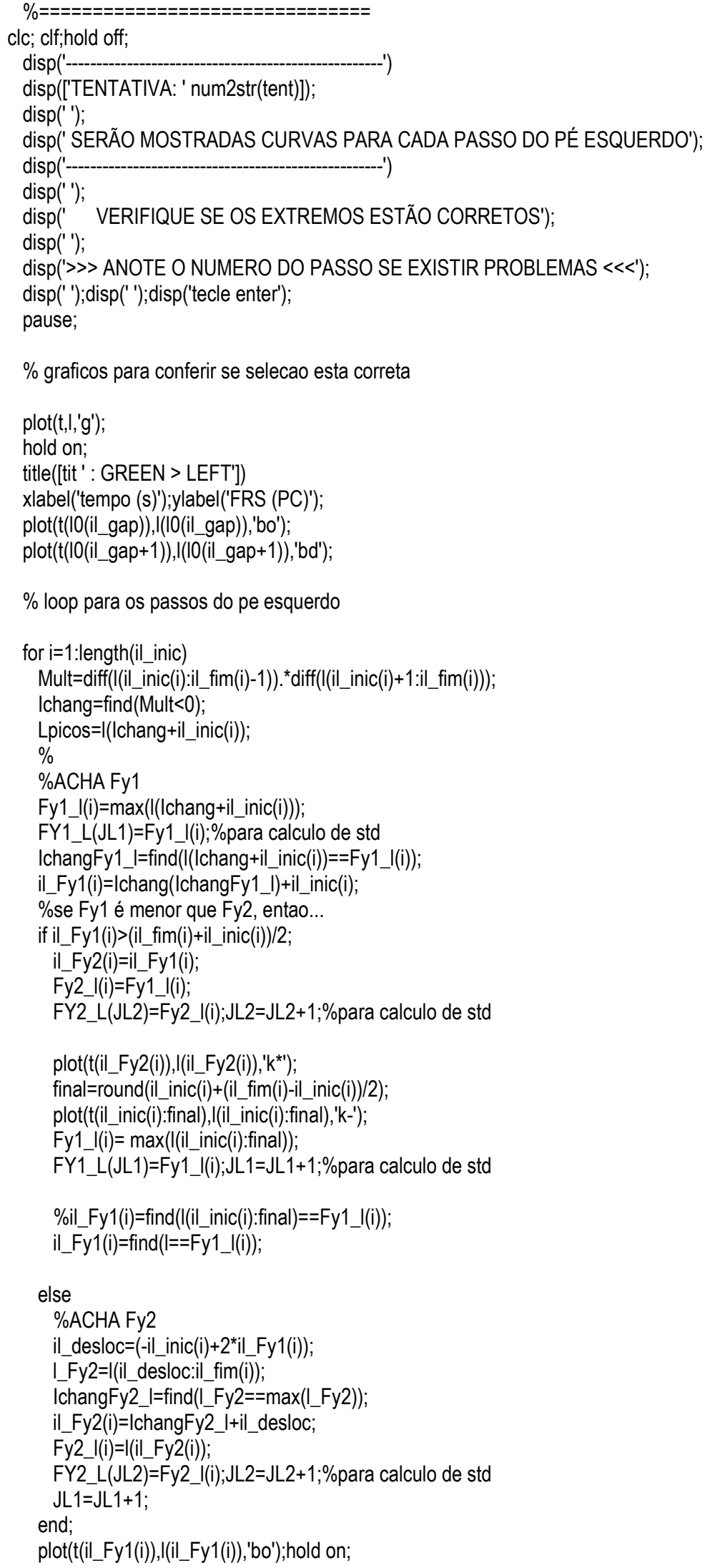




\section{ANEXO IV- Função Matemática GAITWAY desenvolvida em ambiente Matlab v. 5.3 (cont.)}

\%plot(t(il_desloc:il_fim(i)),il_Fy2,'k-'); plot(t(il_Fy2(i)),I(il_Fy2(i)),'k*');

$\%$

\%ACHA Fymin

Fymin_I(i)=min(I(il_Fy1(i):il_Fy2(i)));

FYMIN_L(JL3)=Fymin_(i);JL3=JL3+1;\%para calculo de std

$\%$ se Fymin possuir 2 minimos iguais: $\min ($ find) vai resolver

il_Fymin(i)=min(find(I(il_Fy1(i):il_Fy2(i))==Fymin_l(i)))+il_Fy1(i)-1;

plot(t(il_Fymin(i)),,(il_Fymin(i)),'bd');

axis([t(il_inic(i)) t(il_fim(i)) $0 \max (I)])$;

title([tit ' : GREEN > LEFT : passo=' num2str(i)])

pause(2);

end; \% fim do loop para os passos do pé esquerdo

axis([t(il_inic(1)) t(il_fim(end)) 0 max(l)]);

title([tit ' : GREEN > LEFT '])

$\%$ Corrige os inicios e fins dos passos esquerdos

corr=20;

clc;

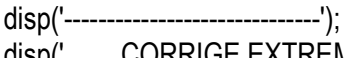

disp(' CORRIGE EXTREMOS')

disp(' ');

disp(['Sujeito: ' label]);

disp(['Tentativa: ' num2str(tent)]);

$\operatorname{disp}('$ ');

disp('Se nao corrige nada >0 ');

disp('------o---');

$\operatorname{disp}(')$;

while corr $=0$

disp(['Qual passo (1 a ' num2str(length(ir_inic)) ')?'])

corr=input('>');

$\operatorname{disp}\left({ }^{\prime \prime}\right) ; \operatorname{disp}('$ ');

if corr $=0$

axis([t(il_inic(corr)) t(il_fim(corr)) 0 max(I)])

title([tit ' : GREEN > LEFT : passo=' num2str(corr)])

[t_ginput,I_ginput,buttom]=ginput(1);

if buttom $==1$;

inic_g=find(t>t_ginput(1));

il_inic(corr)=inic_g(1);

end;

[t_ginput,I_ginput,buttom]=ginput(1);

if buttom==1;

fim_g=find(t<t_ginput(1));

il_fim(corr)=fim_g(end);

plot(t(il_inic(corr)), , ,'mo')

plot(t(il_fim(corr)),0,'md')

end;

axis([t(il_inic(1)) t(il_fim(end)) 0 max(I)]);

title([tit ' : RED > RIGHT '])

$$
\text { end; }
$$

end

clc;

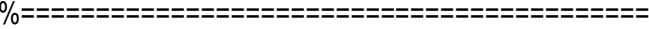

$\%$ ACHA OS TEMPOS DE APOIO SIMPLES E DUPLO

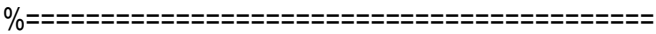

Tinic_r=t(ir_inic);Tinic_l=t(il_inic);

Tfim_r=t(ir_fim);Tfim_l=t(il_fim); 


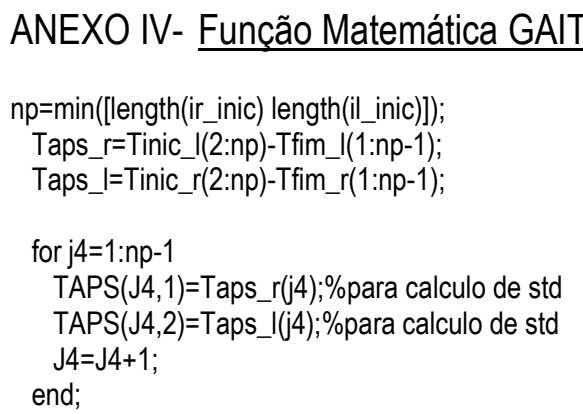

\%acha qual pé começou o teste, se começar com o direito (condição negativa, $\%$ entao executa do primeiro modo, senao comecou com o pé esquerdo e executa $\%$ else.

if Tinic_r(1)-Tinic_l(1)<0; \% inicio pé $D$

Tapd=Tfim_r(1:np)-Tinic_I(1:np); \% apoio duplo com pé direito comecando else

Tapd=Tfim_l(1:np)-Tinic_r(1:np);

end

for $\mathrm{j} 5=1$ :np

TAPD(J5)=Tapd(j5);\%para calculo de std $\mathrm{J} 5=\mathrm{J} 5+1$

end;

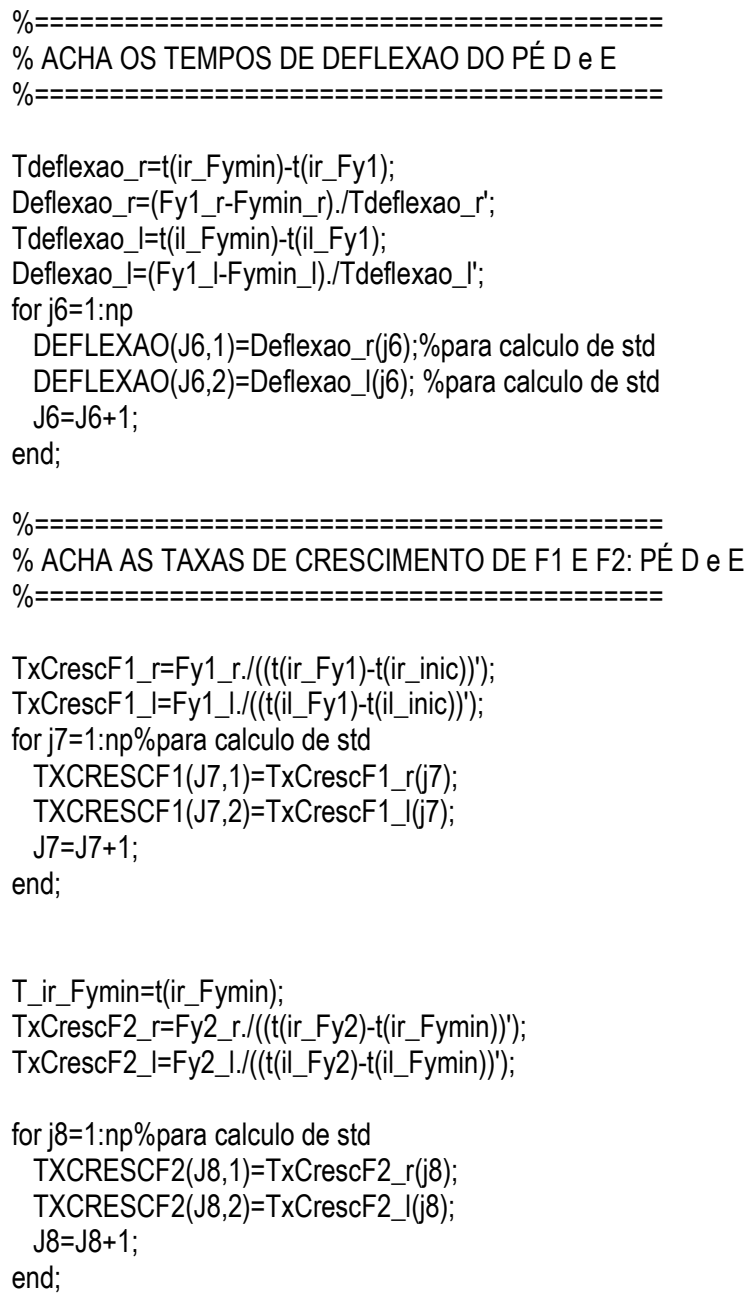


ANEXO IV- Função Matemática GAITWAY desenvolvida em ambiente Matlab v. 5.3 (cont.) end; \%END DAS TENTATIVAS

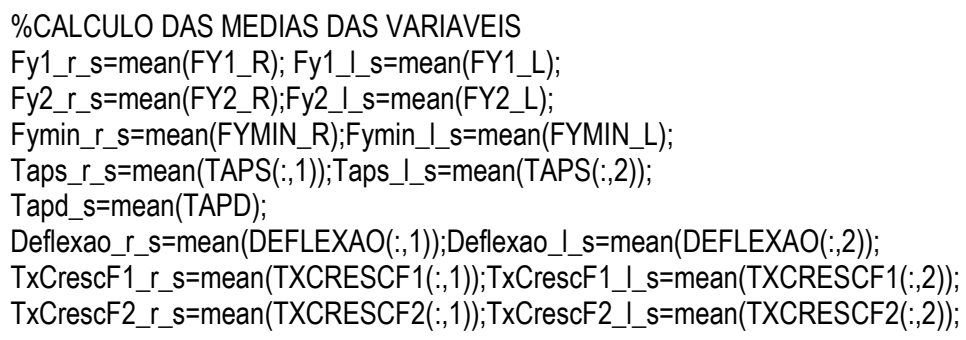




\section{ANEXO IV- Função Matemática GAITWAY desenvolvida em ambiente Matlab v. 5.3 (cont.)}

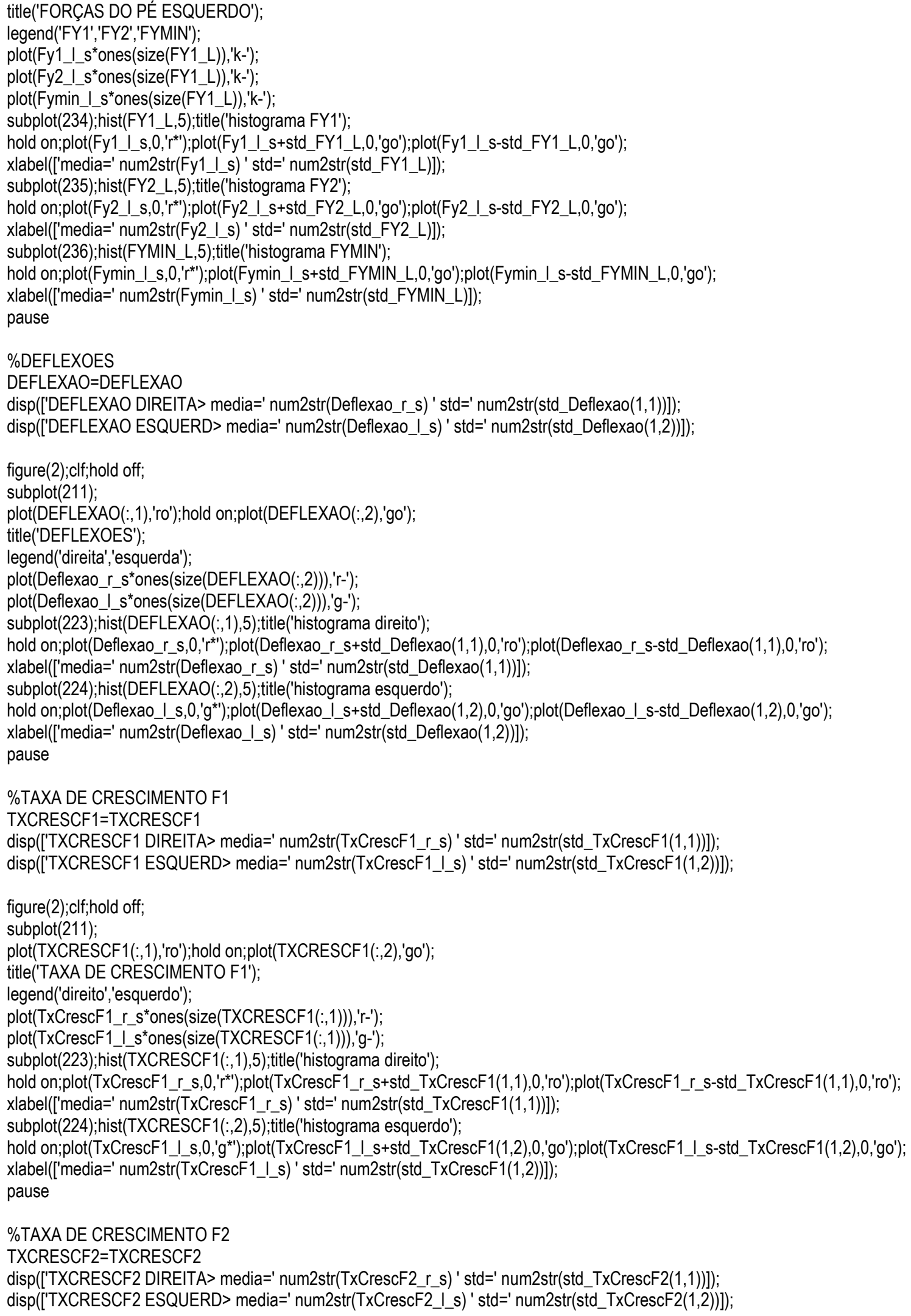




\section{ANEXO IV- Função Matemática GAITWAY desenvolvida em ambiente Matlab v. 5.3 (cont.)}

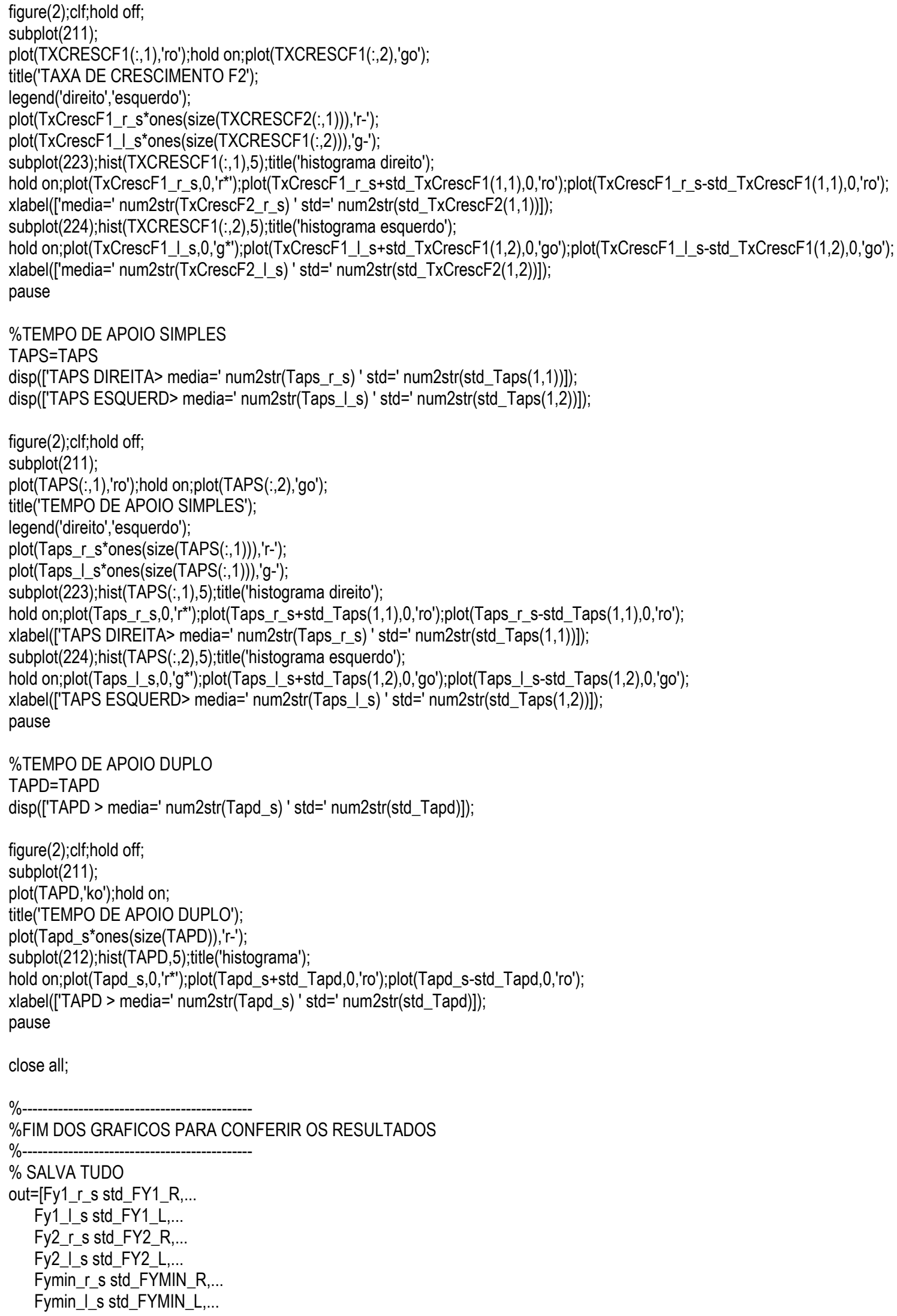


ANEXO IV- Função Matemática GAITWAY desenvolvida em ambiente Matlab v. 5.3 (cont.)

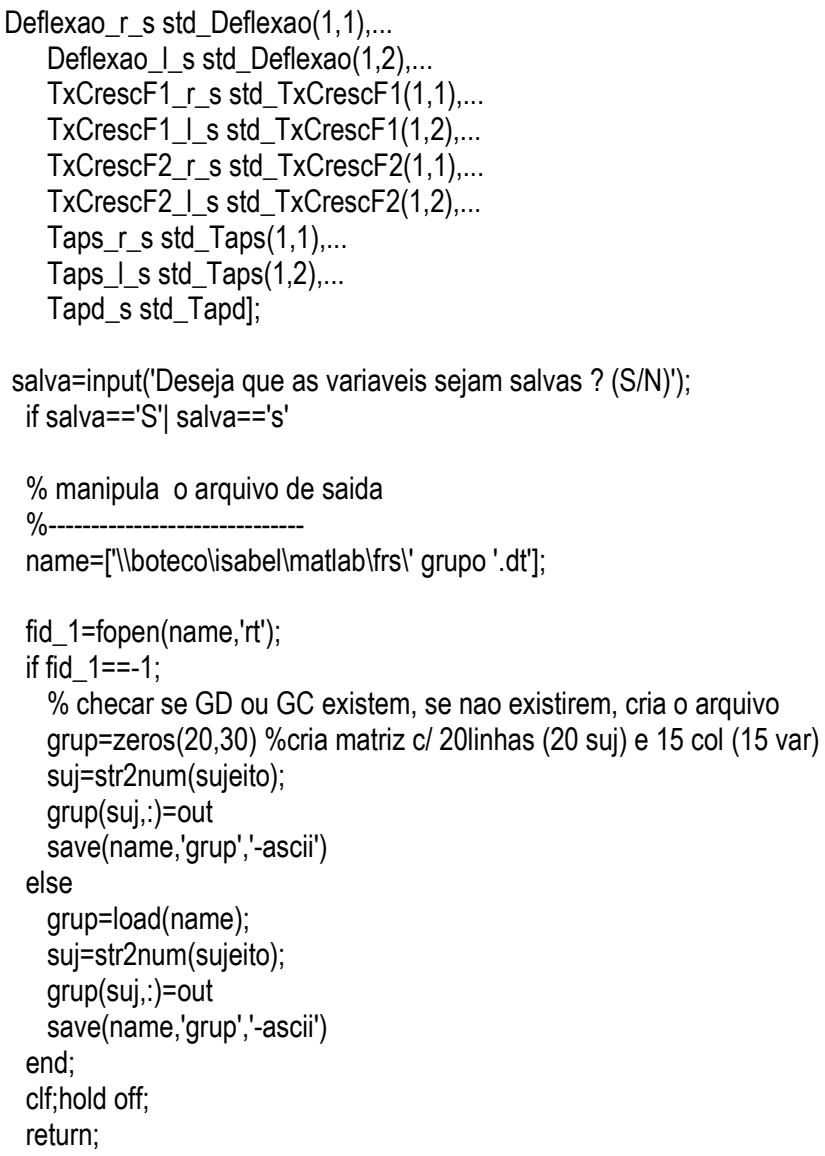


ANEXO V- Função Matemática BIONICA desenvolvida em ambiente Matlab v. 5.3.

\title{
Função BIONICA desenvolvida em ambiente Matlab v. 5.3
}

\author{
function bionica(prefs) \\ $\%$ BIONICA calcula o envoltório linear, normaliza a base de tempo e a intensidade, \\ $\%$ calcula a média das curvas e o coeficiente de variação (CV). \\ $\%$ \\ $\%$ O programa, por meio de perguntas feitas na janela principal do MATLAB, determinará \\ $\%$ as análises a serem feitas. Para cada pergunta, o valor default é dado dentro de \\ $\%$ colchetes, para aceitá-lo, basta teclar ENTER. \\ $\%$ As opções podem ser salvas como um arquivo de preferências que pode ser carregado \\ $\%$ logo no início do programa, ex.: bionica('a:Idados lprefs.m'), e editado separadamente. \\ $\%$ \\ \% Após a escolha das análises, é feita a seleção de todos os arquivos (simultânea) \\ $\%$ que pretende-se analisar. Os arquivos devem estar num mesmo diretório. No caso de seleção \\ $\%$ simultânea, o último arquivo a ser seleciondado é o primeiro a ser analisado e assim por \\ $\%$ diante. Isto é crítico só para o caso de normalização por valores externos. \\ $\%$ Selecione os extremos de quantas tentativas desejar por arquivo (selecione com o mouse \\ $\%$ e aceite a seleção pressionando qualquer tecla); ao final da última tentativa tecle ENTER. \\ $\%$ \\ $\%$ Se existe uma coluna de tempo nos arquivos, ela dever ser a primeira e estar em segundos. \\ $\%$ No processo de filtragem é utilizado um filtro passa baixa Butterworth de 4a ordem e \\ $\%$ atraso de fase zero. Caso esse filtro não seja disponível, é utilizado um filtro de \\ \% média móvel. Há a opção de um segundo processo de filtragen caso haja colunas que ainda \\ $\%$ não foram filtradas. \\ $\%$ \\ \% Para a entrada dos valores de normalização, o número de valores deve ser igual ao número \\ $\%$ de colunas a serem normalizadas ou igual ao número de colunas vezes o número de arquivos. \\ $\%$ Neste caso, entre os valores para o primeiro arquivo, depois para o segundo e assim por \\ $\%$ diante, sempre separados por um espaço. Há a opção de um segundo processo de normalização \\ $\%$ caso haja colunas que ainda não foram normalizadas. \\ $\%$ \\ $\%$ Ao final, é gerado um gráfico contendo os resultados das análises para cada coluna e um \\ $\%$ arquivo com estes resultados onde serão salvos média, desvio padrão e o coeficiente de \\ $\%$ variação para cada conjunto de colunas. \\ $\%$ \\ $\%$ Este software é gratuito, não pode ser comercializado e nem usado para fins lucrativos. \\ $\%$ Nao me responsabilizo por possiveis erros no software nem me predisponho a prestar acessoria. \\ \% Sugestões e comentários são bem vindos e devem ser enviados para mduarte@usp.br \\ \% É desejável que este software seja devidamente citado quando usado em trabalhos científicos. \\ $\%$ \\ \% Versão 2.02 - Matlab5.3\&SPtoolbox@MSWIN9X\&NT. \\ \% Marcos Duarte mduarte@usp.br 1996-2000 \\ clc \\ msg = sprintf('In $\quad$ BIONICA \%s',date); disp(msg) \\ if nargin \\ tmp = textread(prefs, '\%s','delimiter','tt','whitespace','In','commentstyle','matlab'); \\ prefs $=$ cell2struct(tmp (2:2:end)',tmp(1:2:end)',2); \\ prefsfile = 's'; \\ else \\ help bionica \\ msg = sprintf(' PRESSIONE QUALQUER TECLA PARA COMEÇARIn'); disp(msg) \\ pause \\ prefsfile = lower(input(' Deseja carregar arquivo de preferências? (s/[n]): ','s')); \\ if isempty(prefsfile), prefsfile = ' $n$ '; end \\ if prefsfile $==$ ' $s$ ' \\ [file,pathname] = uigetfile('prefs.m', 'Selecione arquivo de preferências'); \\ if file
}




\section{ANEXO V- Função Matemática BIONICA desenvolvida em ambiente Matlab v. 5.3 (cont.)}

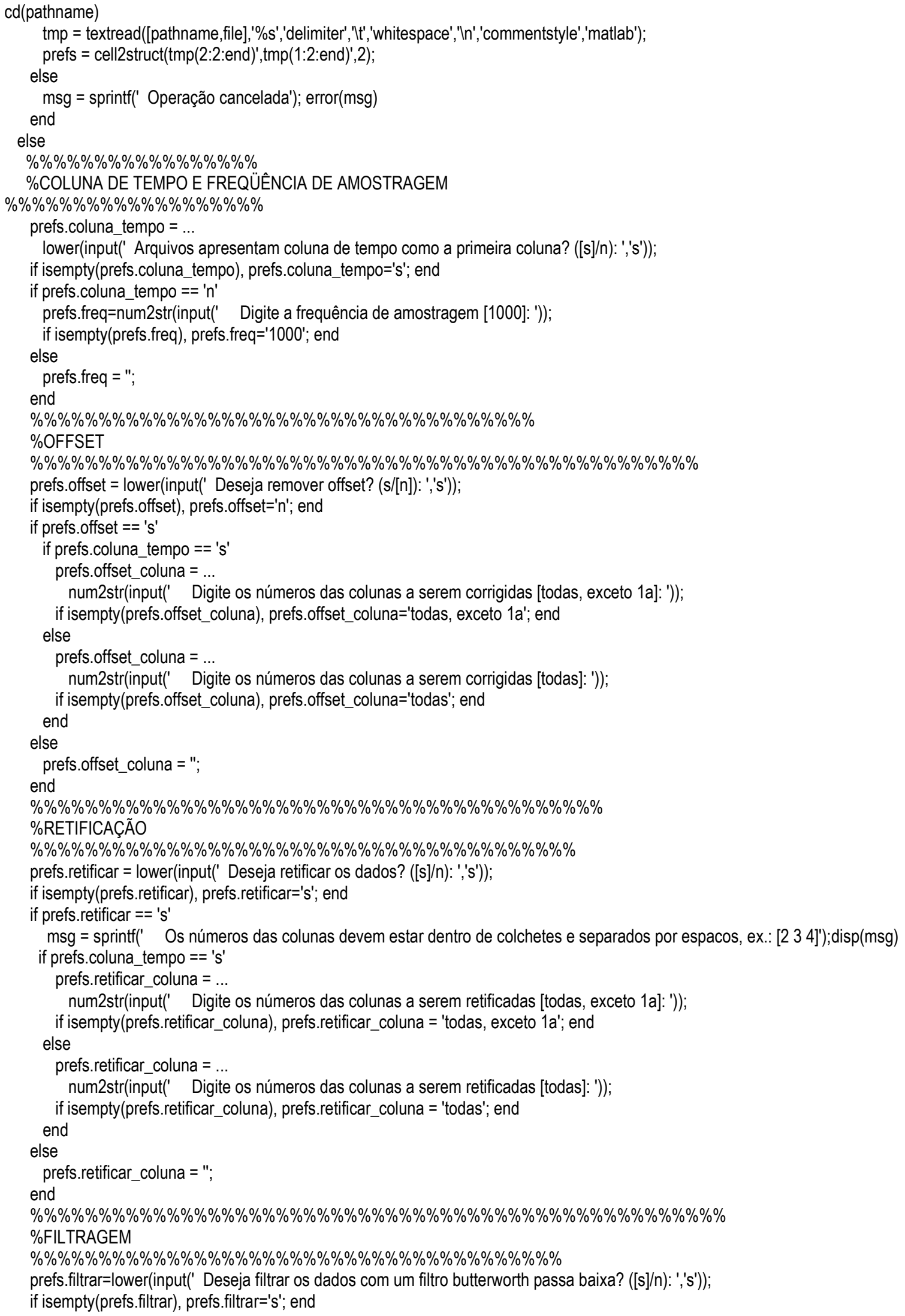




\section{ANEXO V- Função Matemática BIONICA desenvolvida em ambiente Matlab v. 5.3 (cont.)}

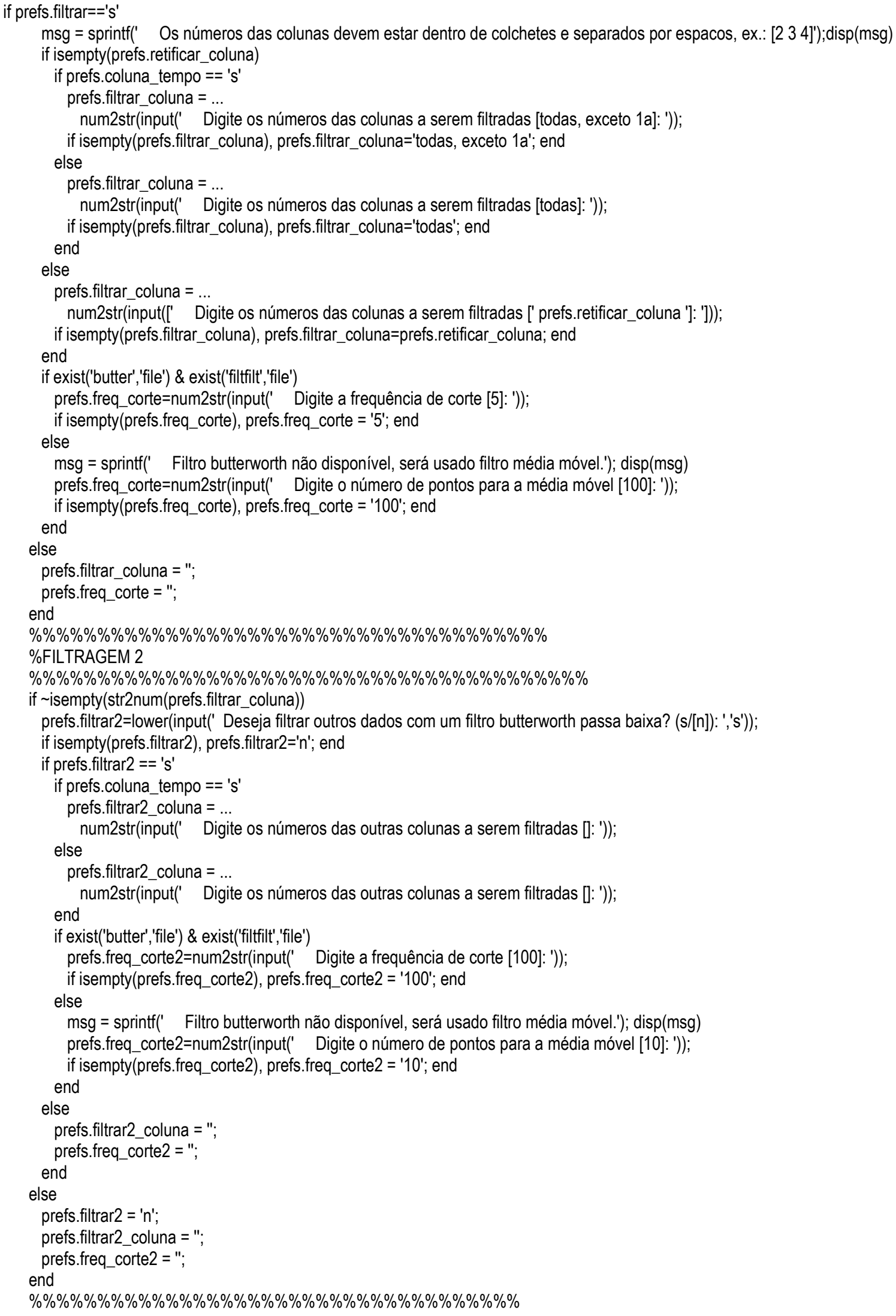




\section{ANEXO V- Função Matemática BIONICA desenvolvida em ambiente Matlab v. 5.3 (cont.)}

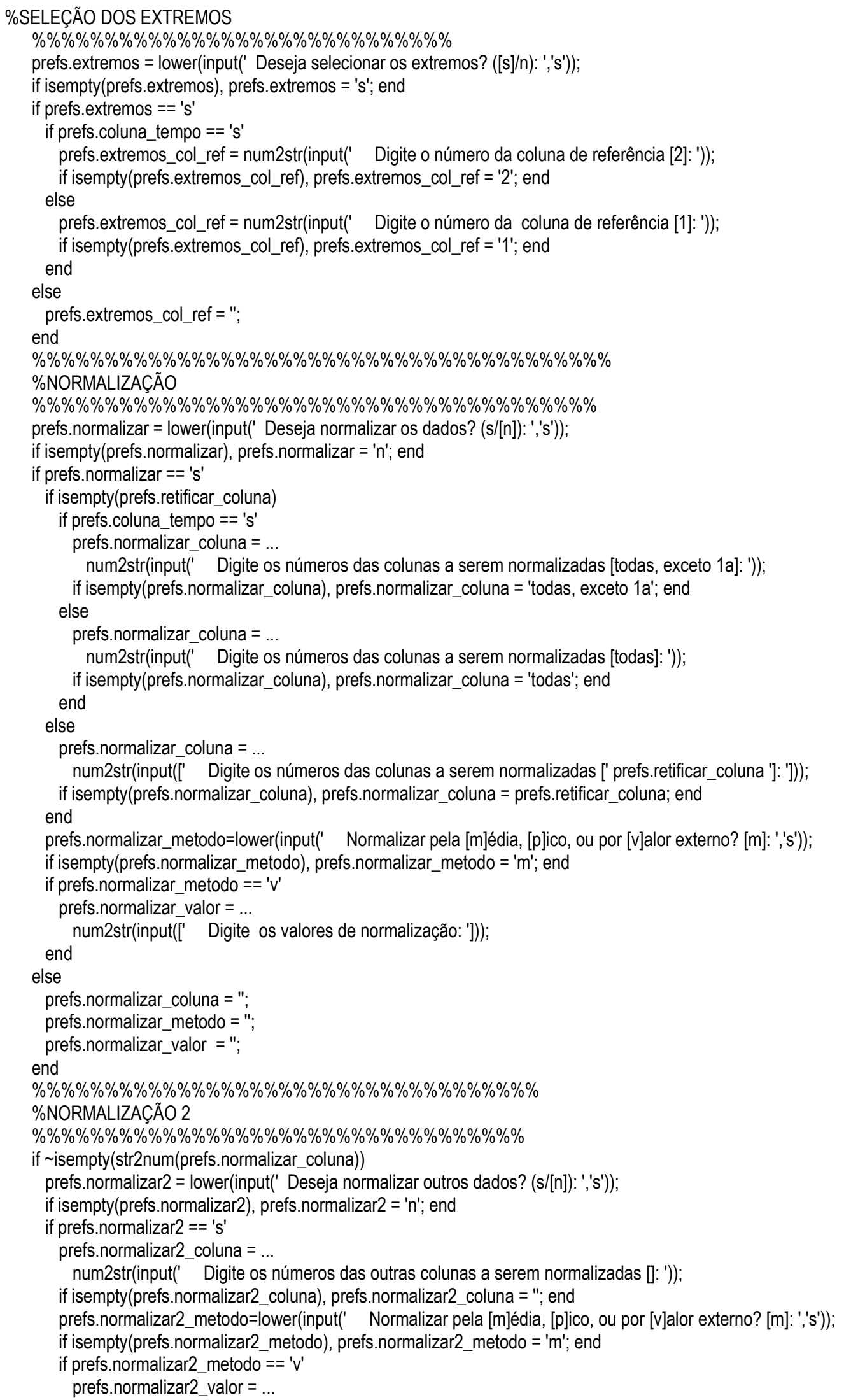




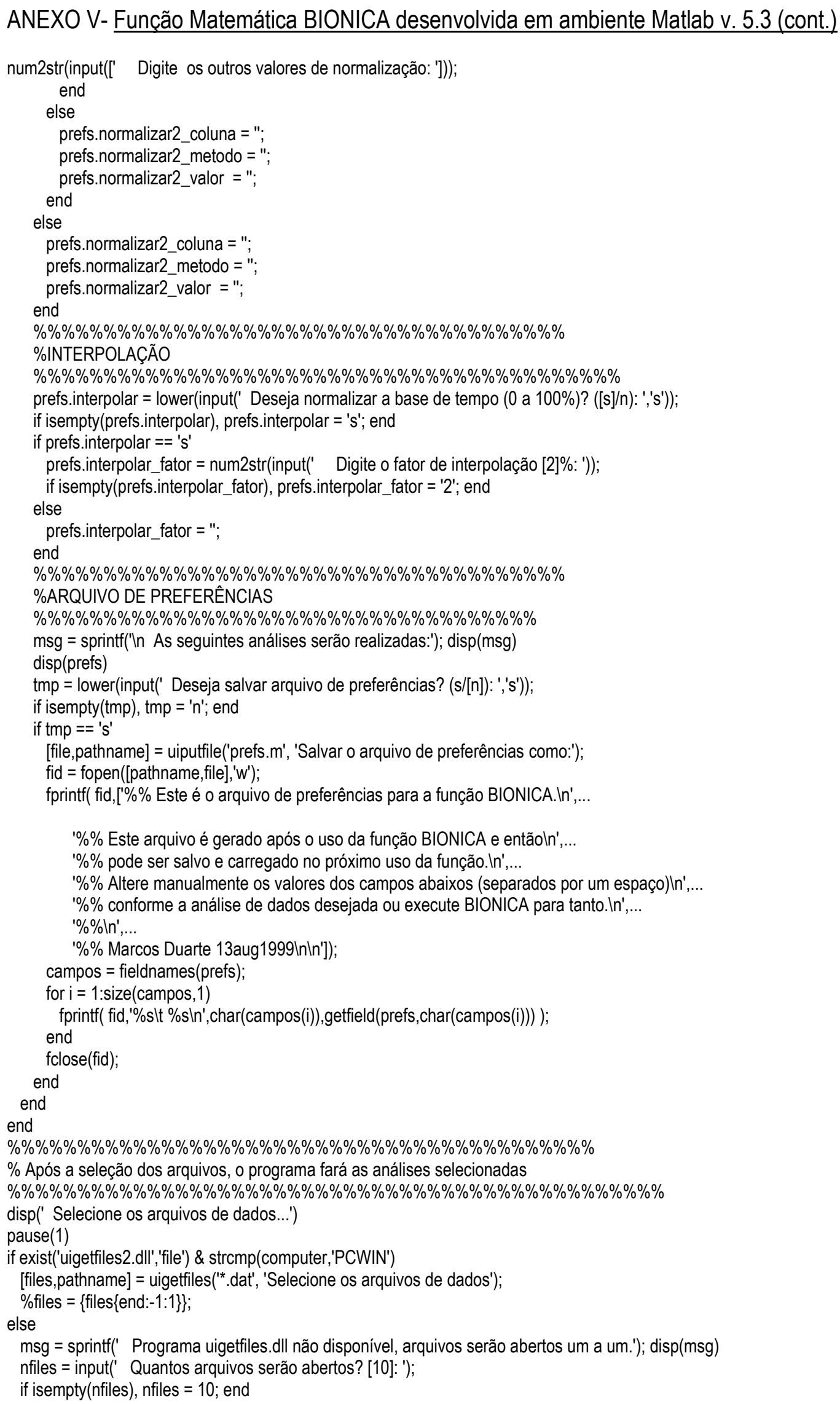




\section{ANEXO V- Função Matemática BIONICA desenvolvida em ambiente Matlab v. 5.3 (cont.)}

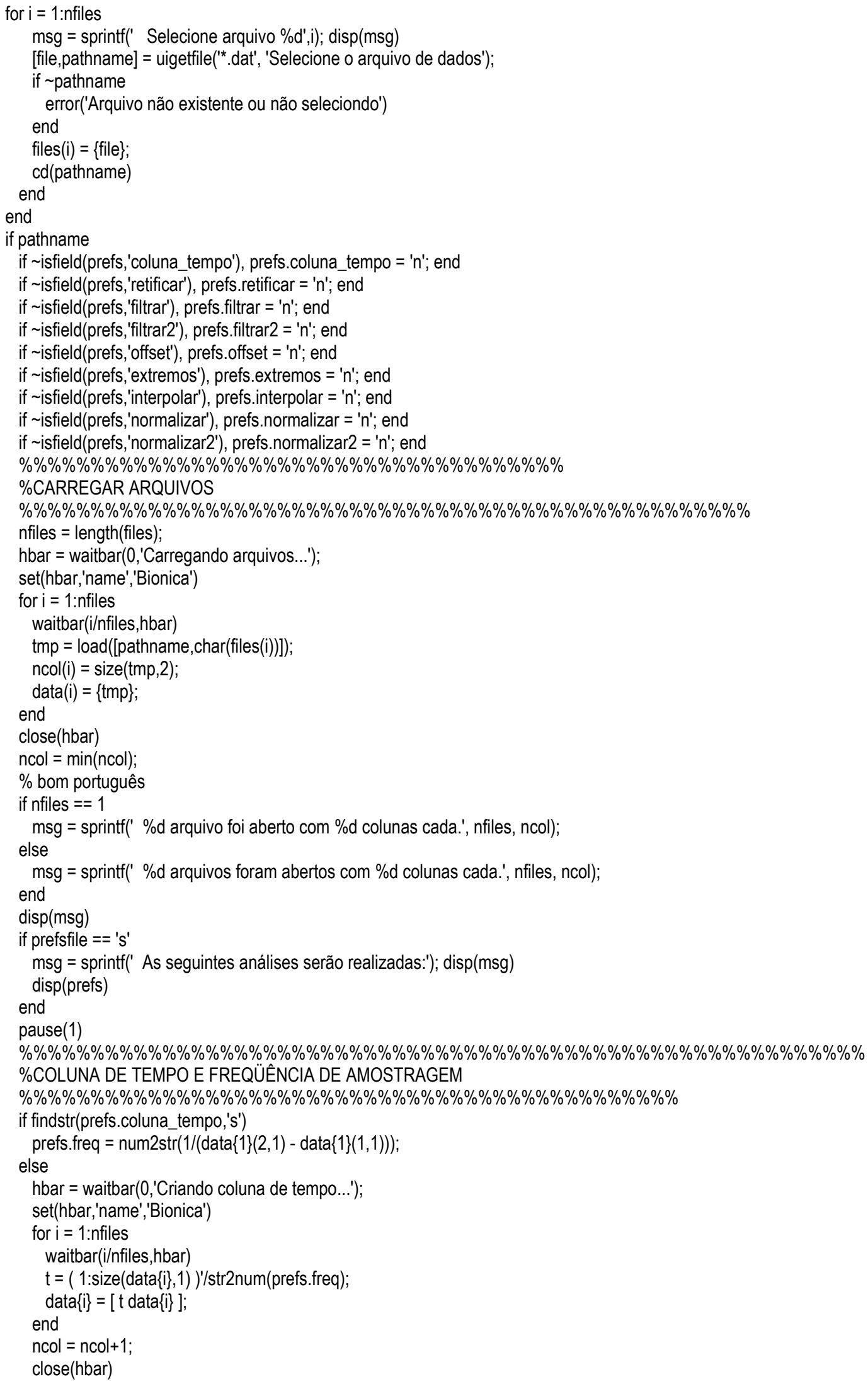




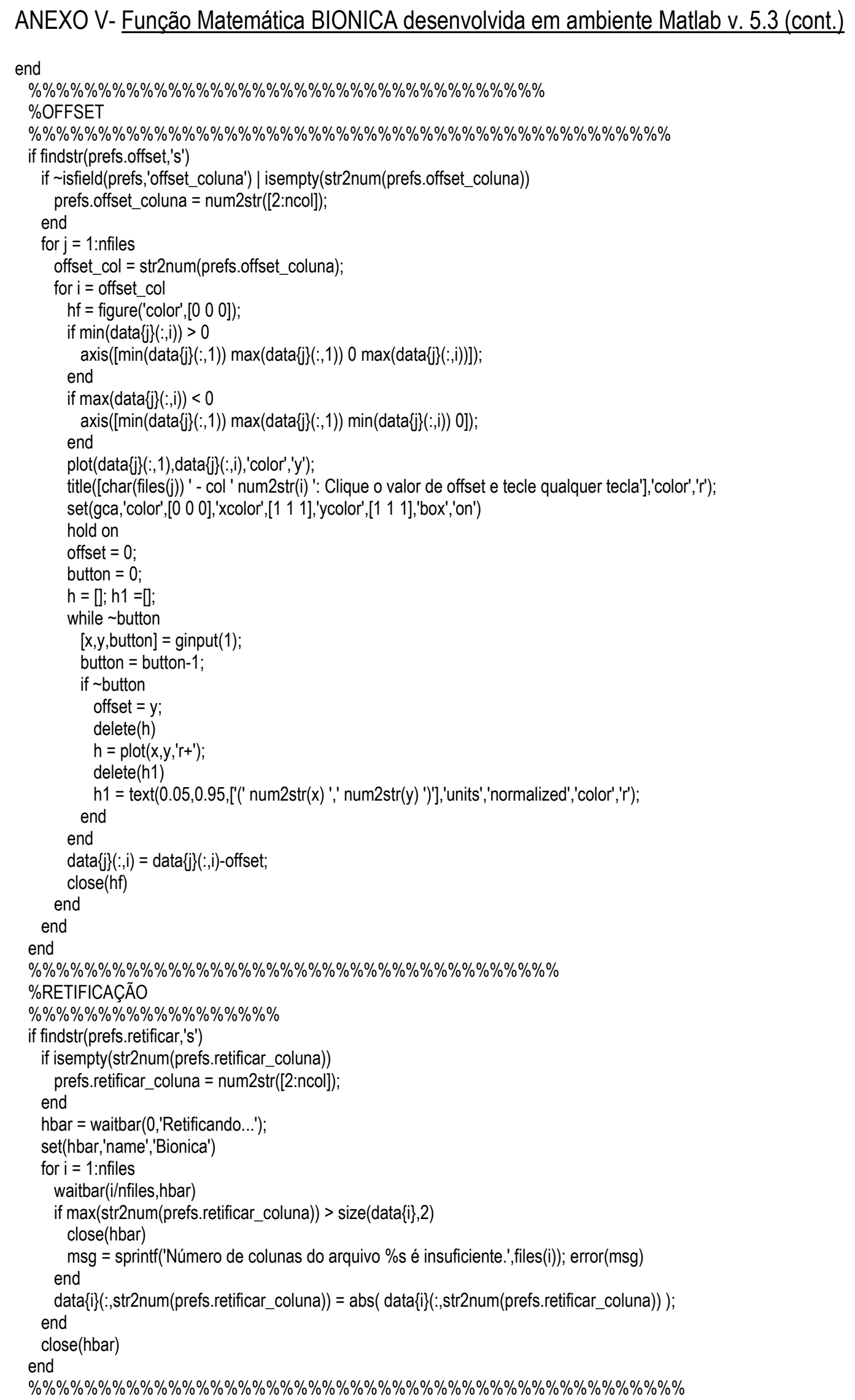




\section{ANEXO V- Função Matemática BIONICA desenvolvida em ambiente Matlab v. 5.3 (cont.)}

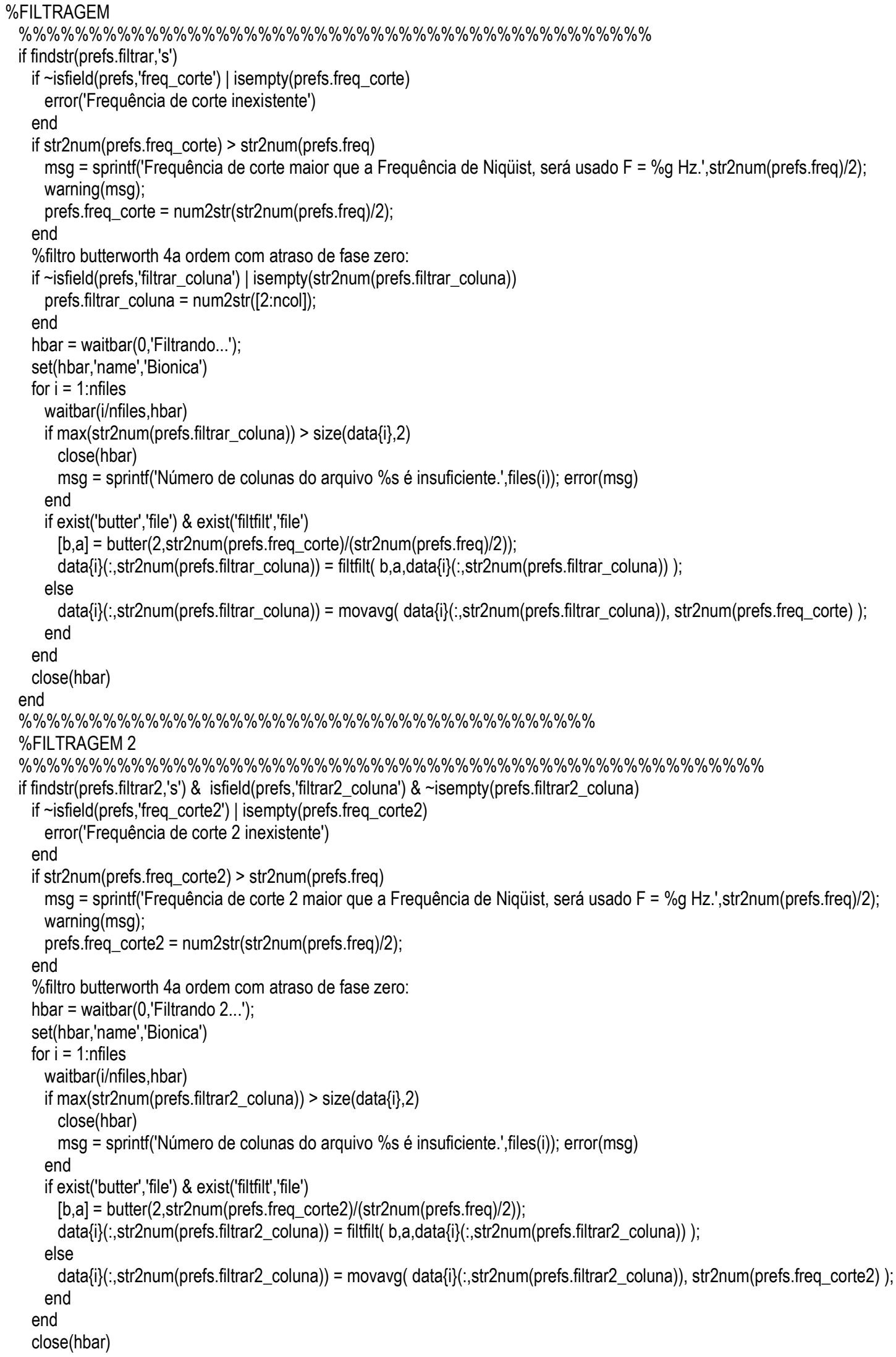




\section{ANEXO V- Função Matemática BIONICA desenvolvida em ambiente Matlab v. 5.3 (cont.)}

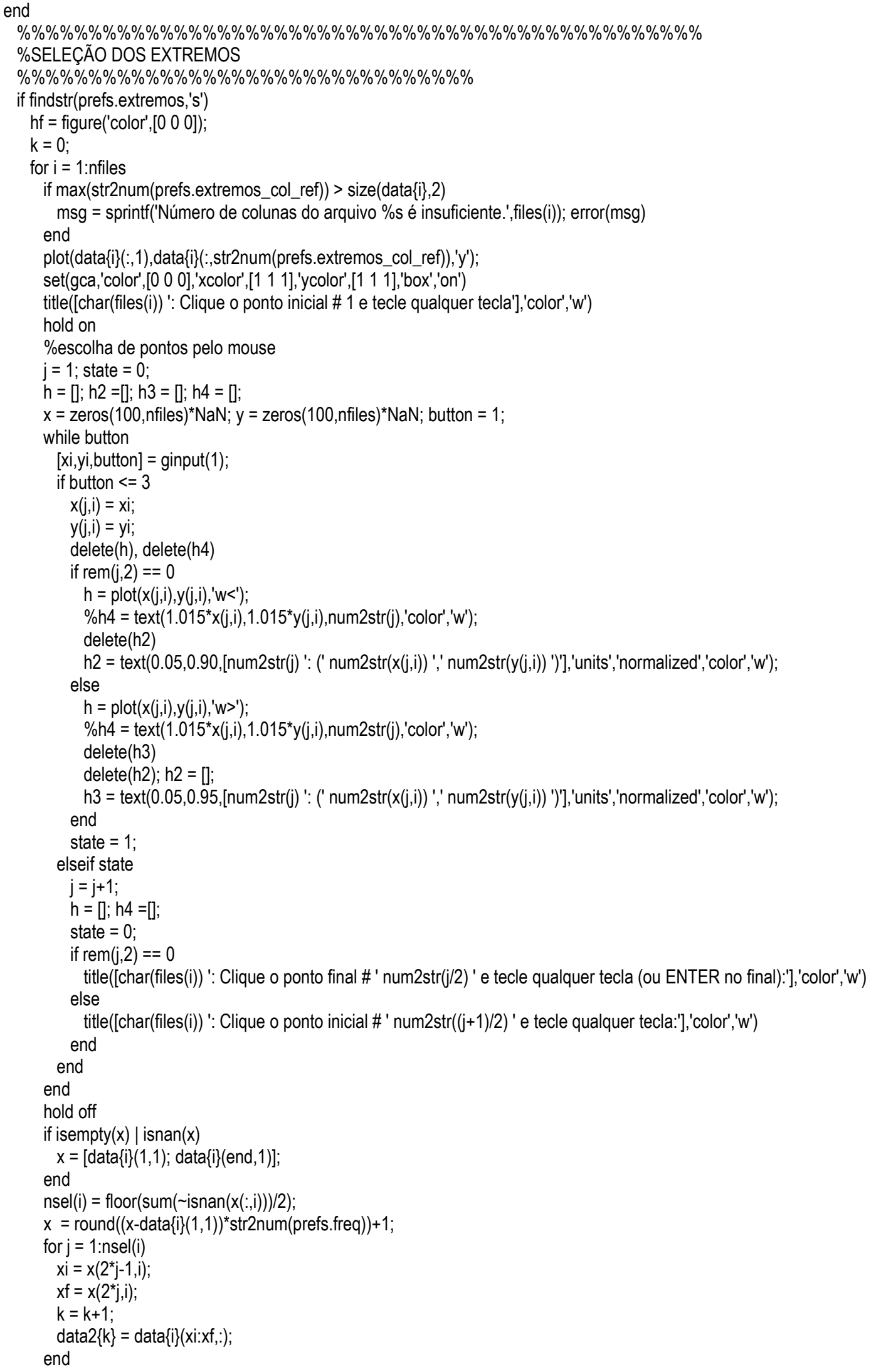




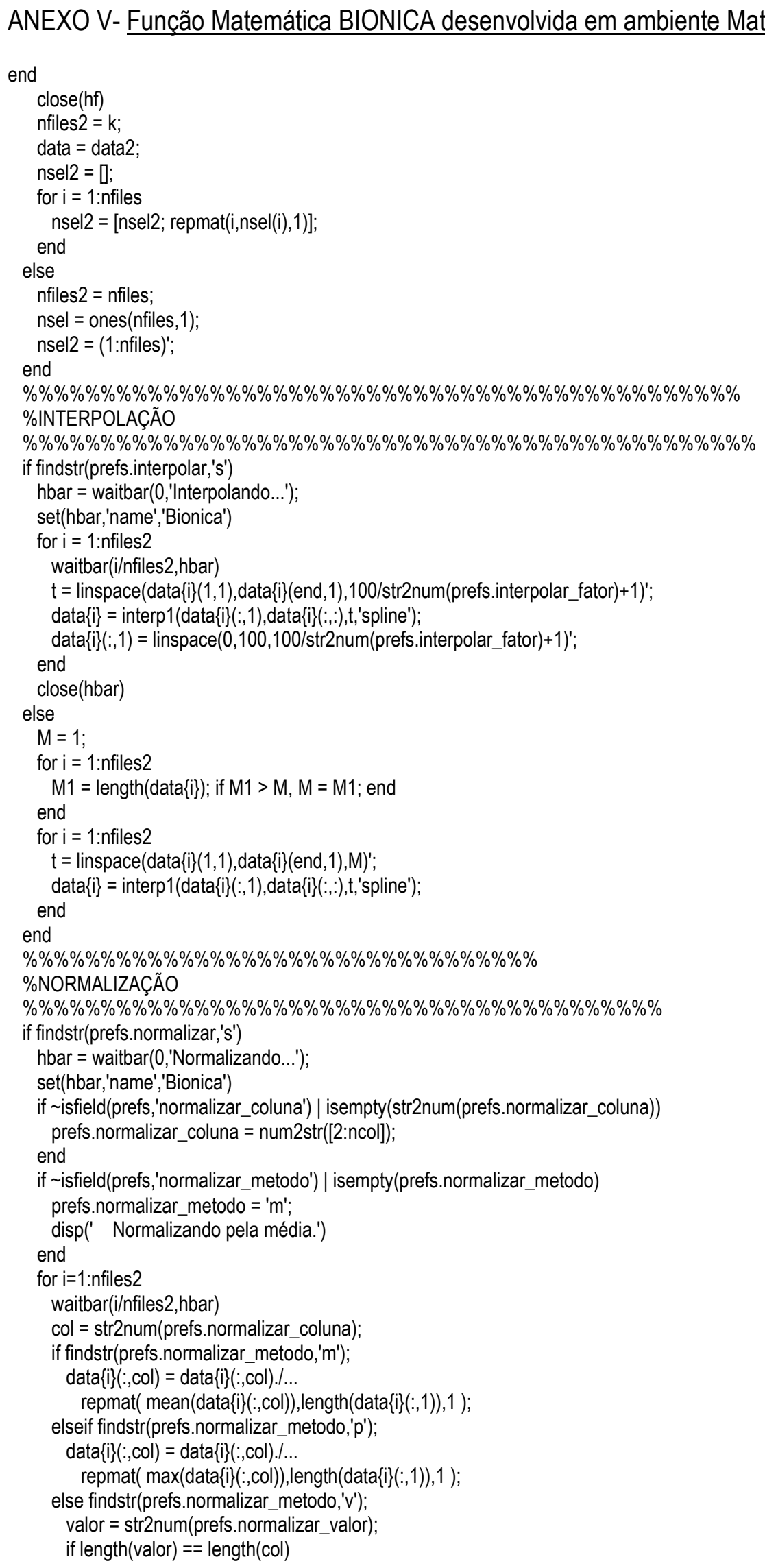




\section{ANEXO V- Função Matemática BIONICA desenvolvida em ambiente Matlab v. 5.3 (cont.)}

if $i==1$

msg = sprintf(' As colunas $[\% s]$ de todos os arquivos foram normalizadas por

$[\% s] . '$,prefs.normalizar_coluna,prefs.normalizar_valor); disp(msg)

end

data $\{i\}(:, \mathrm{col})=$ data\{i\}(:,col)./repmat( valor,length(data\{i\}\}(:,1)),1 $)$;

elseif length (valor) $==$ length $(\mathrm{col})^{*}$ nfiles

data $\{i\}(:, \mathrm{col})=$ data $\{i\}(:, \mathrm{col}) . / .$.

repmat( valor((nsel2(i)-1)*length(col)+1:nsel2(i)*length(col)),length(data\{i\}(:,1)),1 );

if $\mathrm{i}==1, \mathrm{tmp}=\operatorname{diff}([0 ;$ nsel2]); end

if tmp(i)

$\mathrm{msg}=\operatorname{sprintf(} \quad$ As colunas $[\% \mathrm{~s}]$ do arquivo \%s foram normalizadas por $[\% \mathrm{~s}]$. ,',

prefs.normalizar_coluna,char(files(nsel2(i))),num2str(valor((nsel2(i)-1)*length(col)+1:nsel2(i)*length(col)))); disp(msg)

end

else

close(hbar)

msg = sprintf(' Erro: O número de valores de normalização deve ser \%d ou \%d.', length(col),length(col)nfiles); error(msg) end

end

end

close(hbar)

end

\%\%\%\%\%\%\%\%\%\%\%\%\%\%\%\%\%\%\%\%\%\%\%\%\%\%\%\%\%\%\%\%\%\%\%\%\%\%\%\%\%\%\%\%\%

$\%$ NORMALIZAÇÃO 2

\%\% \% \% \% \% \% \% \% \% \% \% \% \% \% \% \% \% \% \% \% \% \% \% \% \% \% \% \% \% \% \% \% \% \% \% \% \% \% \% \% \% \% \% \% \% \% \% \% \% \%

if findstr(prefs.normalizar2,'s')

hbar = waitbar(0,'Normalizando 2...');

set(hbar,'name','Bionica')

if isfield(prefs,'normalizar2_coluna') | isempty(str2num(prefs.normalizar2_coluna))

prefs.normalizar2_coluna = num2str([2:ncol] );

end

if isfield(prefs,'normalizar2_metodo') | isempty(prefs.normalizar2_metodo)

prefs.normalizar2 metodo = ' $\mathrm{m}$ '

disp(' 2: Normalizando pela média.')

end

for $i=1$ :nfiles2

waitbar(i/nfiles2,hbar)

col = str2num(prefs.normalizar2_coluna)

if findstr(prefs.normalizar2_metodo,' $m$ ');

data\{i\} $\}(:, \mathrm{col})=$ data $\{i\}(:, \mathrm{col}) . / \ldots$

repmat( mean(data\{i\}(:,col)), length(data\{i\}(::1)),1 );

elseif findstr(prefs.normalizar2_metodo,' $p$ ');

data\{i\}\}(:,col) = data\{i\} $(:, \mathrm{col}) . / \ldots$

repmat( $\max ($ data $\{i\}(:$, col $))$, length(data\{i\}(:,1)), 1 );

else findstr(prefs.normalizar2_metodo,' $v$ ');

valor = str2num (prefs.normalizar2_valor);

if length(valor) == length(col)

if $\mathrm{i}==1$

msg = sprintf(' 2: As colunas $[\% \mathrm{~s}]$ de todos os arquivos foram normalizadas por

$[\% s]$. , prefs.normalizar2_coluna,prefs.normalizar2_valor); disp(msg)

end

data\{i\}\}(:,col) = data\{i\}(:,col)./repmat( valor,length(data\{i\}\}(:,1)),1 $)$;

elseif length(valor) $==$ length $(\mathrm{col})^{*}$ nfiles

data $\{i\}(:, \mathrm{col})=$ data $\{i\}(:, \mathrm{col}) . / \ldots$

repmat( valor((nsel2(i)-1)*length(col)+1:nsel2(i)*length(col)),length(data\{i\}\}(:,1)),1 );

if $\mathrm{i}==1, \mathrm{tmp}=\operatorname{diff}([0 ;$ nsel2]); end

if tmp(i)

msg = sprintf(' 2: As colunas [\%s] do arquivo \%s foram normalizadas por [\%s].', prefs.normalizar2_coluna,char(files(nsel2(i))),num2str(valor((nsel2(i)-1)*length(col)+1:nsel2(i)*length(col)))); disp(msg) end

else close(hbar) 


\section{ANEXO V- Função Matemática BIONICA desenvolvida em ambiente Matlab v. 5.3 (cont.)}

msg = sprintf(' Erro: O número de valores de normalização deve ser \%d ou \%d.', length(col),length(col)nfiles); error(msg) end

end

close(hbar)

end

pause(1)

\%\%\%\%\%\%\%\%\%\%\%\%\%\%\%\%\%\%\%\%\%\%\%\%\%\%\%\%\%\%\%\%\%\%\%\%\%\%\%\%\%\%\%\%\%\%\%\%\%\%\%\%\%\%

$\%$ GRÁFICOS

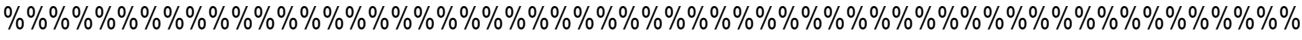

hf = figure('color', [0 0 0],'visible','off');

if nfiles $==1 \&$ nfiles $2==1$

set(hf,'name',[char(files(1)) ' (1 tentativa)'])

for $\mathrm{i}=1$ :ncol-1

if ncol-1>2

subplot(round((ncol-1)/2),2,i);

elseif $\mathrm{ncol}-1==2$

subplot $(2,1, \mathrm{i})$;

end

plot(data\{1\}(:,1),data\{1\}(:,i+1),'color','r');

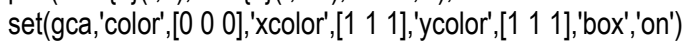

title(['Coluna ' num2str(i+1)],'color','w');

if prefs. interpolar $==$ ' $s$ '

xlabel('Duração (\%)','color','w');

else

xlabel('Duração (s)','color','w');

end

ylabel('Intensidade (U.A.)','color','w');

end

data $=$ data $\{1\}$

else

if nfiles $==1 \&$ nfiles $2>1$

set(hf,'name',[char(files(1)) ' (' num2str(nfiles2) ' tentativas)'])

else

set(hf,'name',[char(files(1)) ' ... ' char(files(nfiles)) ' (' num2str(nfiles) ' arquivos, ' num2str(nfiles2) ' tentativas)']) end

dados $(:, 1)=\operatorname{data}\{1\}(:, 1)$;

hbar = waitbar(0,'Plotando...');

set(hbar,'name','Bionica')

for $\mathrm{i}=1$ :ncol-1

waitbar(i/(ncol-1),hbar)

$\operatorname{tmp}=$ [];

for $\mathrm{j}=1$ :nfiles2

$\operatorname{tmp}(:, j)=$ data $\{j\}(:, i+1)$;

end

$\operatorname{dados}\left(: 2^{*} i\right)=\operatorname{mean}(\operatorname{tmp}, 2)$;

$\operatorname{dados}\left(:, 2^{*} i+1\right)=\operatorname{std}(\operatorname{tmp}, 0,2)$;

$C V(i)=\operatorname{sqrt}\left(\right.$ mean $\left.\left(\operatorname{dados}\left(: 2^{*} i+1\right) .^{\wedge} 2\right)\right) /$ mean $\left(\operatorname{abs}\left(\operatorname{dados}\left(: 2^{*} i\right)\right)\right)$;

$\mathrm{CVpct}=\operatorname{round}\left(\mathrm{CV}^{*} 1000\right) / 10 ; \%$ in \%

if ncol-1>2 subplot(round((ncol-1)/2),2,i);

elseif ncol-1 =- 2 subplot $(2,1, \mathrm{i})$;

end

$h=\operatorname{errorbar2}\left(\operatorname{dados}(:, 1), \operatorname{dados}\left(:, 2^{*} i\right), \operatorname{dados}\left(: 2^{*} i+1\right), r^{\prime}\right)$;

$\operatorname{set}(\mathrm{h}(2)$, 'linewidth', 1.5$)$

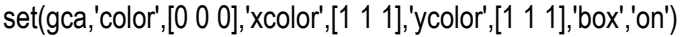

if prefs. interpolar $==$ ' $s$ '

$\operatorname{axis}\left(\left[0100 \min \left(\operatorname{dados}\left(: 2^{*} i\right)\right)-\max \left(\operatorname{dados}\left(:, 2^{*} i+1\right)\right) \max \left(\operatorname{dados}\left(:, 2^{*} i\right)\right)+\max \left(\operatorname{dados}\left(:, 2^{*} i+1\right)\right)\right]\right)$ else

$\operatorname{axis}\left(\left[\min (\operatorname{dados}(:, 1)) \max (\operatorname{dados}(:, 1)) \min \left(\operatorname{dados}\left(: 2^{*} \mathrm{i}\right)\right)-\max \left(\operatorname{dados}\left(: 2^{*} i+1\right)\right) \max \left(\operatorname{dados}\left(:, 2^{*} \mathrm{i}\right)\right)+\max \left(\operatorname{dados}\left(: 2^{*} i+1\right)\right)\right]\right)$ end

ylabel('Intensidade (U.A.)','color','w'); 


\section{ANEXO V- Função Matemática BIONICA desenvolvida em ambiente Matlab v. 5.3 (cont.)}

if i>ncol-3

if prefs.interpolar $==$ ' $s$ '

xlabel('Duração (\%)','color','w');

else

xlabel('Duração (s)','color','w');

end

end

title(['CV(' num2str(i+1) ')= ' num2str(CVpct(i)) ' \%'],'color','w');

end

hold off

data=dados;

data(1:length (CVpct), size $($ data,2)+1) = CVpct';

close(hbar)

$\mathrm{msg}=$ sprintf('In Coeficientes de variação, CV (\%\%):'); disp(msg)

msg = sprintf(' \%3.1f $\backslash n$ ', CVpct); disp(msg)

end

set(hf,'visible','on')

pause(1)

\%\% \% \% \% \% \% \% \% \% \% \% \% \% \% \% \% \% \% \% \% \% \% \% \% \% \% \% \% \% \% \% \% \% \% \% \% \% \% \% \% \% \% \% \% \% \% \% \% \%

$\%$ SALVAR ARQUIVO

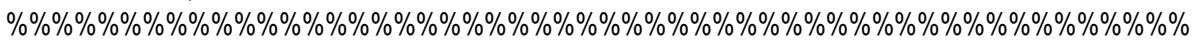

[file,pathname] = uiputfile('dados.dat','Salvar os dados como:');

if file

save([pathname,file],'data','-ascii',-'-tabs')

end

msg = sprintf(' Operações processadas com êxito, fim do programa. In'); disp(msg)

else

msg = sprintf(' Arquivos inexistentes ou não foram selecionados, fim do programa. In'); disp(msg)

end

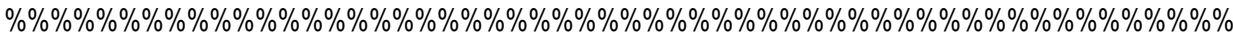

function $\mathrm{y}=\operatorname{movavg}(\mathrm{x}$, win)

$\%$ MOVMEAN Moving average value.

$\%$ For vectors, MOVAVG $(\mathrm{X}, \mathrm{WIN})$ is the moving average values of the elements in $\mathrm{X}$.

$\%$ WIN specifies how many points are considered in the average (odd number)

$\%$ MOVAVG performs the moving average across the rows of a matrix

$\%$

\% Marcos Duarte mduarte@usp.br 10mar2000

if nargin $\sim=2$, disp(' Number of input variables must be 2.'), return, end

if $\operatorname{size}(x, 1)==1, x=x^{\prime}$; end

if $\sim \operatorname{rem}($ win, 2$)$

if win< 2 , win=2; end

win $=$ win $+1 ; \%$ win must be an odd number, mainly because I'm lazy

end

if win >= size $(x, 1)$, disp(' WIN is too big.'), return, end

win $=$ floor $($ win/2);

$y=x^{*} 0$;

for $\mathrm{i}=1$ : win

$y(i,)=.\operatorname{sum}(x(1: i+w i n,:), 1) /($ win+i);

end

for $\mathrm{i}=1+$ win:size $(x, 1)$-win

$y(i,:)=\operatorname{sum}(x(i-w i n: i+w i n,:), 1) /\left(\operatorname{win}^{\star} 2+1\right)$;

end

for $\mathrm{i}=\operatorname{size}(\mathrm{x}, 1)-\mathrm{win}+1 \mathrm{size}(\mathrm{x}, 1)$

$y(i,:)=\operatorname{sum}(x(i-w i n: e n d,:), 1) /(\operatorname{win}+\operatorname{size}(x, 1)-i+1)$;

end

function $\mathrm{h}=$ errorbar2 $(\mathrm{x}, \mathrm{y}, \mathrm{l}, \mathrm{u}, \mathrm{symbol})$

$\%$ L. Shure 5-17-88, 10-1-91 B.A. Jones 4-5-93 
ANEXO V- Função Matemática BIONICA desenvolvida em ambiente Matlab v. 5.3 (cont.)

$\%$ Copyright (c) 1984-98 by The MathWorks, Inc.

\% \$Revision: 5.14 \$ \$Date: 1997/12/02 19:47:51 \$

$\%$ Modified by Marcos

$\mathrm{npt}=$ length $(\mathrm{x})$;

$x=x(:)$;

$y=y(:)$

$\mathrm{I}=\mathrm{I}(:)$

symbol = $\mathrm{u}$;

$\mathrm{u}=\mathrm{l}$;

$\mathrm{u}=\mathrm{abs}(\mathrm{u})$;

$\mathrm{I}=\mathrm{abs}(\mathrm{l})$;

tee $=(\max (x(:))-\min (x(:))) / 100 ; \%$ make tee $.02 x$-distance for error bars

tee $=0$;

$\mathrm{xl}=\mathrm{x}-$ tee;

$\mathrm{xr}=\mathrm{x}+$ tee;

ytop $=y+u$

ybot = y - I;

$\mathrm{n}=\operatorname{size}(\mathrm{y}, 2)$;

$\%$ Plot graph and bars

hold state $=$ ishold;

cax = newplot:

next $=$ lower(get $($ cax,'NextPlot' $)$;

$\%$ build up nan-separated vector for bars

$\mathrm{xb}=$ zeros $\left(\mathrm{npt}{ }^{*} 9, \mathrm{n}\right)$;

$\mathrm{xb}(1: 9:$ end,$:)=\mathrm{x}$;

$\mathrm{xb}(2: 9:$ end,: $)=\mathrm{x}$;

$\mathrm{xb}(3: 9$ :end,: $)=\mathrm{NaN}$

$\mathrm{xb}(4: 9:$ end,:: $=\mathrm{xl}$;

$\mathrm{xb}(5: 9:$ end,: $)=\mathrm{xr}$;

$\mathrm{xb}(6: 9:$ end,: $)=\mathrm{NaN}$;

$\mathrm{xb}(7: 9$ :end,:) $=\mathrm{xl}$;

$\mathrm{xb}(8: 9$ :end,: $)=\mathrm{xr}$;

$\mathrm{xb}(9: 9:$ end, $:)=\mathrm{NaN}$;

$\mathrm{yb}=\operatorname{zeros}\left(\mathrm{npt}^{\star} 9, \mathrm{n}\right)$;

$\mathrm{yb}(1: 9:$ end,: $)=y$ top;

yb(2:9:end,: $)=$ ybot;

$\mathrm{yb}(3: 9:$ end,$:)=\mathrm{NaN}$;

yb(4:9:end,: $)=$ ytop;

yb(5:9:end,: $)=$ ytop;

yb(6:9:end,: $)=\mathrm{NaN}$

yb(7:9:end,: $)=$ ybot;

$\mathrm{yb}(8: 9:$ end,:: $)=y b o t$

yb(9:9:end,: $)=\mathrm{NaN}$;

[ls,col,mark,msg] = colstyle(symbol); if isempty (msg), error(msg); end symbol = [ls mark col]; \% Use marker only on data part

esymbol $=['-'$ col]; \% Make sure bars are solid

$h=\operatorname{plot}(x b, y b, e s y m b o l) ;$ hold on

$\mathrm{h}=[\mathrm{h} ;$ plot $(\mathrm{x}, \mathrm{y}, \mathrm{symbol})]$; 
ANEXO VI- Curvas da FRS e eletromiografia referentes ao andar em esteira de todos os sujeitos do grupo controle (GC).
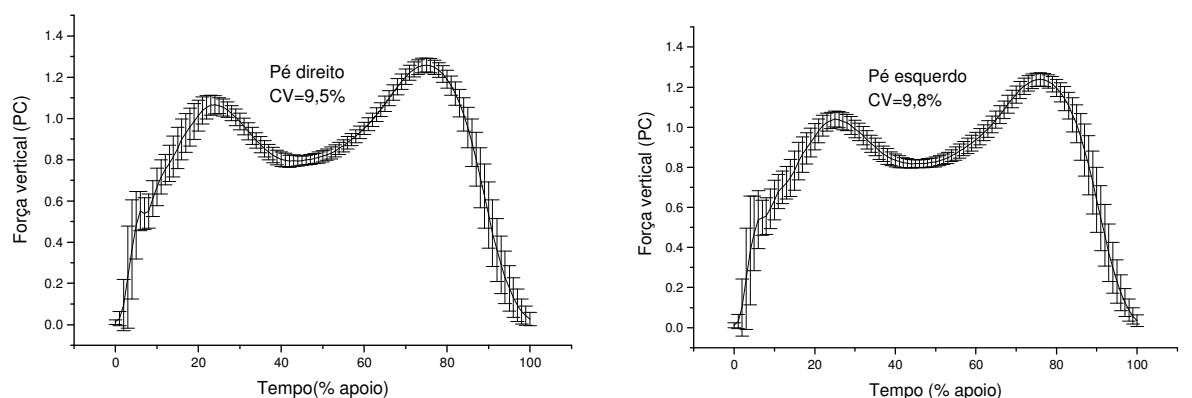

Força vertical média em função do peso corporal (PC) do pé direito e esquerdo do sujeito GC01, durante o andar em esteira
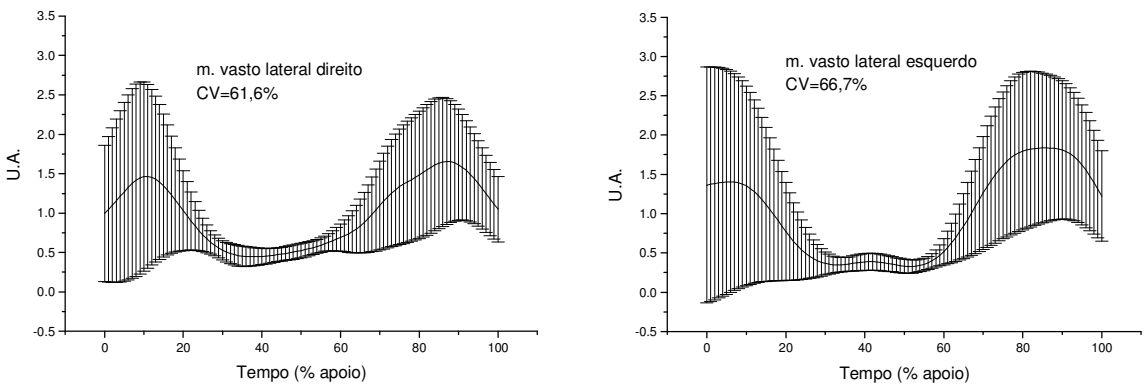

Curvas médias e desvios padrão da EMG do m. vasto lateral direito e esquerdo do sujeito GC01, durante o andar em esteira.
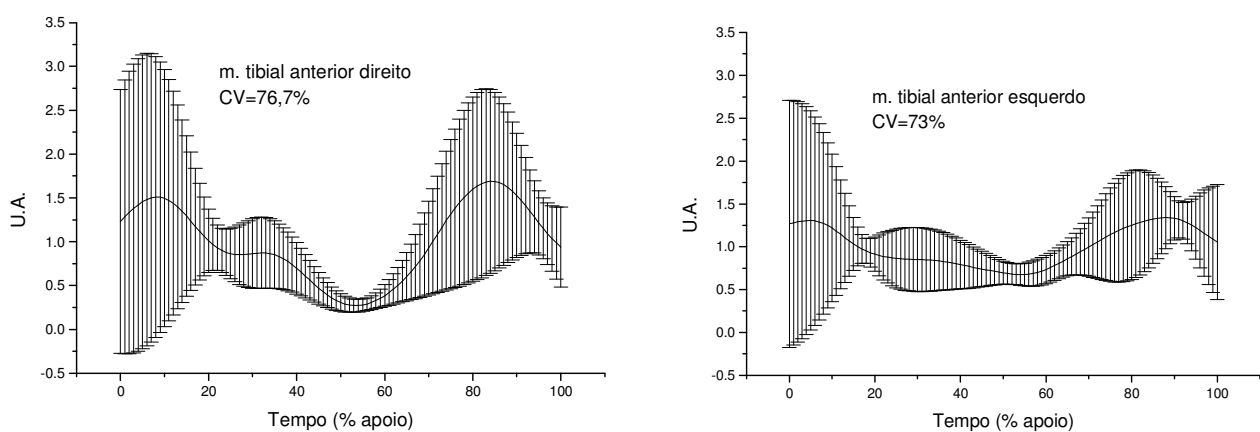

Curvas médias e desvios padrão da EMG do m. tibial anterior direito e esquerdo do sujeito GC01, durante o andar em esteira.
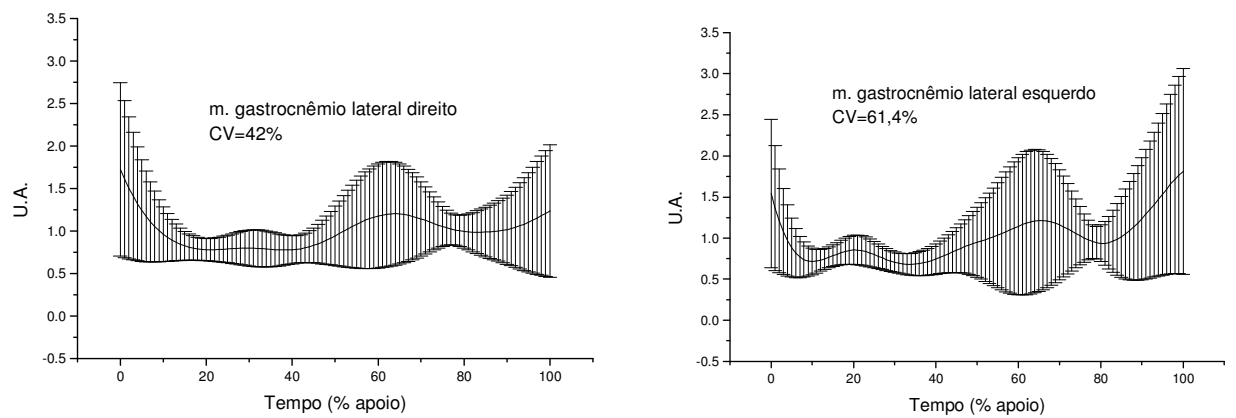

Curvas médias e desvios padrão da EMG do m. gastrocnêmio lateral direito e esquerdo do sujeito GC01, durante o andar em esteira. 
ANEXO VI - Curvas da FRS e eletromiografia referentes ao andar em esteira de todos os sujeitos do grupo controle (GC) (cont.)
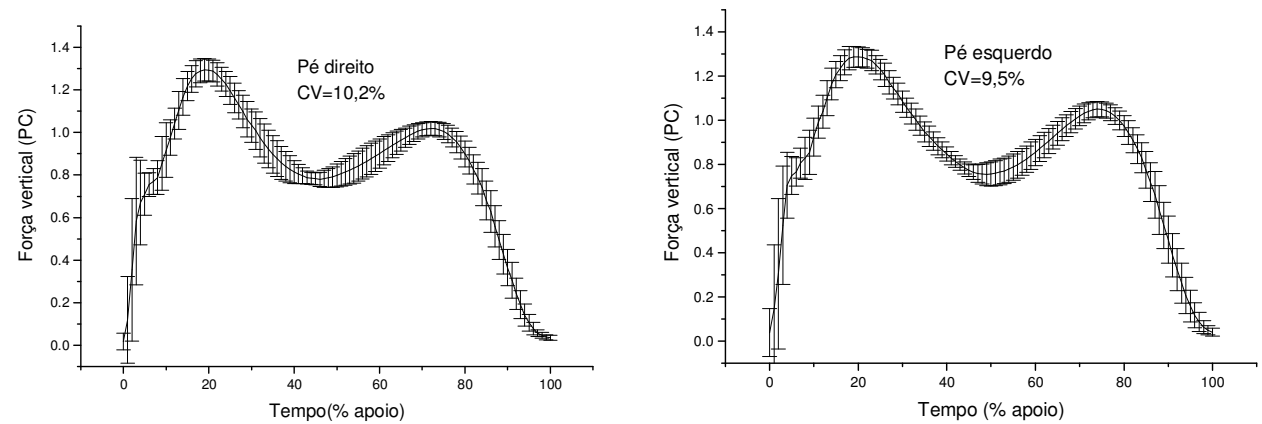

Força vertical média em função do peso corporal $(\mathrm{PC})$ do pé direito e esquerdo do sujeito GC02, durante o andar em esteira
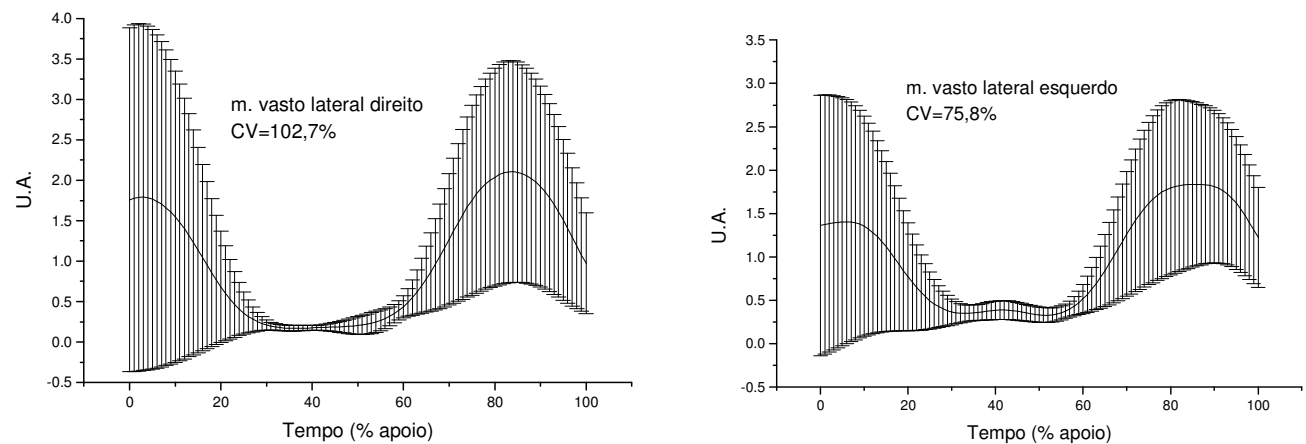

Curvas médias e desvios padrão da EMG do m. vasto lateral direito e esquerdo do sujeito GC02, durante 0 andar em esteira.
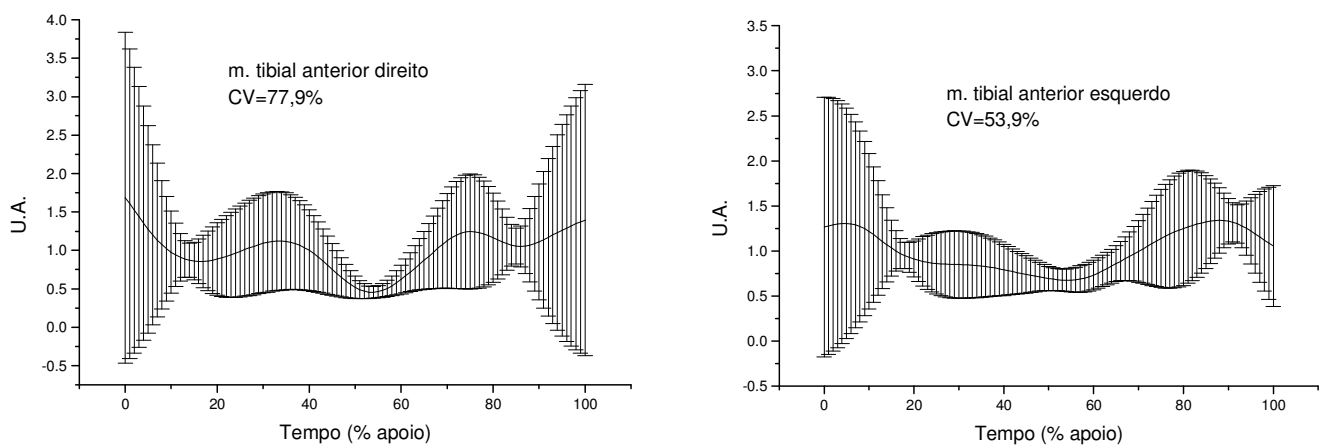

Curvas médias e desvios padrão da EMG do m. tibial anterior direito e esquerdo do sujeito GC02, durante o andar em esteira.
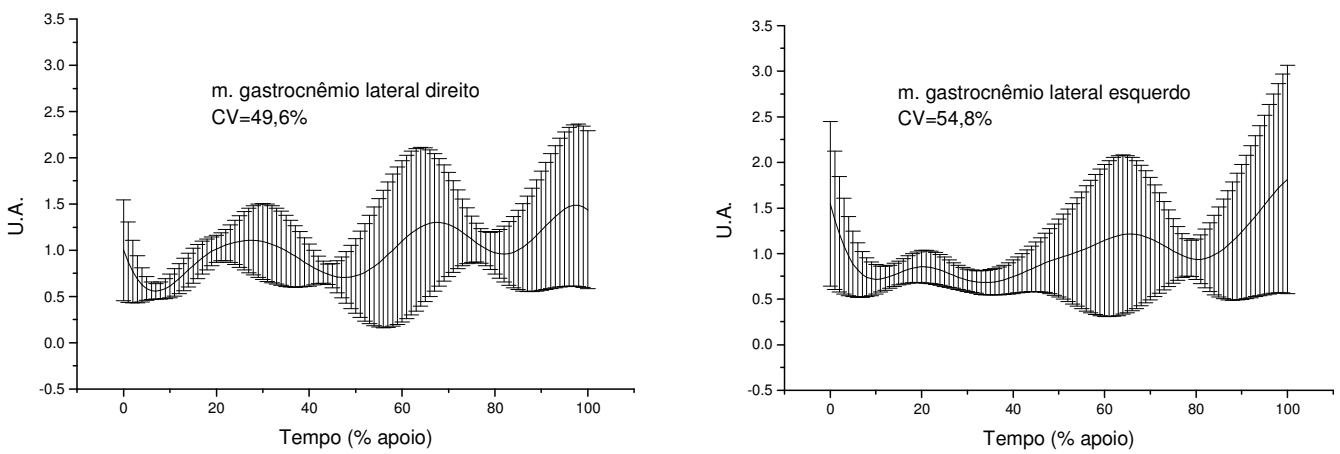

Curvas médias e desvios padrão da EMG do m. gastrocnêmio lateral direito e esquerdo do sujeito GC02, durante o andar em esteira. 
ANEXO VI - Curvas da FRS e eletromiografia referentes ao andar em esteira de todos os sujeitos do grupo controle (GC) (cont.)
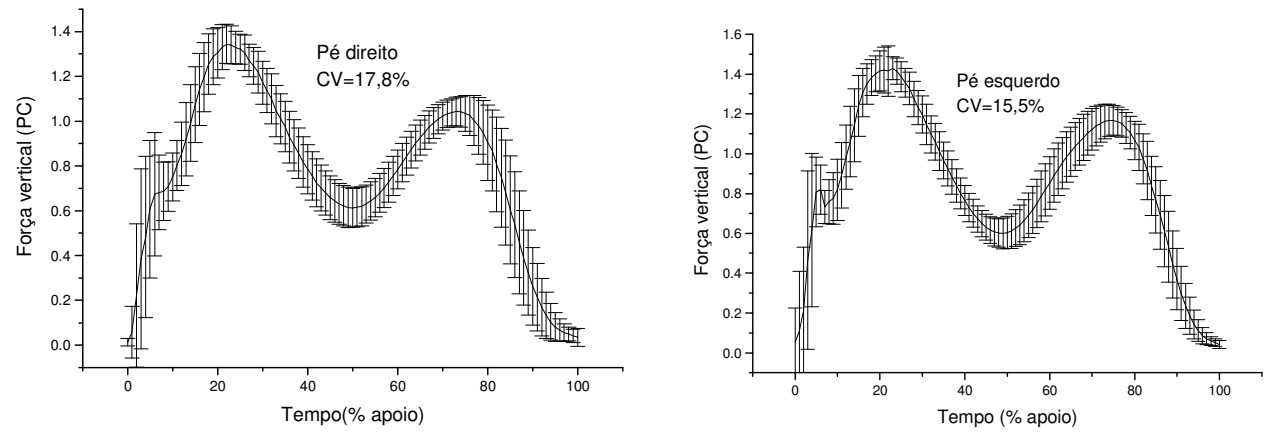

Força vertical média em função do peso corporal $(\mathrm{PC})$ do pé direito e esquerdo do sujeito $\mathrm{GC03}$, durante 0 andar em esteira
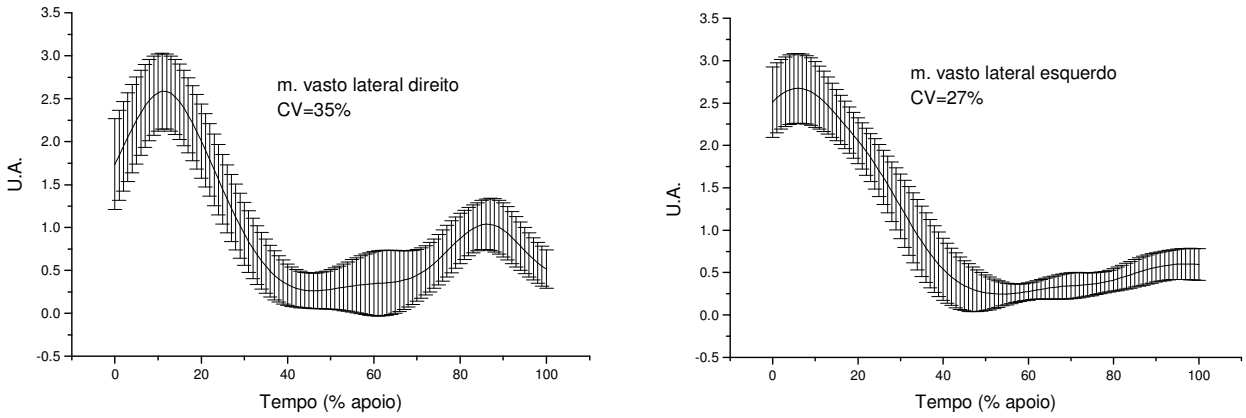

Curvas médias e desvios padrão da EMG do m. vasto lateral direito e esquerdo do sujeito GC03, durante o andar em esteira.
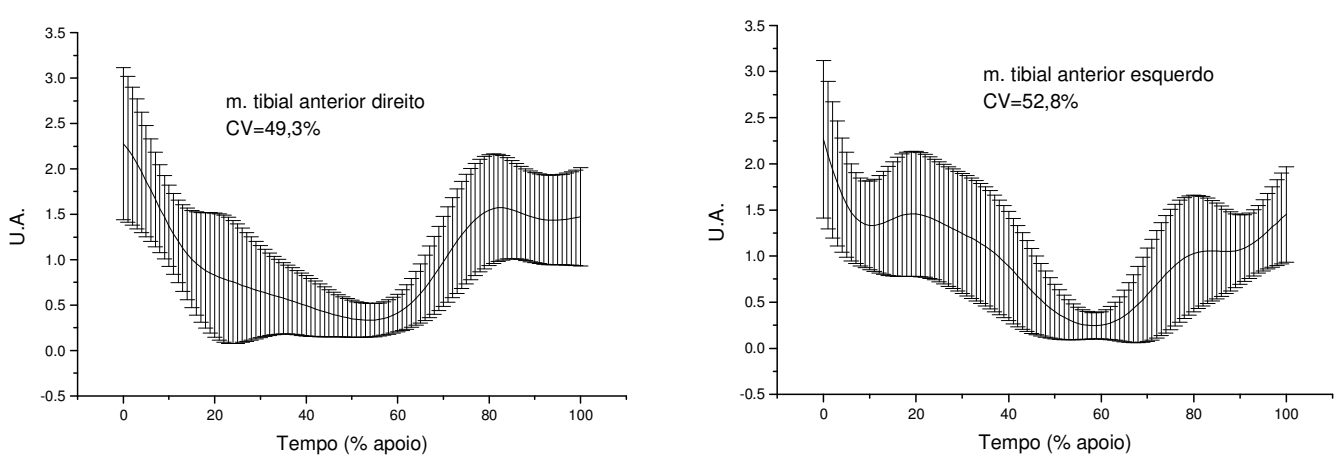

Curvas médias e desvios padrão da EMG do m. tibial anterior direito e esquerdo do sujeito GC03, durante o andar em esteira.
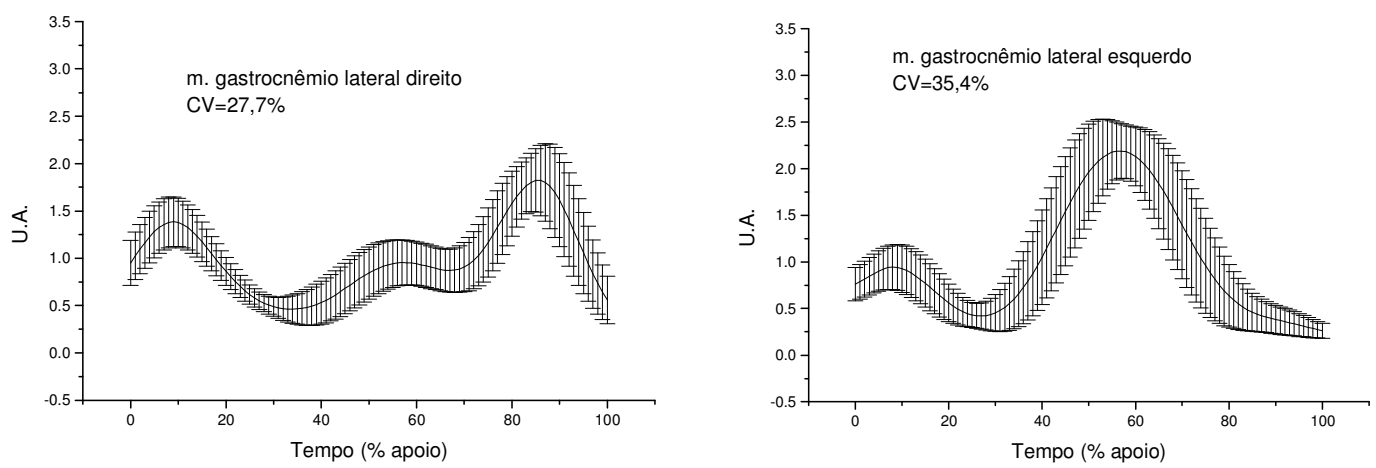

Curvas médias e desvios padrão da EMG do m. gastrocnêmio lateral direito e esquerdo do sujeito GC03, durante o andar em esteira. 
ANEXO VI - Curvas da FRS e eletromiografia referentes ao andar em esteira de todos os sujeitos do grupo controle (GC) (cont.)
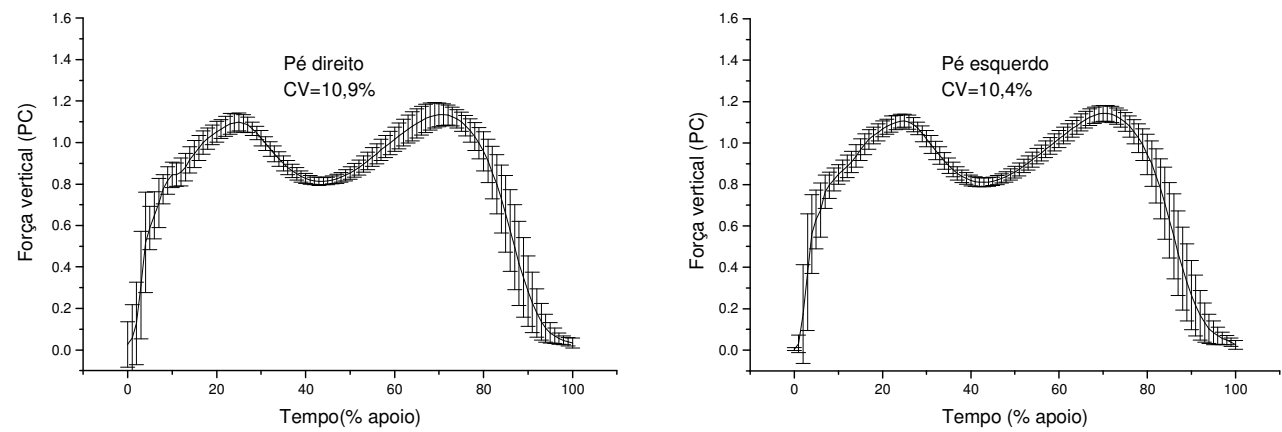

Força vertical média em função do peso corporal (PC) do pé direito e esquerdo do sujeito GC04, durante 0 andar em esteira
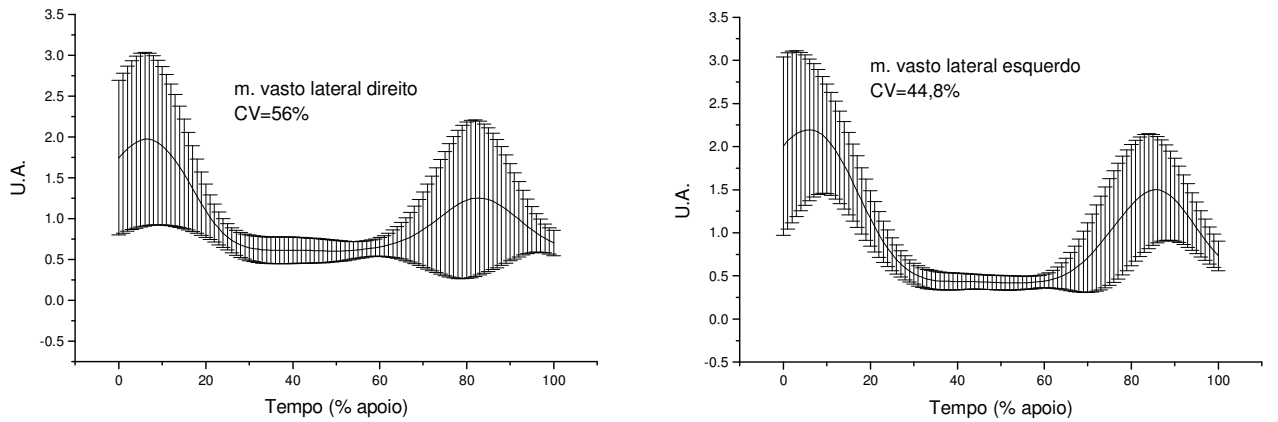

Curvas médias e desvios padrão da EMG do m. vasto lateral direito e esquerdo do sujeito GC04, durante 0 andar em esteira.
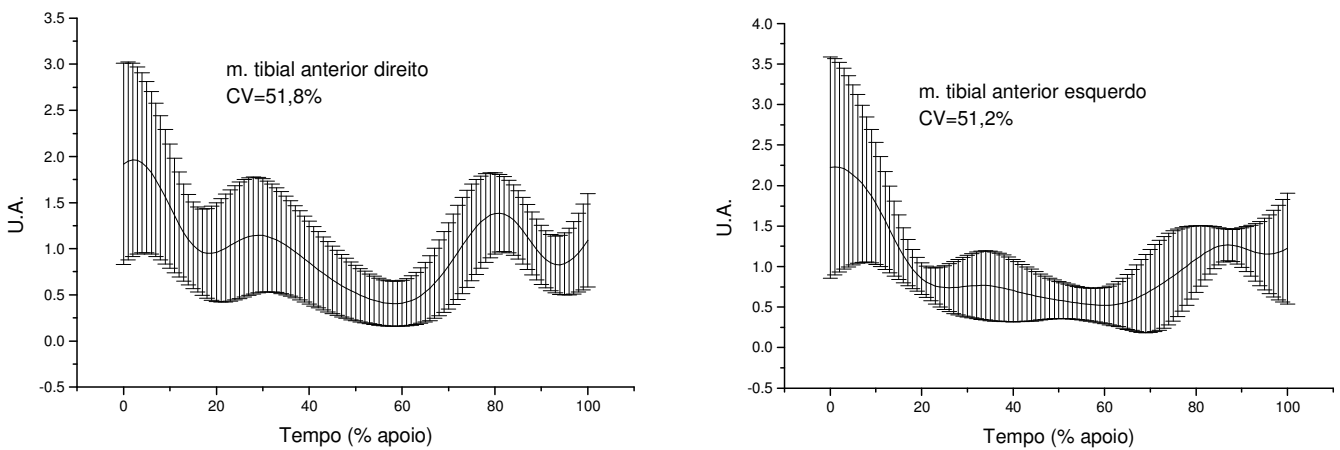

Curvas médias e desvios padrão da EMG do m. tibial anterior direito e esquerdo do sujeito GC04, durante o andar em esteira.
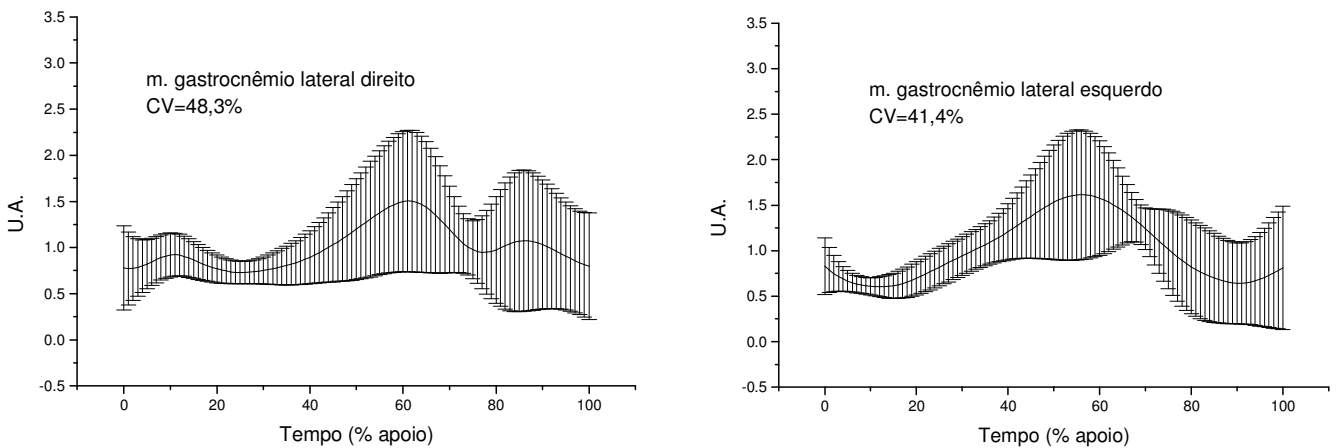

Curvas médias e desvios padrão da EMG do m. gastrocnêmio lateral direito e esquerdo do sujeito GC04, durante 0 andar em esteira. 
ANEXO VI - Curvas da FRS e eletromiografia referentes ao andar em esteira de todos os sujeitos do grupo controle (GC) (cont.)
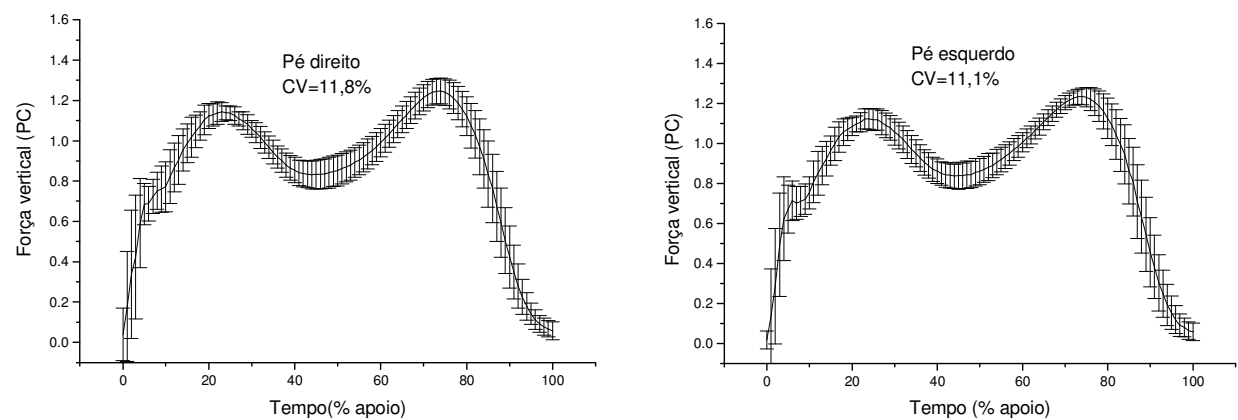

Força vertical média em função do peso corporal (PC) do pé direito e esquerdo do sujeito GC05, durante 0 andar em esteira.
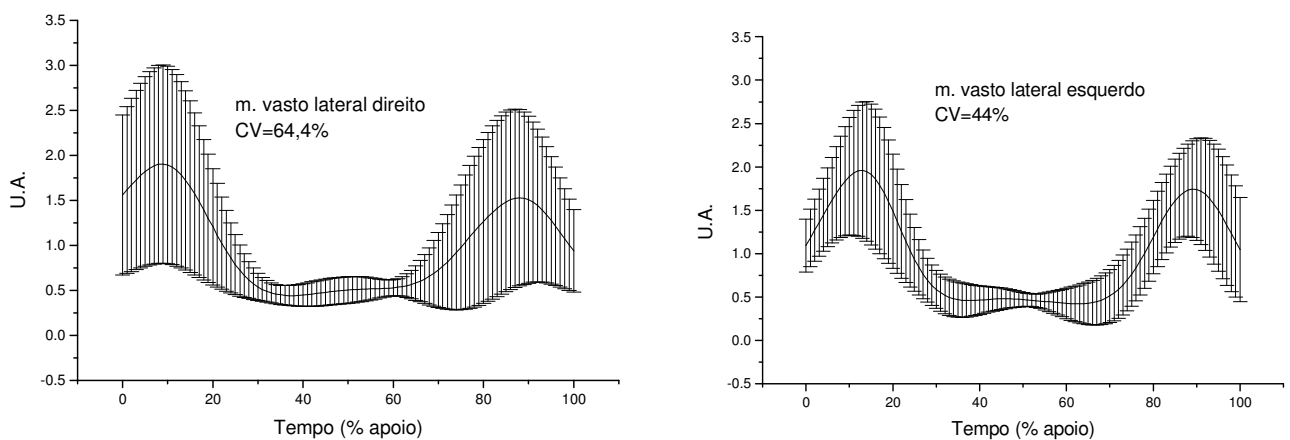

Curvas médias e desvios padrão da EMG do m. vasto lateral direito e esquerdo do sujeito GC05, durante 0 andar em esteira.
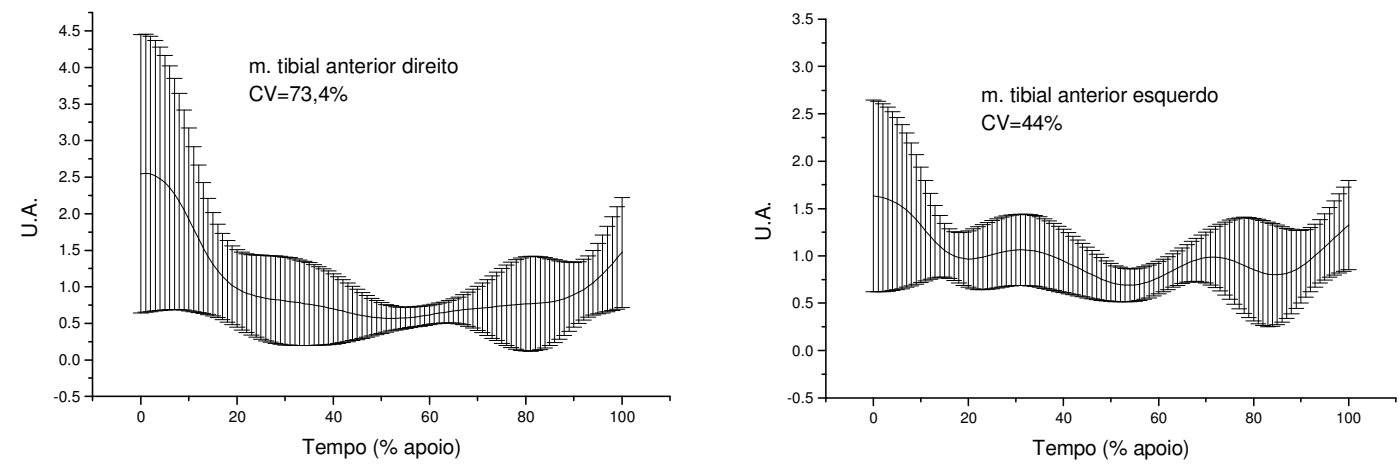

Curvas médias e desvios padrão da EMG do m. tibial anterior direito e esquerdo do sujeito GC05, durante o andar em esteira.
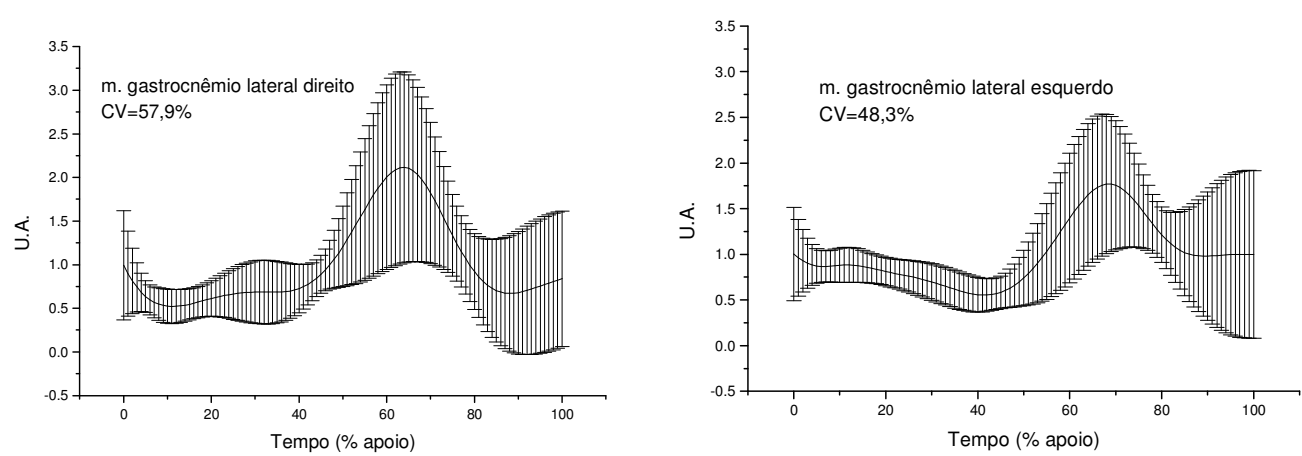

Curvas médias e desvios padrão da EMG do m. gastrocnêmio lateral direito e esquerdo do sujeito GC05, durante o andar em esteira. 
ANEXO VI - Curvas da FRS e eletromiografia referentes ao andar em esteira de todos os sujeitos do grupo controle (GC) (cont.)
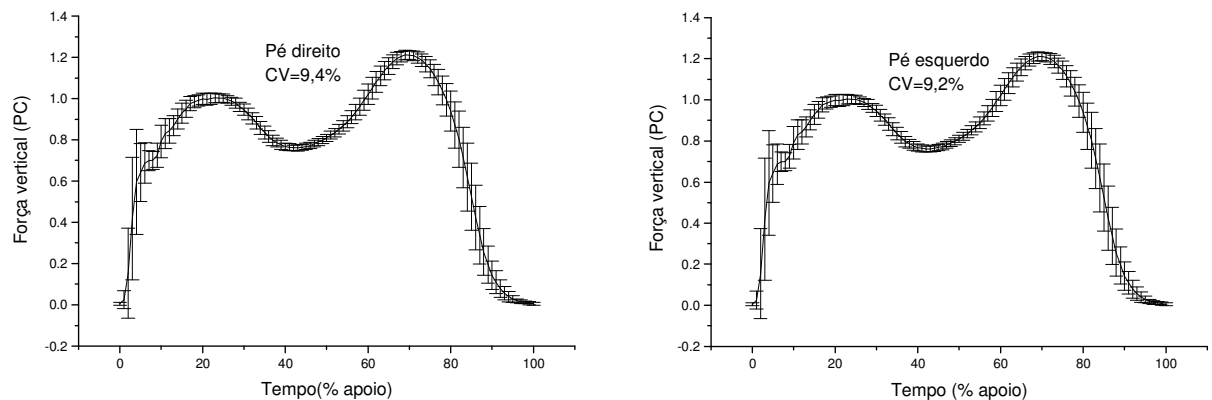

Força vertical média em função do peso corporal (PC) do pé direito e esquerdo do sujeito GC06, durante 0 andar em esteira.
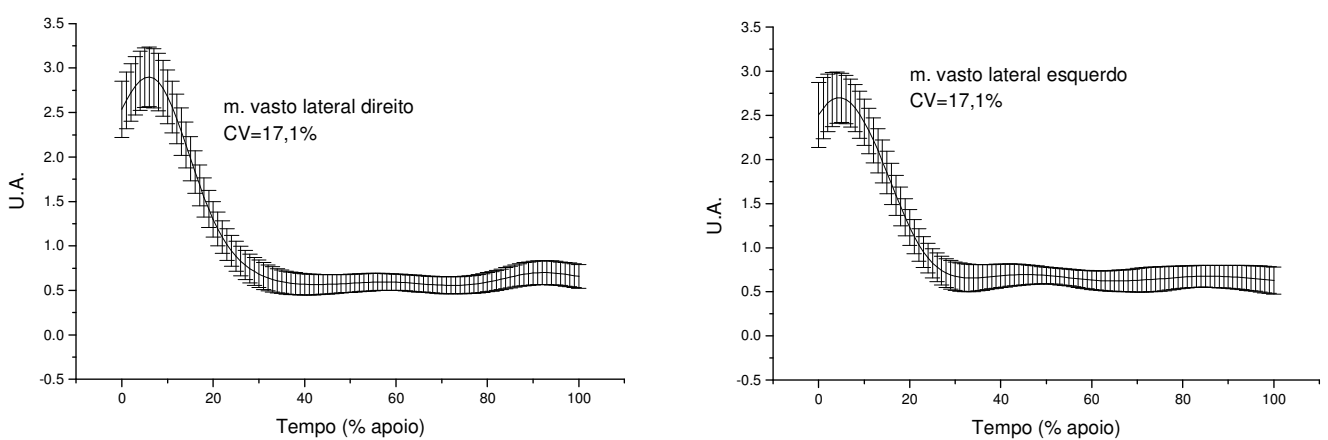

Curvas médias e desvios padrão da EMG do m. vasto lateral direito e esquerdo do sujeito GC06, durante o andar em esteira.
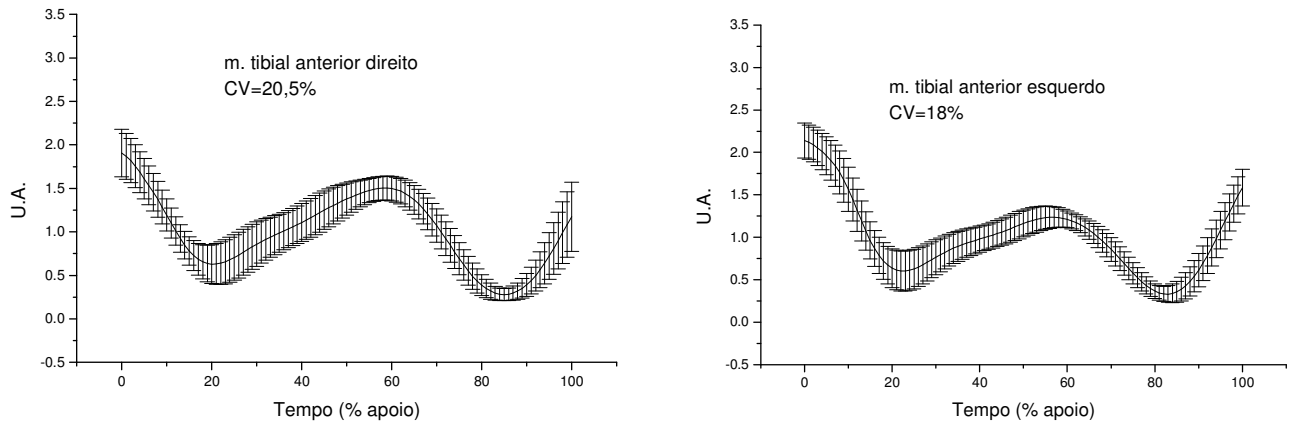

Curvas médias e desvios padrão da EMG do m. tibial anterior direito e esquerdo do sujeito GC06, durante 0 andar em esteira.
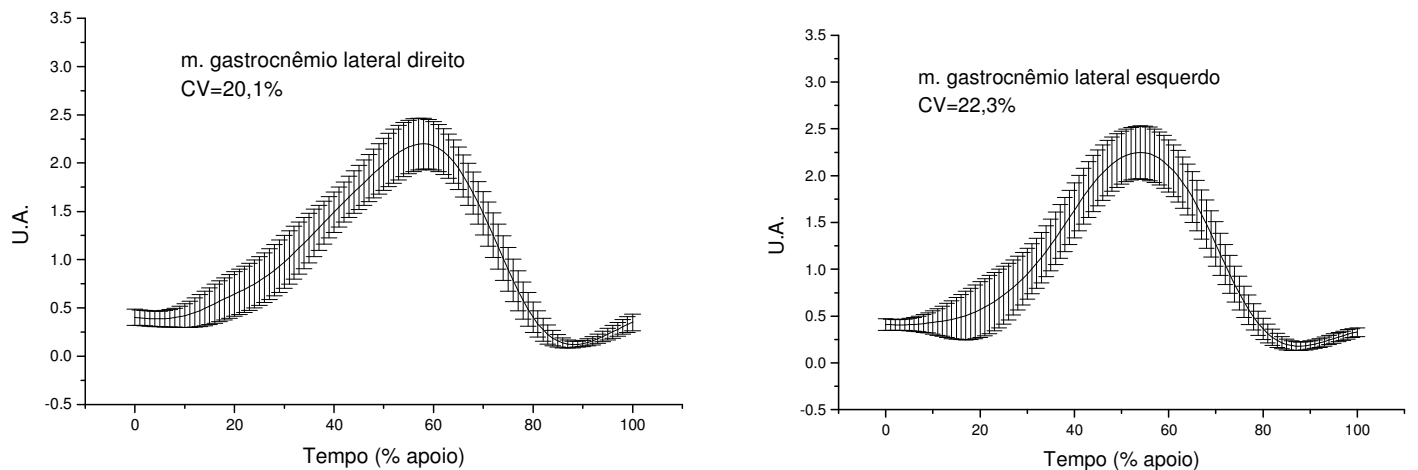

Curvas médias e desvios padrão da EMG do m. gastrocnêmio lateral direito e esquerdo do sujeito GC06, durante o andar em esteira. 
ANEXO VI - Curvas da FRS e eletromiografia referentes ao andar em esteira de todos os sujeitos do grupo controle (GC) (cont.)
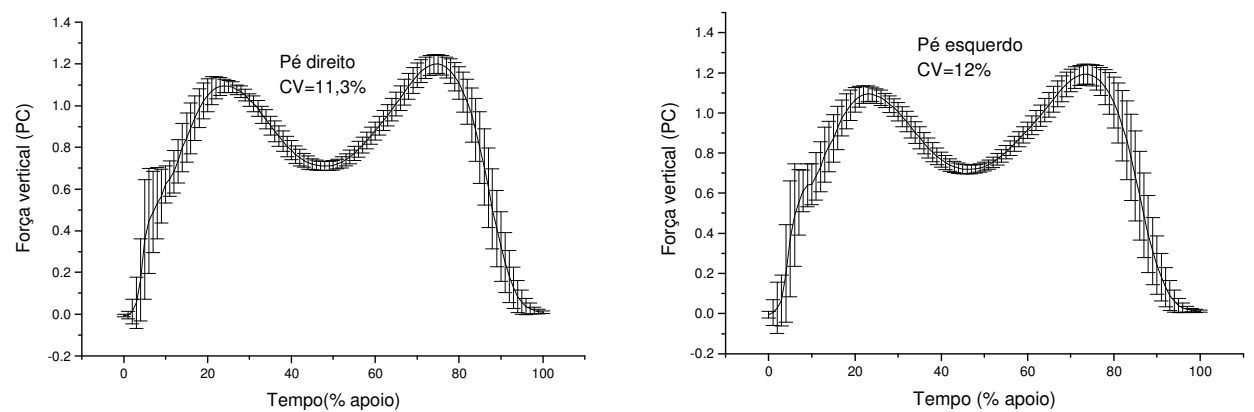

Força vertical média em função do peso corporal (PC) do pé direito e esquerdo do sujeito GC07, durante 0 andar em esteira.
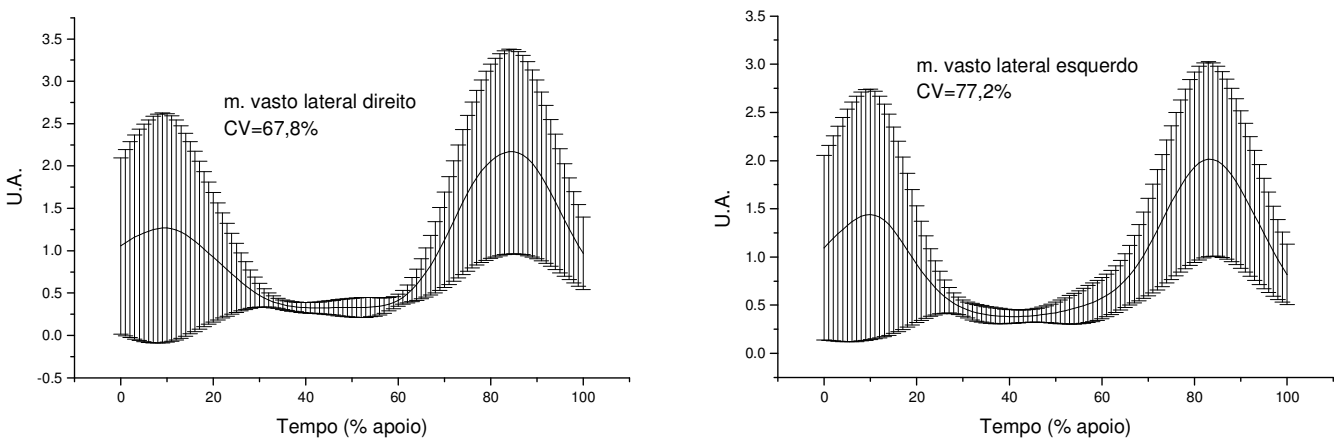

Curvas médias e desvios padrão da EMG do m. vasto lateral direito e esquerdo do sujeito GC07, durante o andar em esteira.
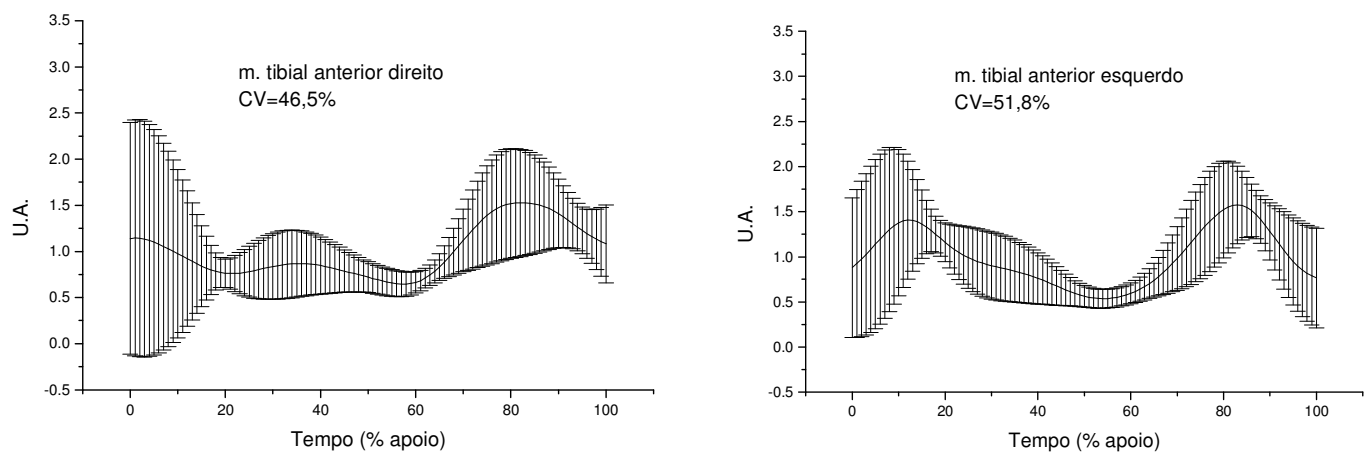

Curvas médias e desvios padrão da EMG do m. tibial anterior direito e esquerdo do sujeito GC07, durante o andar em esteira.
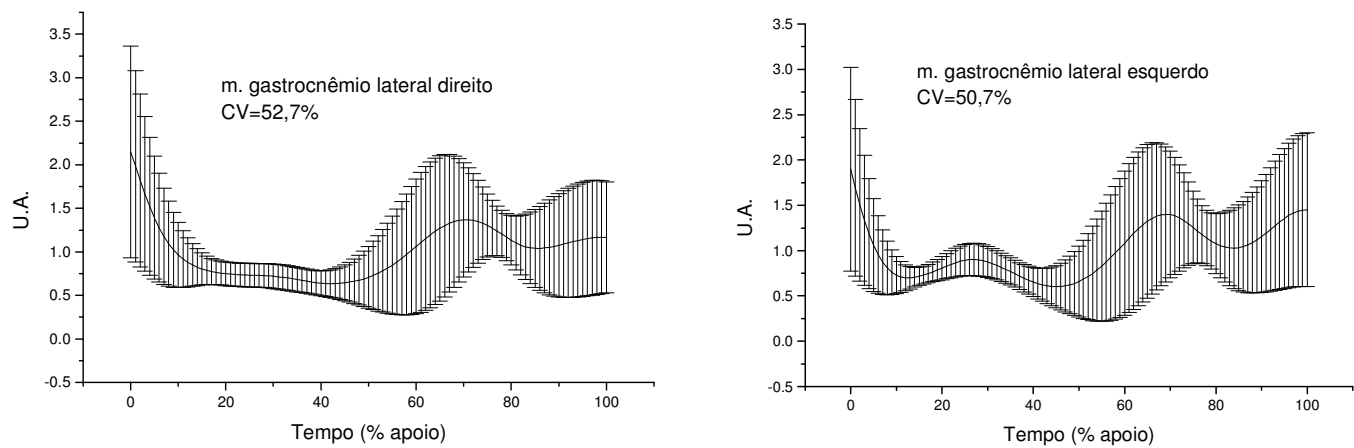

Curvas médias e desvios padrão da EMG do m. gastrocnêmio lateral direito e esquerdo do sujeito GC07, durante o andar em esteira. 


\section{ANEXO VI - Curvas da FRS e eletromiografia referentes ao andar em esteira de todos os sujeitos do} grupo controle (GC) (cont.)
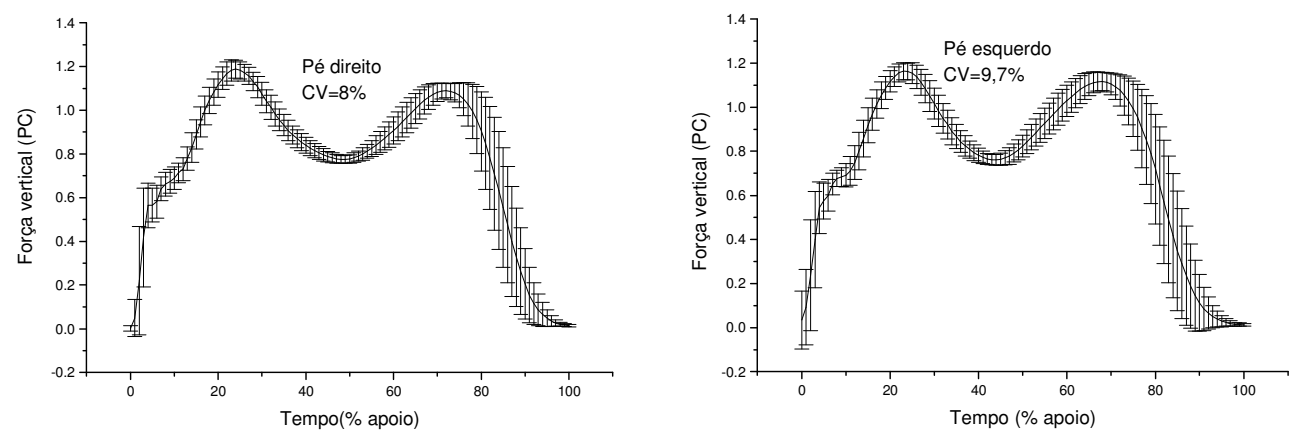

Força vertical média em função do peso corporal (PC) do pé direito e esquerdo do sujeito GC08, durante o andar em esteira.
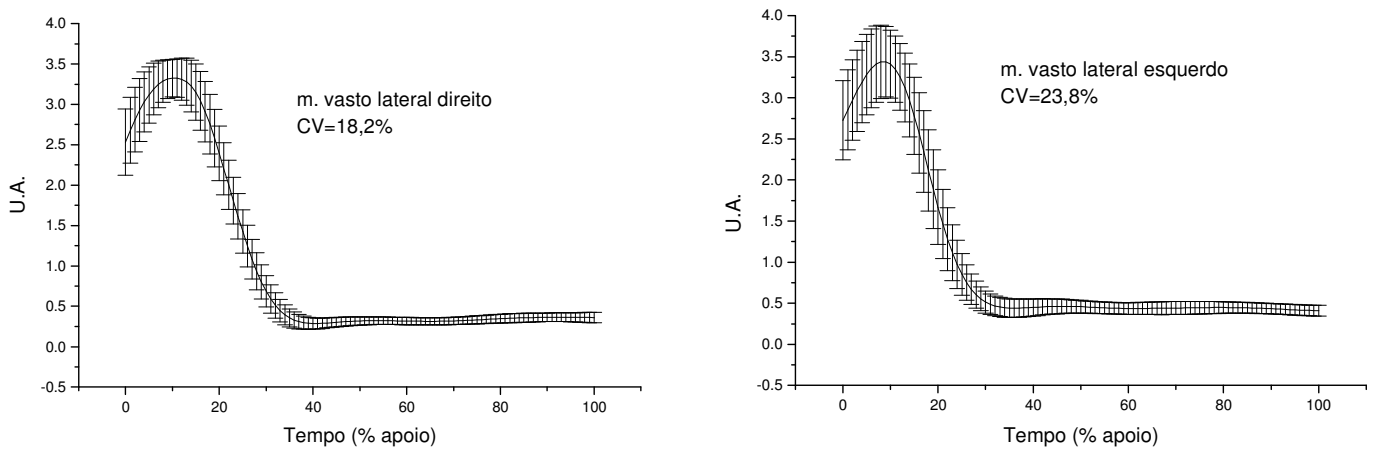

Curvas médias e desvios padrão da EMG do m. vasto lateral direito e esquerdo do sujeito GC08, durante o andar em esteira.
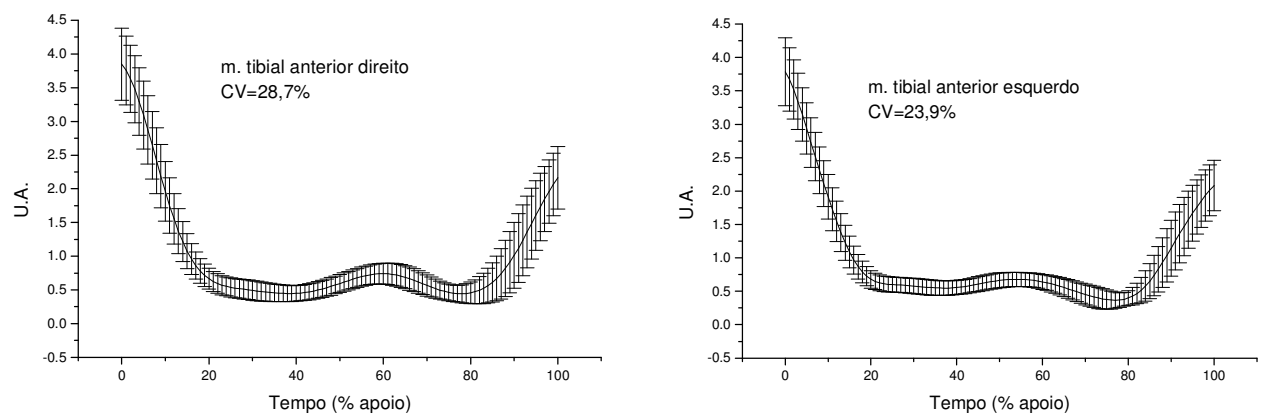

Curvas médias e desvios padrão da EMG do m. tibial anterior direito e esquerdo do sujeito GC08, durante o andar em esteira.
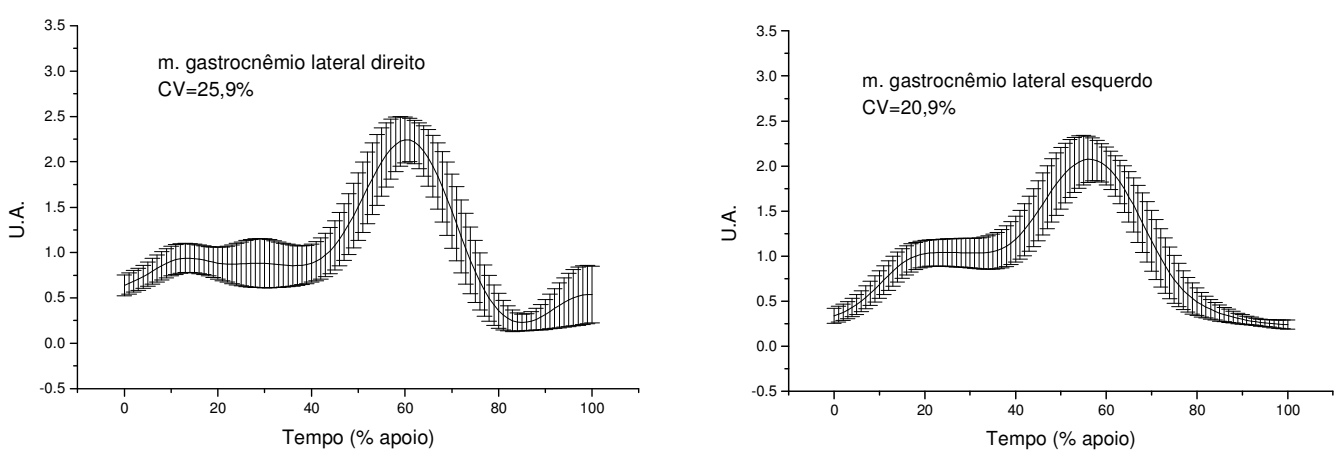

Curvas médias e desvios padrão da EMG do m. gastrocnêmio lateral direito e esquerdo do sujeito GC08, durante o andar em esteira. 
ANEXO VI - Curvas da FRS e eletromiografia referentes ao andar em esteira de todos os sujeitos do grupo controle (GC) (cont.)
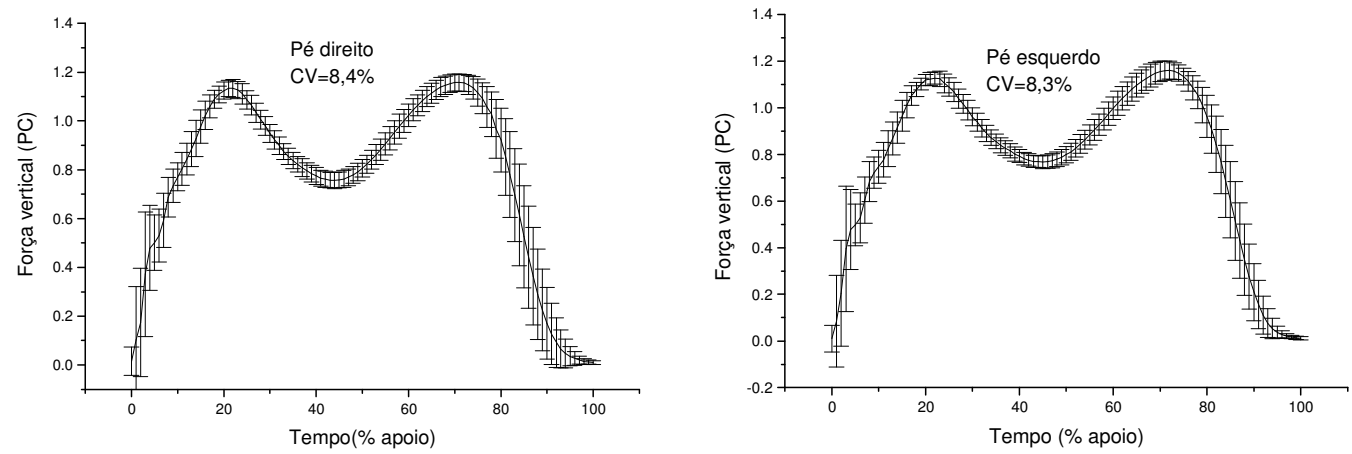

Força vertical média em função do peso corporal $(\mathrm{PC})$ do pé direito e esquerdo do sujeito GC09, durante 0 andar em esteira.
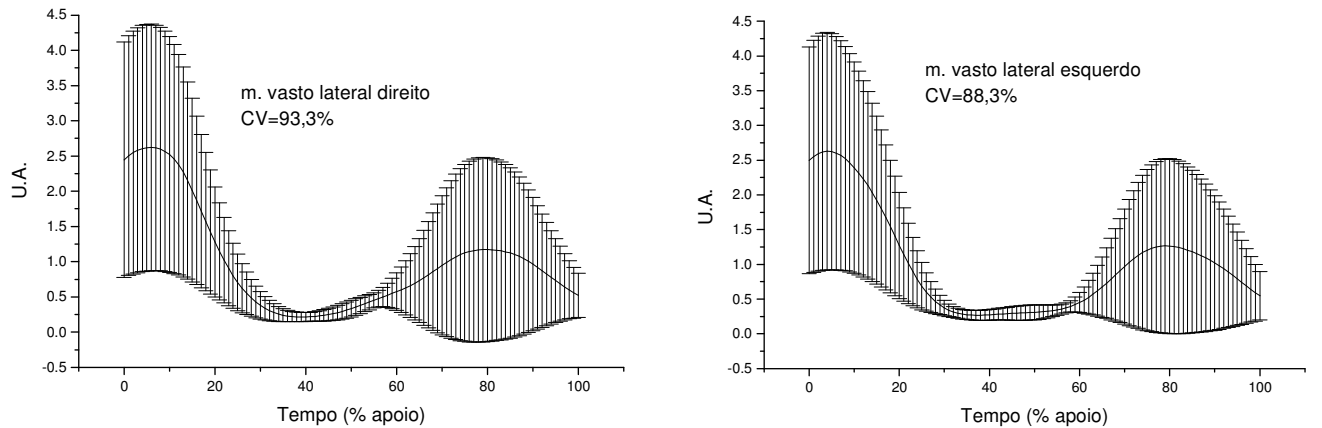

Curvas médias e desvios padrão da EMG do m. vasto lateral direito e esquerdo do sujeito GC09, durante 0 andar em esteira.
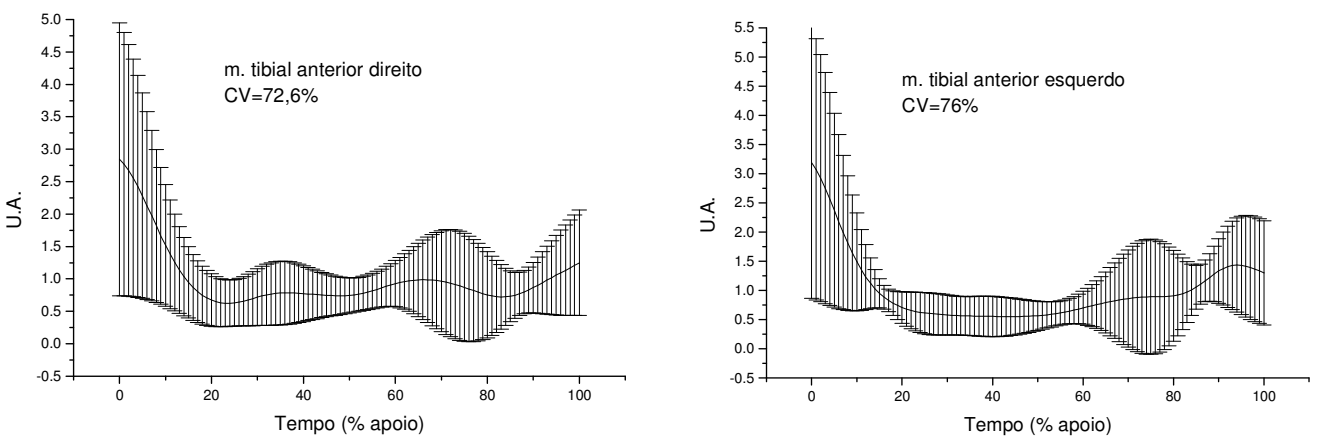

Curvas médias e desvios padrão da EMG do m. tibial anterior direito e esquerdo do sujeito GC09, durante o andar em esteira.
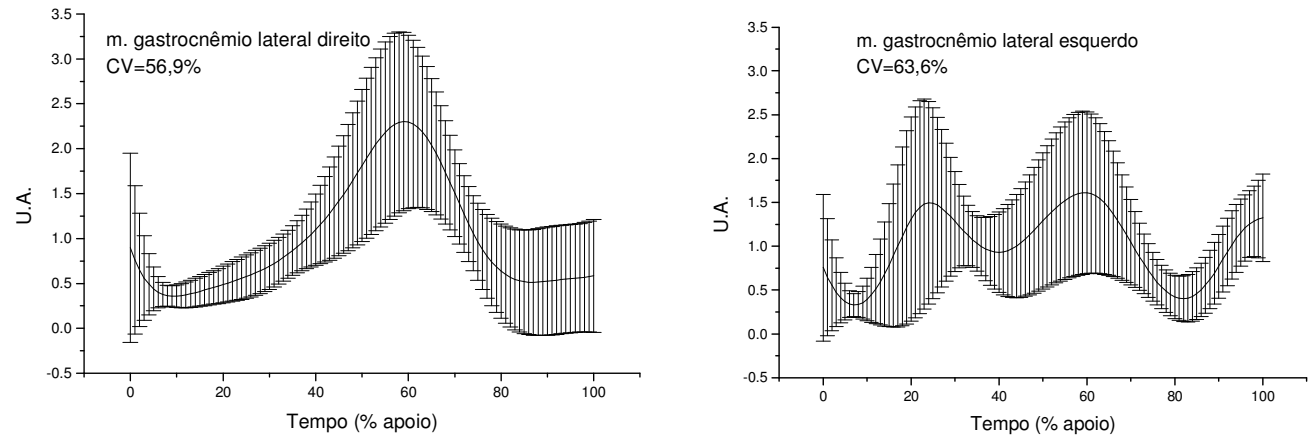

Curvas médias e desvios padrão da EMG do m. gastrocnêmio lateral direito e esquerdo do sujeito GC09, durante o andar em esteira. 
ANEXO VI - Curvas da FRS e eletromiografia referentes ao andar em esteira de todos os sujeitos do grupo controle (GC) (cont.)
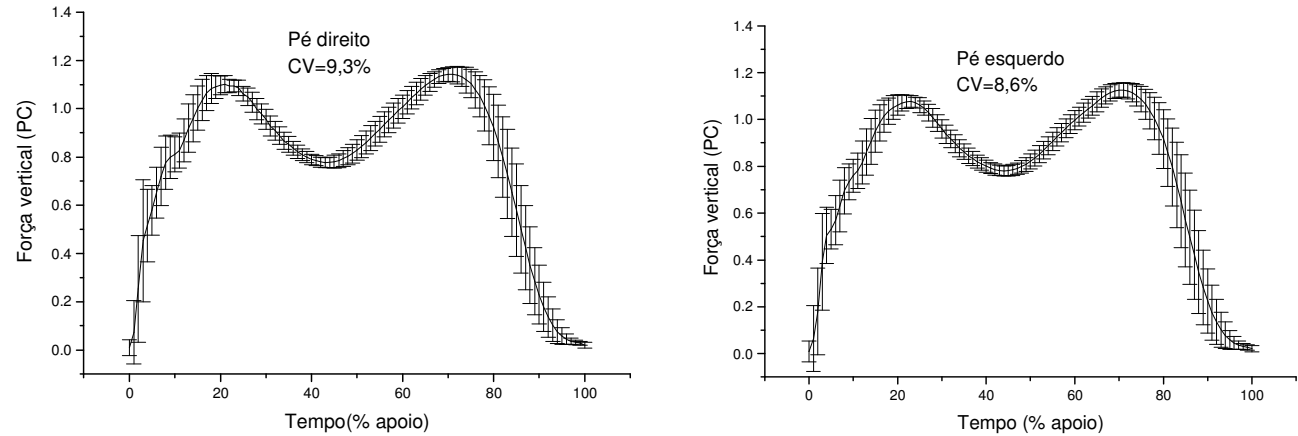

Força vertical média em função do peso corporal $(P C)$ do pé direito e esquerdo do sujeito GC10, durante 0 andar em esteira.
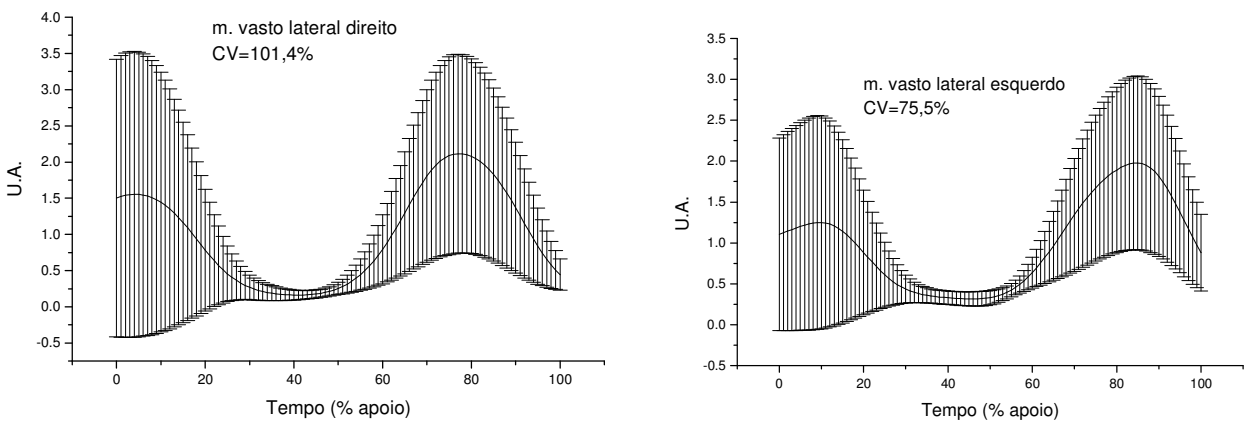

Curvas médias e desvios padrão da EMG do m. vasto lateral direito e esquerdo do sujeito GC10, durante 0 andar em esteira.
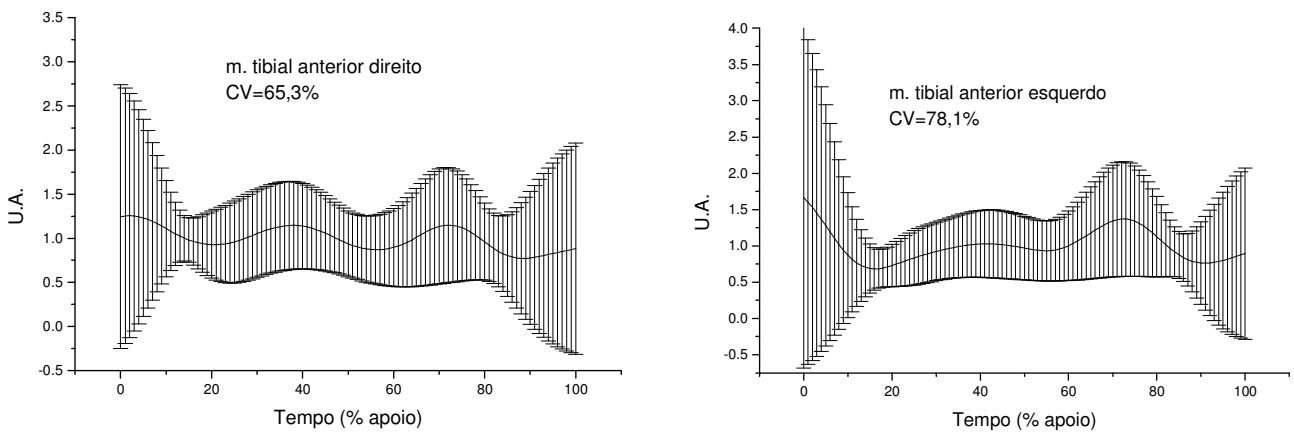

Curvas médias e desvios padrão da EMG do m. tibial anterior direito e esquerdo do sujeito GC10, durante 0 andar em esteira.
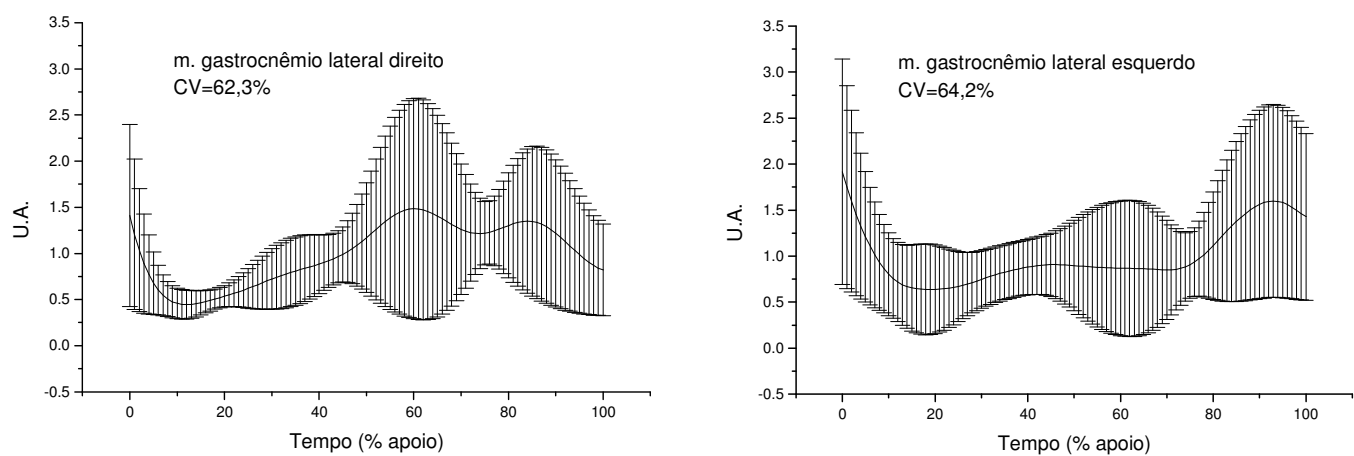

Curvas médias e desvios padrão da EMG do m. gastrocnêmio lateral direito e esquerdo do sujeito GC10, durante o andar em esteira. 
ANEXO VI - Curvas da FRS e eletromiografia referentes ao andar em esteira de todos os sujeitos do grupo controle (GC) (cont.)
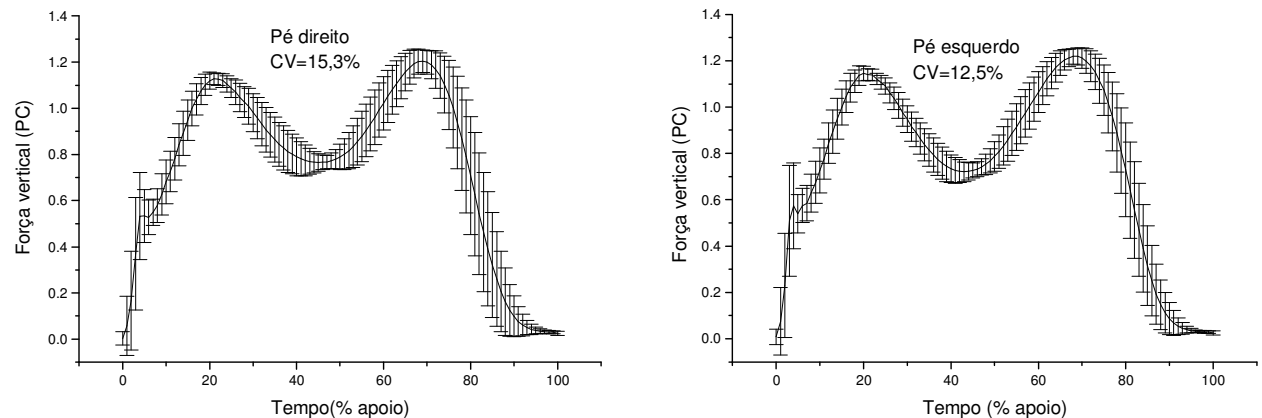

Força vertical média em função do peso corporal $(\mathrm{PC})$ do pé direito e esquerdo do sujeito $\mathrm{GC11}$, durante 0 andar em esteira.
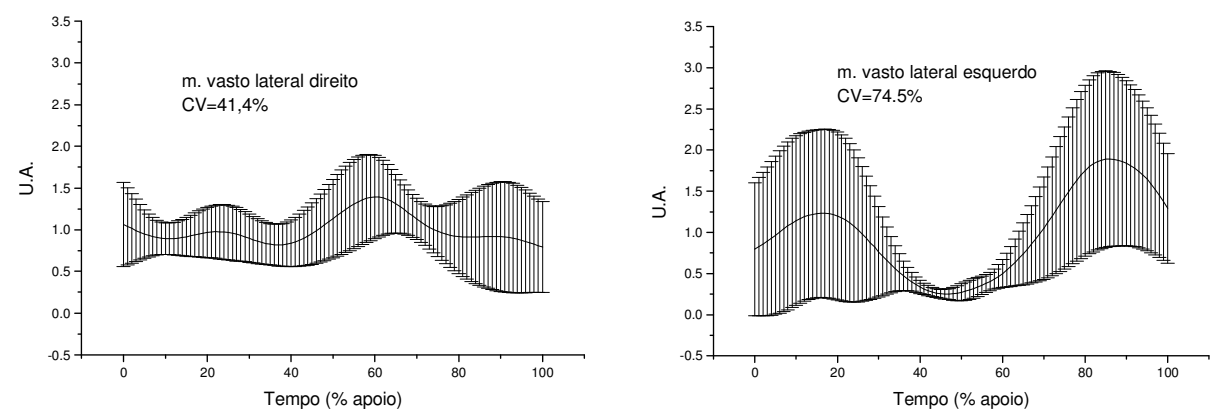

Curvas médias e desvios padrão da EMG do m. vasto lateral direito e esquerdo do sujeito GC11, durante o andar em esteira.
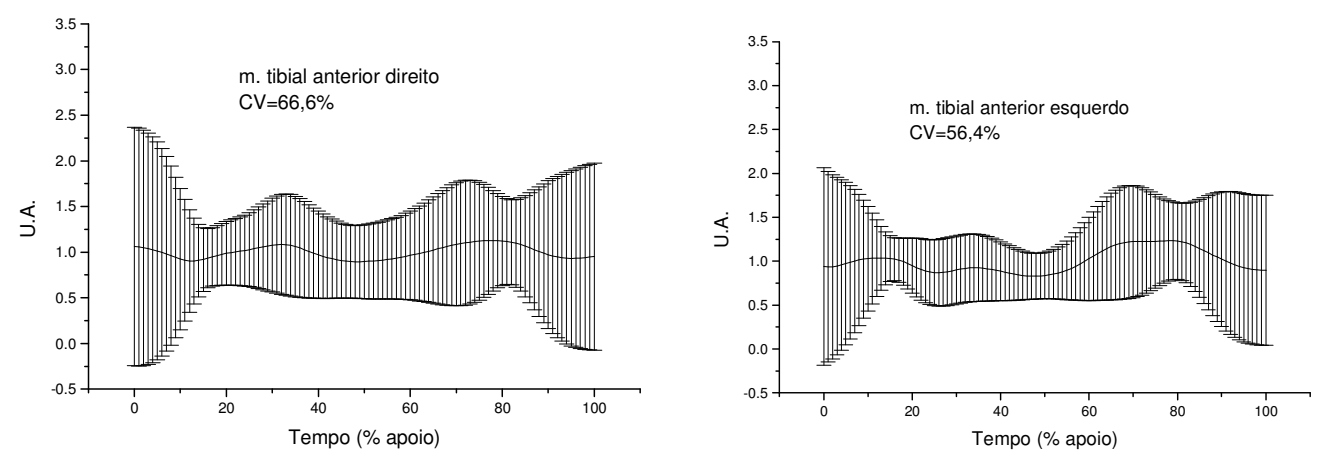

Curvas médias e desvios padrão da EMG do m. tibial anterior direito e esquerdo do sujeito GC11, durante o andar em esteira.
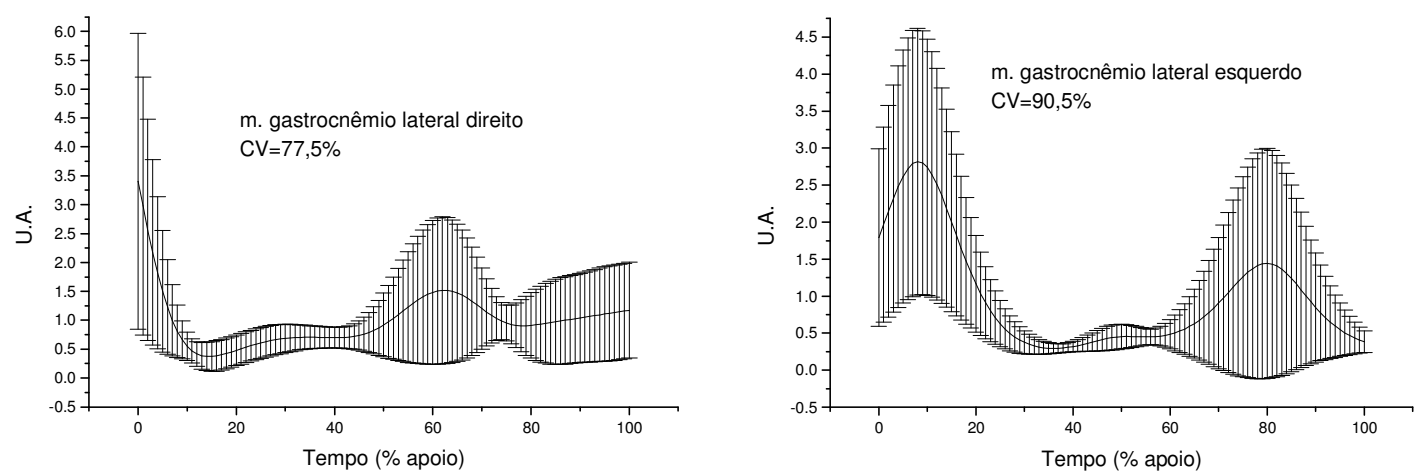

Curvas médias e desvios padrão da EMG do m. gastrocnêmio lateral direito e esquerdo do sujeito GC11, durante o andar em esteira. 
ANEXO VI - Curvas da FRS e eletromiografia referentes ao andar em esteira de todos os sujeitos do grupo controle (GC) (cont.)
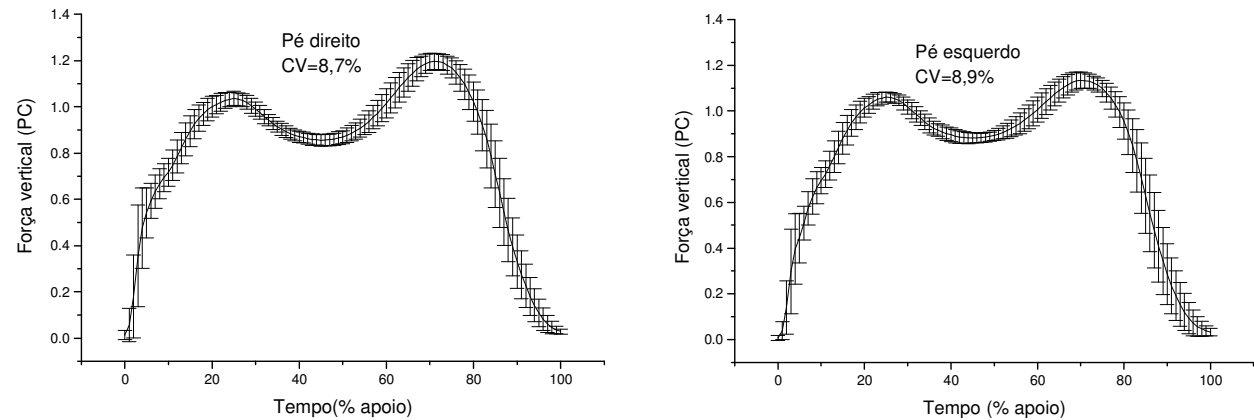

Força vertical média em função do peso corporal $(P C)$ do pé direito e esquerdo do sujeito $G C 12$, durante 0 andar em esteira.
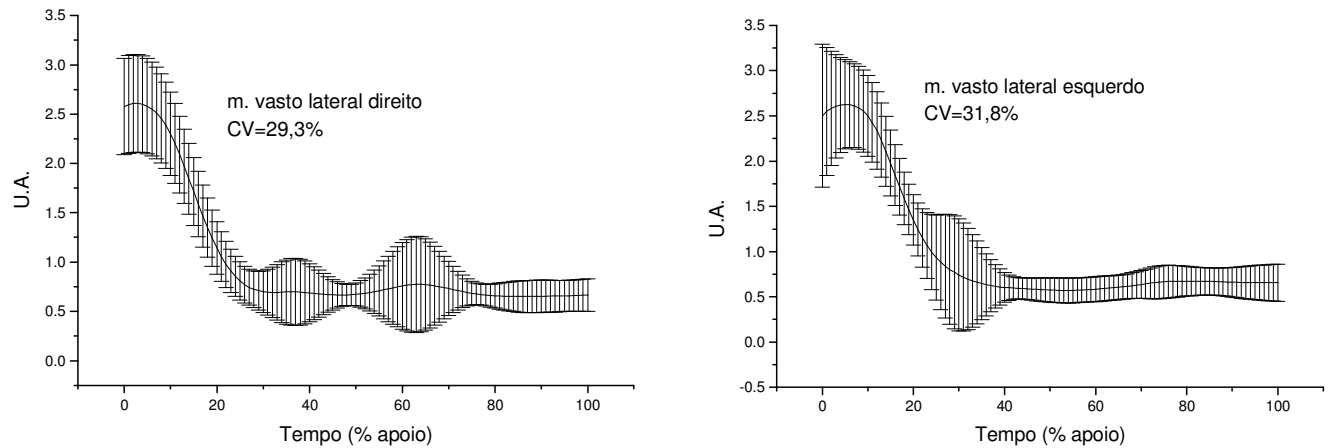

Curvas médias e desvios padrão da EMG do m. vasto lateral direito e esquerdo do sujeito GC12, durante 0 andar em esteira.
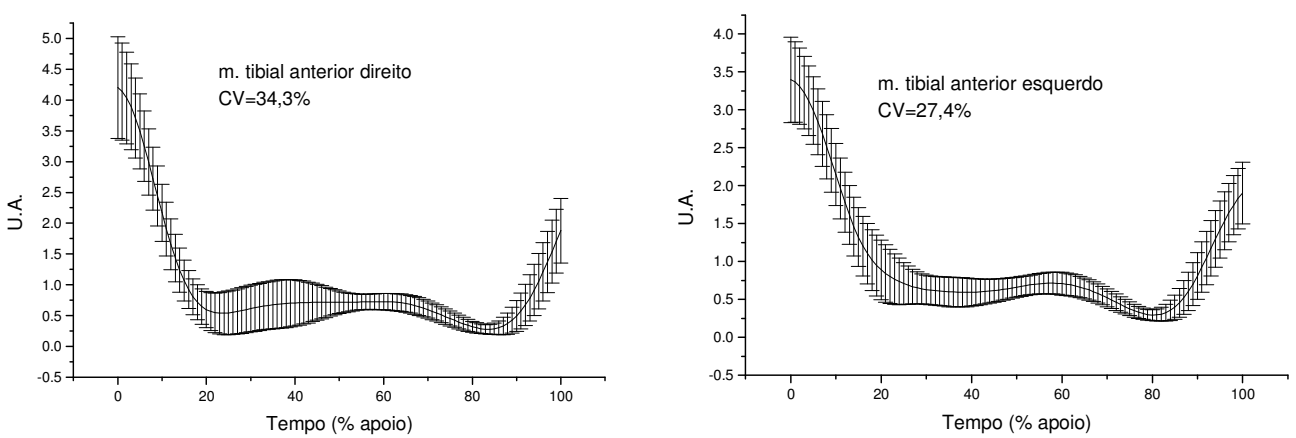

Curvas médias e desvios padrão da EMG do m. tibial anterior direito e esquerdo do sujeito GC12, durante o andar em esteira.
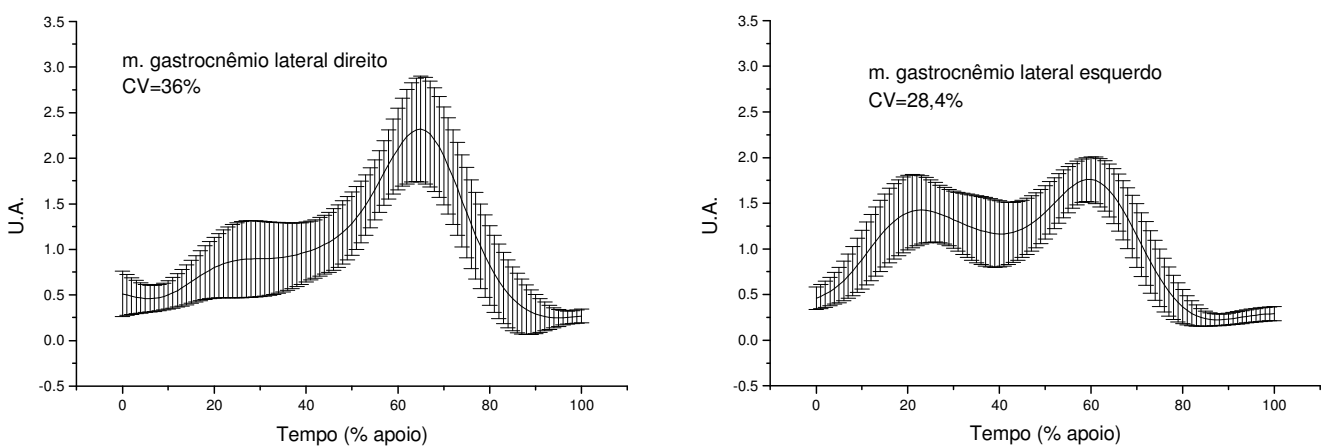

Curvas médias e desvios padrão da EMG do m. gastrocnêmio lateral direito e esquerdo do sujeito GC12, durante o andar em esteira. 
ANEXO VI - Curvas da FRS e eletromiografia referentes ao andar em esteira de todos os sujeitos do grupo controle (GC) (cont.)
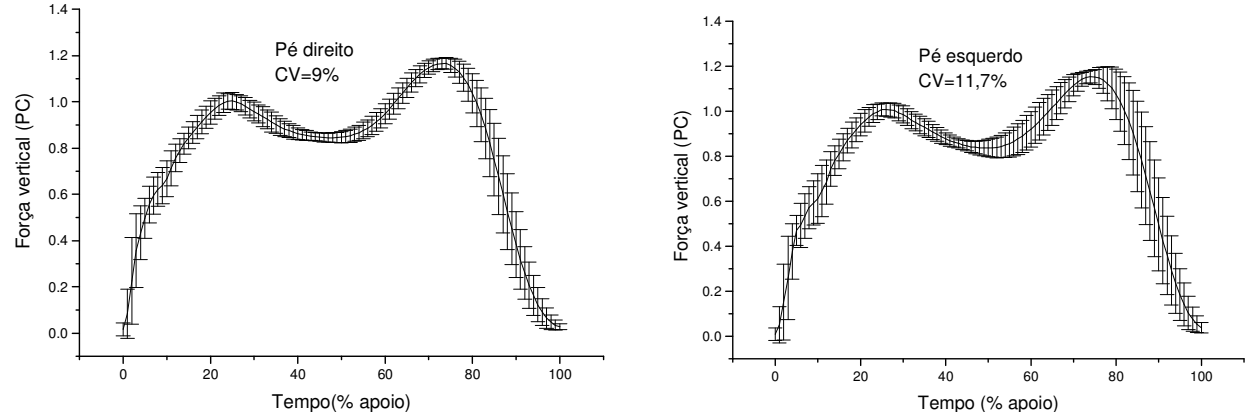

Força vertical média em função do peso corporal $(P C)$ do pé direito e esquerdo do sujeito $G C 13$, durante 0 andar em esteira.
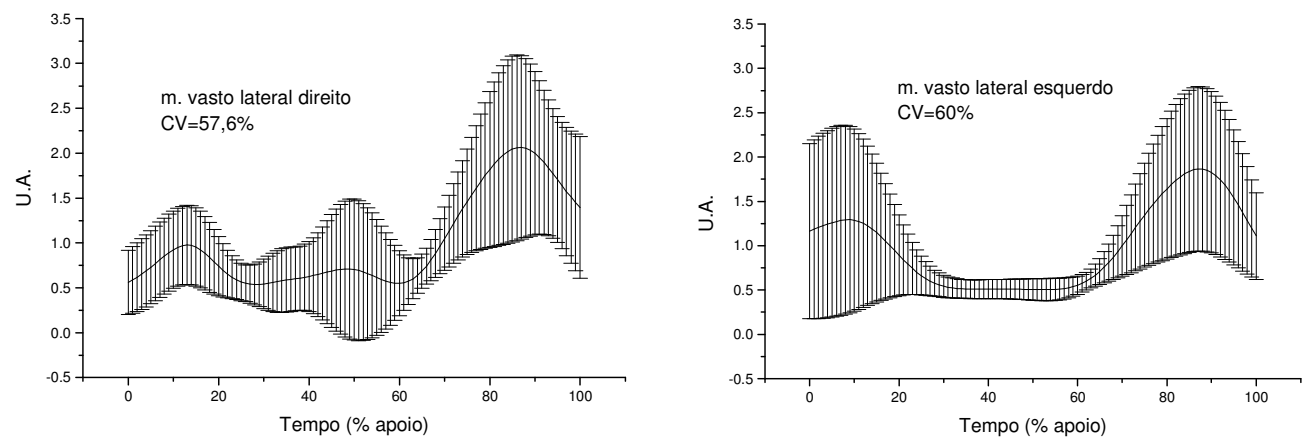

Curvas médias e desvios padrão da EMG do m. vasto lateral direito e esquerdo do sujeito GC13, durante o andar em esteira.
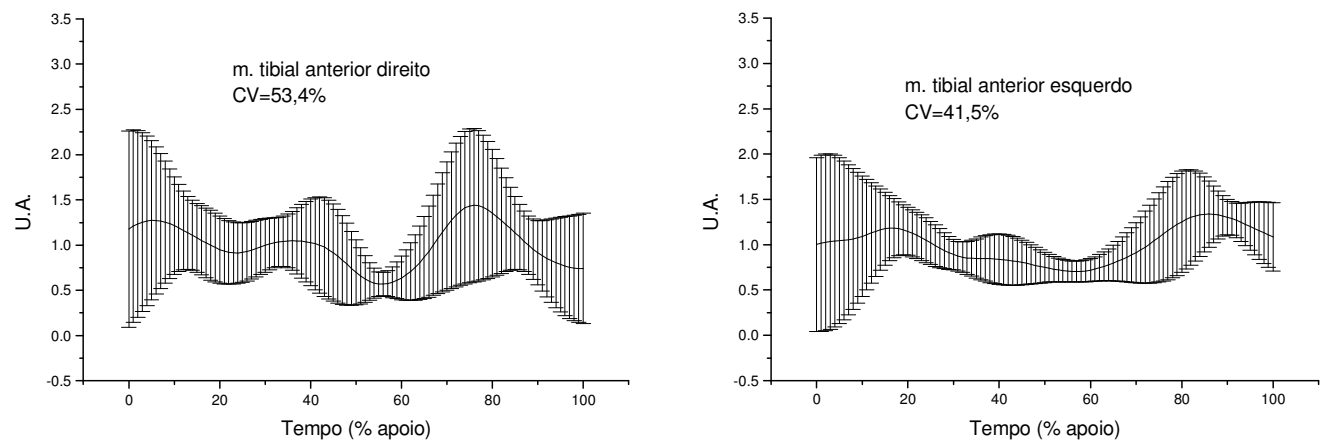

Curvas médias e desvios padrão da EMG do m. tibial anterior direito e esquerdo do sujeito GC13, durante o andar em esteira.
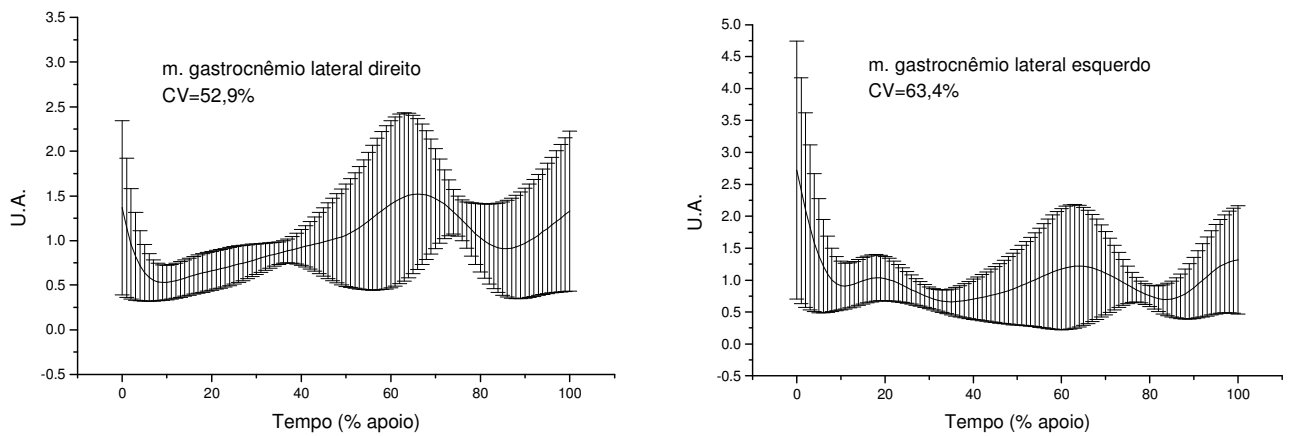

Curvas médias e desvios padrão da EMG do m. gastrocnêmio lateral direito e esquerdo do sujeito GC13, durante o andar em esteira. 
ANEXO VI - Curvas da FRS e eletromiografia referentes ao andar em esteira de todos os sujeitos do grupo controle (GC) (cont.)
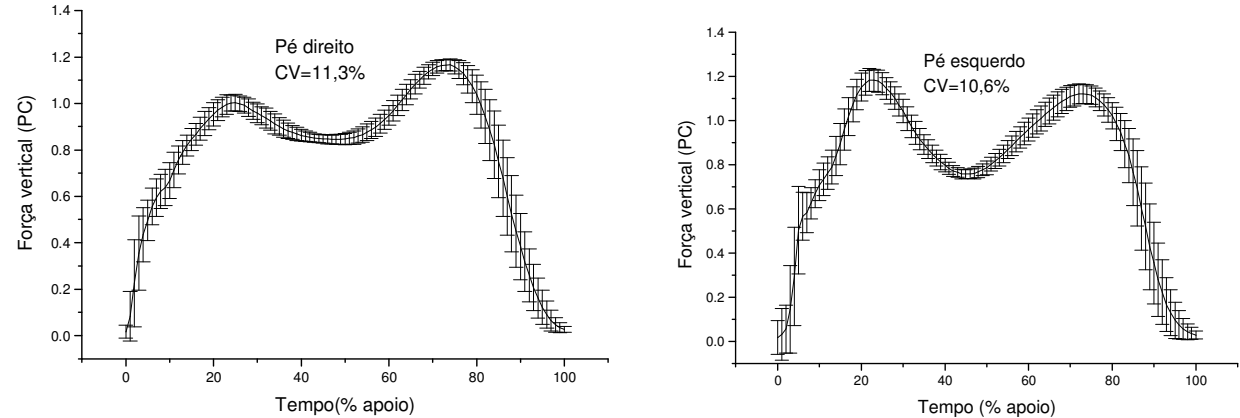

Força vertical média em função do peso corporal (PC) do pé direito e esquerdo do sujeito GC14, durante o andar em esteira.
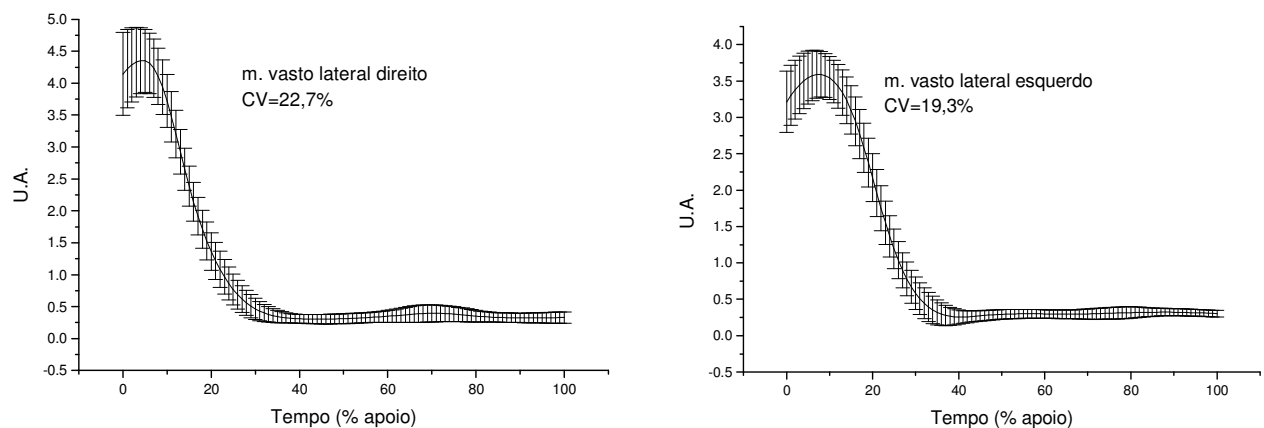

Curvas médias e desvios padrão da EMG do m. vasto lateral direito e esquerdo do sujeito GC14, durante 0 andar em esteira.
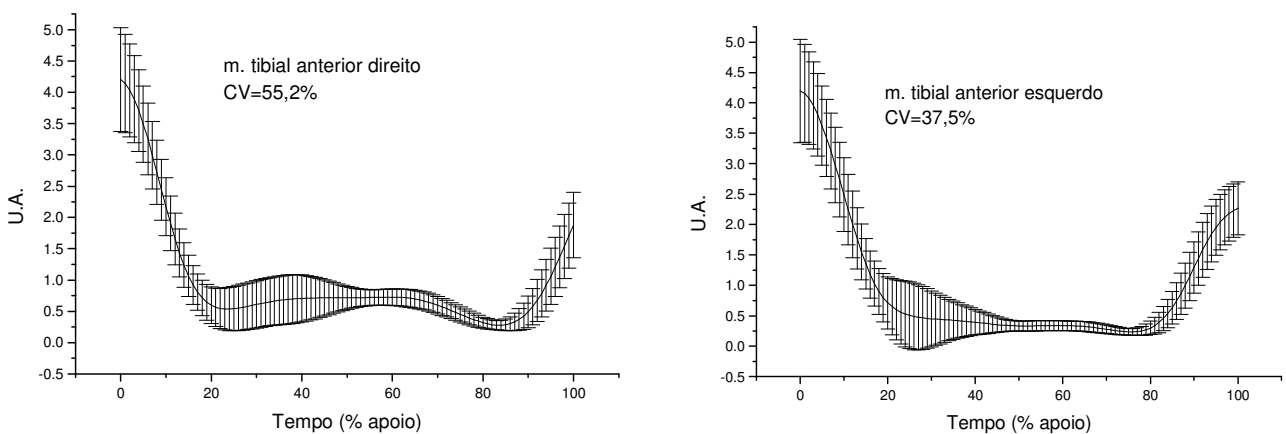

Curvas médias e desvios padrão da EMG do m. tibial anterior direito e esquerdo do sujeito GC14, durante 0 andar em esteira.
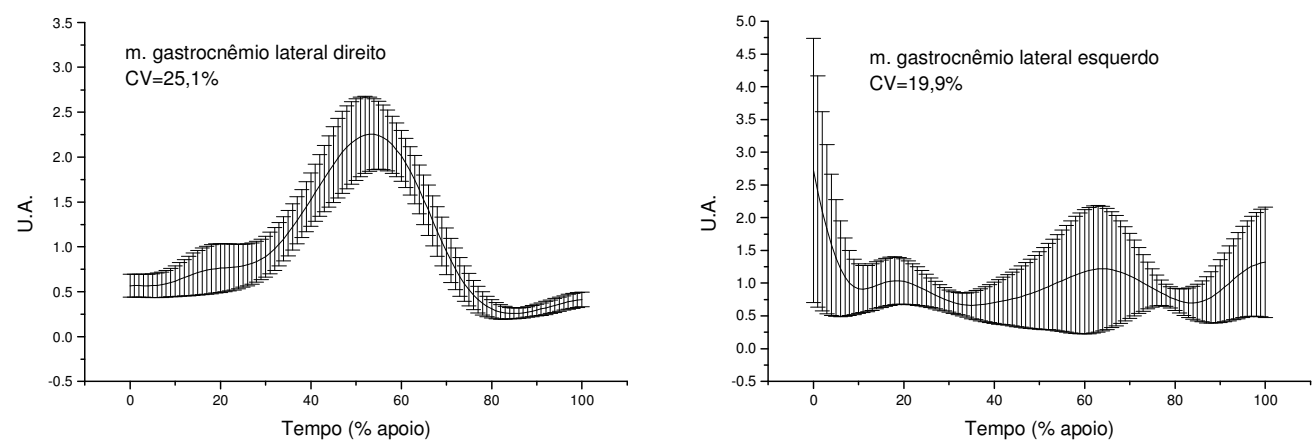

Curvas médias e desvios padrão da EMG do m. gastrocnêmio lateral direito e esquerdo do sujeito GC14, durante o andar em esteira. 
ANEXO VI - Curvas da FRS e eletromiografia referentes ao andar em esteira de todos os sujeitos do grupo controle (GC) (cont.)
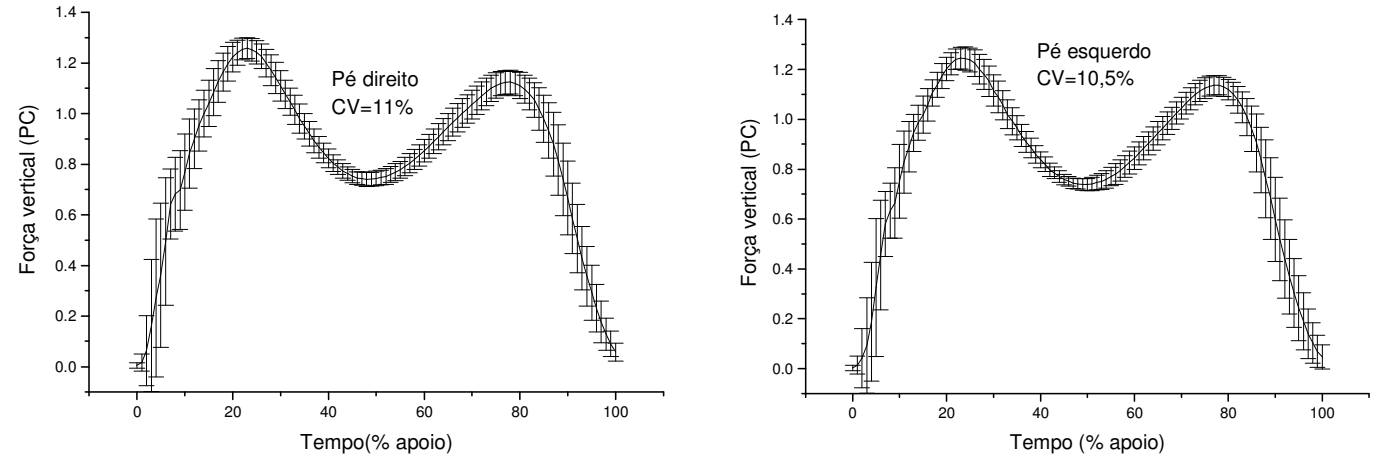

Força vertical média em função do peso corporal (PC) do pé direito e esquerdo do sujeito GC15, durante 0 andar em esteira.
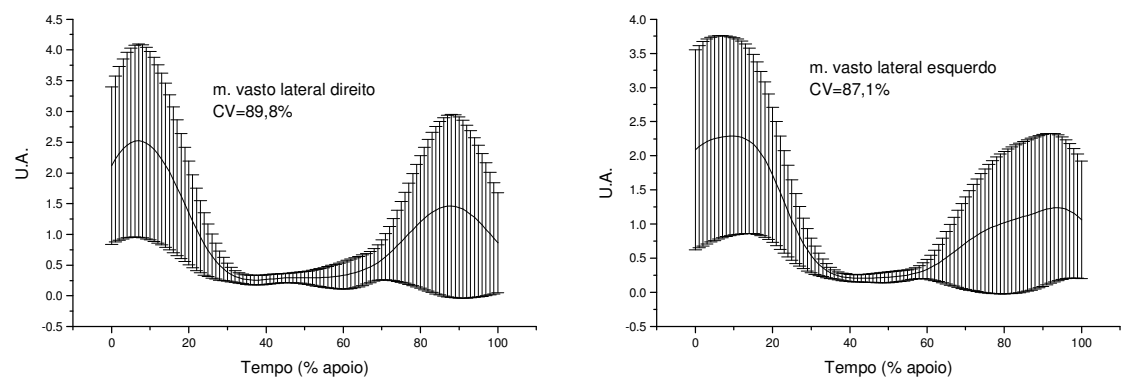

Curvas médias e desvios padrão da EMG do m. vasto lateral direito e esquerdo do sujeito GC15, durante 0 andar em esteira.
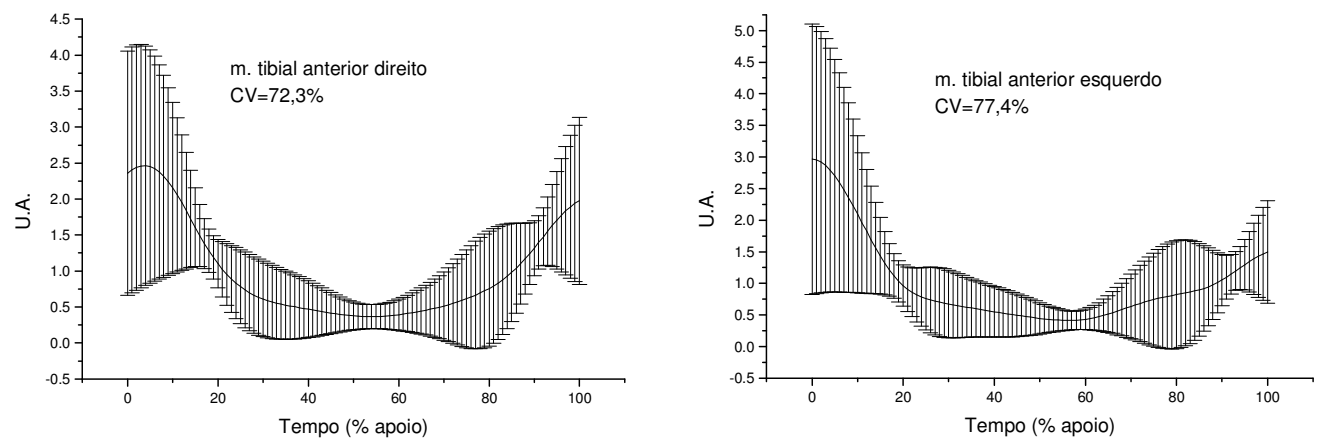

Curvas médias e desvios padrão da EMG do m. tibial anterior direito e esquerdo do sujeito GC15, durante o andar em esteira.
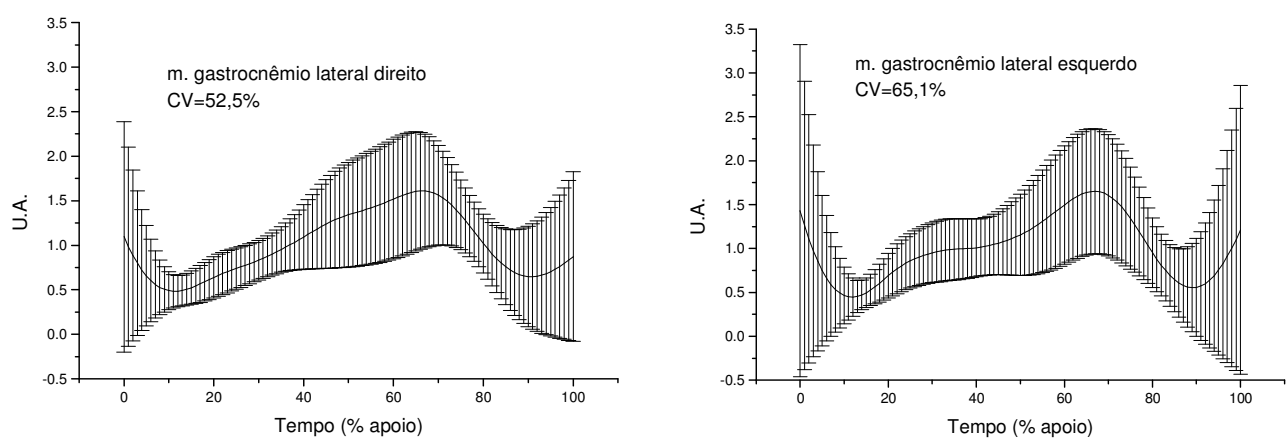

Curvas médias e desvios padrão da EMG do m. gastrocnêmio lateral direito e esquerdo do sujeito GC15, durante o andar em esteira. 
ANEXO VI - Curvas da FRS e eletromiografia referentes ao andar em esteira de todos os sujeitos do grupo controle (GC) (cont.)
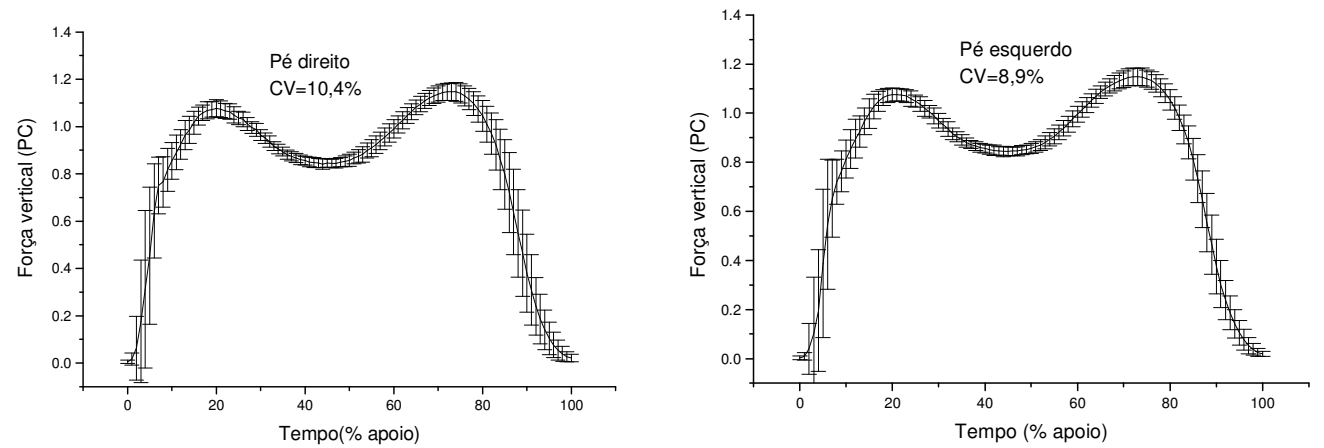

Força vertical média em função do peso corporal (PC) do pé direito e esquerdo do sujeito GC16, durante 0 andar em esteira.
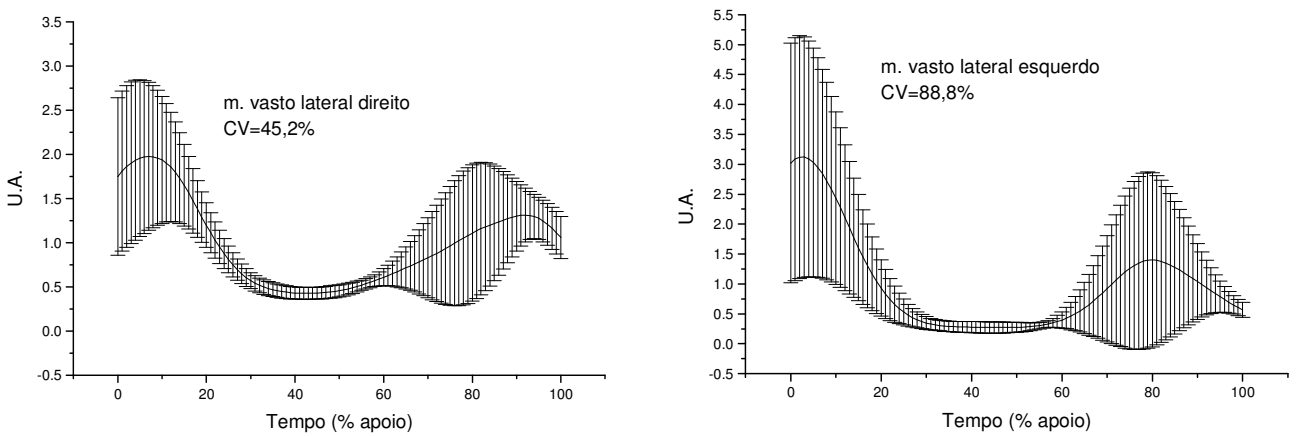

Curvas médias e desvios padrão da EMG do m. vasto lateral direito e esquerdo do sujeito GC16, durante 0 andar em esteira.
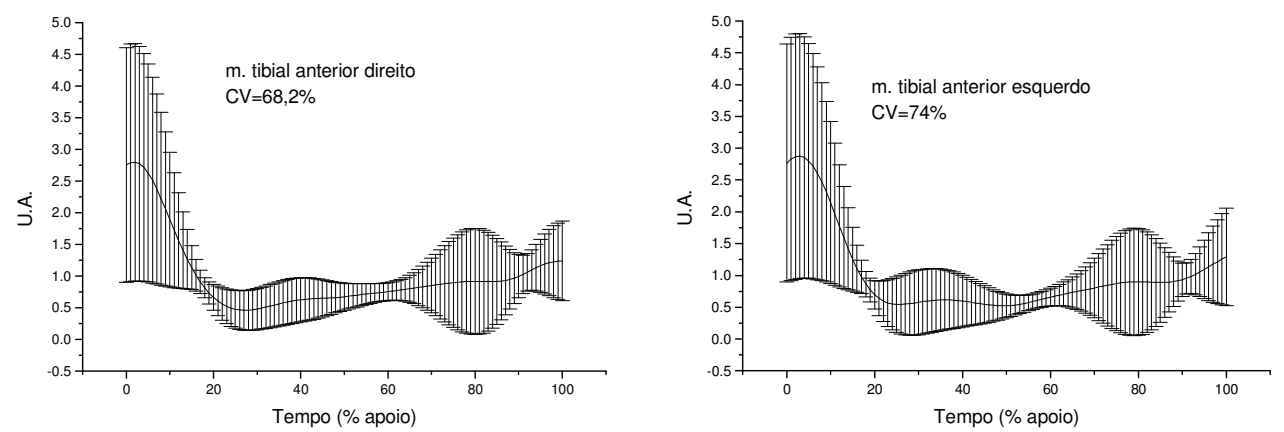

Curvas médias e desvios padrão da EMG do m. tibial anterior direito e esquerdo do sujeito GC16, durante o andar em esteira.
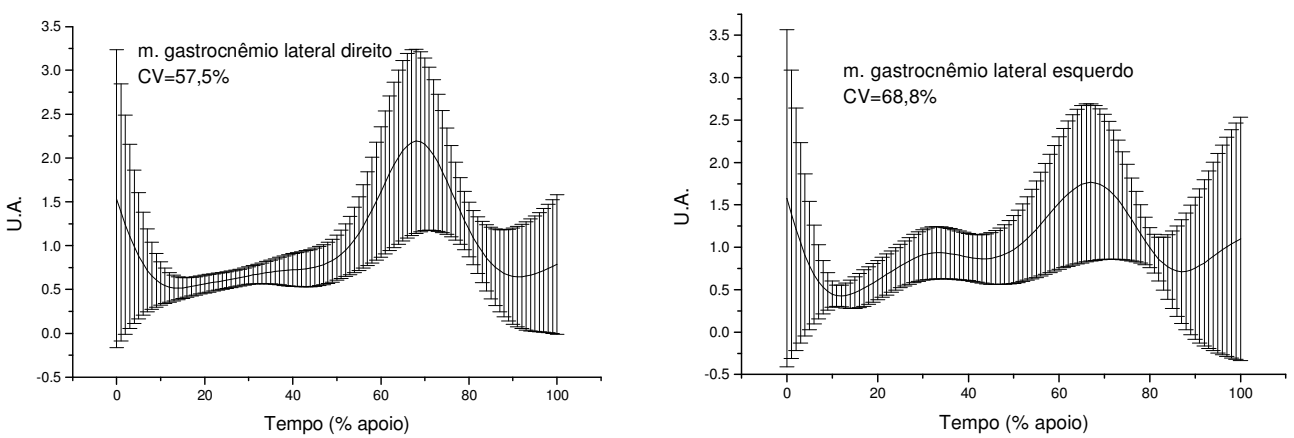

Curvas médias e desvios padrão da EMG do m. gastrocnêmio lateral direito e esquerdo do sujeito GC16, durante o andar em esteira. 
ANEXO VI - Curvas da FRS e eletromiografia referentes ao andar em esteira de todos os sujeitos do grupo controle (GC) (cont.)
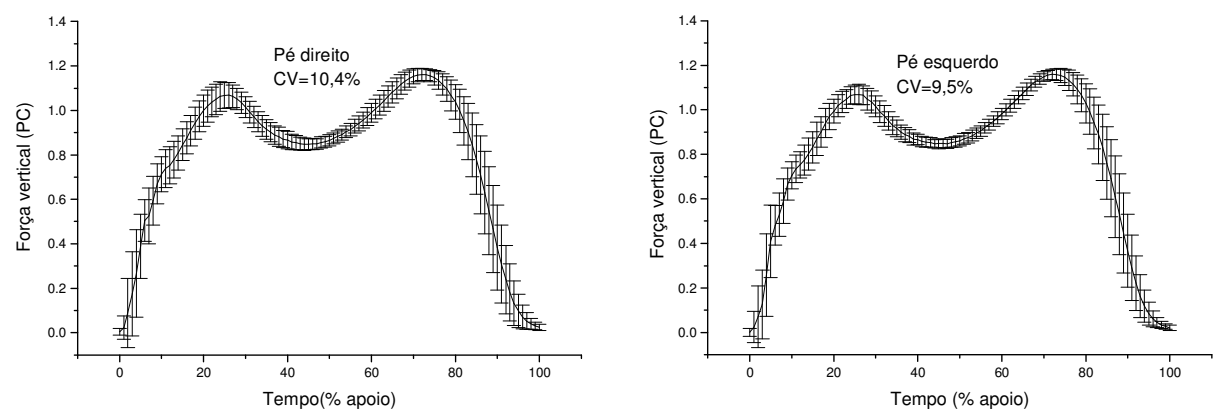

Força vertical média em função do peso corporal (PC) do pé direito e esquerdo do sujeito GC17, durante o andar em esteira.
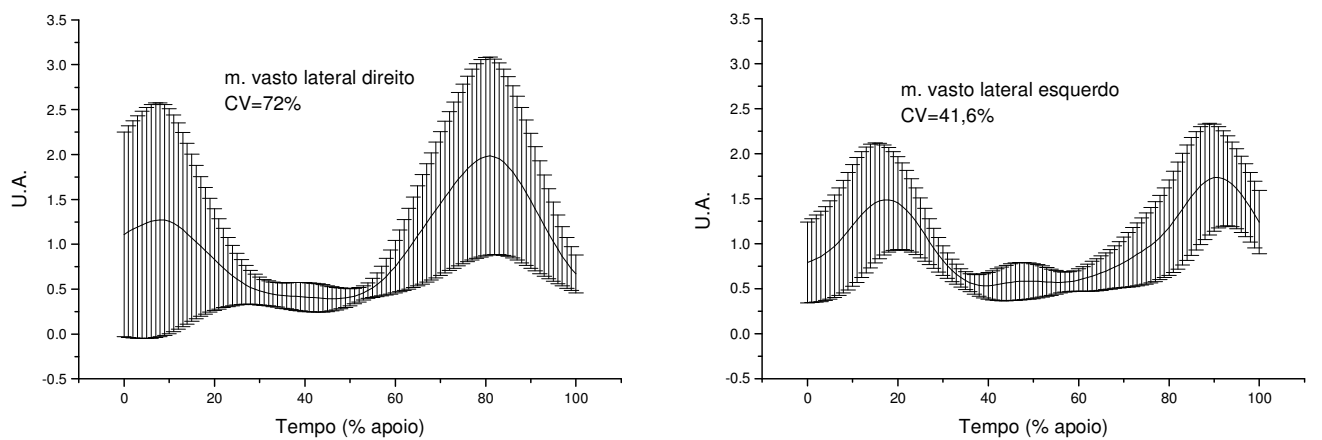

Curvas médias e desvios padrão da EMG do m. vasto lateral direito e esquerdo do sujeito GC17, durante o andar em esteira.
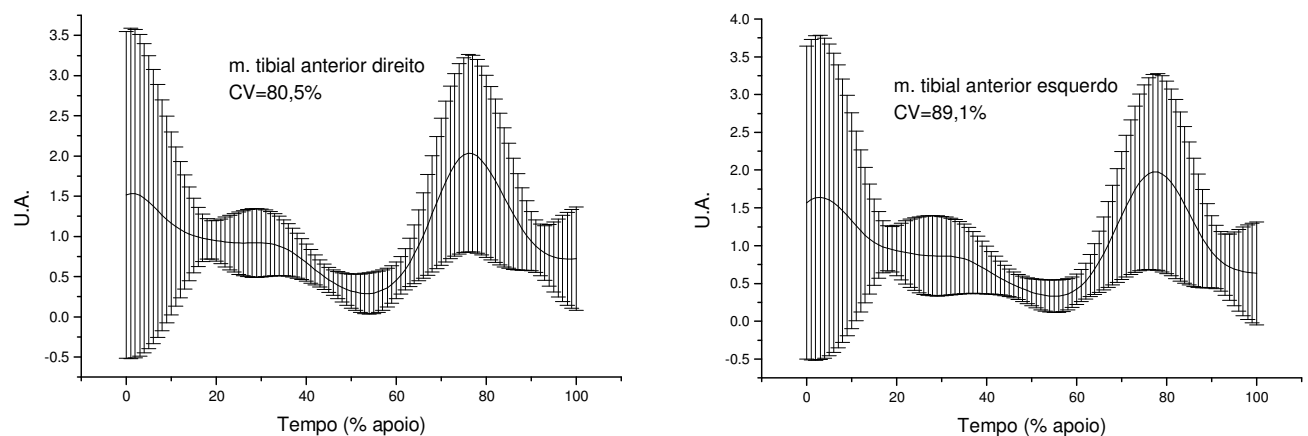

Curvas médias e desvios padrão da EMG do m. tibial anterior direito e esquerdo do sujeito GC17, durante 0 andar em esteira.
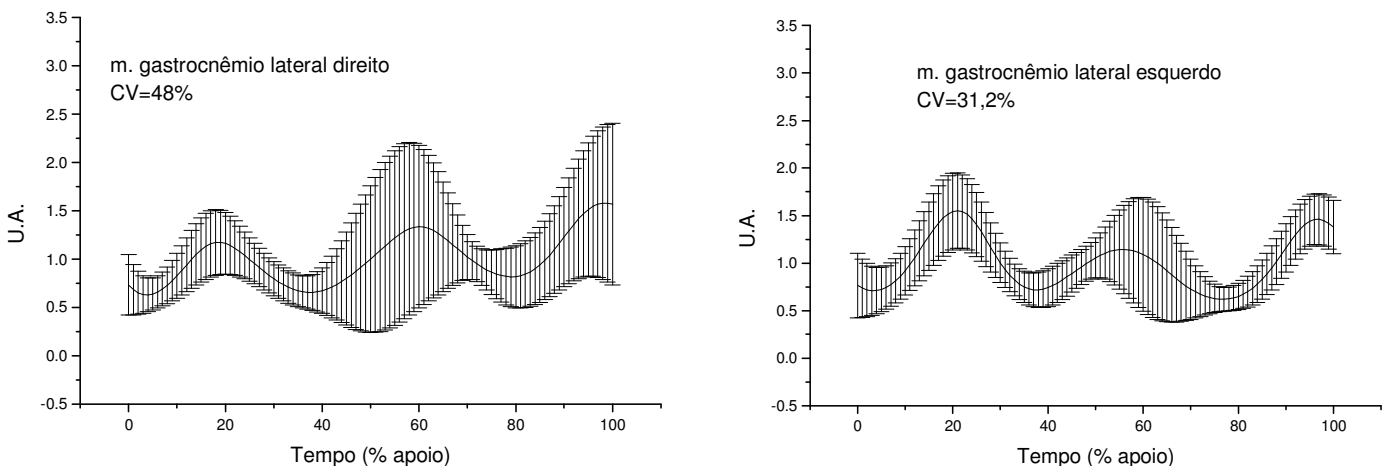

Curvas médias e desvios padrão da EMG do m. gastrocnêmio lateral direito e esquerdo do sujeito GC17, durante o andar em esteira. 
ANEXO VI - Curvas da FRS e eletromiografia referentes ao andar em esteira de todos os sujeitos do grupo controle (GC) (cont.)
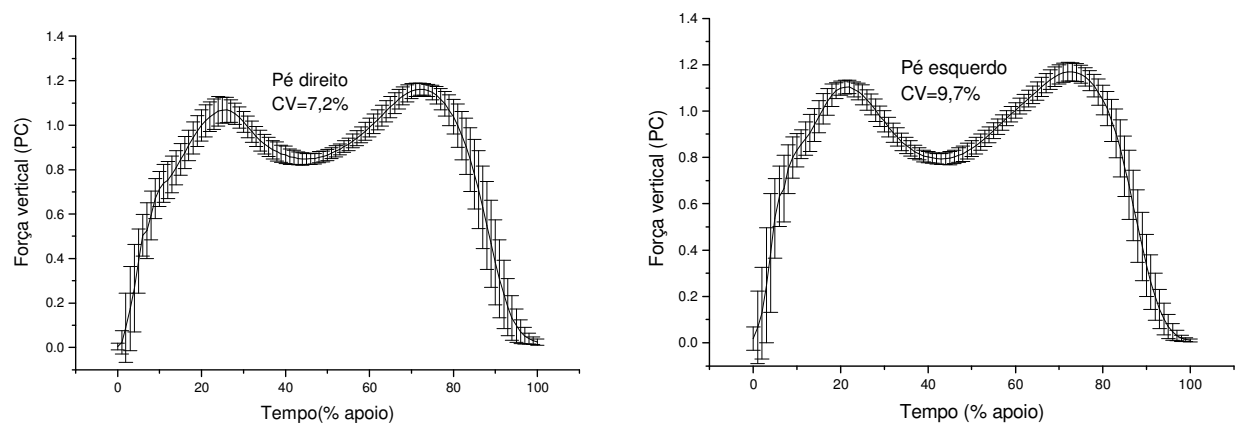

Força vertical média em função do peso corporal (PC) do pé direito e esquerdo do sujeito GC18, durante o andar em esteira.
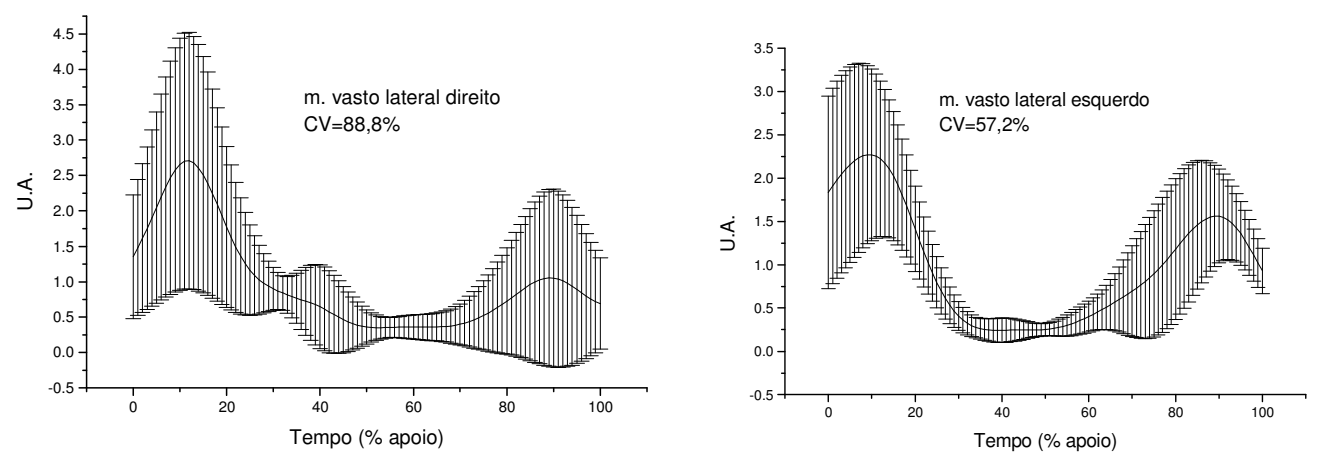

Curvas médias e desvios padrão da EMG do m. vasto lateral direito e esquerdo do sujeito GC18, durante o andar em esteira.
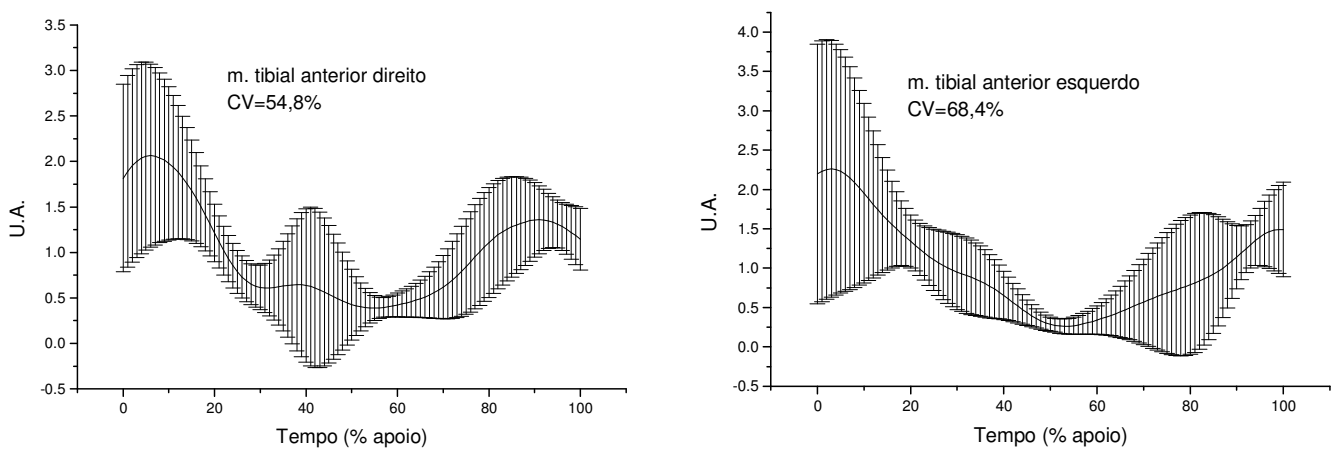

Curvas médias e desvios padrão da EMG do m. tibial anterior direito e esquerdo do sujeito GC18, durante o andar em esteira.
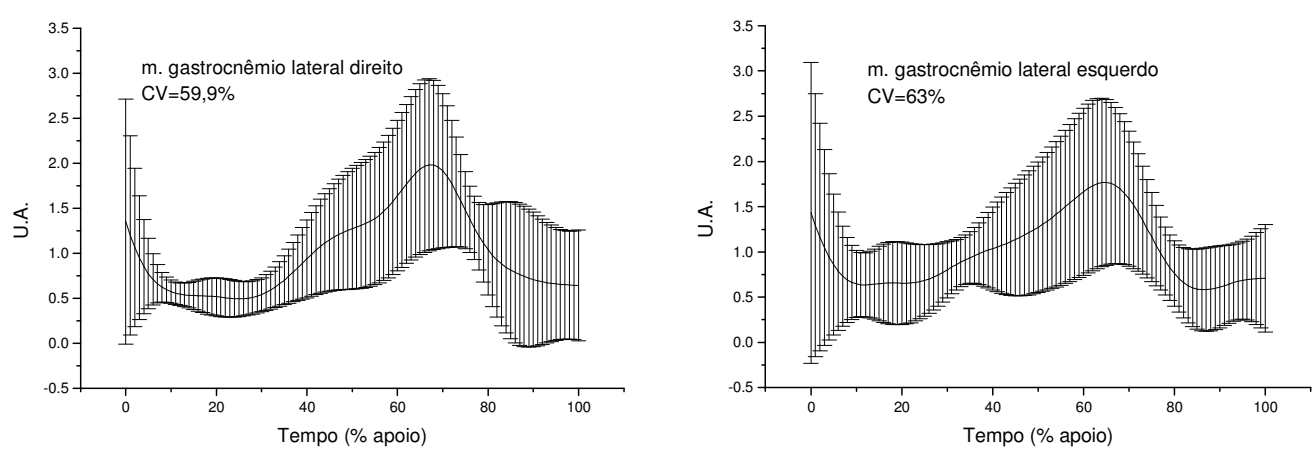

Curvas médias e desvios padrão da EMG do m. gastrocnêmio lateral direito e esquerdo do sujeito GC18, durante o andar em esteira. 
ANEXO VI - Curvas da FRS e eletromiografia referentes ao andar em esteira de todos os sujeitos do grupo controle (GC) (cont.)
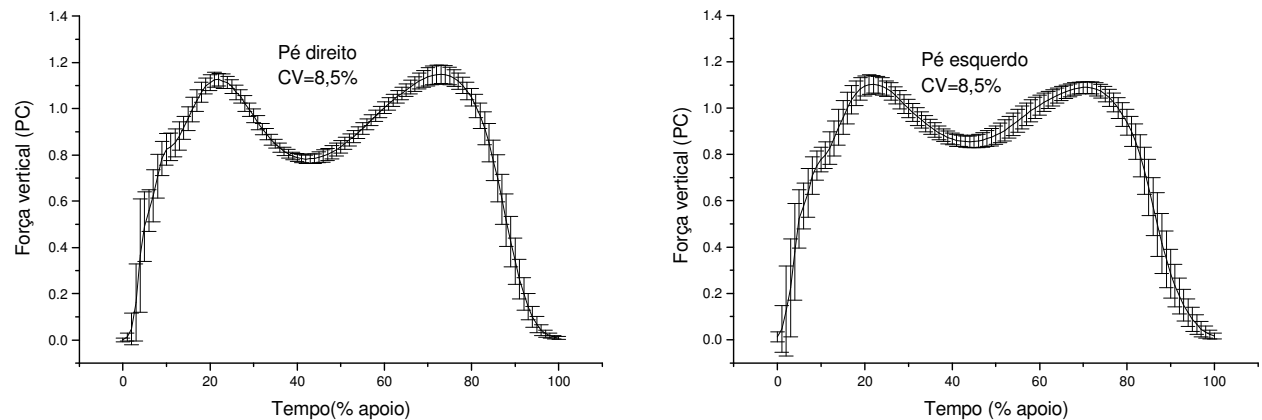

Força vertical média em função do peso corporal (PC) do pé direito e esquerdo do sujeito GC19, durante o andar em esteira.
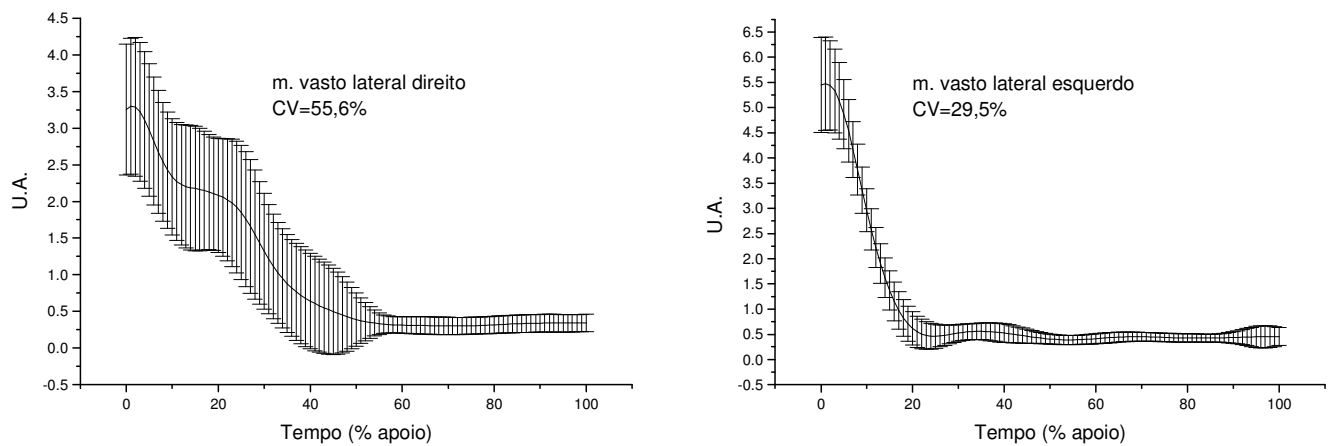

Curvas médias e desvios padrão da EMG do m. vasto lateral direito e esquerdo do sujeito GC19, durante o andar em esteira.
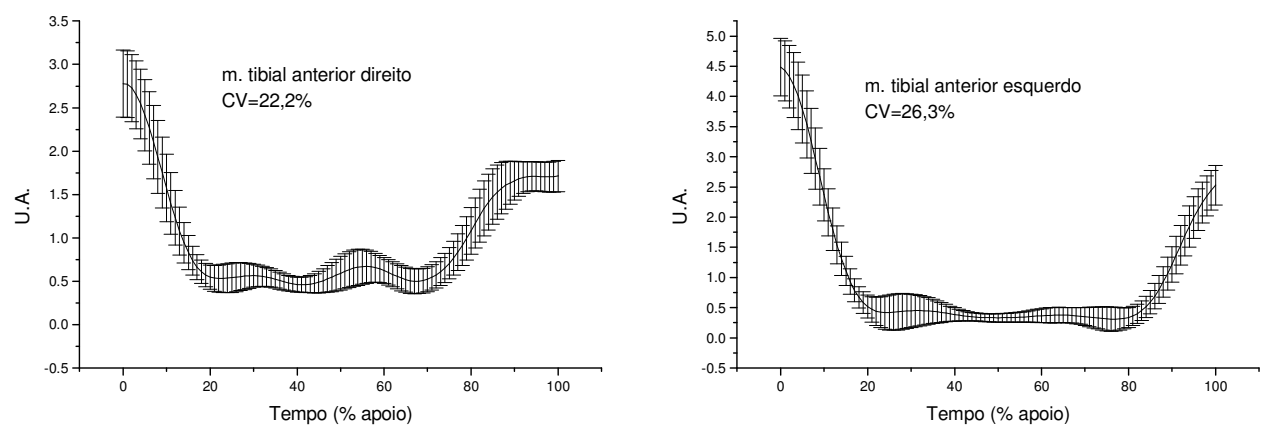

Curvas médias e desvios padrão da EMG do m. tibial anterior direito e esquerdo do sujeito GC19, durante o andar em esteira.
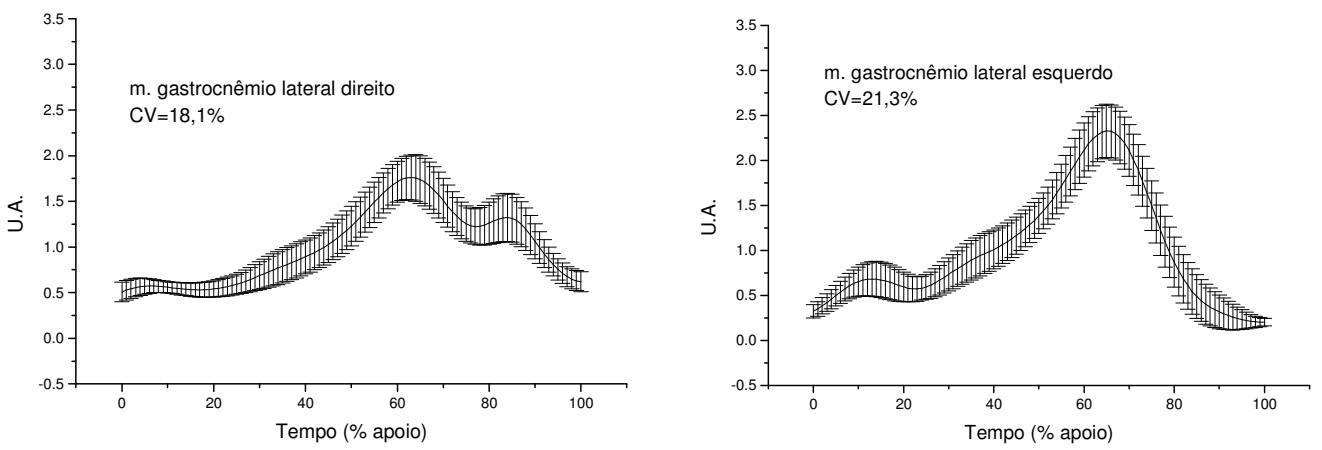

Curvas médias e desvios padrão da EMG do m. gastrocnêmio lateral direito e esquerdo do sujeito GC19, durante o andar em esteira. 
ANEXO VI - Curvas da FRS e eletromiografia referentes ao andar em esteira de todos os sujeitos do grupo controle (GC) (cont.)
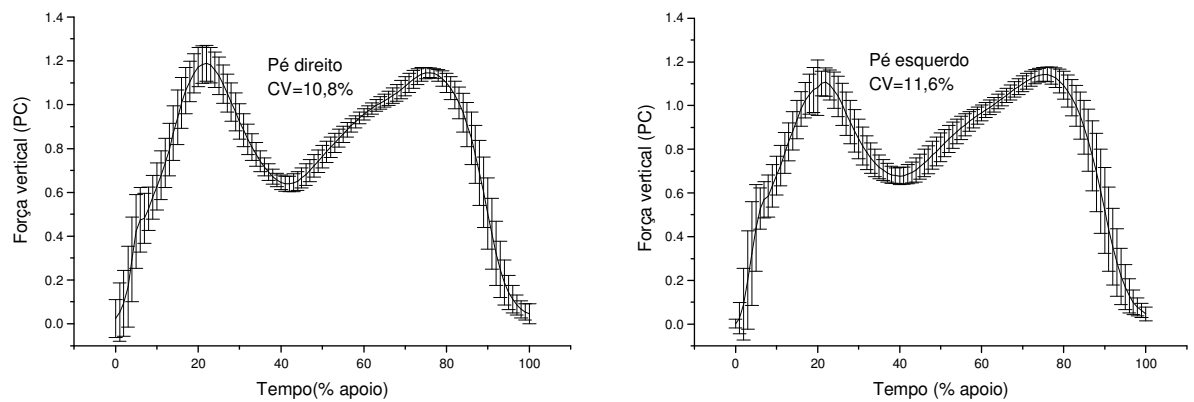

Força vertical média em função do peso corporal $(\mathrm{PC})$ do pé direito e esquerdo do sujeito GC20, durante o andar em esteira.
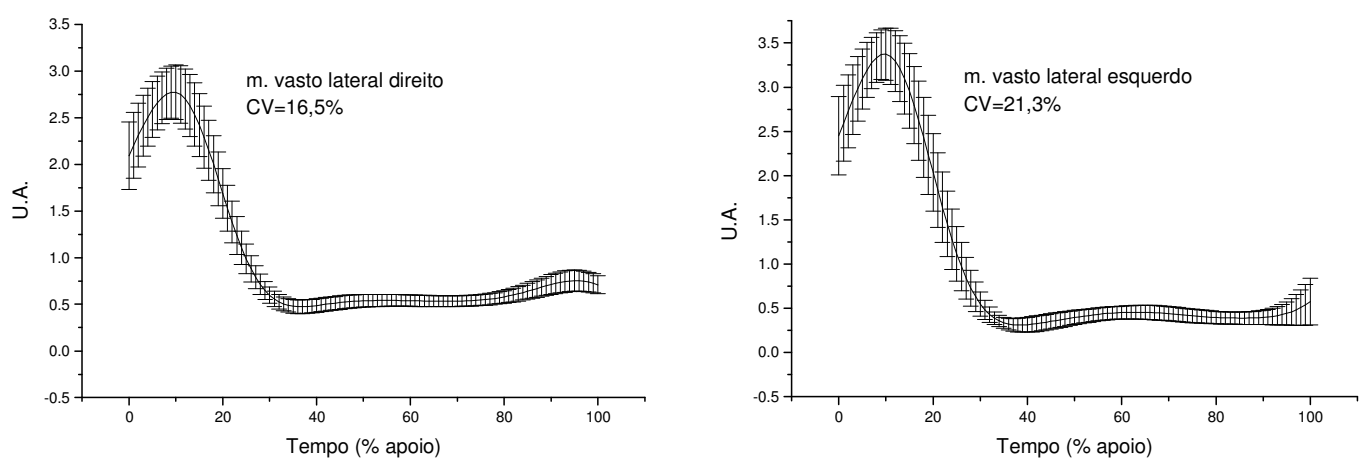

Curvas médias e desvios padrão da EMG do m. vasto lateral direito e esquerdo do sujeito GC20, durante 0 andar em esteira.
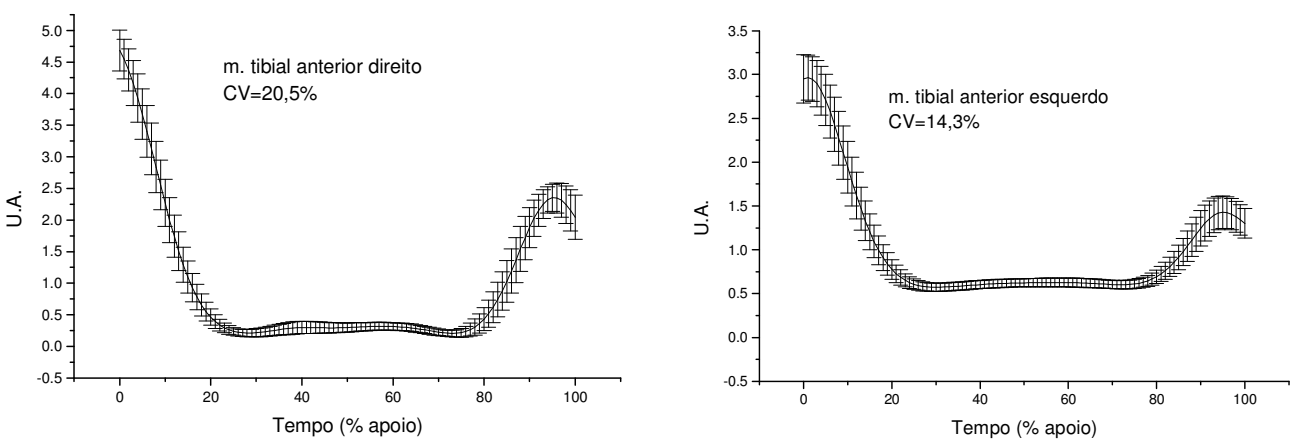

Curvas médias e desvios padrão da EMG do m. tibial anterior direito e esquerdo do sujeito GC20, durante o andar em esteira.
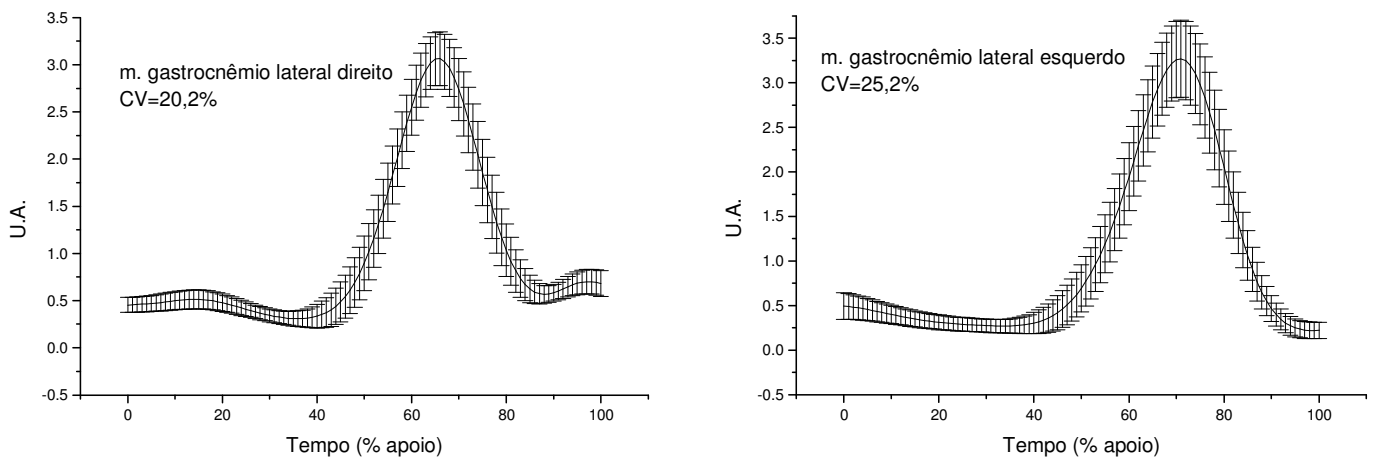

Curvas médias e desvios padrão da EMG do m. gastrocnêmio lateral direito e esquerdo do sujeito GC20, durante o andar em esteira. 
ANEXO VII- Curvas da FRS e eletromiografia referentes ao andar em esteira de todos os sujeitos do grupo diabético (GD).
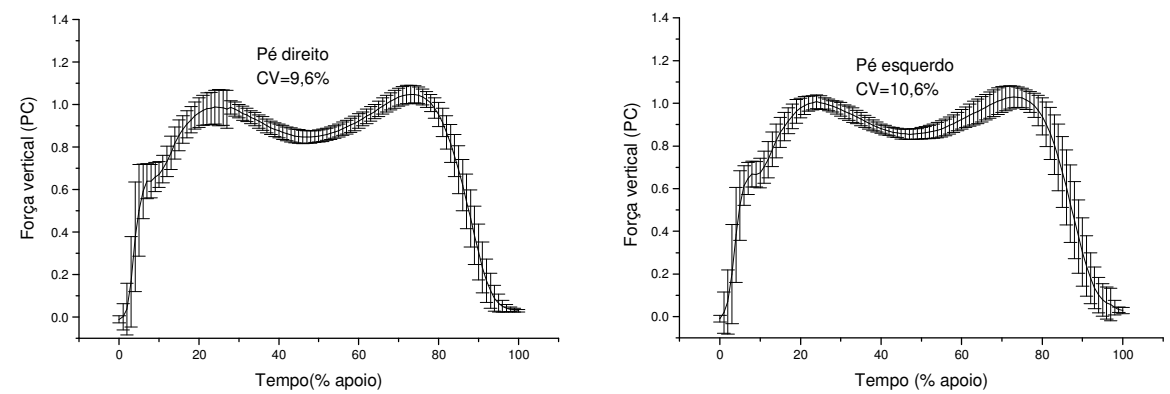

Força vertical média em função do peso corporal (PC) do pé direito e esquerdo do sujeito GD01, durante o andar em esteira
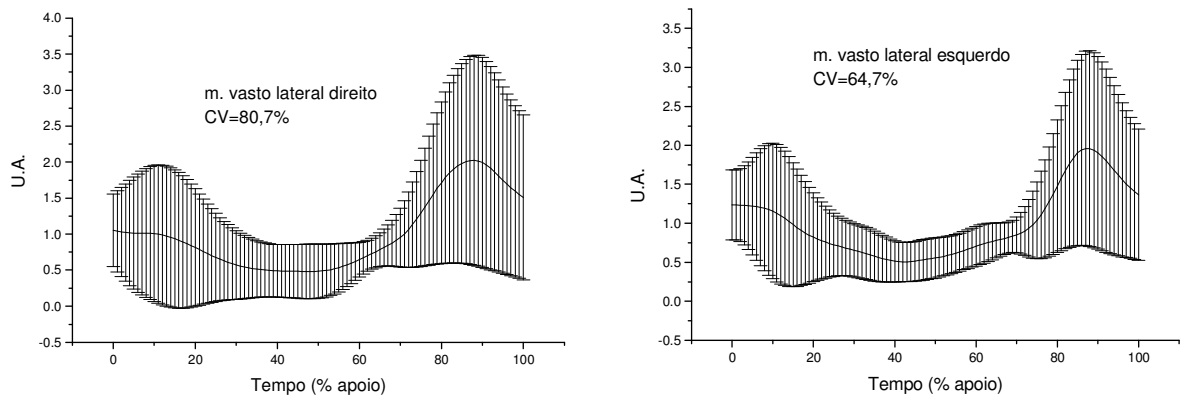

Curvas médias e desvios padrão da EMG do m. vasto lateral direito e esquerdo do sujeito GD01, durante 0 andar em esteira.
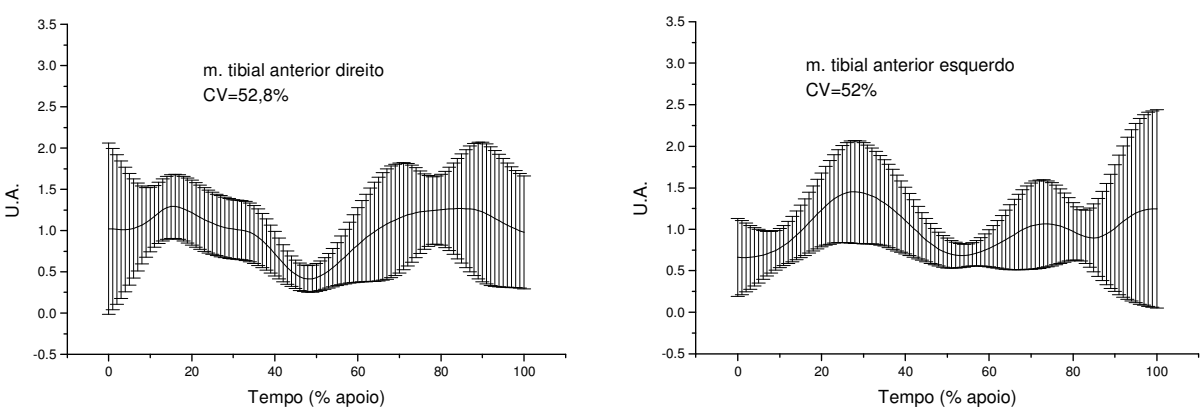

Curvas médias e desvios padrão da EMG do m. tibial anterior direito e esquerdo do sujeito GD01, durante o andar em esteira.
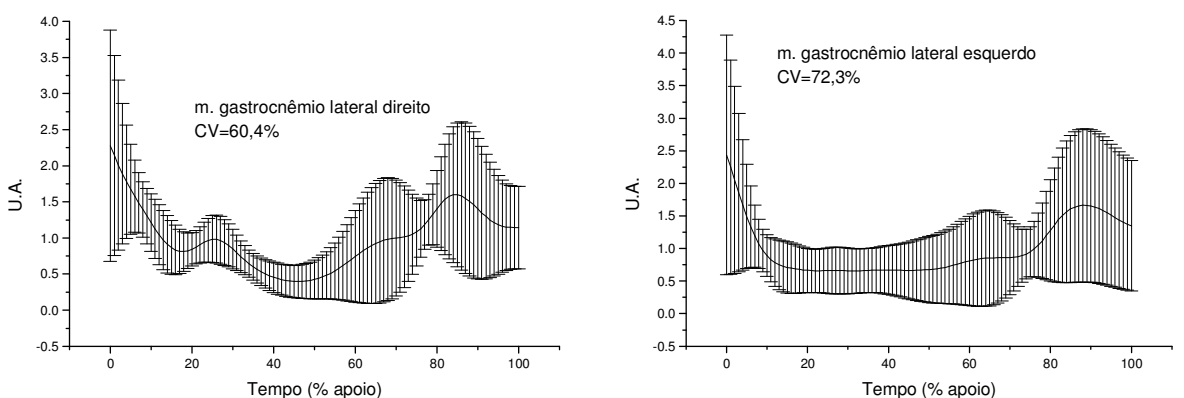

Curvas médias e desvios padrão da EMG do m. gastrocnêmio lateral direito e esquerdo do sujeito GD01, durante o andar em esteira. 


\section{ANEXO VII - Curvas da FRS e eletromiografia referentes ao andar em esteira de todos os sujeitos do grupo diabético (GD) (cont.)}
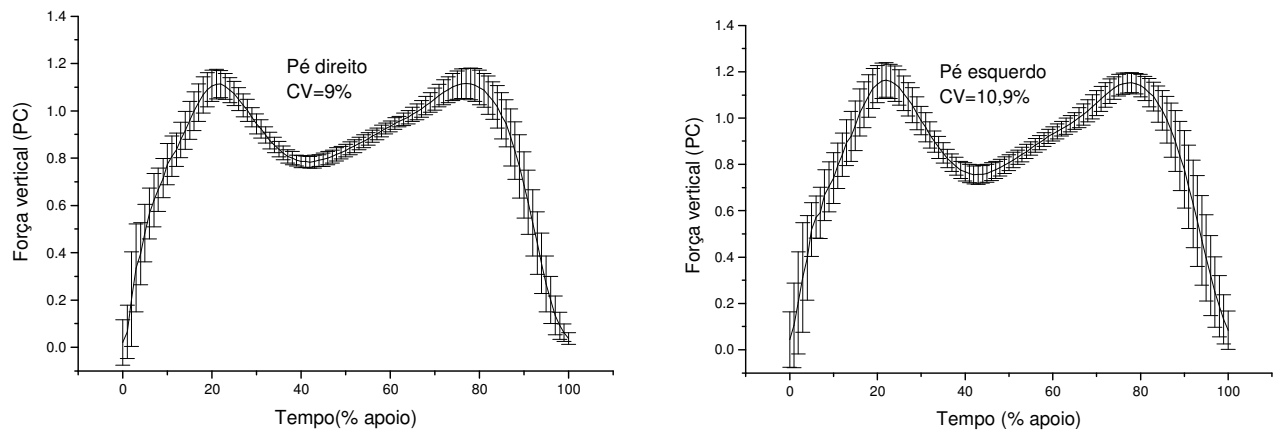

Força vertical média em função do peso corporal $(P C)$ do pé direito e esquerdo do sujeito GD02, durante o andar em esteira
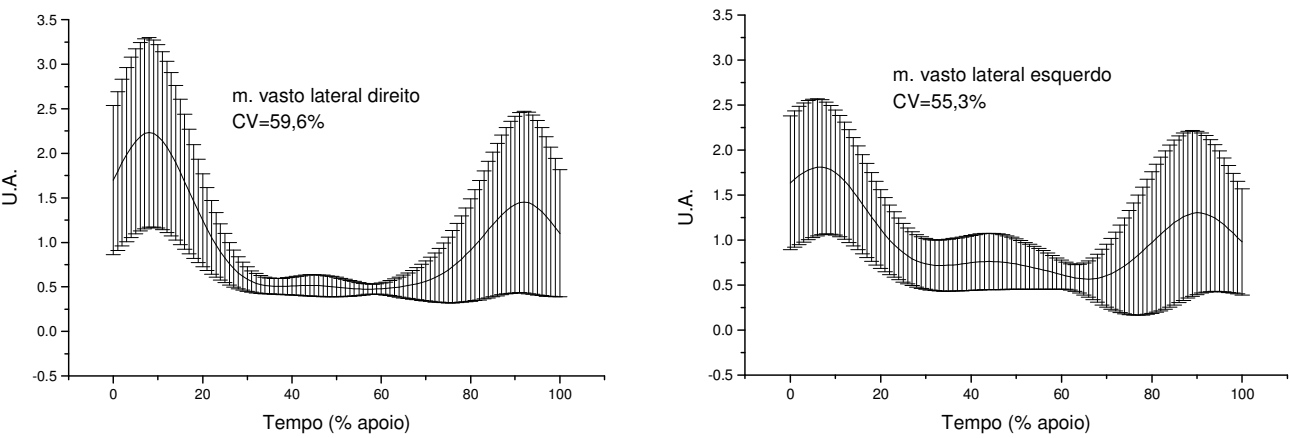

Curvas médias e desvios padrão da EMG do m. vasto lateral direito e esquerdo do sujeito GD02, durante 0 andar em esteira.
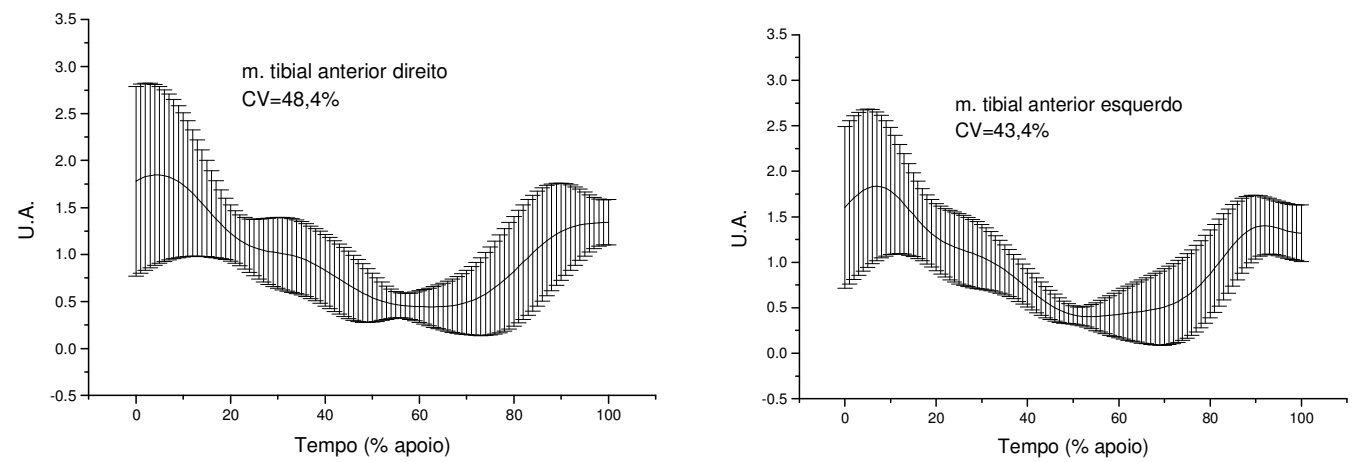

Curvas médias e desvios padrão da EMG do m. tibial anterior direito e esquerdo do sujeito GD02, durante o andar em esteira.
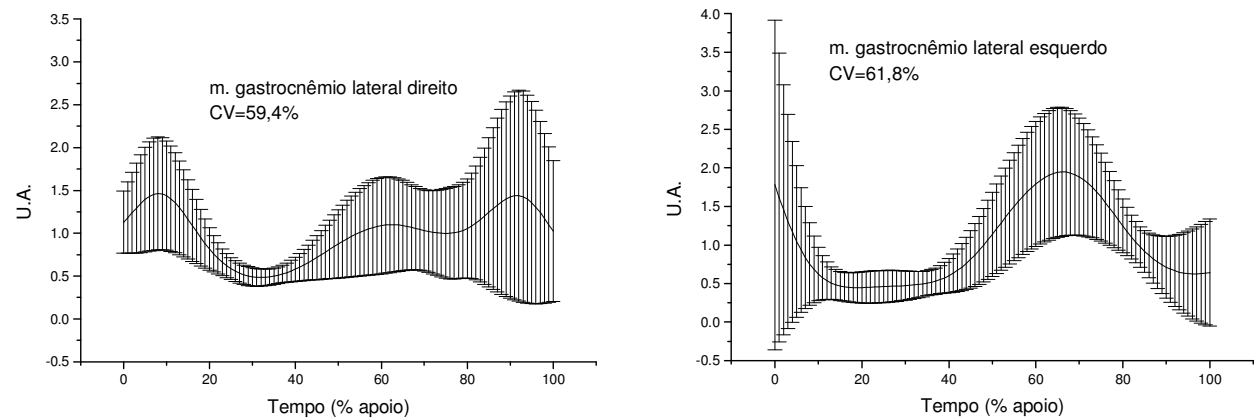

Curvas médias e desvios padrão da EMG do m. gastrocnêmio lateral direito e esquerdo do sujeito GD02, durante o andar em esteira. 
ANEXO VII - Curvas da FRS e eletromiografia referentes ao andar em esteira de todos os sujeitos do grupo diabético (GD) (cont.)
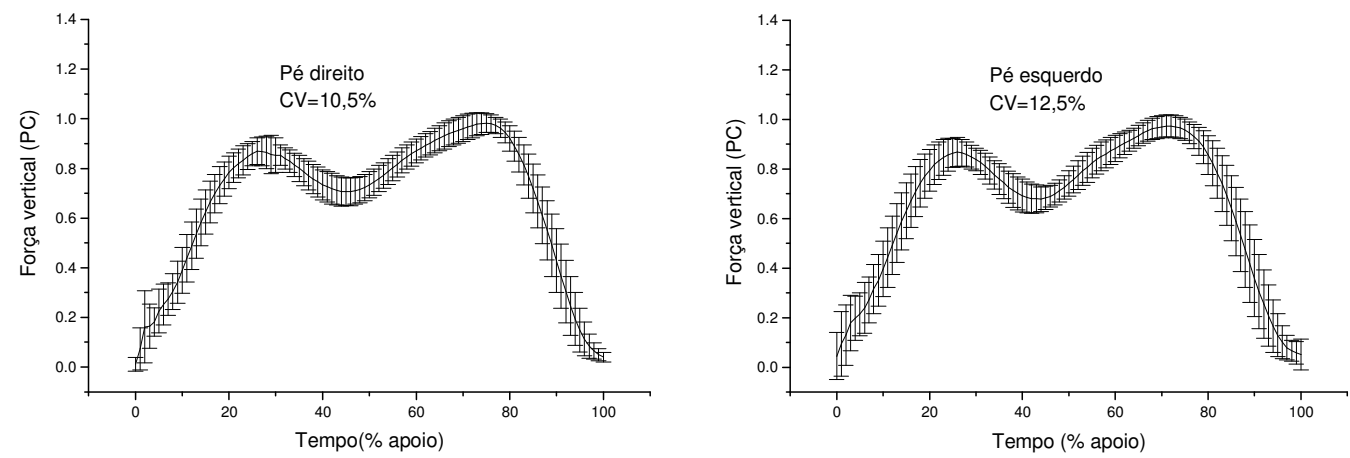

Força vertical média em função do peso corporal $(\mathrm{PC})$ do pé direito e esquerdo do sujeito GD03, durante o andar em esteira
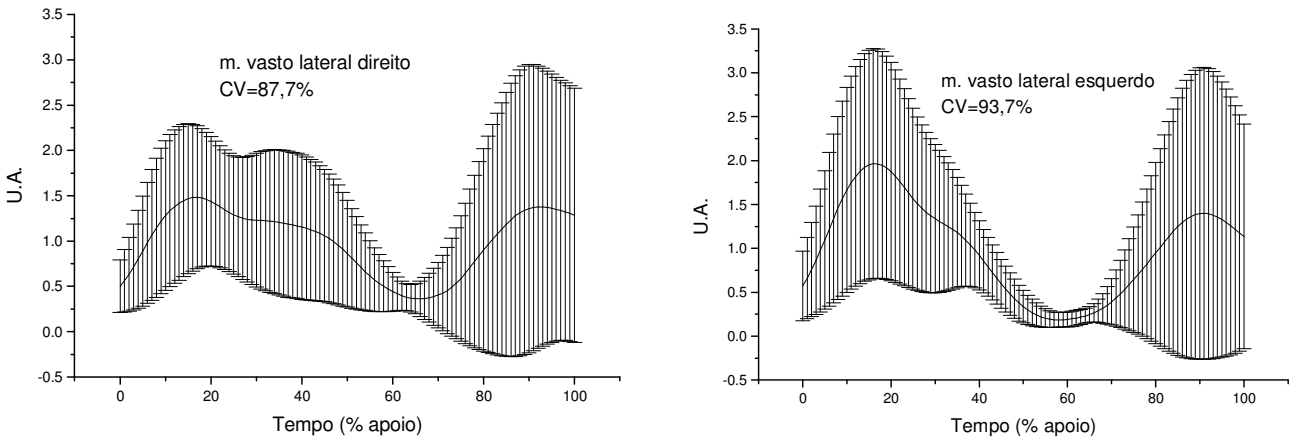

Curvas médias e desvios padrão da EMG do m. vasto lateral direito e esquerdo do sujeito GD03, durante o andar em esteira.
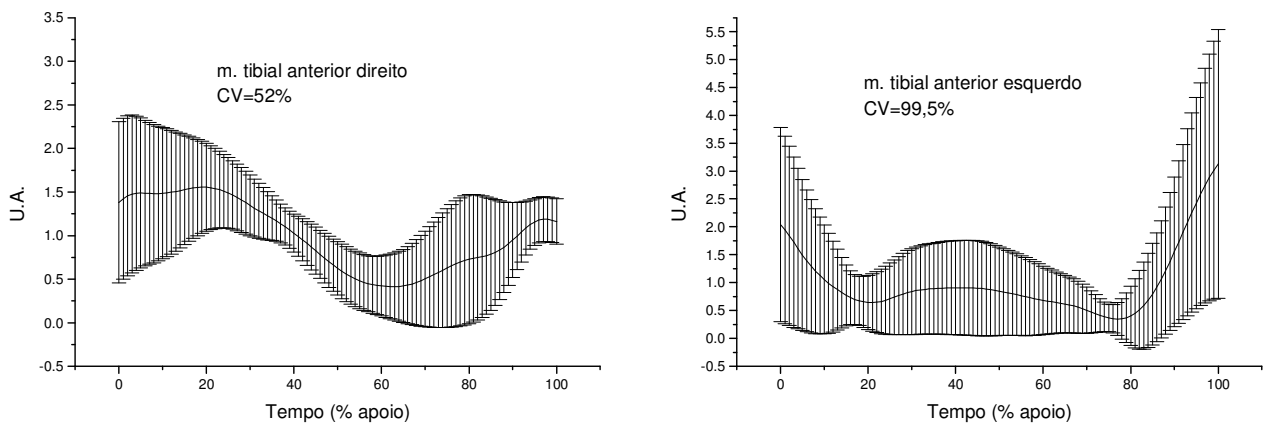

Curvas médias e desvios padrão da EMG do m. tibial anterior direito e esquerdo do sujeito GD03, durante o andar em esteira.
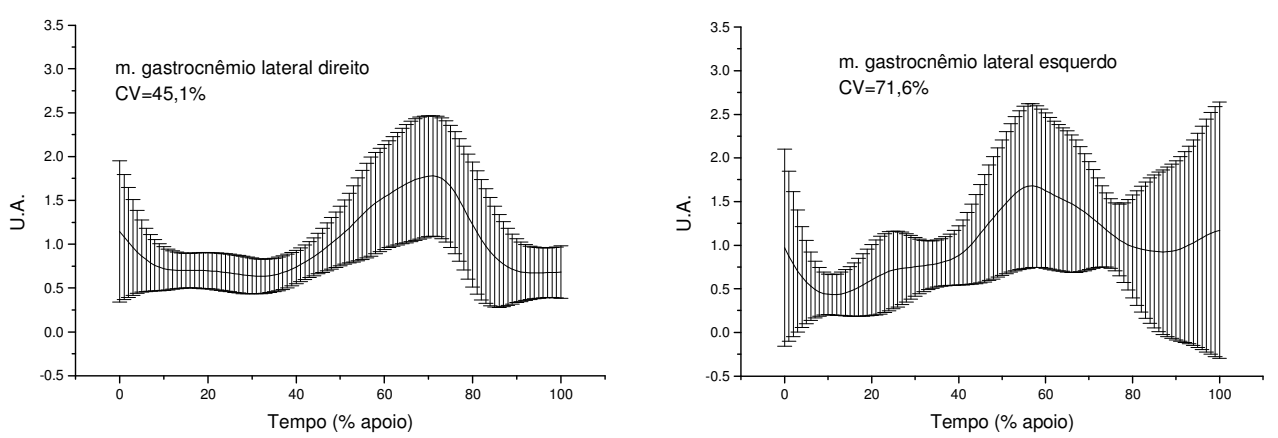

Curvas médias e desvios padrão da EMG do m. gastrocnêmio lateral direito e esquerdo do sujeito GD03, durante o andar em esteira. 
ANEXO VII - Curvas da FRS e eletromiografia referentes ao andar em esteira de todos os sujeitos do grupo diabético (GD) (cont.)
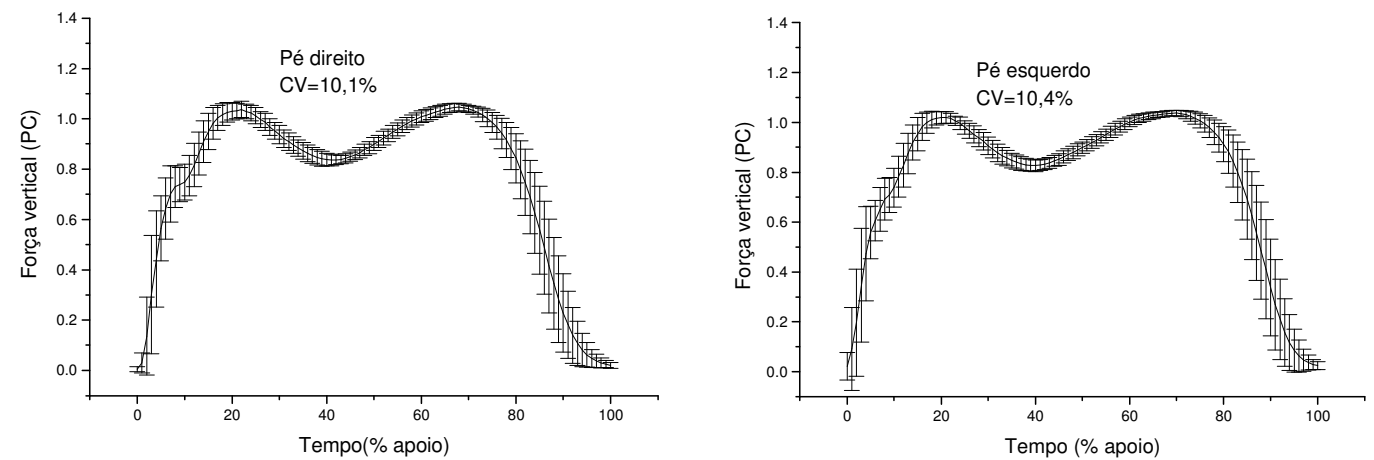

Força vertical média em função do peso corporal (PC) do pé direito e esquerdo do sujeito GD04, durante o andar em esteira
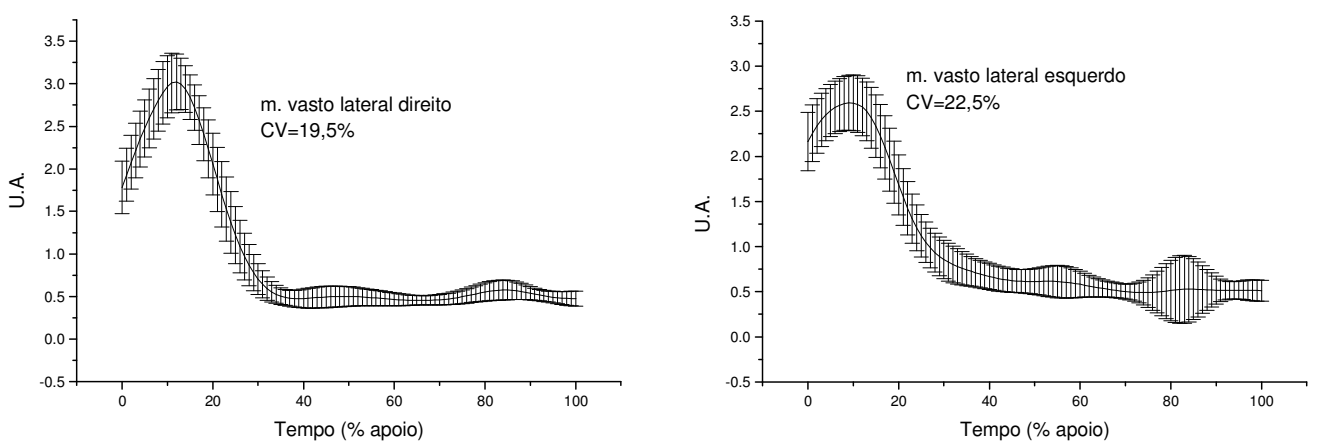

Curvas médias e desvios padrão da EMG do m. vasto lateral direito e esquerdo do sujeito GD04, durante 0 andar em esteira.
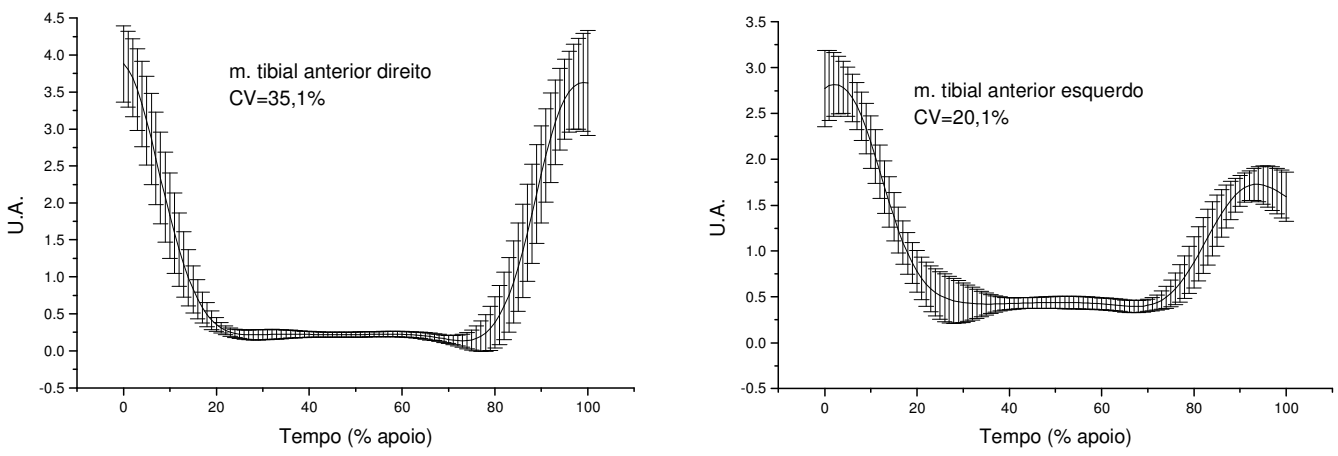

Curvas médias e desvios padrão da EMG do m. tibial anterior direito e esquerdo do sujeito GD04, durante o andar em esteira.
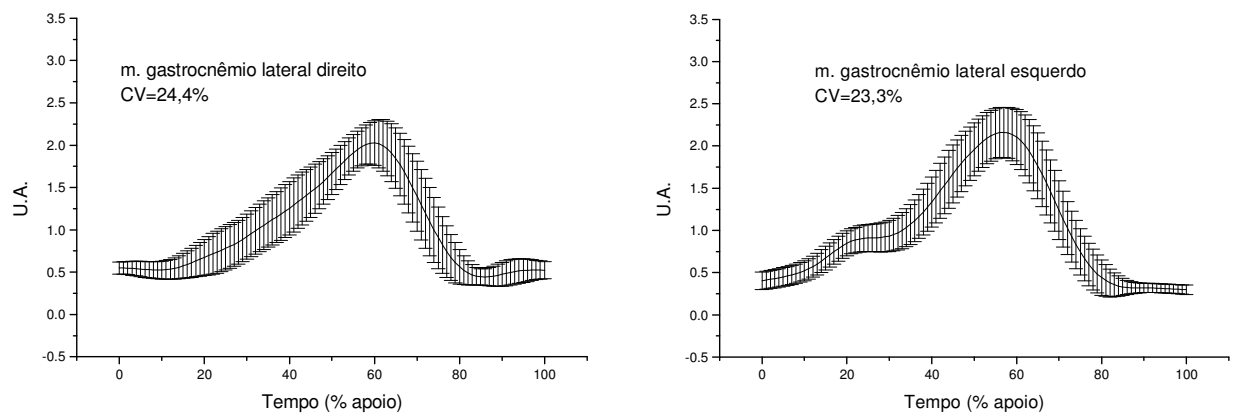

Curvas médias e desvios padrão da EMG do m. gastrocnêmio lateral direito e esquerdo do sujeito GD04, durante o andar em esteira. 
ANEXO VII - Curvas da FRS e eletromiografia referentes ao andar em esteira de todos os sujeitos do grupo diabético (GD) (cont.)
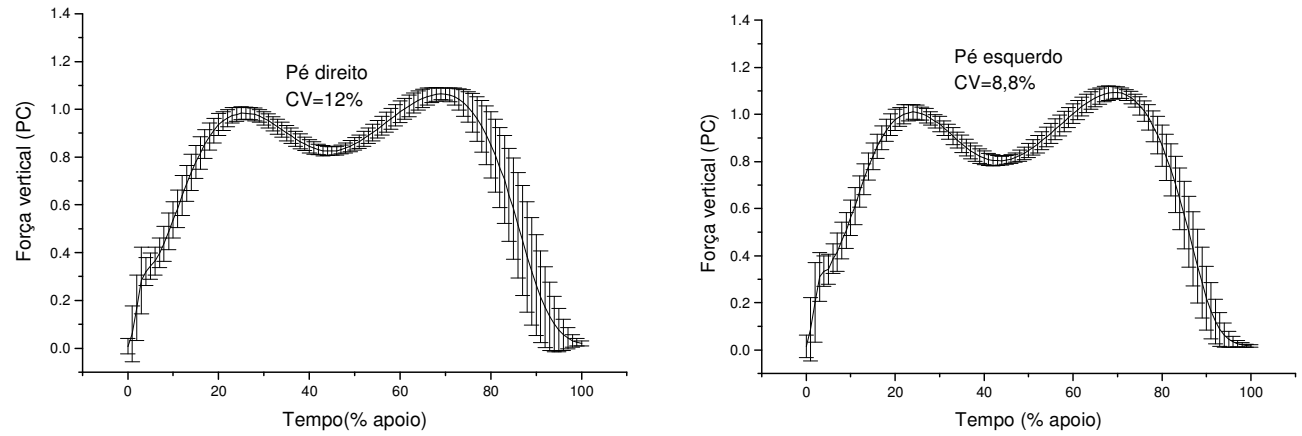

Força vertical média em função do peso corporal (PC) do pé direito e esquerdo do sujeito GD05, durante o andar em esteira.
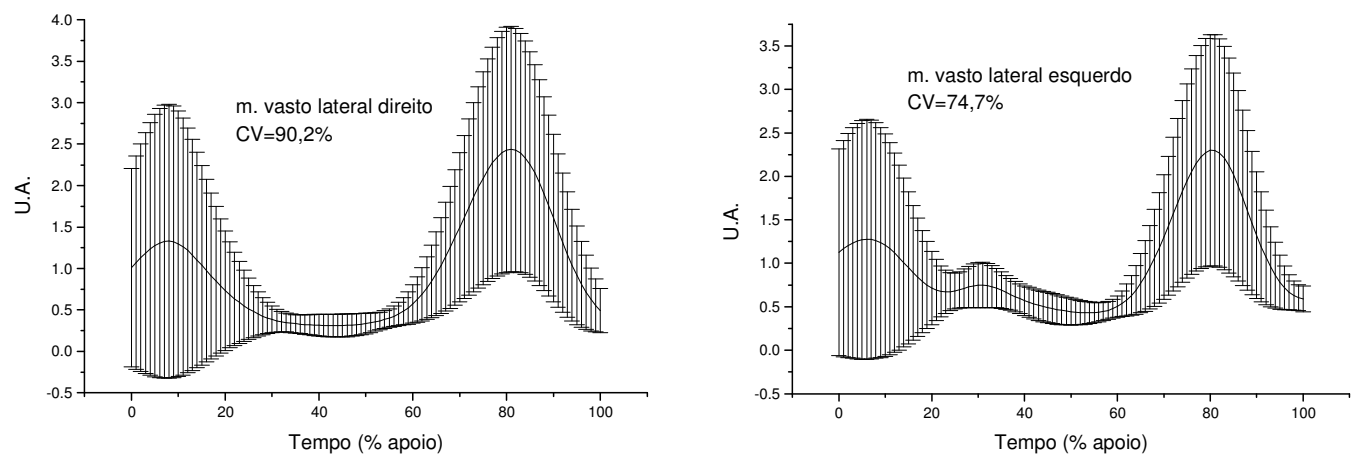

Curvas médias e desvios padrão da EMG do m. vasto lateral direito e esquerdo do sujeito GD05, durante o andar em esteira.
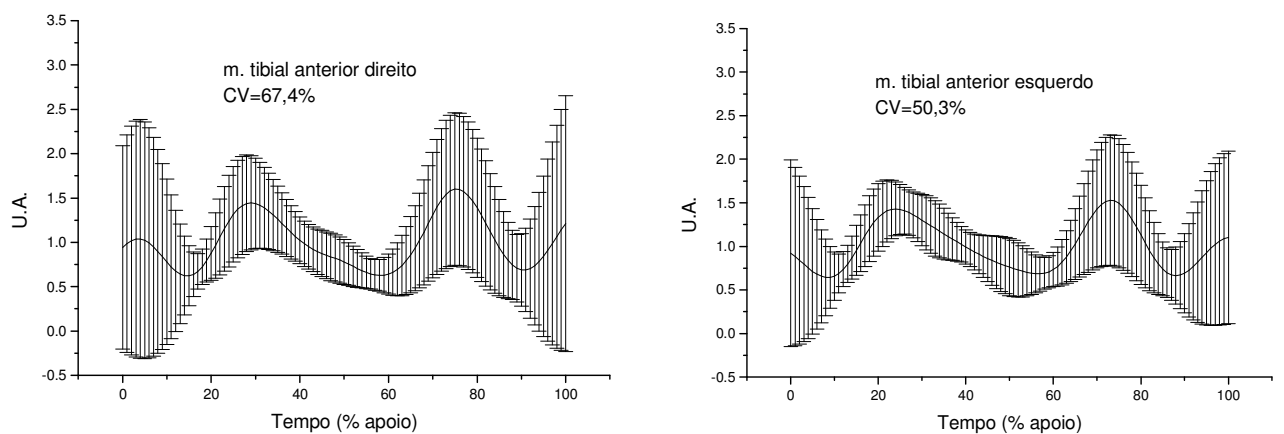

Curvas médias e desvios padrão da EMG do m. tibial anterior direito e esquerdo do sujeito GD05, durante o andar em esteira.
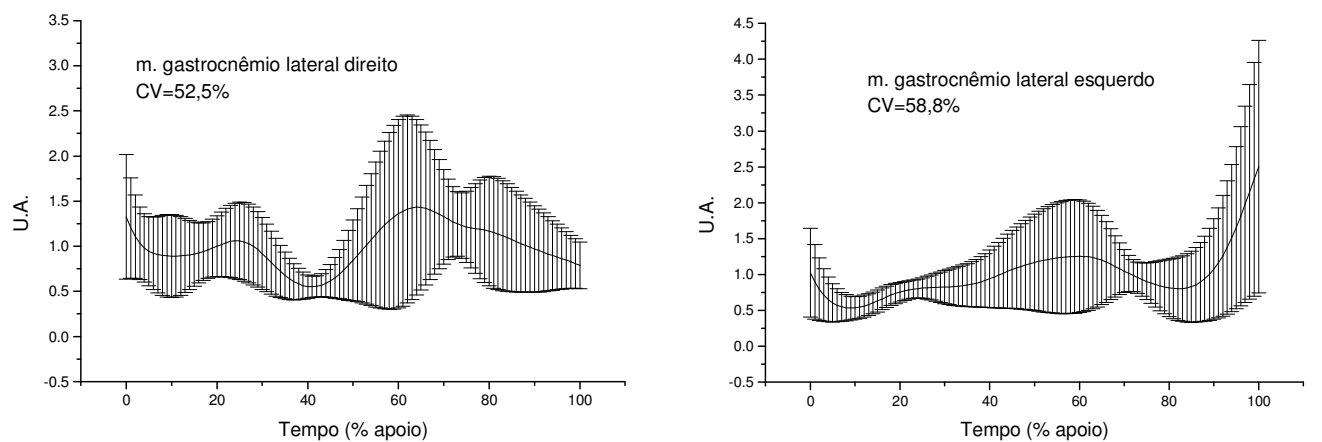

Curvas médias e desvios padrão da EMG do m. gastrocnêmio lateral direito e esquerdo do sujeito GD05, durante o andar em esteira. 
ANEXO VII - Curvas da FRS e eletromiografia referentes ao andar em esteira de todos os sujeitos do grupo diabético (GD) (cont.)
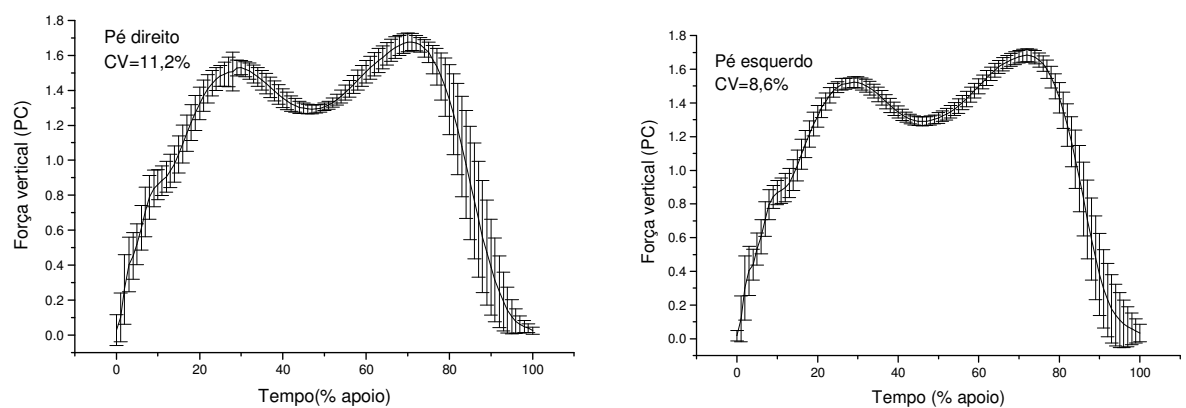

Força vertical média em função do peso corporal (PC) do pé direito e esquerdo do sujeito GD06, durante o andar em esteira.
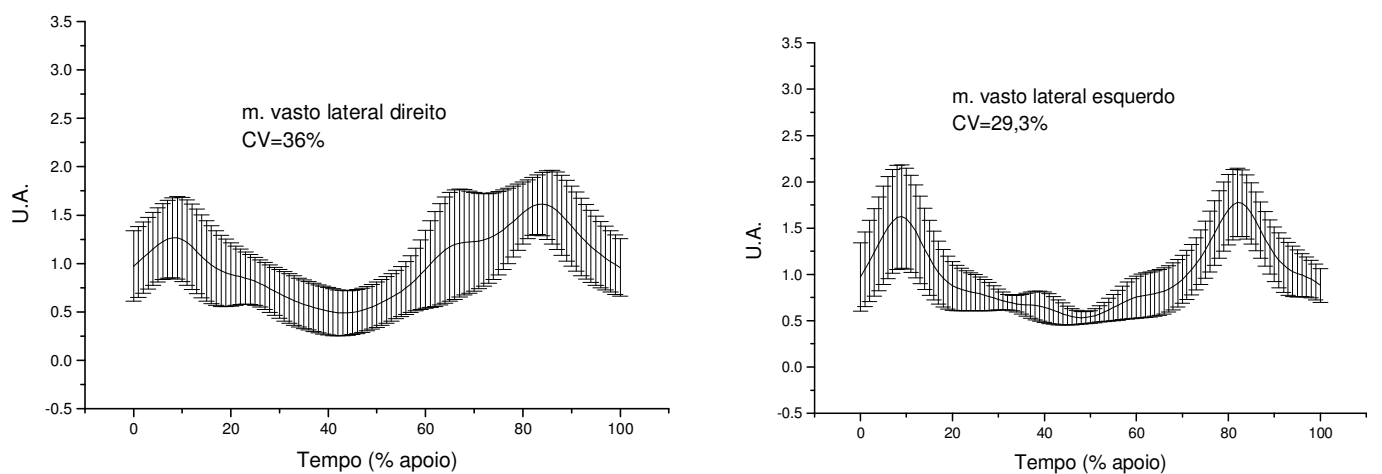

Curvas médias e desvios padrão da EMG do m. vasto lateral direito e esquerdo do sujeito GD06, durante o andar em esteira.
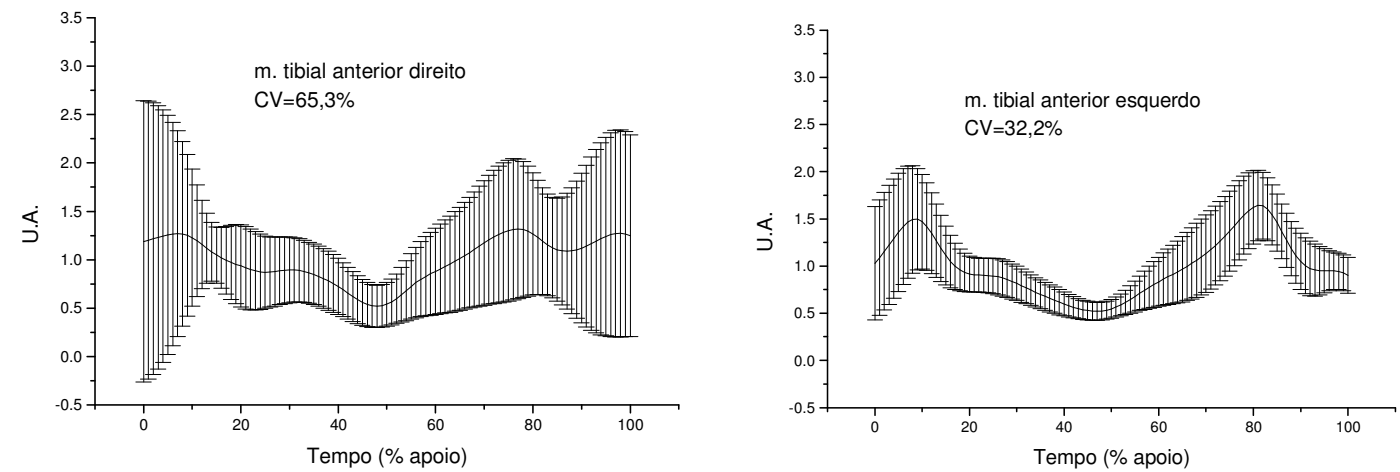

Curvas médias e desvios padrão da EMG do m. tibial anterior direito e esquerdo do sujeito GD06, durante o andar em esteira.
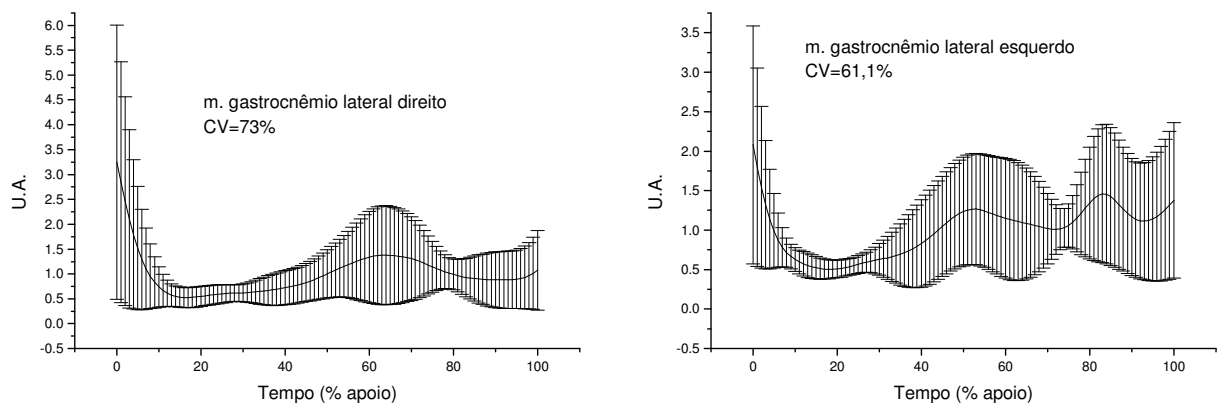

Curvas médias e desvios padrão da EMG do m. gastrocnêmio lateral direito e esquerdo do sujeito GD06, durante o andar em esteira. 
ANEXO VII - Curvas da FRS e eletromiografia referentes ao andar em esteira de todos os sujeitos do grupo diabético (GD) (cont.)
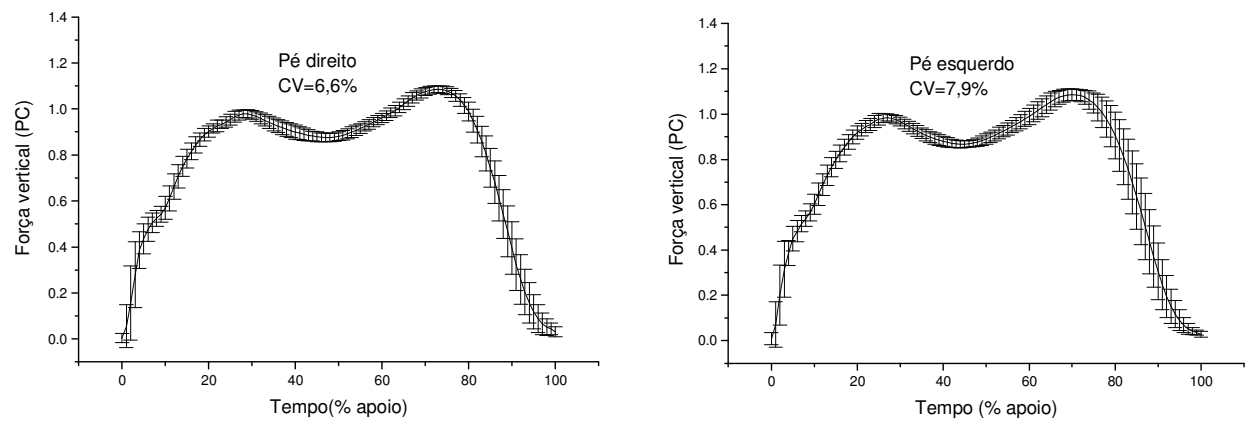

Força vertical média em função do peso corporal (PC) do pé direito e esquerdo do sujeito GD07, durante o andar em esteira.
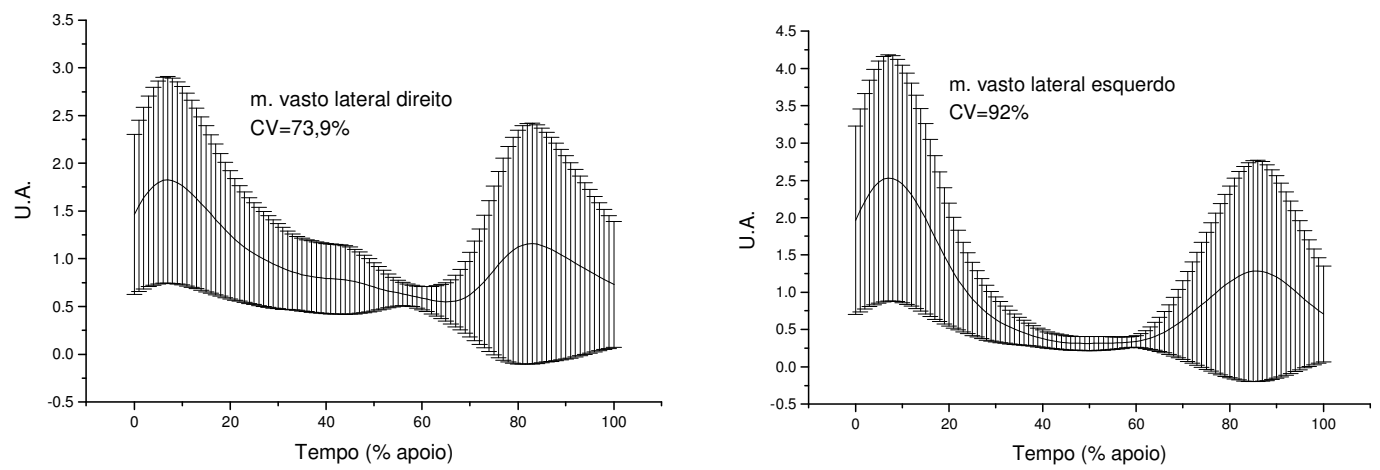

Curvas médias e desvios padrão da EMG do m. vasto lateral direito e esquerdo do sujeito GD07, durante o andar em esteira.
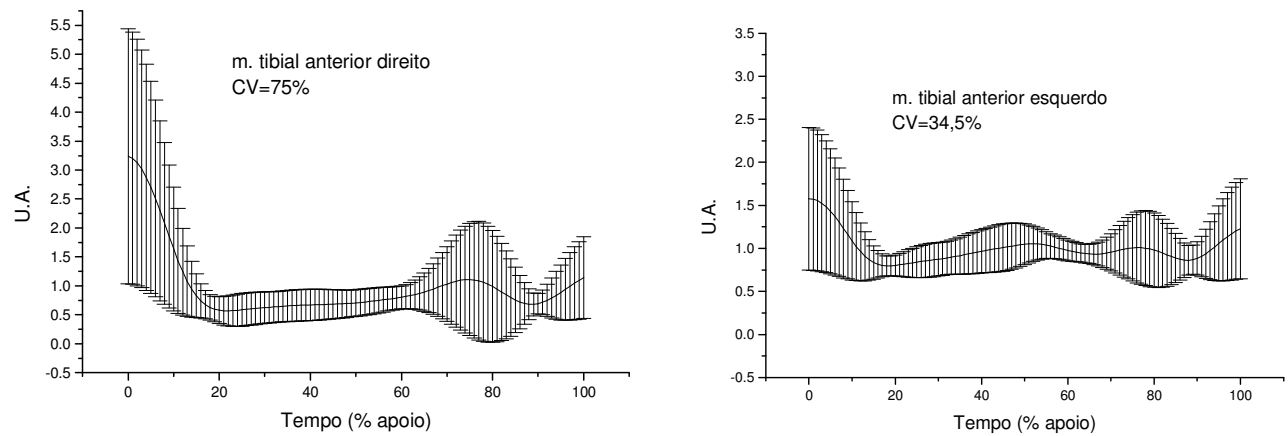

Curvas médias e desvios padrão da EMG do m. tibial anterior direito e esquerdo do sujeito GD07, durante o andar em esteira.
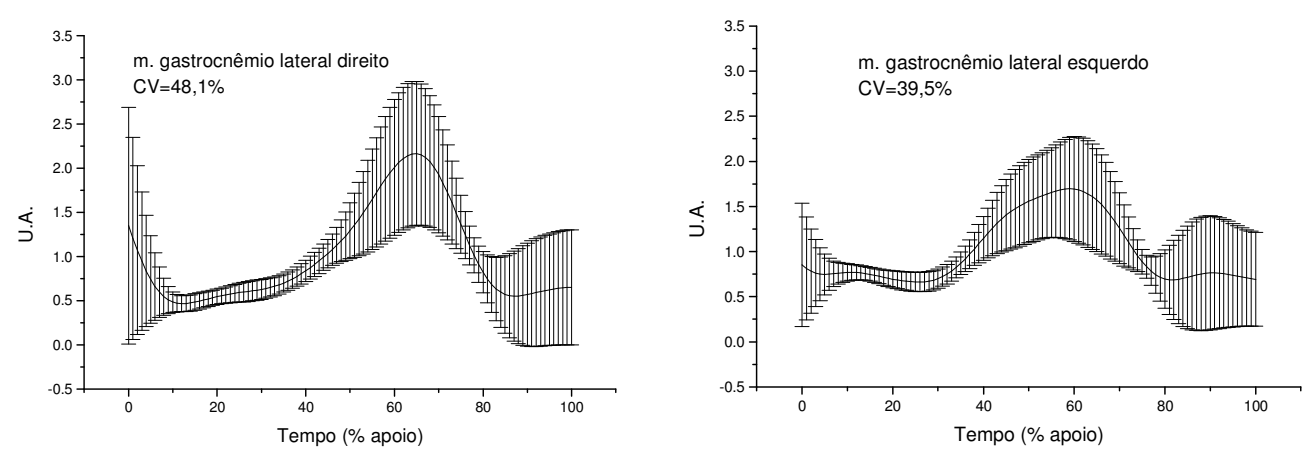

Curvas médias e desvios padrão da EMG do m. gastrocnêmio lateral direito e esquerdo do sujeito GD07, durante o andar em esteira. 


\section{ANEXO VII - Curvas da FRS e eletromiografia referentes ao andar em esteira de todos os sujeitos do} grupo diabético (GD) (cont.)
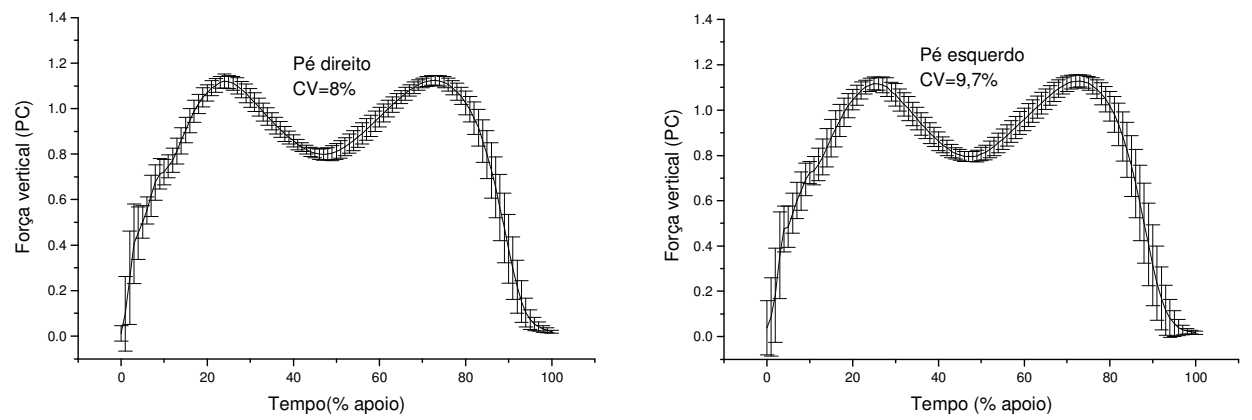

Força vertical média em função do peso corporal (PC) do pé direito e esquerdo do sujeito GD08, durante o andar em esteira.
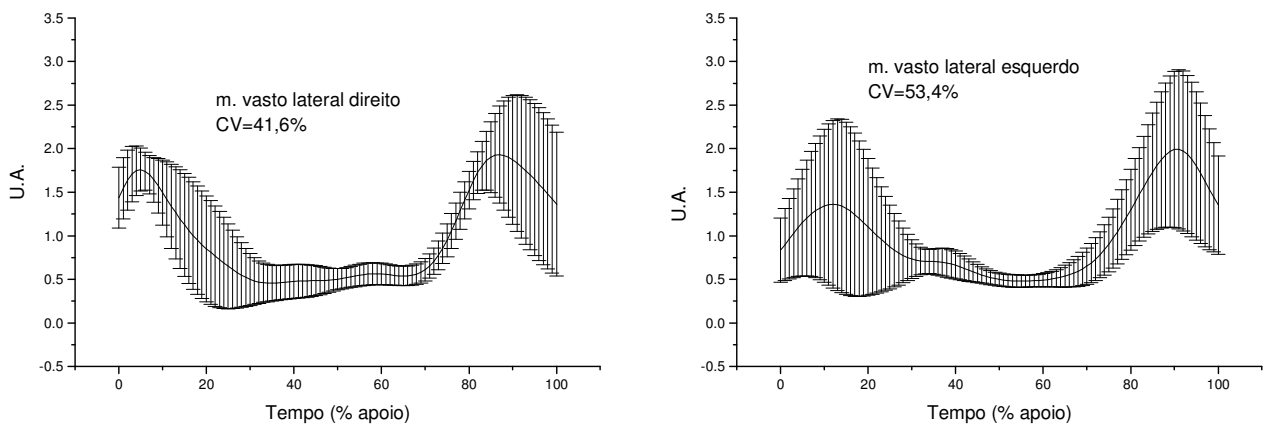

Curvas médias e desvios padrão da EMG do m. vasto lateral direito e esquerdo do sujeito GD08, durante 0 andar em esteira.
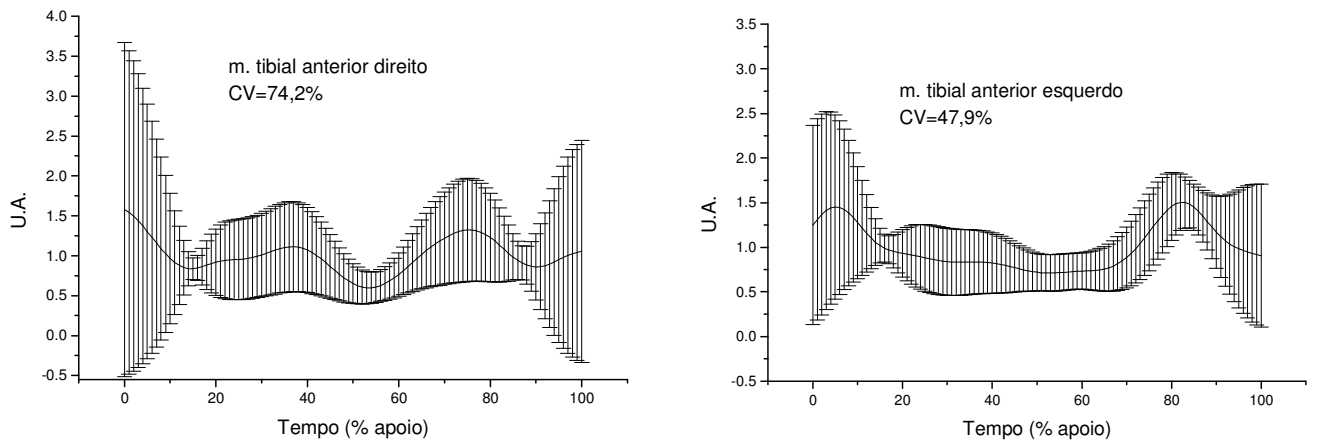

Curvas médias e desvios padrão da EMG do m. tibial anterior direito e esquerdo do sujeito GD08, durante o andar em esteira.
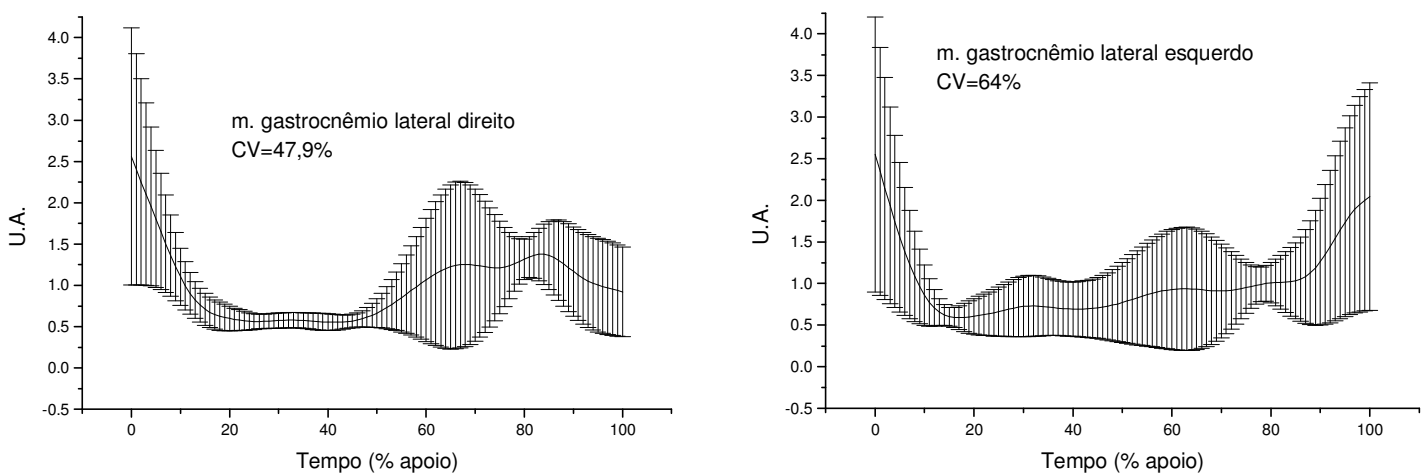

Curvas médias e desvios padrão da EMG do m. gastrocnêmio lateral direito e esquerdo do sujeito GD08, durante o andar em esteira. 
ANEXO VII - Curvas da FRS e eletromiografia referentes ao andar em esteira de todos os sujeitos do grupo diabético (GD) (cont.)
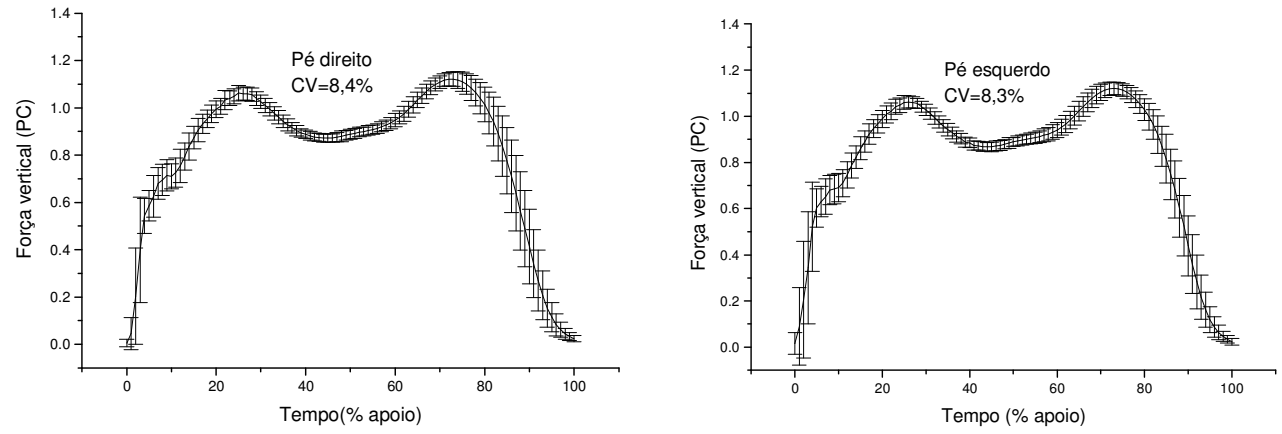

Força vertical média em função do peso corporal (PC) do pé direito e esquerdo do sujeito GD09, durante o andar em esteira.
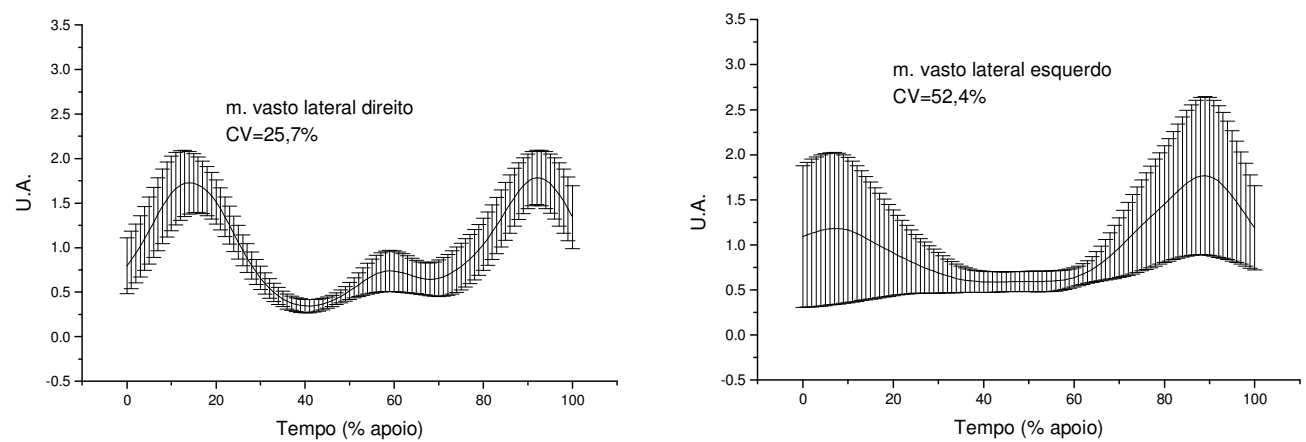

Curvas médias e desvios padrão da EMG do m. vasto lateral direito e esquerdo do sujeito GD09, durante o andar em esteira.
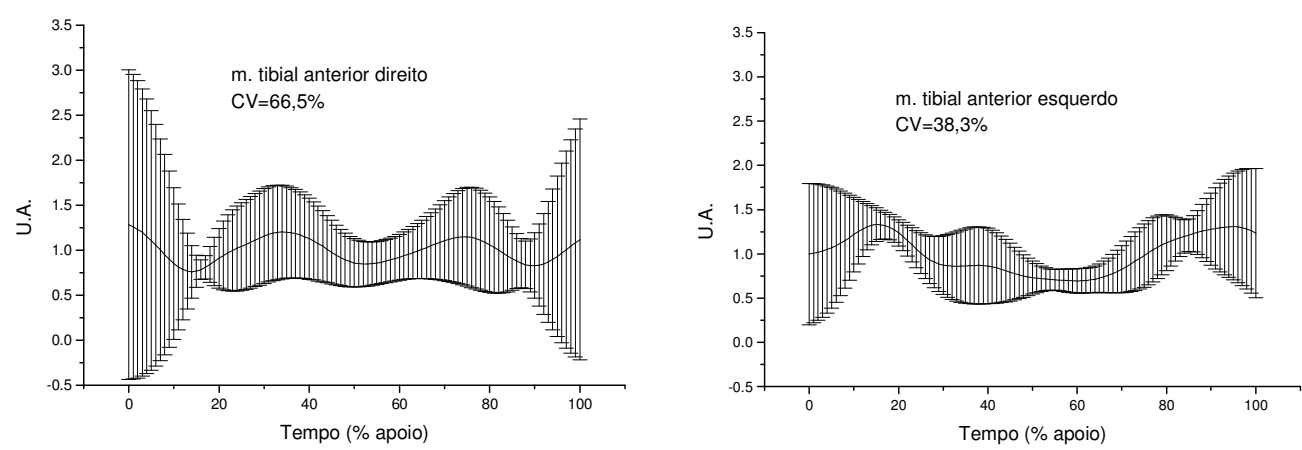

Curvas médias e desvios padrão da EMG do m. tibial anterior direito e esquerdo do sujeito GD09, durante o andar em esteira.
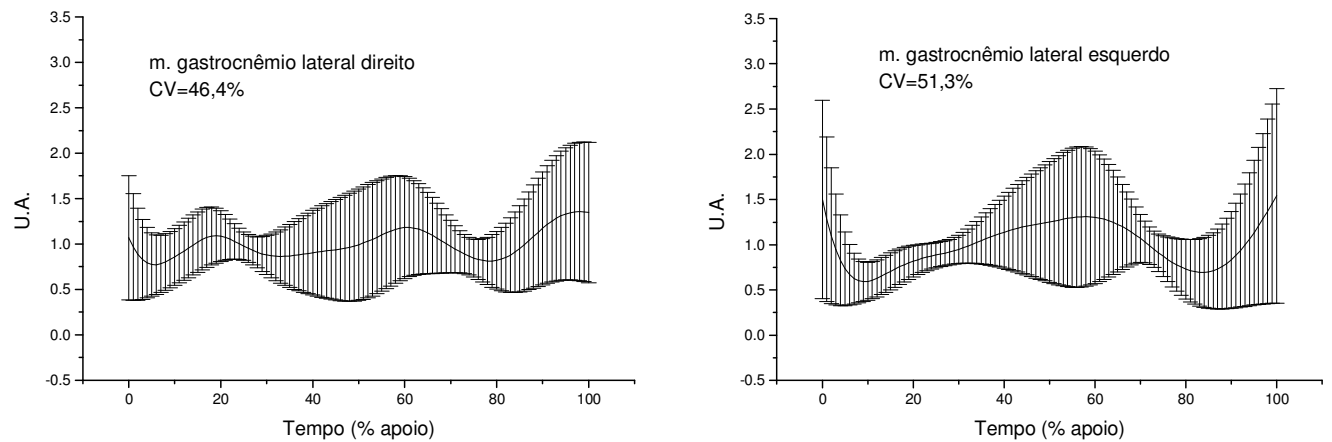

Curvas médias e desvios padrão da EMG do m. gastrocnêmio lateral direito e esquerdo do sujeito GD09, durante o andar em esteira. 
ANEXO VII - Curvas da FRS e eletromiografia referentes ao andar em esteira de todos os sujeitos do grupo diabético (GD) (cont.)
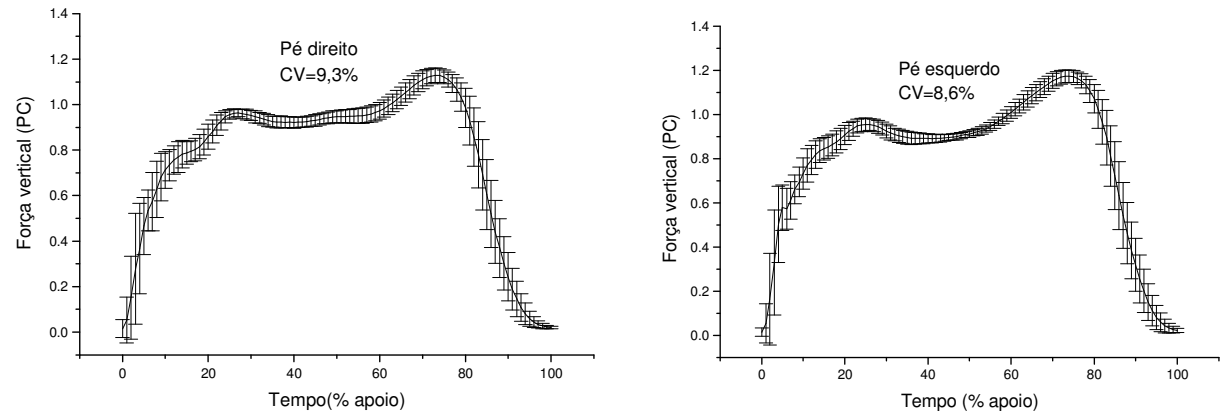

Força vertical média em função do peso corporal (PC) do pé direito e esquerdo do sujeito GD10, durante o andar em esteira.
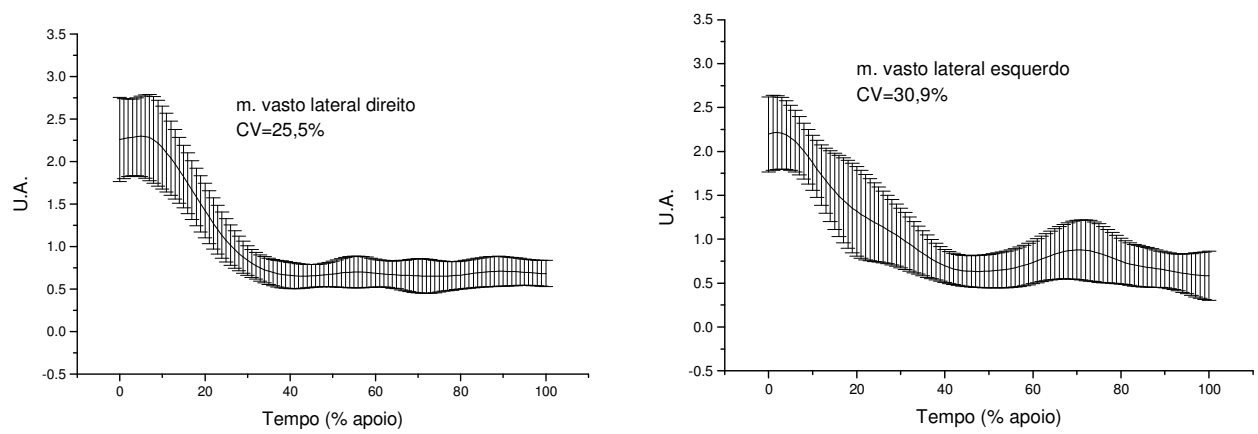

Curvas médias e desvios padrão da EMG do m. vasto lateral direito e esquerdo do sujeito GD10, durante o andar em esteira.
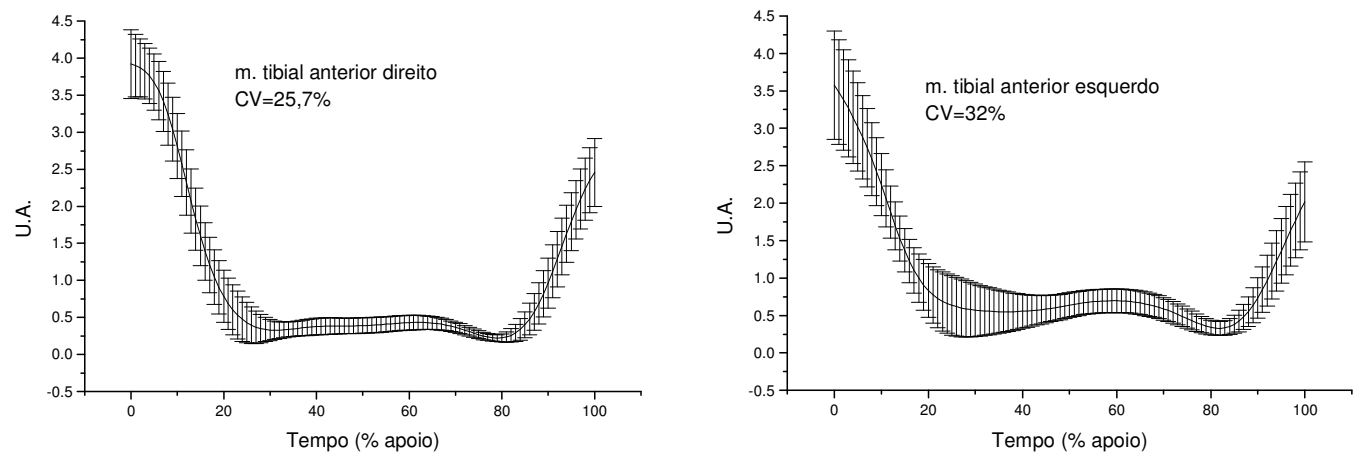

Curvas médias e desvios padrão da EMG do m. tibial anterior direito e esquerdo do sujeito GD10, durante 0 andar em esteira.
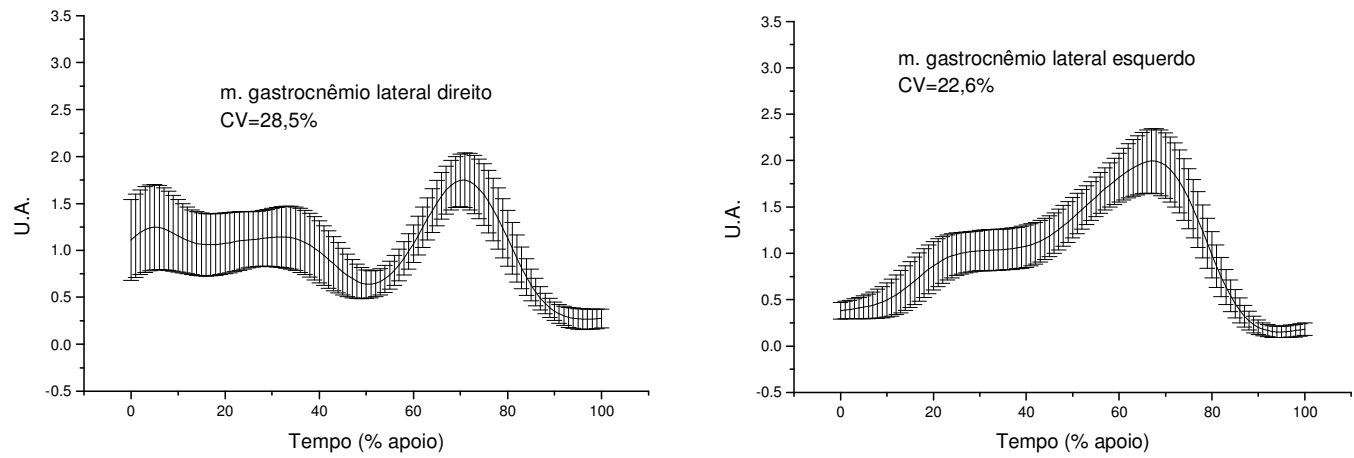

Curvas médias e desvios padrão da EMG do m. gastrocnêmio lateral direito e esquerdo do sujeito GD10, durante o andar em esteira. 
ANEXO VII - Curvas da FRS e eletromiografia referentes ao andar em esteira de todos os sujeitos do grupo diabético (GD) (cont.)
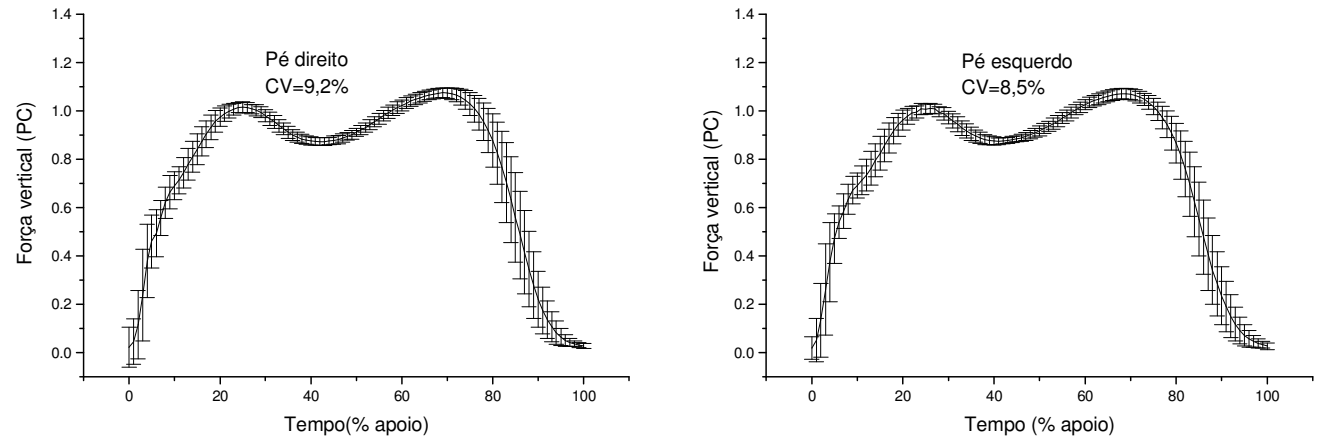

Força vertical média em função do peso corporal (PC) do pé direito e esquerdo do sujeito GD11, durante o andar em esteira.
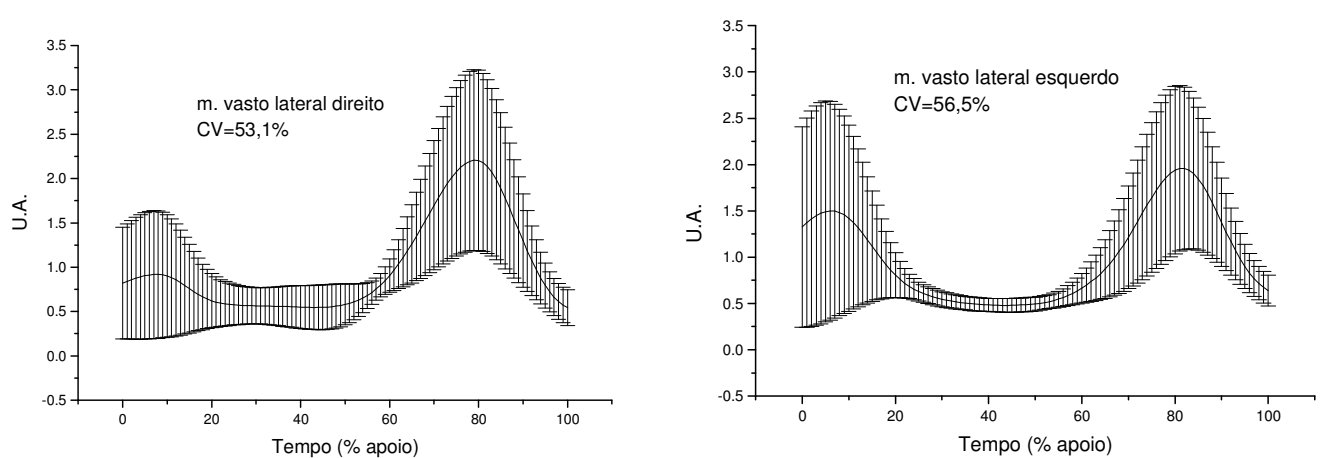

Curvas médias e desvios padrão da EMG do m. vasto lateral direito e esquerdo do sujeito GD11, durante 0 andar em esteira.
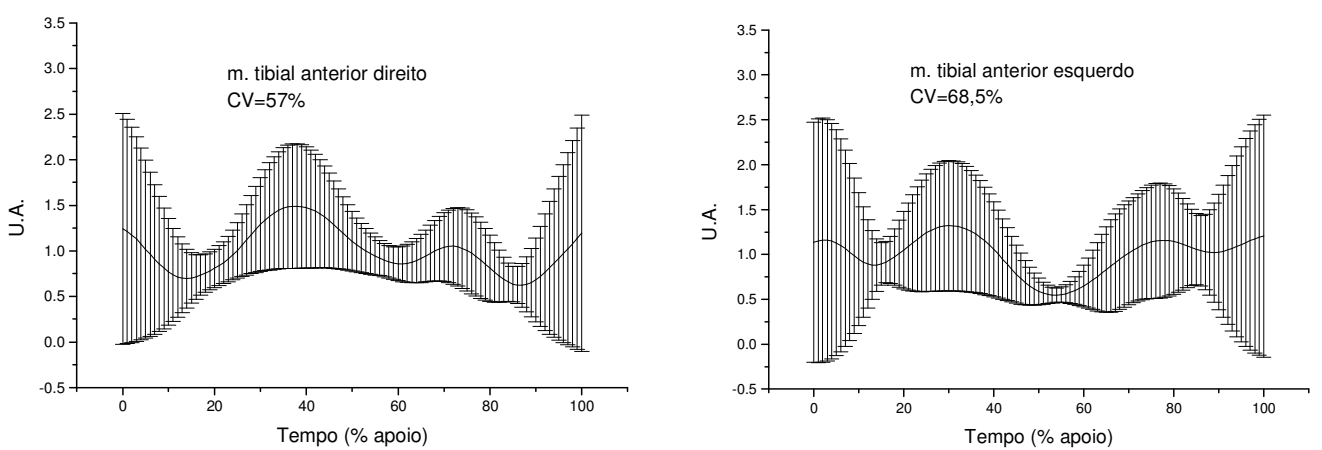

Curvas médias e desvios padrão da EMG do m. tibial anterior direito e esquerdo do sujeito GD11, durante o andar em esteira.
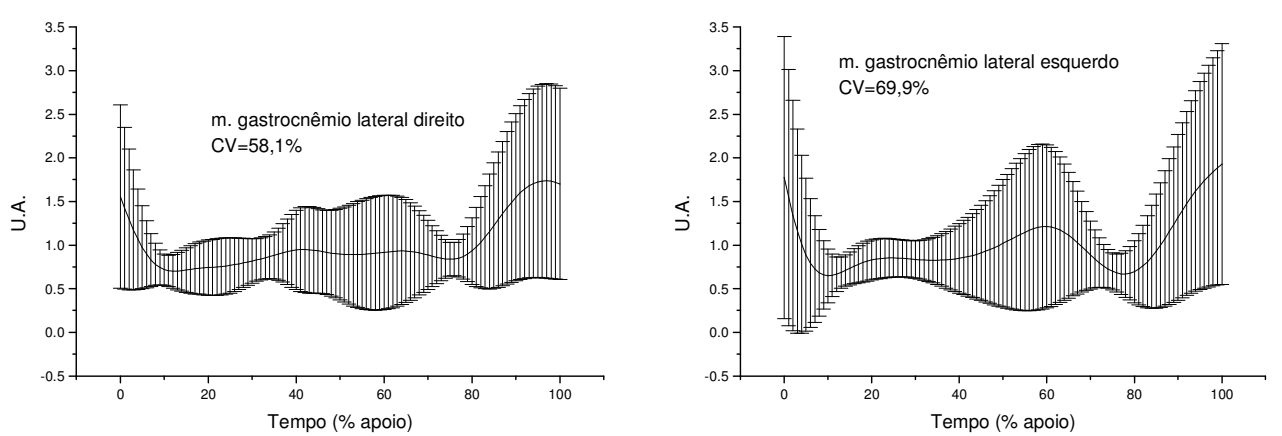

Curvas médias e desvios padrão da EMG do m. gastrocnêmio lateral direito e esquerdo do sujeito GD11, durante o andar em esteira. 
ANEXO VII - Curvas da FRS e eletromiografia referentes ao andar em esteira de todos os sujeitos do grupo diabético (GD) (cont.)
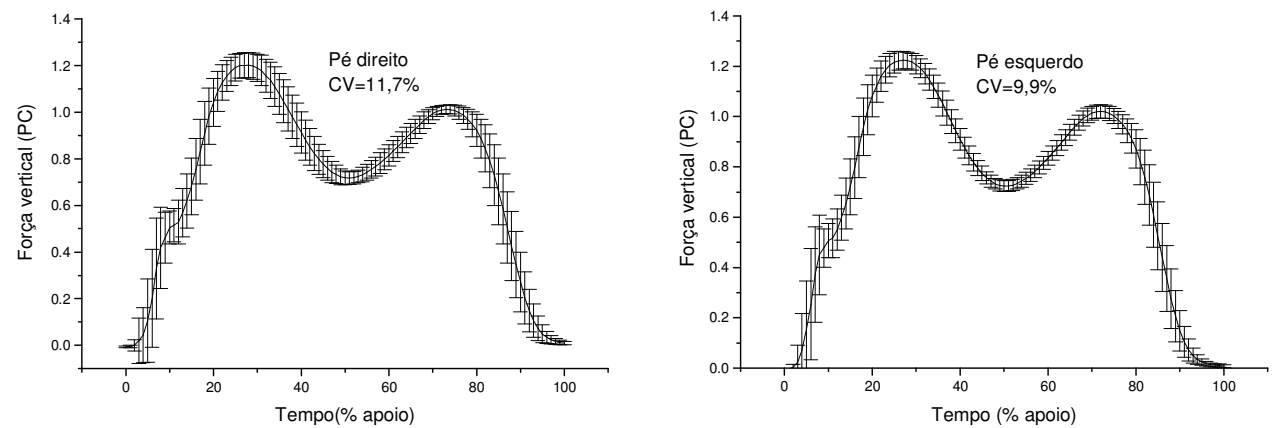

Força vertical média em função do peso corporal (PC) do pé direito e esquerdo do sujeito GD12, durante 0 andar em esteira.
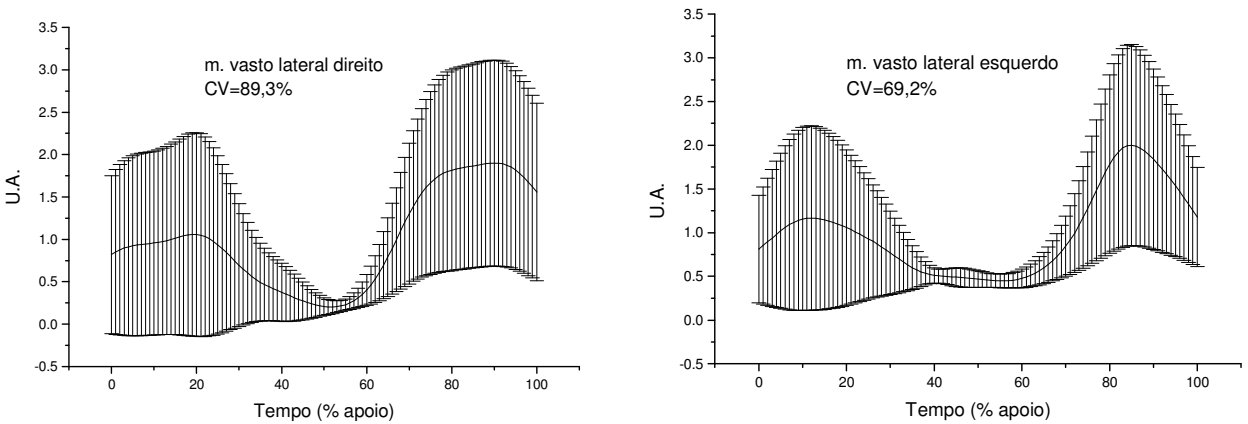

Curvas médias e desvios padrão da EMG do m. vasto lateral direito e esquerdo do sujeito GD12, durante o andar em esteira.
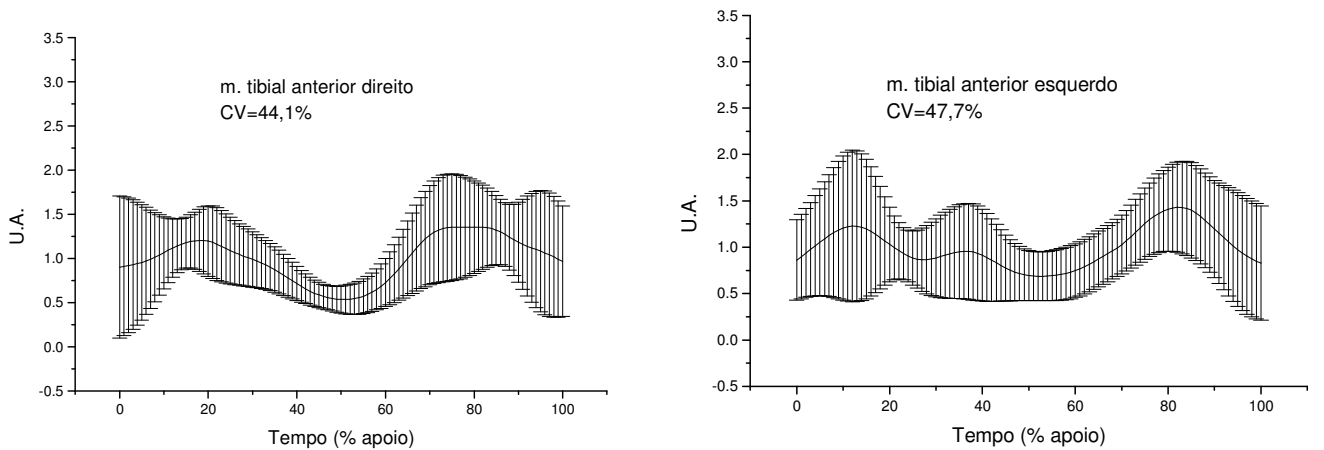

Curvas médias e desvios padrão da EMG do m. tibial anterior direito e esquerdo do sujeito GD12, durante o andar em esteira.
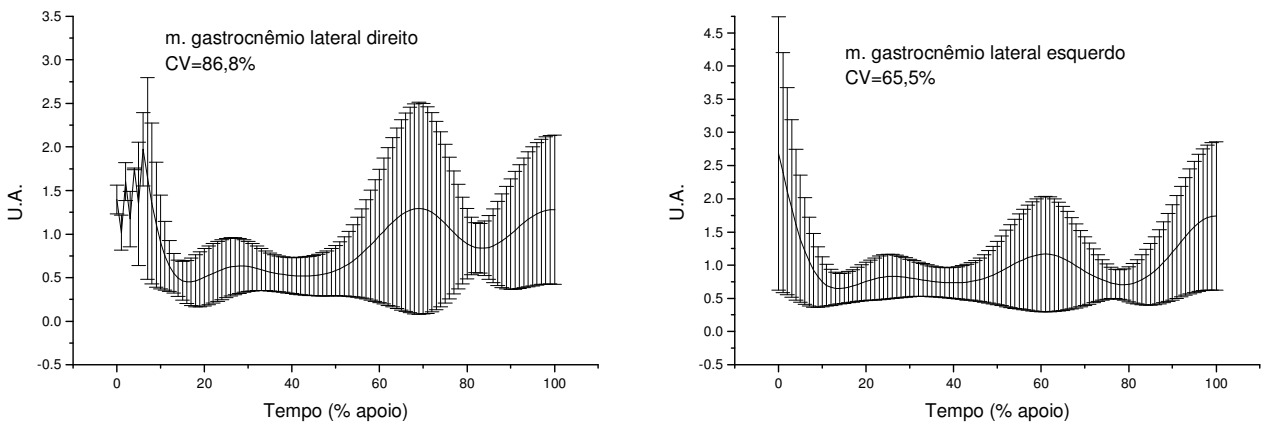

Curvas médias e desvios padrão da EMG do m. gastrocnêmio lateral direito e esquerdo do sujeito GD12, durante o andar em esteira. 


\section{ANEXO VII - Curvas da FRS e eletromiografia referentes ao andar em esteira de todos os sujeitos do} grupo diabético (GD) (cont.)
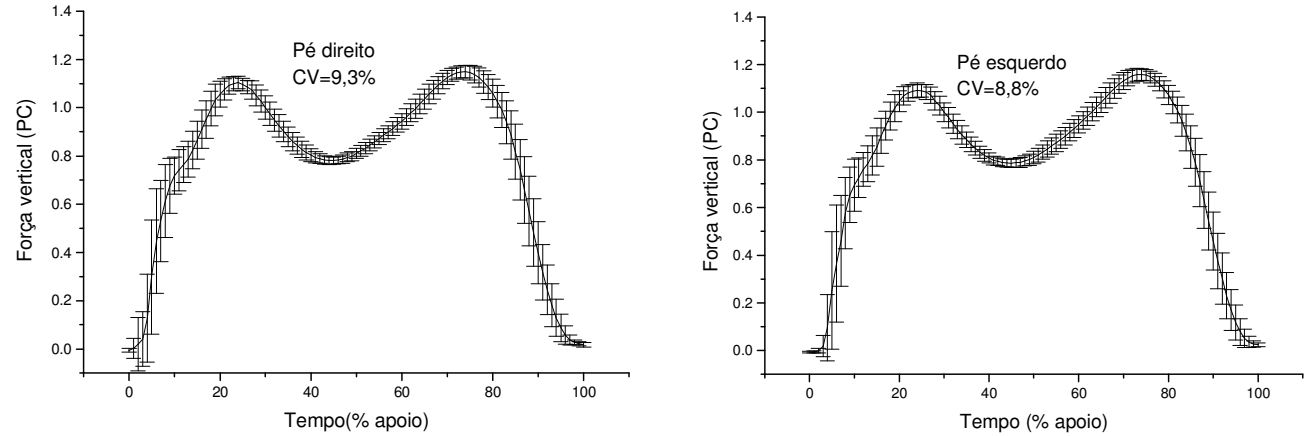

Força vertical média em função do peso corporal (PC) do pé direito e esquerdo do sujeito GD14, durante o andar em esteira.
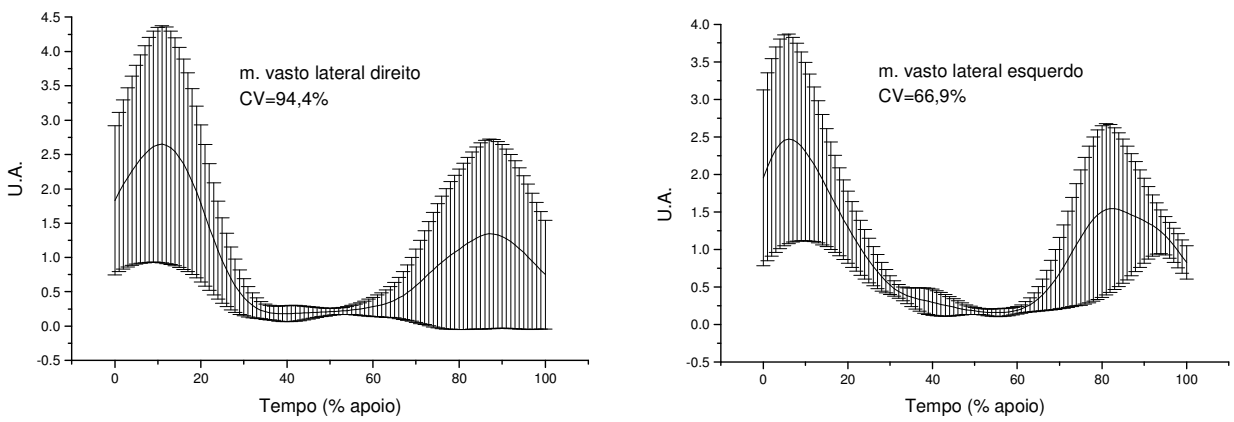

Curvas médias e desvios padrão da EMG do m. vasto lateral direito e esquerdo do sujeito GD14, durante o andar em esteira.
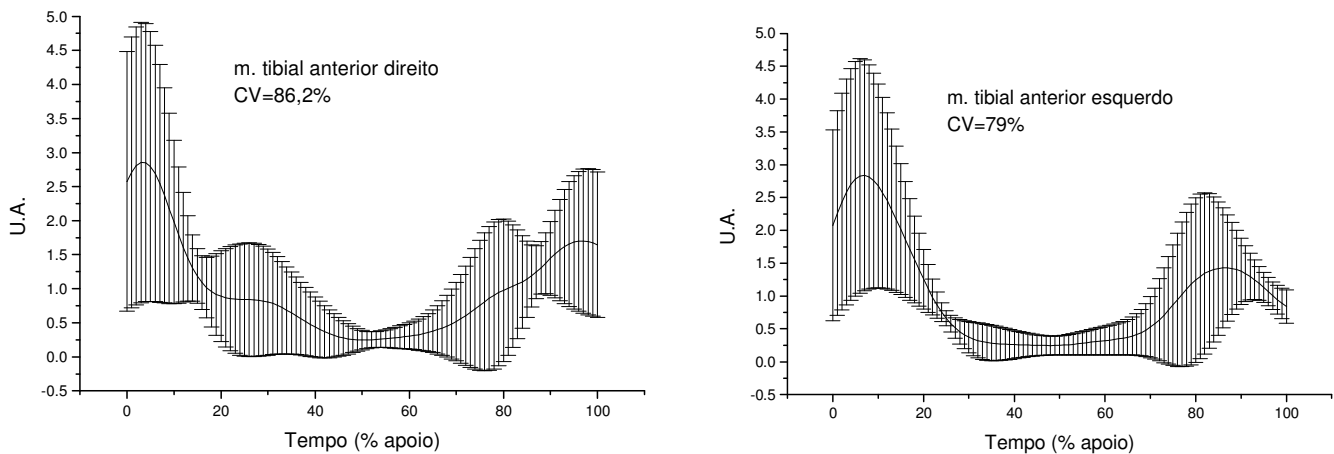

Curvas médias e desvios padrão da EMG do m. tibial anterior direito e esquerdo do sujeito GD14, durante o andar em esteira.
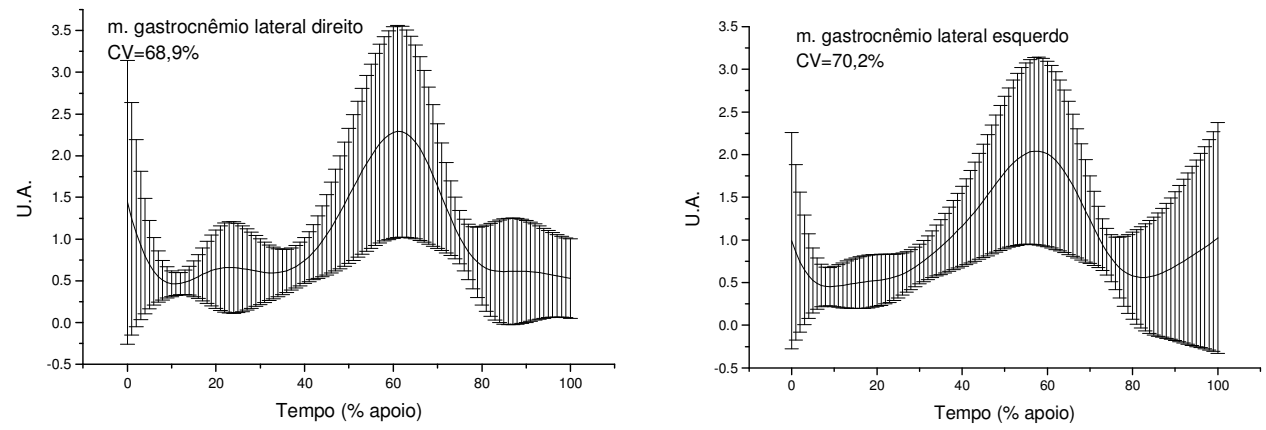

Curvas médias e desvios padrão da EMG do m. gastrocnêmio lateral direito e esquerdo do sujeito GD14, durante o andar em esteira. 
ANEXO VII - Curvas da FRS e eletromiografia referentes ao andar em esteira de todos os sujeitos do grupo diabético (GD) (cont.)
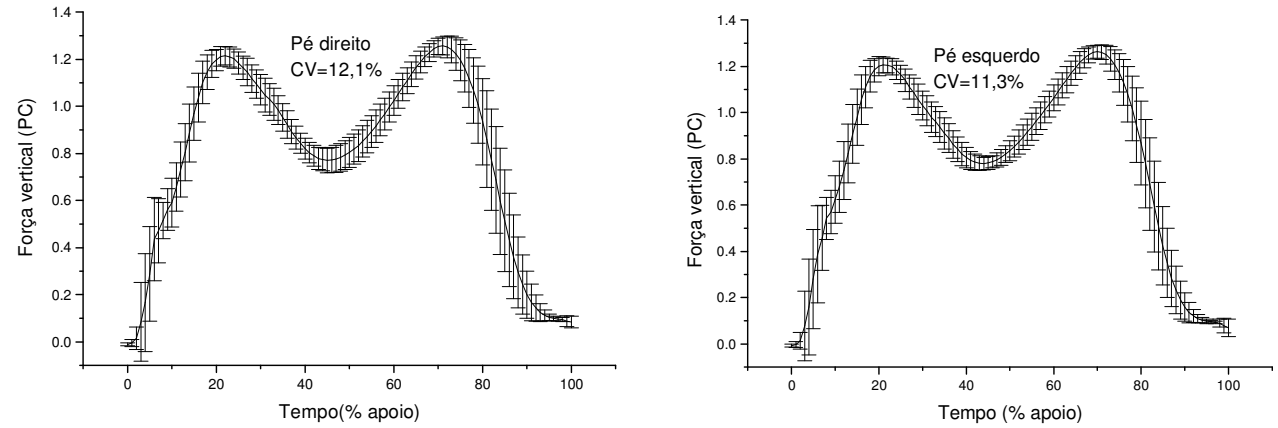

Força vertical média em função do peso corporal (PC) do pé direito e esquerdo do sujeito GD15, durante o andar em esteira.
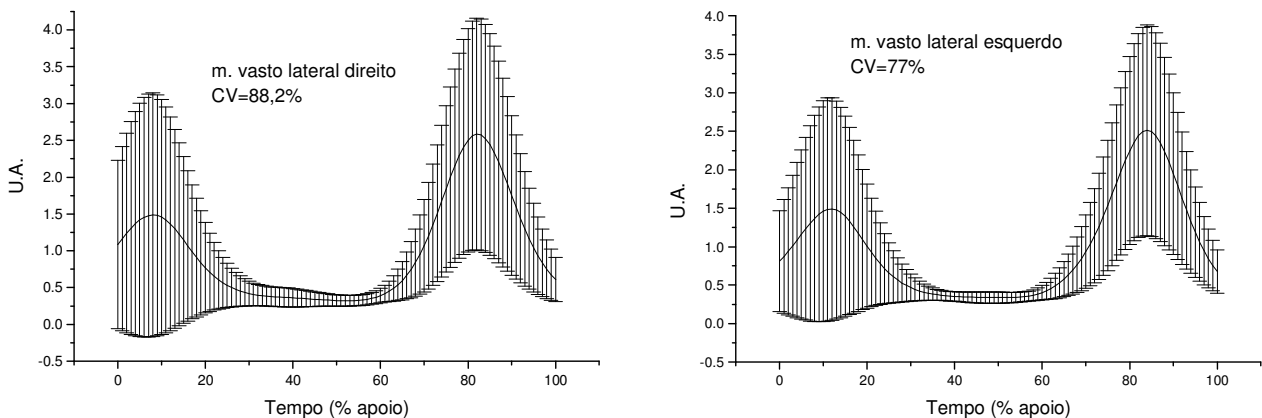

Curvas médias e desvios padrão da EMG do m. vasto lateral direito e esquerdo do sujeito GD15, durante o andar em esteira.
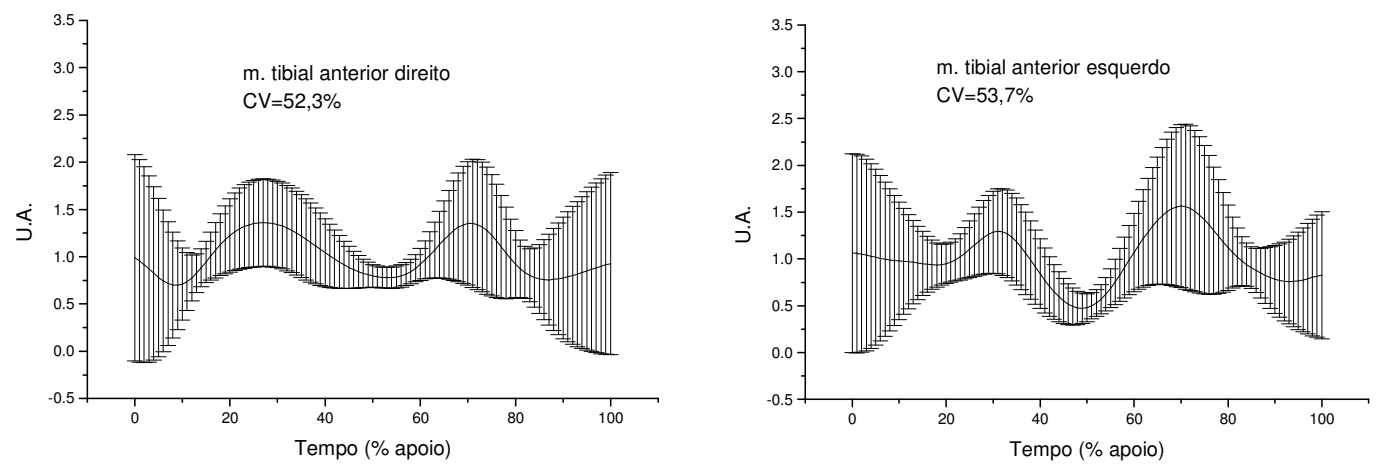

Curvas médias e desvios padrão da EMG do m. tibial anterior direito e esquerdo do sujeito GD15, durante o andar em esteira.
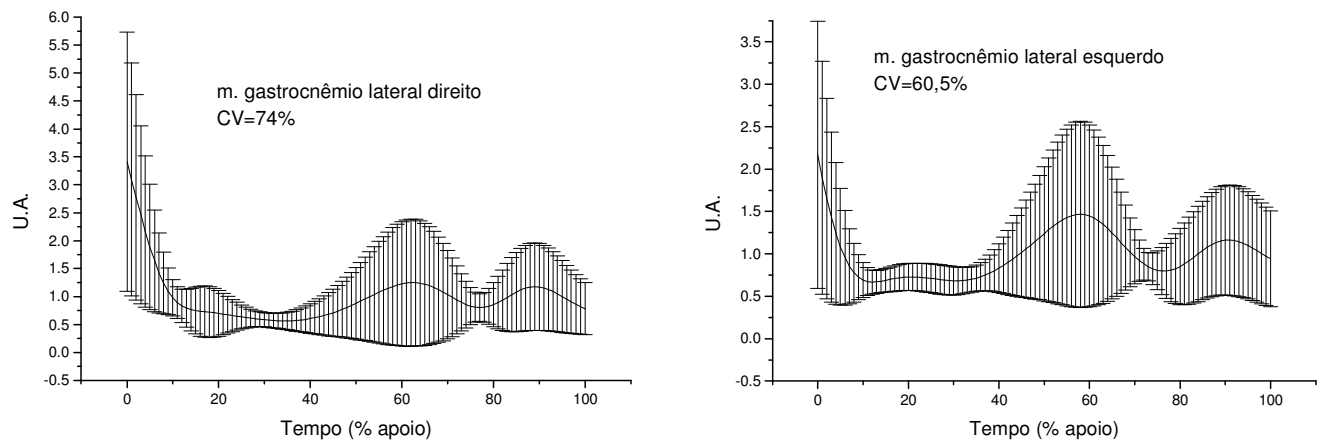

Curvas médias e desvios padrão da EMG do m. gastrocnêmio lateral direito e esquerdo do sujeito GD15, durante o andar em esteira. 
ANEXO VII - Curvas da FRS e eletromiografia referentes ao andar em esteira de todos os sujeitos do grupo diabético (GD) (cont.)
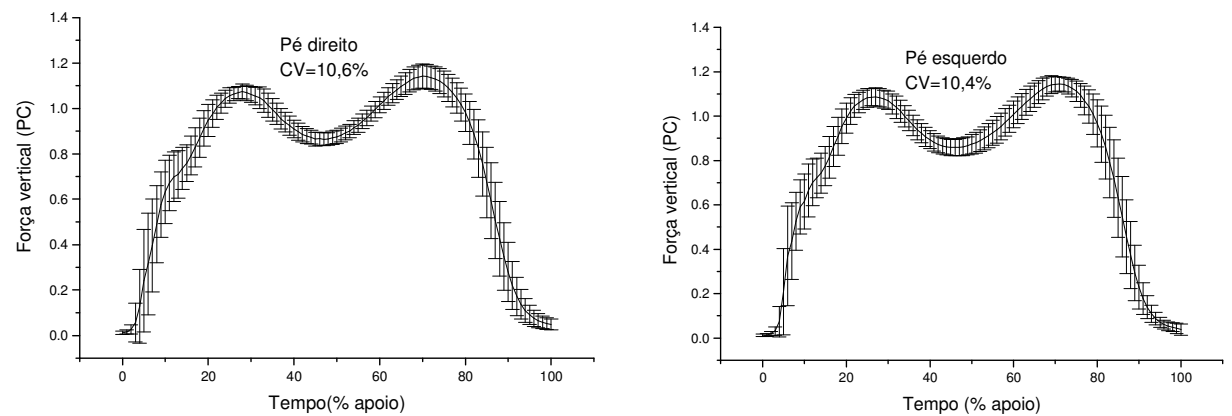

Força vertical média em função do peso corporal $(P C)$ do pé direito e esquerdo do sujeito GD16, durante o andar em esteira.
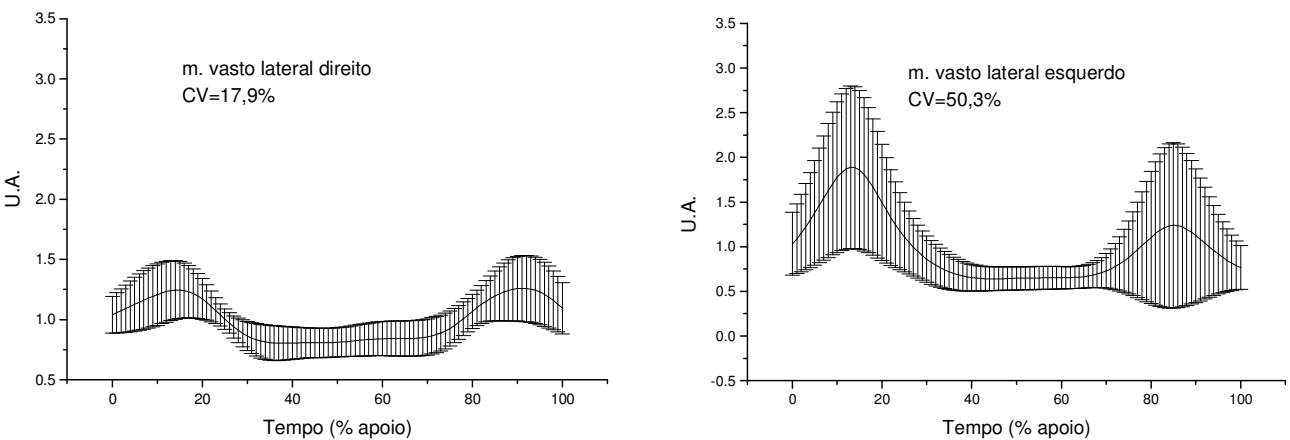

Curvas médias e desvios padrão da EMG do m. vasto lateral direito e esquerdo do sujeito GD16, durante 0 andar em esteira.
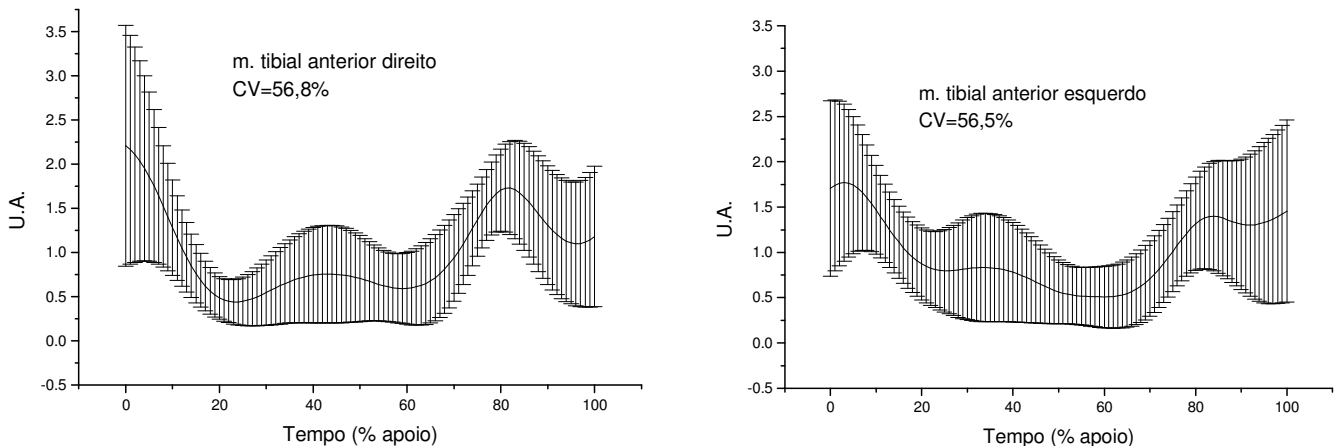

Curvas médias e desvios padrão da EMG do m. tibial anterior direito e esquerdo do sujeito GD16, durante 0 andar em esteira.
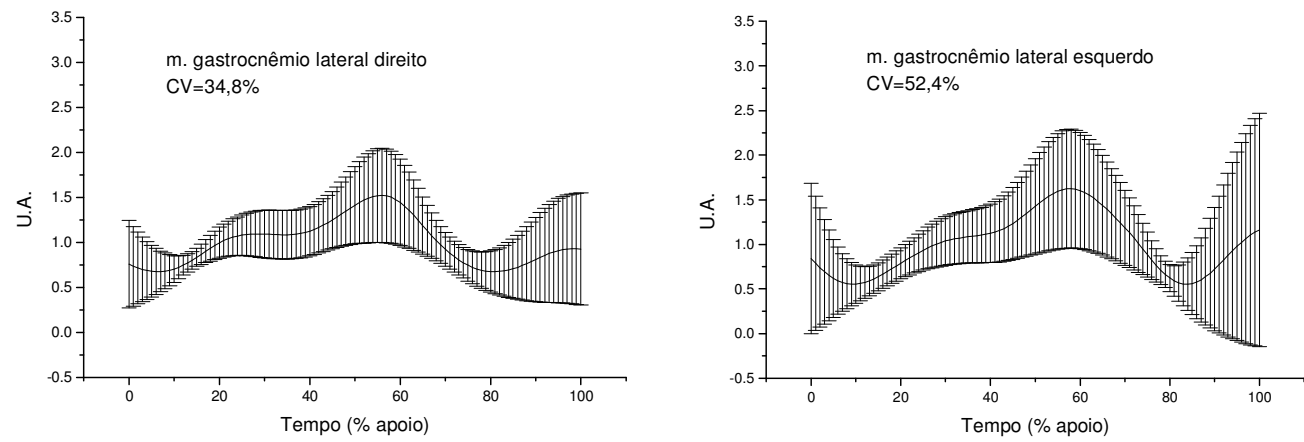

Curvas médias e desvios padrão da EMG do m. gastrocnêmio lateral direito e esquerdo do sujeito GD16, durante o andar em esteira. 